\title{
Environmental drivers of the abundance and distribution of forage fishes on the Northeast US shelf, with a particular emphasis on northern sand lance
}

By

Justin J. Suca

B.S.M.A.S., University of Miami, 2016

Submitted to the Department of Biology in partial fulfillment of the requirements for the degree of

Doctor of Philosophy

at the

\section{MASSACHUSETTS INSTITUTE OF TECHNOLOGY \\ and the \\ WOODS HOLE OCEANOGRAPHIC INSTITUTION}

September 2021

(C) 2021 Justin J. Suca. All Rights Reserved

The author hereby grants to MIT and WHOI permission to reproduce and to distribute publicly paper and electronic copies of this thesis document in whole or in part in any medium now known or hereafter created.

Signature of Author

Joint Program in Oceanography/Applied Ocean Science and Engineering Massachusetts Institute of Technology and Woods Hole Oceanographic Institution August 2, 2021

Certified by

Joel K. Llopiz

Thesis Supervisor Woods Hole Oceanographic Institution

Accepted by

Mick Follows

Chair, Joint Committee for Biological Oceanography Massachusetts Institute of Technology/ Woods Hole Oceanographic Institution 


\title{
Environmental drivers of the abundance and distribution of forage fishes on the Northeast US shelf, with a particular emphasis on northern sand lance
}

\author{
by \\ Justin J. Suca \\ Submitted to the Department of Biology \\ on August 2, 2021, in partial fulfillment of the \\ requirements for the degree of \\ Doctor of Philosophy
}

\begin{abstract}
Small pelagic fishes, also termed forage fishes, represent a critical link between secondary production and myriad top predators in marine ecosystems, including the Northeast US shelf. In this dissertation, I analyze the drivers of forage fish distribution throughout the Northeast US shelf and the drivers of the abundance of the ecologically important northern sand lance. Chapter 2 examines the basic ecology of northern sand lance and uses these insights to identify mechanistic drivers of their abundance. I then explore different scenarios of these drivers to project sand lance abundance through the end of the $21^{\text {st }}$ century, which appears precarious for adult sand lance unless current trajectories change. Chapter 3 analyzes the environmental drivers of the distribution of the six dominant, offshore forage fish species (northern sand lance, Atlantic herring, alewife, blueback herring, Atlantic mackerel, and Atlantic butterfish) on the Northeast US shelf to elucidate the role of environmental covariates in shelf occupancy by these taxa. The results of this chapter indicate shelf occupancy of butterfish and Atlantic mackerel are increasing through time while occupancy of sand lance is decreasing with time. The occurrence of most of these species is also moving deeper and northward with time. Chapter 4 assesses the source-sink dynamics of three sand lance hotspots through Lagrangian particle tracking models simulating larval sand lance transport. Connectivity varies among these hotspots with Georges Bank and Stellwagen Bank having notable retention while the Great South Channel relies on larvae from other hotspots. Retention on Stellwagen Bank and Georges Bank are linked to strong wind events during the larval period of sand lance. Collectively, this dissertation improves our understanding of the dynamics driving variability in the Northeast US shelf forage fish complex, particularly for northern sand lance.

Thesis Supervisor: Joel Llopiz

Title: Associate Scientist

Woods Hole Oceanographic Institution
\end{abstract}




\section{Acknowledgements}

The research within this dissertation was funded by a National Science Foundation Graduate Research Fellowship (awarded to JJS), Woods Hole Sea Grant (NA18OAR4170104, Project No. R/O-57), the Bureau of Ocean Energy Management (IA agreement M17PG0019), and the National Marine Sanctuary Foundation.

Nothing within this dissertation, nor my ability to personally reach this stage would have been possible without the personal and scientific support of innumerable people.

Foremost, I would like to thank my partner Jessica Perelman for her unwavering support and patience as I pushed through the analysis and writing of this dissertation. Her patience with me running code overnight in our studio apartment, my working of late nights and odd hours, and her unrelenting positivity and support made this thesis possible.

I would never have even pursued this track without the support of my parents and their encouragement for me to follow my individual passion and dreams. Studying the ocean is rarely considered a viable career and I am very lucky that my parents encouraged me to follow this path.

This dissertation and maintaining some level of happiness after five years of graduate school, would not have been possible without the support, advice, and patience of my thesis advisor Dr. Joel Llopiz. His willingness to give me scientific freedom in my pursuits was unparalleled and truly allowed me to make major growth during these five years. His flexibility and understanding of priorities larger than science were inspiring and immensely helpful for my pursuits in improving the culture of WHOI and oceanography at large.

I would also like to thank all my thesis committee members, Dr. Carin Ashjian, Dr. Rubao Ji, Dr. David Richardson, and Dr. Glenn Flierl for their helpful input throughout my dissertation and providing that input in supportive and constructive ways. I would like to especially emphasize support from Dr. David Richardson who offered detailed feedback for all three of my data chapters and Dr. Rubao Ji for his assistance with tackling a technique foreign to me and helping me develop this into a full chapter. Finally, I would like to Dr. Carin Ashjian for her positive and helpful advice throughout my $\mathrm{PhD}$ and helping provide me the opportunity to experience sea time in the Arctic.

The members of the Stellwagen Bank National Marine Sanctuary have played an essential role in so much of the research presented here. Dr. David Wiley, Dr. Tammy Silva, Dr. Anna Robuck (not with Stellwagen, but Stellwagen associated), Mike Thompson, Peter Hong, and the crew of $R / V A u k$ made so much of the data collection for this dissertation not only possible, but genuinely enjoyable.

I would also like to thank Dr. Andrew Solow and Dr. Jonathan Deroba for their assistance and advice in the development of statistical models used in this dissertation. My understanding and capabilities in this field have grown substantially in the past five years which would not have been possible without them.

Finally, I would like to thank all my friends from undergrad, Woods Hole, and, most recently, on $\mathrm{O}^{\prime} \mathrm{ahu}$, for providing me support and happy times during the course of this thesis. This is especially true for those friends in Woods Hole. They made the long, dark winters of Woods Hole brighter, especially for an outdoorsy, warm weather person like myself. 


\section{Table of Contents}

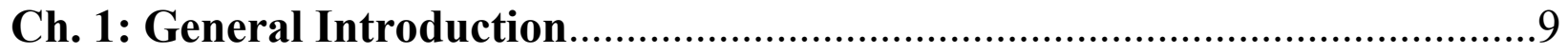

Ch. 2: Sensitivity of sand lance to shifting prey and hydrography indicates forthcoming change to the northeast US shelf forage fish complex .................17

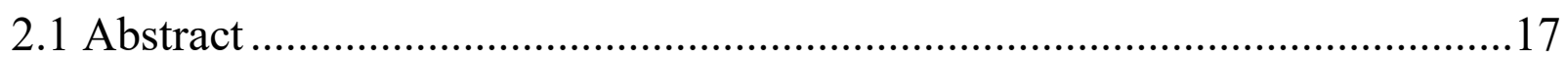

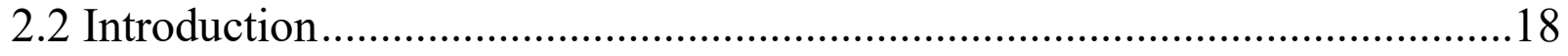

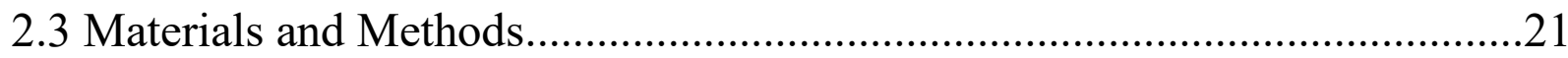

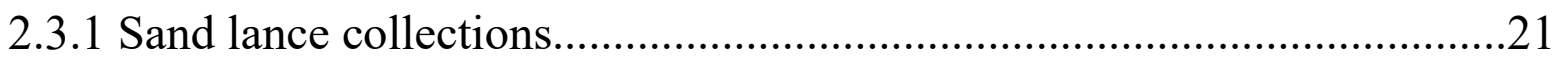

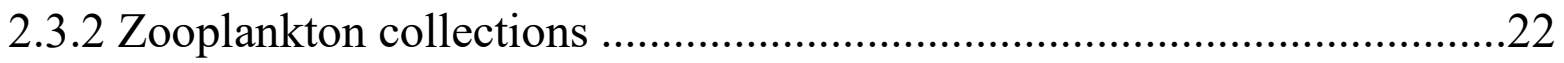

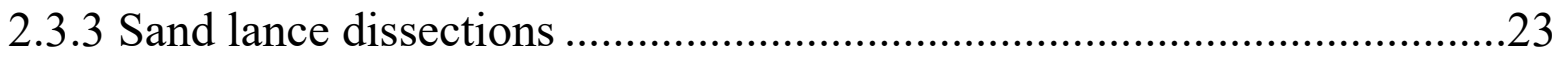

2.3.4 Stomach content identification .......................................................23

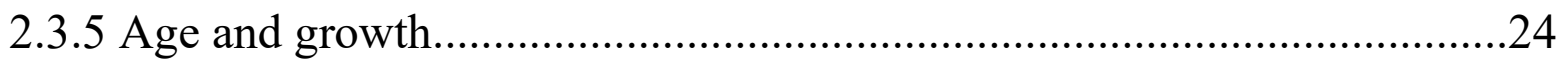

2.3.6 Lipid extraction and content analysis ................................................24

2.3.7 Northeast US shelf sand lance abundance..........................................25

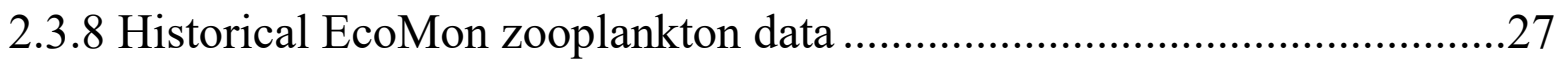

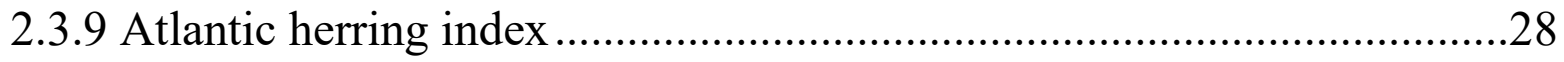

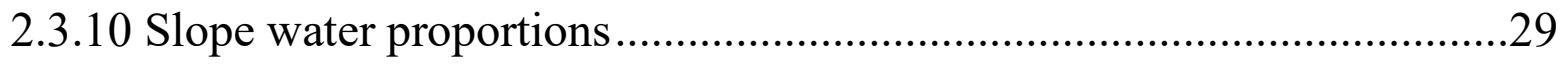

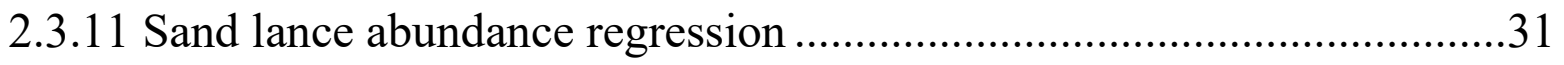

2.3.12 Change in slope water proportions with time.......................................32

2.3.13 Projections of sand lance abundance ….................................................33

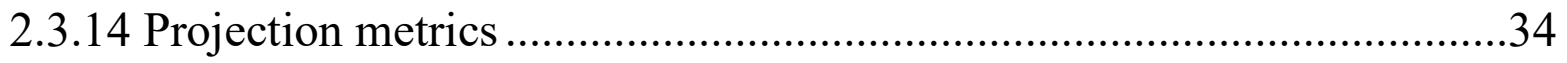




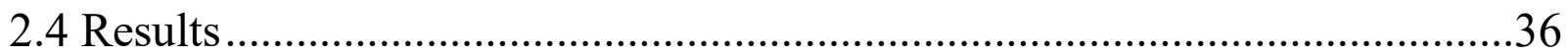

2.4.1 Sand lance feeding, lipid accumulation, and growth..............................36

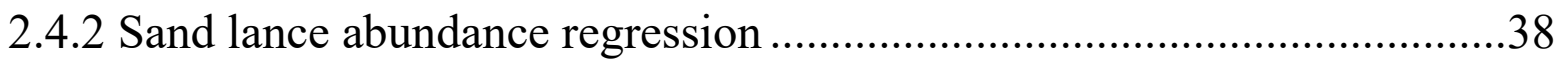

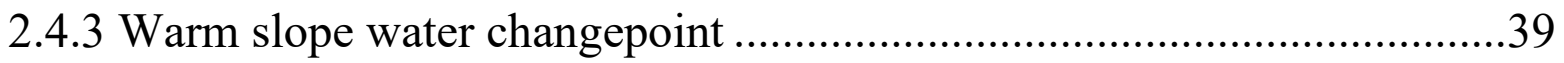

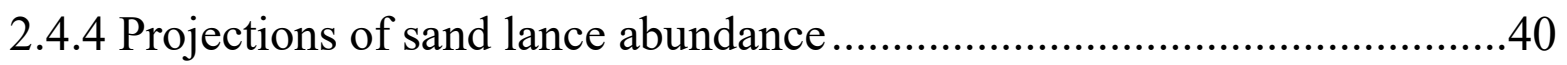

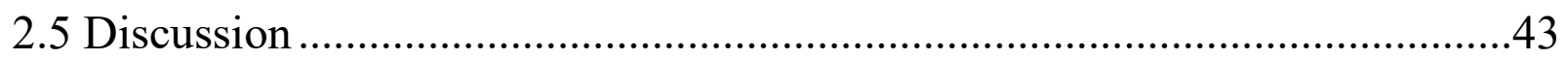

2.6 Supplemental Methods, Figures, and Tables..............................................50

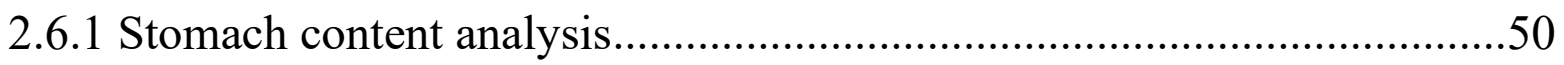

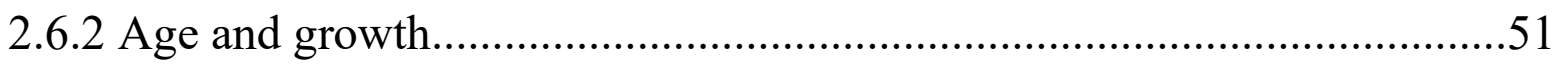

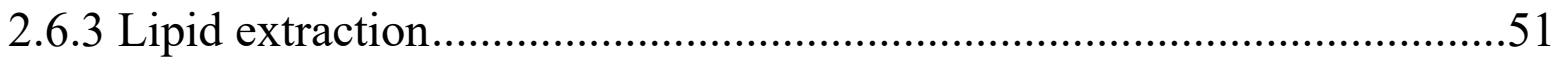

2.6.4 FVCOM bottom temperature analysis................................................51

Ch. 3: Environmental drivers and trends in forage fish occupancy of the

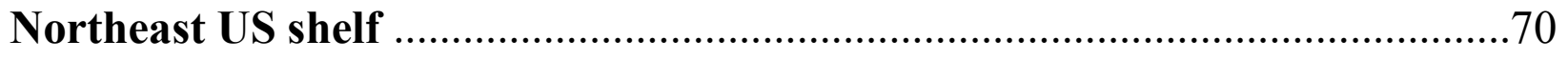

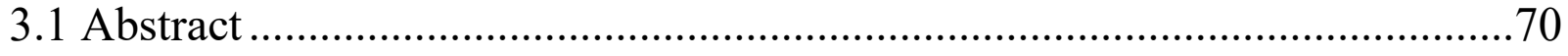

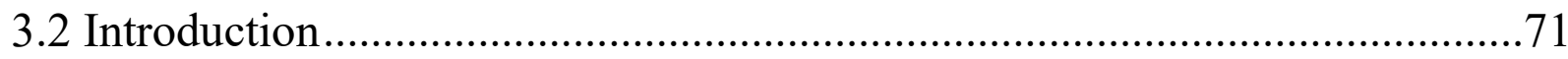

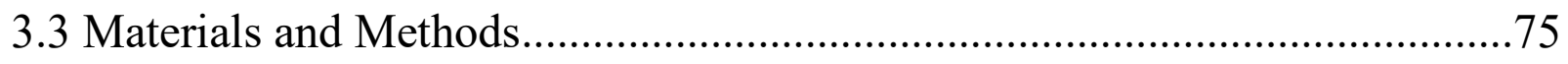

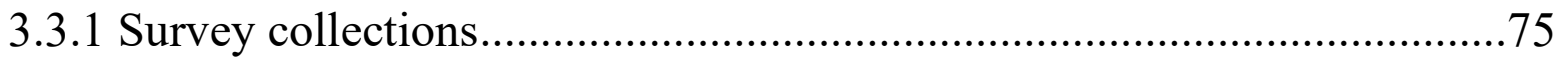

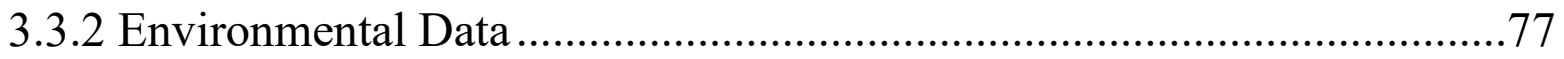

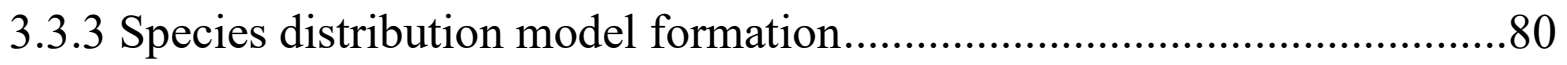

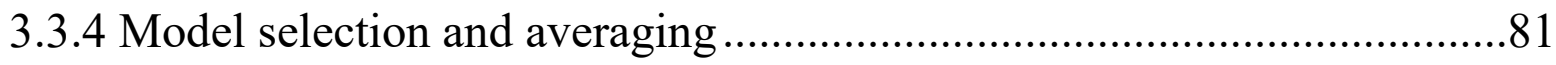

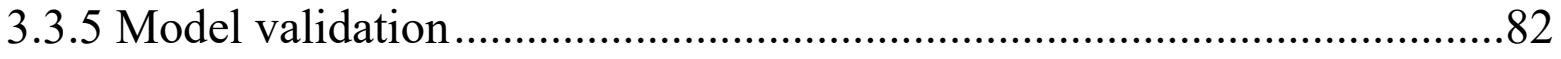

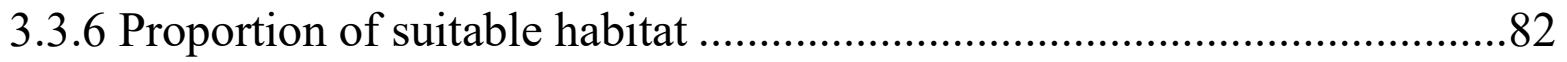




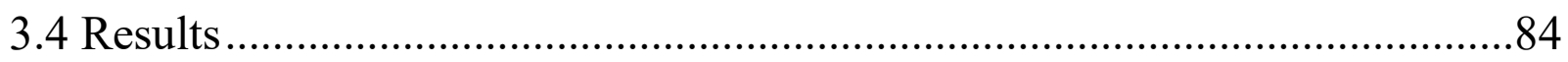

3.4.1 Predictor importance and predictive capability ..........................................84

3.4.2 Year and gear-specific intercepts and catch comparisons.........................88

3.4.3 Trends in occupiable habitat................................................................... 89

3.4.4 Mean weighted latitude and depth............................................................92

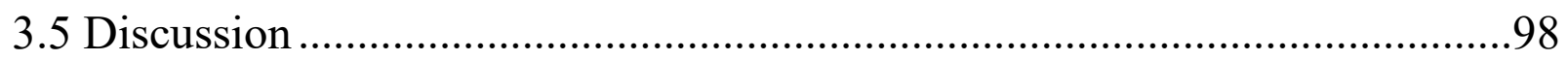

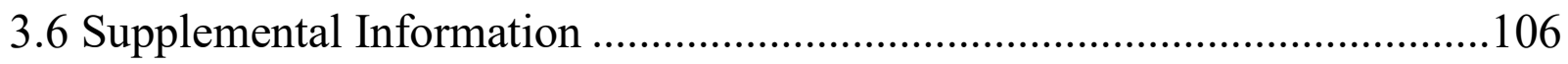

\section{Ch. 4: Larval transport pathways from three prominent sand lance hotspots in the Gulf of Maine/Georges Bank region....................................................113}

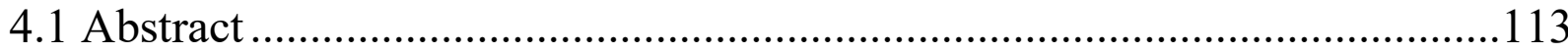

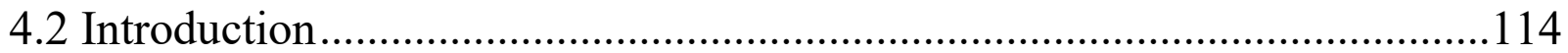

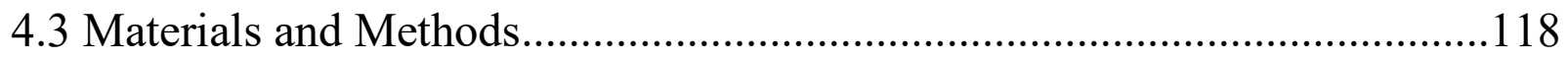

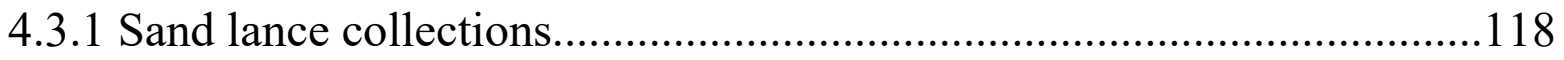

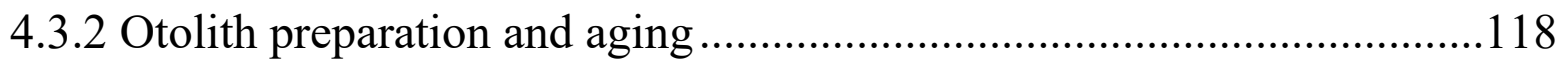

4.3.3 Bio-physical individual based model ..................................................119

4.3.4 Temporal and spatial estimates of hotspot connectivity ......................122

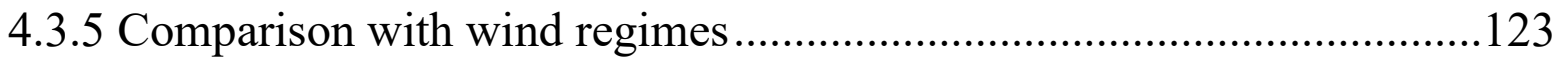

4.3.6 Comparison with Stellwagen Bank surveys .........................................124

4.3.7 Connectivity and retention among Stellwagen Bank sub-regions .........125

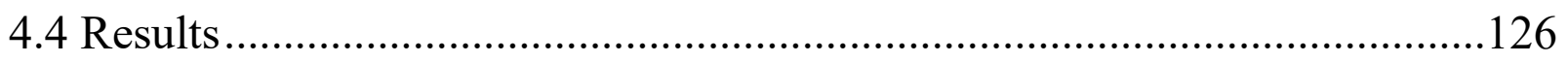

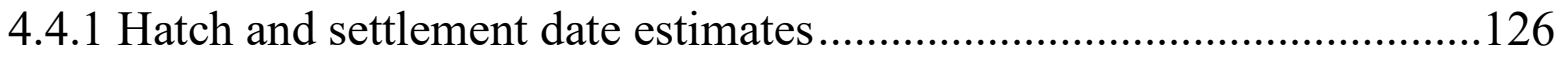

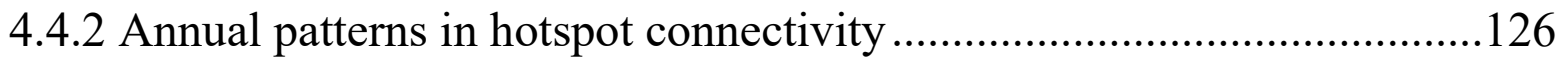


4.4.3 Spatial patterns in connectivity

4.4.4 Relationship of interannual retention with wind metrics

4.4.5 Comparison of retention with Stellwagen abundance

4.4.6 Connectivity and retention among Stellwagen Bank sub-regions

4.5 Discussion 138

4.6 Supplemental Methods, Figures, and Tables 148

4.6.1 Depth cut-off analysis

4.6.2 Tidal experiment

4.6.3 Calanus and sea surface temperature calculations 149

4.6.4 Particle dispersal comparison

Ch. 5 Conclusions 160

Bibliography .168 


\section{Chapter 1}

\section{General Introduction}

Small pelagic fishes are critical components of global marine ecosystems, representing the link between zooplankton and pelagic top predators. Their role as prey for many commercially and ecologically important organisms has led to these fishes earning the moniker "forage fishes." The importance of forage fish is so ubiquitous that $75 \%$ of all marine ecosystems have at least one predator with a diet that that is $50 \%$ or greater composed of forage fish (Pikitch et al., 2014). These fishes are critical to human consumption and usage as well. Forage fish species presently represent half of the top ten fisheries species by landings (Alder et al. 2008; Pikitch et al. 2014). While these fishes remain important food fish for regions such as western Africa and the Mediterranean, nearly $90 \%$ of forage fish landings are directed for uses such as fish oil and fish meal (Alder et al. 2008). The balance between human demand for these fishes, particularly for agricultural and aquacultural production, and the need to maintain large numbers in the wild to provide food for other important species is a contentious and difficult balance to strike. Understanding the drivers of forage fish abundance is therefore critical to the global economy, food security, and the stability of many marine ecosystems.

Forage fishes are typically abundant in productive shelf ecosystems and upwelling regions throughout the world's oceans. However, they typically only represent one to less than a dozen species in a given region (Cury et al. 2000). This high abundance and low diversity leads to many of these ecosystem being term "wasp-waist" ecosystems. This term originates from most of a region's production — generated by a diversity of phytoplankton and zooplankton—being funneled through a handful of species that provide forage to a large diversity of predators. These handful of species in turn feed a diverse array of predators including marine mammal, seabirds, 
and large pelagic fishes. The dominance of these fishes, and their essential trophic level, can cause shifts in their abundance to have large scale ecosystems consequences. This includes decreases in abundance of predators, as seen for seabirds in Alaska and the Northeast Atlantic (Divoky et al. 2015; Carroll et al. 2017). It can also lead to a release of top-down pressure on plankton communities, leading to excessive production that may reach the sea floor, as observed off Namibia following the overfishing of the local sardine (Bakun, 2017). However, it is common for small pelagic species in wasp-waist ecosystems to oscillate out of phase with one another, leaving an abundance of at least one species in the ecosystem at any given time. The most famous example of this is the sardine and anchoveta of Peru, where climate and fishing induced changes to the ecosystems led to large scale collapse of the Peruvian anchoveta in the 1970s and the subsequent rise of sardine in response (Bertrand et al. 2014). However, as is the case with the anchoveta, a shift in species often does not result in an identical ecosystem, with shifts in forage species often leading to shifts in the distribution and availability of prey to top predators. Thus, understanding the drivers of forage fish abundance and distribution, and ultimately forecasting these factors, is essential to our understanding of marine ecosystems and their future under changing conditions.

The Northeast US shelf represents an ecosystem with a large abundance of forage fishes serving as the prey for predators ranging from groundfish to large marine mammals. This region, spanning from Cape Hatteras through the Gulf of Maine, has historically represented one the of most economically valuable regions in terms of fisheries. The most iconic finfish fisheries include Atlantic cod and bluefin tuna, both notable forage fish predators (Richardson et al. 2014; Logan et al. 2015). The forage fishes of the region include six abundant offshore species: Atlantic herring (Clupea harengus), Atlantic mackerel (Scomber scombrus), alewife (Alosa 
pseudoharengus), blueback herring (Alosa aestivalis), Atlantic butterfish (Peprilus triacanthus) and northern sand lance (Ammodytes dubius). This moderately diverse forage fish complex causes the Northeast shelf to only exhibit partial wasp-waist behavior, with a broader diversity of energy pathways than most upwelling centric wasp-waist ecosystems. Nonetheless, the forage fishes of the region both serve as important prey for iconic species and notable fisheries in the case of Atlantic herring, butterfish, and Atlantic mackerel leading to a desire to understand drivers of forage fish abundance and distribution throughout the region.

Given the Northeast US shelf spans greater than six degrees of latitude along the western Atlantic, the region harbors a variety of environmental gradients, hydrography, and hydrodynamics. The southern extent of the region, Cape Hatteras, represents the detachment point for the Gulf Stream where this western boundary current becomes a free jet causing spatiotemporal variability in the influence of Gulf Stream waters on the region. Above Cape Hatteras through the southern coast of Cape Cod lies the Mid-Atlantic Bight, a region characterized by large areas of sandy substrate and typically strong seasonal stratification. Wind stress and lower temperatures lead to a largely cool and well-mixed water column from late fall through spring but warming temperatures in the late spring/early summer lead to strong stratification in this region and a "cold pool" of winter bottom water, creating habitat for many colder water demersal species (Chen et al. 2018). Georges Bank lies to the northeast of the MidAtlantic Bight and east of Cape Cod. Georges Bank is a largely shallow and sandy bank harboring well mixed waters throughout the year due to strong tidal forcing. The region has a clockwise gyre due to tidal rectification for much of the year, though the strength of this gyre varies seasonally based on stratification (Naimie et al., 2014). The tidal mixing of the region and upwelling from the edges of the bank lead Georges Bank to be one of the most productive 
regions in the ocean and harbor some of the historically largest groundfish and scallop fisheries in the world, in addition to habitat for many forage fishes. To the north of Georges Bank lies the Gulf of Maine, a deeper, colder region with highly dynamic hydrography. The deep basins of the Gulf of Maine and the Northeast Channel allow deep, nutrient rich slope waters from the Gulf Stream influenced Slope Sea and Arctic influenced Labrador Sea to enter the region and form large portions of the region's bottom water (Mountain, 2012; Townsend et al., 2015). The competing influences of Gulf Stream waters from the south and Arctic waters from the Labrador current lead to marked interannual variability in primary and secondary production throughout the Gulf of Maine (Greene and Pershing, 2007; Mountain, 2012). The southward flow of the majority of the Northeast US shelf also leads to characteristics of the Gulf of Maine, such as changes in bottom water composition and production, that influence much of the Northeast US shelf.

The spatiotemporal variability in hydrographic and hydrodynamics lead to a moderate diversity of marine organisms occupying the region, including the aforementioned diversity of forage fishes. Atlantic herring, northern sand lance, and alewife represent the colder-water species of the complex, while blueback herring, Atlantic mackerel and butterfish typically occupy warmer waters. All six species are primarily zooplanktivores, with most of these species primarily feeding on copepods (Suca et al. 2018). However, diets do vary such as consumption of fish larvae in the case of the clupeids and Atlantic mackerel and the consumption of gelatinous zooplankton by butterfish. Other than the site-attached northern sand lance, each of the species within the forage fish complex exhibit seasonal shifts in distribution largely linked to spawning. For example, species such as Atlantic butterfish are known to occupy warmer waters of the region, such as the deep slope waters, in the winter and early spring, while occupying the shelf 
waters of the Mid-Atlantic Bight and Gulf of Maine in the fall (Adams, 2017). The river herrings, alewife and blueback herring, which migrate into rivers in the late spring to spawn in freshwater systems and return to the coastal ocean in the summer and early fall are another example. These spawning centered migrations provide some insight into the general distribution of these fishes by season, but finer scale understanding of their distribution and interannual variability in this distribution and its relationship to hydrography are largely understudied.

Of the six dominant forage fishes, northern sand lance and Atlantic herring have typically represented the most abundant species in any given year. These two species exhibit out-of-phase oscillations in abundance, similar to that observed in other forage fish complexes. The cause of this oscillation remains largely unknown, though hypotheses such as intra-guild predation have been put forth (i.e. the consumption of sand lance larvae by Atlantic herring; Fogarty, 1991) However, we do know that the oscillation between the dominance of these two species affects the distribution of these fishes' predators, including Atlantic cod (Richardson et al. 2014). A better understanding the drivers of this oscillation will have implications for the Northeast US shelf ecosystem.

Understanding the drivers of sand lance abundance across the Northeast US shelf is essential for answering the question of why these species oscillate out-of-phase. Sand lance abundance varies by orders of magnitude from one year to the next. When abundant, sand lance may represent the largest biomass of any fish species across the Northeast US shelf (Staudinger et al., 2020). However, sand lance abundance also crashes episodically, such it did for much of the 1990s when abundance was a small fraction of what it was in 1980s. This species is not actively fished, thus environmental drivers of abundance are most likely at play. The lack of a directed fishery has also led to few studies being focused on the species despite its ecological 
importance. Factors such as bottom-up, top-down, and hydrographic forcing may have a large role in the recruitment dynamics and survival of this species, yet this has largely been left unexplored.

In addition to shelf-wide changes in abundance, sand lance abundance and presence varies notably on regional scales, with individual banks having episodic explosions in abundance while others are empty (Staudinger et al., 2020). Given that sand lance are unlikely to make large scale migrations as adults, these dynamics are assumed to be largely driven by differential recruitment at these smaller scales. Larval transport is one of the largest drivers of spatial variability in recruitment for site attached species (Pineda et al., 2007). Variability in hydrodynamics can lead larvae to settle in vastly different locations and in different abundances from year to year. A common method for better understanding the potential role of larval transport in small scale recruitment variability is through Lagrangian tracking models where larvae are simulated as particles according to their hatch dates, larval durations, vertical distributions, behavior and settlement timing (Cowen and Sponaugle, 2009). However, a key component necessary for these models to be accurate is tuning the parameters based on observations, most notably the expected hatch dates, settlement dates, and the vertical distribution of larvae. Much of this information is unknown about sand lance and thus attaining this information on which to base subsequent simulations may shed light on the drivers of their small-scale spatial variability.

The study of fishes on the modern-day Northeast US shelf and the future of their abundance and distribution requires the incorporation of the shifting climate of the region. The Northeast US shelf is one of the fastest warming regions of the global oceans, with ecosystems such as the Gulf of Maine warming faster than $99 \%$ of all ocean waters (Pershing et al. 2015). 
The physical drivers of these changes include increased heat flux from the warming local climate and shifts in the path of the Gulf Stream. The Gulf Stream has begun to meander and shed rings at rate nearly double its historical rate since 2000 , resulting in large volumes of warm, salty water from warm core rings occupying the Mid-Atlantic Bight (Gangopadhyay et al. 2020). Tropical species have increasingly been observed in the region corresponding with these changes in Gulf Stream behavior, leading to new and dynamic species interactions. Additionally, the more northward position of the Gulf Stream in recent years has led to an increased influence of warm, salty slope water on the Gulf of Maine and larger Northeast US shelf. A regime shift in the Gulf Stream position started around 2009, where sea surface height values began to change along the Tail of the Grand Banks and bottom temperatures throughout the Gulf of Maine began to rise at unprecedented rates (Friedland et al. 2020; Neto et al. 2021). Understanding the relationship between forage fish distribution and hydrography throughout our historical records is essential to model forage fish responses to the hydrographic conditions that are now changing dramatically. Given the importance of these fishes for their ecological role and their value to fisheries, understanding the fate of forage fishes will be essential for preparing communities along the Northeast US shelf for a changing climate and ecosystem.

In this thesis, I aim to better understand the role of hydrography, hydrodynamics, and trophic influences on the distribution of forage fishes and the abundance of northern sand lance. In chapter 2, I study the life history of northern sand lance to elucidate mechanistic drivers of their abundance throughout the Northeast US shelf. I then use different scenarios of projected changes to these drivers to forecast scenarios of future adult sand lance abundance through the end of the $21^{\text {st }}$ century. In chapter 3, I use the Northeast Fisheries Science Center bottom trawl survey data to construct models of shelf occupancy for the six dominant forage fish species of 
the Northeast US shelf. I further analyze how these changes in shelf occupancy are related to local hydrographic and hydrodynamic conditions relative to interannual differences in overall presence from factors such as recruitment variability. Finally, in chapter 4, I aim to better understand the source-sink dynamics of three sand lance hotspots within the Gulf of Maine through models of larval transport. I also analyze how interannual variability in these transport pathways relate to local wind phenomena and how retention within each hotspot varies on small scales. Collectively, this thesis advances our state of knowledge on the relationships between forage fishes on the Northeast US shelf and the hydrography and hydrodynamics of the region. This work provides a clearer picture of how the forage fish complex, especially northern sand lance, will behave in response to a rapidly shifting climate through the end of the century. 


\title{
Chapter 2
}

\section{Sensitivity of sand lance to shifting prey and hydrography indicates forthcoming change to the northeast US shelf forage fish complex}

\author{
Reprinted with permission of ICES Journal of Marine Science
}

\subsection{Abstract}

Northern sand lance (Ammodytes dubius) and Atlantic herring (Clupea harengus) represent the dominant lipid-rich forage fish species throughout the Northeast US shelf and are critical prey for numerous top predators. However, unlike Atlantic herring, there is little research on sand lance or information about drivers of their abundance. We use intra-annual measurements of sand lance diet, growth, and condition to explain annual variability in sand lance abundance on the Northeast US Shelf. Our observations indicate that northern sand lance feed, grow, and accumulate lipids in the late winter through summer, predominantly consuming the copepod Calanus finmarchicus. Sand lance then cease feeding, utilize lipids, and begin gonad development in the fall. We show that the abundance of $C$. finmarchicus influences sand lance parental condition and recruitment. Atlantic herring can mute this effect through intra-guild predation. Hydrography further impacts sand lance abundance as increases in warm slope water decrease overwinter survival of reproductive adults. The predicted changes to these drivers indicate that sand lance will no longer be able to fill the role of lipid-rich forage during times of low Atlantic herring abundance — changing the Northeast US shelf forage fish complex by the end of the century. 


\subsection{Introduction}

Small pelagic fishes, or forage fishes, are critical components of both neritic and oceanic food webs. They represent an important link between planktonic production and a diversity of larger predators, including numerous endangered species. However, forage fish abundance and recruitment are often sensitive to temperature and secondary production, leading to large fluctuations in abundance, making this trophic link highly variable in space and time (Chavez et al., 2003; Clausen et al., 2018; Thompson et al., 2019; Sydeman et al., 2020). Further, numerous studies show that fluctuations in forage fish abundance can lead to marked effects on predator condition and breeding success (Barrett et al., 2012; Kadin et al., 2012; Engelhard et al., 2013; Church et al., 2019). Owing to the sensitivity of forage fish to climate regimes, and, in turn, the breeding and condition of their predators, there is great interest in understanding climate-forage fish relationships and using them to project forage fish abundances into the future (Fréon et al., 2005; Alder et al., 2008; Checkley et al., 2017) .

Sand lances (family Ammodytidae) are one such group of quintessential forage fishes throughout temperate and sub-polar shelf ecosystems of the Northern Hemisphere. This is particularly true for northern sand lance (Ammodytes dubius) in the Northeast US Shelf ecosystem (Figure 2-1A). Of 72 regional predators consuming sand lance, populations of humpback whales (Megaptera novaeangilae) and numerous seabirds are particularly reliant on this resource (Staudinger et al., 2020). However, the lack of a directed sand lance fishery and, therefore, regular assessments, has hampered our understanding of basic sand lance ecology that is needed to predict the species' characteristically large interannual fluctuations in abundance (Figure 2-1B,C; (Nelson and Ross, 1991; Richardson et al., 2014; Staudinger et al., 2020). 


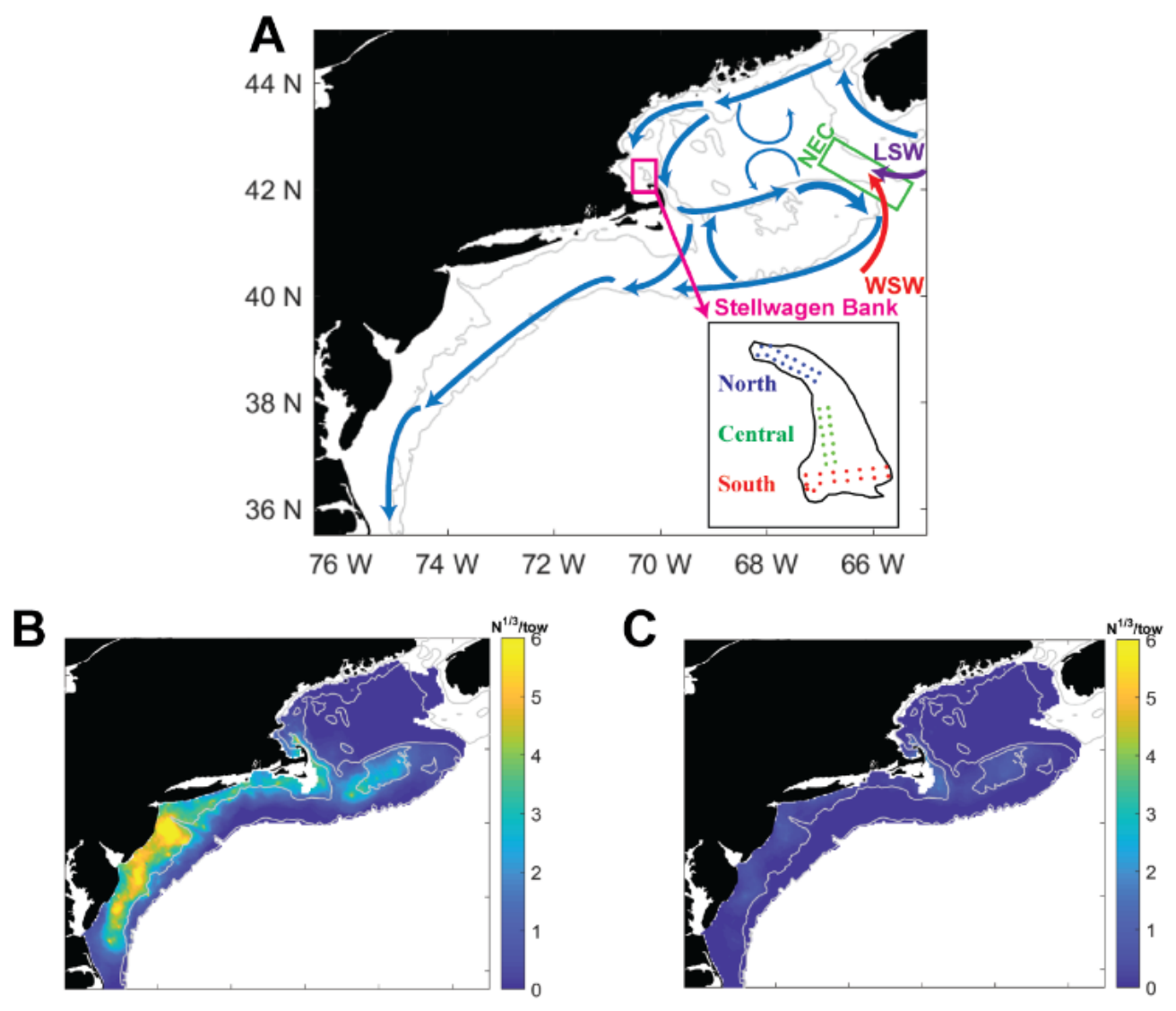

Figure 2-1. Hydrography of the Northeast US Shelf and sand lance abundance. (a) Overview of the Northeast US Shelf with blue arrows indicating prevailing surface currents of the region, red arrow indicating path of warm slope water entering the Northeast Channel (green box), and the purple arrow indicating flow of LSW entering the Northeast Channel. Inset displaying the $40 \mathrm{~m}$ isobath of Stellwagen Bank, and the three regions of the bank (north, central, and south) including trawl locations referenced throughout the text. (b) Mean interpolated cube-root catch of sand lance over the Northeast US shelf as part of the NEFSC spring bottom trawl survey from 1978 to 1982. (c) Same as (b), except for the period of 1991-1995.

Evidence indicates other sand lances of the genus Ammodytes are particularly sensitive to prey availability and temperature regimes at multiple life stages throughout their range (Winslade, 1974; Tomiyama and Yanagibashi, 2004; van Deurs et al., 2011, 2014, 2015; Régnier et al., 2017, 2018; Clausen et al., 2018; Wright et al., 2017; Murray et al., 2019; Von Biela et al., 2019). Larval prey availability and adult exposure to elevated overwintering temperatures are hypothesized to drive variability in catch of the species $A$. marinus (T. Régnier et al., 2017; 
Wright et al., 2017). Further, significant reductions in size-at-age were observed for $A$.

personatus off Alaska during the warm and zooplankton-poor "blob" event, and reductions in catch of $A$. japonicus were correlated with decreasing zooplankton abundance off Japan (Von Biela et al., 2019; Nishikawa et al., 2020). These relationships indicate that recruitment and condition of sand lances are linked to prey availability, although existing studies have not explicitly connected adult prey availability and condition to recruitment. Despite numerous studies on congeners, little to no information currently exists on the drivers of northern sand lance abundance throughout its range.

In addition to most forage fish species individually exhibiting population fluctuations, they often oscillate out-of-phase with one another, leading to one species replacing the role of the other when environmental conditions change (Bakun and Broad, 2003; Möllmann et al., 2008; Alheit et al., 2014). The Northeast US Shelf forage fish complex has historically exhibited an oscillation between dominance of northern sand lance and Atlantic herring (Clupea harengus; Sherman et al., 1981; Richardson et al., 2014). The causes of this oscillation remain unknown, especially regarding sand lance. Intra-guild predation, zooplankton prey availability, and habitat suitability may be contributing factors (Sherman et al., 1981; Fogarty et al., 1991; Richardson et al., 2014). Intra-guild predation, when a species not only competes with (e.g. for food) but also consumes another species, can lead to an overwhelming competitive advantage in food webs, driving oscillatory patterns of competitor abundance (Polis et al., 1989). Zooplankton regimes in the region also fluctuate on seasonal to decadal scales, resulting in temporally inconsistent prey availability for small pelagic fishes (Kane, 2007; Morse et al., 2017; Perretti et al., 2017).

Beyond natural variability in zooplankton regimes, the Northeast US shelf has experienced dramatic warming of both surface and bottom waters throughout the late $20^{\text {th }}$ and 
early $21^{\text {st }}$ century. Warming has been linked to changes in heat flux from atmospheric forcing and changes in Gulf Stream dynamics that alter advective processes in the region (Greene and Pershing, 2007; Pershing et al., 2015; Kavanaugh et al., 2017; Gangopadhyay et al., 2019; Chen et al., 2020). This recent warming has negatively impacted temperate fish species occupying the shelf, driving both implied direct mortality and range shifts of numerous fishes (Pershing et al., 2015; Henderson et al., 2017; Kleisner et al., 2017).

Here, we combine stomach content, lipid content, and growth analyses of sand lance to better understand their ecology and phenology, and then use these results to inform a mechanistic approach to understanding the drivers of sand lance population fluctuations across the Northeast US shelf. We hypothesize that northern sand lance abundance on the Northeast US shelf is controlled by a combination of adult prey availability, intra-guild predation on larvae, and winter hydrographic conditions. We then predict sand lance abundance throughout the $21^{\text {st }}$ century on the Northeast US shelf using projections of the primary drivers of sand lance abundance that we identified: Calanus finmarchicus abundance, Atlantic herring abundance, and warm slope water proportions.

\subsection{Materials and Methods}

\subsubsection{Sand lance collections}

Adult sand lance (age 1+) were collected from Stellwagen Bank with a $1.0 \times 0.5 \mathrm{~m}$, small-mesh $(0.63 \mathrm{~cm})$ beam trawl (Figure 2-1A). Stellwagen Bank, a sandy bank in Massachusetts Bay within the Gulf of Maine, is a top predator hotspot and representative of typical sand lance habitat throughout the Northeast US shelf (Hazen et al., 2009; Richardson et al., 2014). Thus, our insights from Stellwagen Bank collections were used to better understand the ecology and predict environmental drivers of this species across their range. 
Collections occurred monthly in 2019 (except January, July, and December) and opportunistically on cruises from 2016 through 2018 (Table 2-S1). Trawl duration was 10 minutes and distances ranged from $0.5-1 \mathrm{~km}$. Collected sand lance in 2019 were flash frozen in foil in liquid nitrogen upon retrieval. Sand lance collected prior to 2019 were placed in a $-20^{\circ} \mathrm{C}$ freezer and then stored in ice for transportation. All specimens were collected in accordance with the guidelines and approval of Woods Hole Oceanographic Institution's Institutional Animal Care and Use Committee (approval \#23453).

Stellwagen Bank can be split into three larger "regions", south, central, and north (Figure 2-1A). Collections aimed to cover both the northern and southern regions of Stellwagen Bank where sand lance density is historically high, except for February when collections solely occurred in the southern and central regions of the bank due to limited ship time.

\subsubsection{Zooplankton collections}

Simultaneous CTD and zooplankton tows were performed at each station where sand lance were captured. A SeaBird 19plus was lowered to $1 \mathrm{~m}$ above the bottom, coupled with a 30$\mathrm{cm}$ diameter, $150-\mu \mathrm{m}$ mesh zooplankton net that sampled vertically on the upcast. This resulted in a cast from $3 \mathrm{~m}$ above the bottom to the surface, allowing for the calculation of water volume sampled. Zooplankton samples were immediately preserved in $95 \%$ ethanol upon retrieval.

Prior to processing, zooplankton samples were reduced to approximately 500 organisms with a modified box splitter. Zooplankton were sorted, counted, and identified to the lowest possible taxa at the Polish Plankton Sorting and Identification Centre and in the lab at Woods Hole Oceanographic Institution following Kane (2007). 


\subsubsection{Sand lance dissections}

Adult sand lance were thawed to near room temperature in the laboratory for dissections. Standard length, fork length, whole weight, eviscerated weight, liver weight, stomach content weight, and gonad weight were recorded for each fish. Stomach contents were preserved in $95 \%$ ethanol after weighing. Heads of each fish were removed for otolith extraction and ageing by making a vertical cut immediately posterior to the opercula. The remaining portion of each fish (stomach contents and head removed) was weighed and freeze dried for subsequent lipid extraction (see lipid extractions). Gonadosomatic index was calculated as the ratio between gonad weight and somatic weight.

\subsubsection{Stomach content identification}

Stomach contents of each fish that contained prey were examined to identify the specific zooplankton prey of sand lance and how consumption varies seasonally. Details of stomach content identification methods can be found in the supplementary information. Feeding incidence was defined as the proportion of stomachs inspected on each sampling date that contained prey items. An overall proportion of prey taxa by number and biomass was also calculated for each month of collection.

For pre-2019 samples, feeding incidence was assessed as the presence or absence of prey in the stomach under a microscope after dissection. Samples collected before 2019 were not flash frozen, and thus prey items were often degraded and thus may have biased results toward items that were more robust to digestion. We therefore did not calculate diet by biomass or number for pre-2019 collected sand lance. 


\subsubsection{Age and growth}

A subset of fish from March, April, June, August and November of 2019 were haphazardly selected for otolith-based ageing. Full details of ageing analysis can be found in the supplementary information. For abundant age classes, a von-Bertalanffy growth curve was fit to standard length $(S L)$ by month $(m)$ for each age class with sufficient number of individuals (n >30) following the equation:

$$
S L_{m}=S L_{\infty}\left(1-e^{-k\left(m-m_{0}\right)}\right)
$$

where $\mathrm{k}$ is the growth coefficient. Von-Bertalanffy growth curves were fit primarily to estimate the parameter SL $\infty$ in order to determine which month standard length of individuals in an age class approached their annual maximum when somatic growth ceases. The equation thus follows the standard von-Bertalanffy growth equation except for using month as the time scale. VonBertalanffy curve fitting was performed using the vB function in the FSA package in R (Derek and Wheeler, 2020).

\subsubsection{Lipid extraction and content analysis}

Lipid extractions were performed for opportunistically collected sand lance prior to 2019 following the exact modified Folch method presented in Post \& Parkinson (2001). For 2019 collected sand lance, up to 25 fish per month of collection were processed for lipid extraction following a further modified method to minimize lipid oxidation. Details of this method are described in the supplementary material.

Percent lipid values were then fit with a cyclic penalized cubic regression spline with day of collection as the predictor and region of collection on Stellwagen Bank (north, central, south) as a factor via the $m g c v$ package in $\mathrm{R}$ to determine the effect of day of year on sand lance lipid content while accounting for regional variability (Wood, 2017). Region of collection within 
Stellwagen Bank (north, central, south) was included due to observed differences in zooplankton and hydrography by region (Figure 2-S1, 2-S2). The model was written as follows:

$$
\text { Percent Lipid }=\beta_{0}+s(D O Y)+\text { Region }
$$

Where percent lipid represents percent lipid of whole sand lance, $\mathrm{s}(D O Y)$ represents the fitted smoothing function for day of year (DOY), and region is fit as a categorical predictor. We report change in deviance explained $(\triangle \mathrm{DE})$ from the full model for each variable as an estimate of their relative importance.

Eighteen individuals were selected for duplicates, encompassing two individuals from each month of collection, to determine intra-fish variability in lipid content estimates. Duplicates indicated $<3 \%$ intra-fish difference.

\subsubsection{Northeast US shelf sand lance abundance}

Estimations of Northeast US shelf sand lance abundance came from the spring Northeast Fisheries Science Center (NEFSC) bottom trawl survey, spanning from 1968 to present. During each survey, 300-400 stations are sampled in a random stratified design, ranging from the Western Scotian Shelf to Cape Hatteras (Figure 2-1B,C). At each station, all sand lance are weighed and individuals are measured, with sub-sampling occurring when catches were large. Further details of the survey and sampling gear are found within Politis et al. (2014). The log area weighted stratified mean abundance in catch of each survey was calculated to estimate interannual variability in sand lance abundance (Richardson et al., 2014). The spring survey typically occurs in March and April, well within the feeding window of sand lance (see Results), and has largely been consistent in timing, gear, and vessel—allowing the survey to provide a consistent index of northern sand lance abundance (Politis et al. 2014). This is opposed to the fall 
survey which occurs at a transitional window in sand lance life history from feeding to preparing for fall reproduction, leading to possible conflation of abundance trends with inter-annual variability in behavior (see Results; Murray et al. 2019). The survey is also not explicitly designed to sample sand lance habitat and thus there are rarely multiple trawls within a stratum that represent equivalent sand lance habitat quality. We therefore focused on the log area weighted stratified mean abundance for the entire survey region, assuming the broad spatial range and large sample size mitigated the likelihood of spurious or small-scale behavior related biases in abundances estimates. Sand lance abundance exhibits major fluctuations, ranging orders of magnitude, allowing the survey to represent sand lance abundance trends despite being imprecise.

In 2009, the survey changed vessels and gear, notably switching the net liner from 1.27 to $2.54 \mathrm{~cm}$, leading to a noticeable decrease in sand lance catchability during the calibration study (Miller et al., 2010; Richardson et al. 2014). The time series of sand lance abundance thus ends in 2008 to avoid conflation of gear selectivity with abundance trends. We do not have age estimates for each year of the survey, and thus all age classes of sand lance are included in the $\log$ area-weighted stratified mean abundance. The most comprehensive ageing of sand lance from the NEFSC spring trawl survey suggests $>90 \%$ of individuals collected in the survey are age-2 or age-3 (Nelson and Ross, 1991). Due to this finding, we assumed that abundance of age2 and age-3 individuals were responsible for the changes in overall sand lance abundance in the survey. While the survey provides a robust estimate of the abundance of age- 2 and age- 3 sand lance throughout the Northeast US Shelf, overall abundance of sand lance is likely underestimated due to low selectivity of age-1 individuals (Nelson and Ross, 1991). 


\subsubsection{Historical EcoMon zooplankton data}

Calanus abundance anomalies were calculated following Kane (2007) and Perretti et al., (2017) from collections of the NEFSC EcoMon sampling program spanning 1977 to present. Briefly, a mean abundance by date is computed by area for Calanus finmarchicus. This is accomplished by binning all samples for a given species to bi-monthly collection dates based on median cruise date, taking the mean abundance, then fitting a spline interpolation between mean bi-monthly abundance to give expected abundance on any given day of the year. Data were spatially constrained to the Gulf of Maine ecological production unit (Lucey and Fogarty, 2013). All years (1977-2008) were used because annual sampling effort included at least 35\% spatial coverage of the Gulf of Maine ecological production unit (Morse et al., 2017). The Gulf of Maine was chosen as opposed to the full Northeast US shelf as this region serves as the source of Calanus finmarchicus for much of the Northeast US shelf. The Gulf of Maine has deep basins that provide habitat for diapausing Calanus and the general southward flow of the region advects Calanus to the other regions of the Northeast US shelf (Kane, 2005, 2007; Runge et al., 2015; Ji et al., 2017).

Zooplankton data were constrained to cruises centering around bi-monthly dates from January to July to correspond with our observed feeding patterns for sand lance. Winter-summer Calanus abundance anomalies were then lagged to approximate an average Gulf of Maine Calanus abundance at 3-4 years prior to the spring bottom trawl survey estimate of sand lance abundance. A 3-4 year lag was selected as this represents the years in which the parents of fish collected in the survey (age-2s and 3s) would be feeding on Calanus prior to spawning in the fall. The specific selection of this time lag was based upon our observations of sand lance feeding, growth, and lipid content being tightly coupled with their feeding on Calanus. The time lag used therefore represents a test of the parental condition hypothesis, whereby higher 
abundances of Calanus available to parents would result in either more or higher quality eggs, and thus higher abundances of sand lance in the survey three and four years later when they become catchable in the survey as age- 2 and age- 3 individuals. We specifically focus on this time lag because of the results of our sampling of seasonal feeding and reproductive ecology of sand lance as opposed to testing multiple time lags to isolate the lag with the highest correlation coefficient.

\subsubsection{Atlantic herring index}

Atlantic herring are intra-guild predators of northern sand lance, meaning that adults of each species are competitors for prey but Atlantic herring also consume the larvae and juveniles of northern sand lance (Suca et al., 2018). Hence, Atlantic herring may exert a strong top-down influence on northern sand lance abundance by consuming the early life stages of sand lance (Polis et al., 1989).

Similar to sand lance, Atlantic herring catchability in the NEFSC bottom trawl survey changed during the time series. Catchability of Atlantic herring substantially increased on the survey in the mid-1980s, possibly due to a change in trawl doors (which has been consistently noted; NEFSC, 2018; Miller et al., 2010). Richardson et al. (2014) thus developed a composite index of Atlantic herring abundance, from 1968 through 2010, combining numerous state and federal fisheries independent surveys of Atlantic herring using a non-linear least-square optimization procedure. This composite index represents an estimation of the overall Atlantic herring abundance on the Northeast US Shelf. It is worth noting that Atlantic mackerel likely also exert a top-down effect on sand lance via intra-guild predation but their transitory use of the region and tendency to avoid gear used in standardized surveys precluded effective use of Atlantic mackerel abundance as a predictor (Mbaye et al., 2020). 
The composite Atlantic herring index was lagged to represent Atlantic herring abundance 2-3 years prior to the bottom trawl survey estimate of sand lance. This lag indicates the abundance of Atlantic herring on the Northeast US shelf when survey-collected sand lance were larvae and early juveniles and thus susceptible to predation by Atlantic herring. We specifically focus on this time lag because of the results of previous research (Polis et al. 1989; Suca et al. 2018) as opposed to testing multiple time lags to isolate the lag with the highest correlation coefficient.

\subsubsection{Slope water proportions}

We then further explored hydrographic drivers of variability in sand lance abundance on the Northeast US Shelf in conjunction with trophic (prey availability and predation) effects. We tested the hypothesis that increasing warm slope water proportion would have a direct detrimental effect on adult northern sand lance abundance on the Northeast US shelf. Slope waters enter the Gulf of Maine through the Northeast Channel (Figure 2-1) and are composed largely of two sources, colder and fresher Arctic-influenced Labrador slope water (LSW) and warmer, saltier Slope Sea and Gulf Stream-influenced "warm" slope waters (WSW) of which the relative proportions of each source vary interannually (Mountain, 2012). These slope waters then mix and circulate around the Gulf of Maine, becoming a substantial portion of the shelf water of the Northeast US shelf (Mountain, 2012), the primary habitat of northern sand lance on the Northeast US shelf. These warm slope waters have been shown to have deleterious effects to wintertime populations of Calanus, the primary prey of sand lance (Record et al., 2019). This deleterious effect of warm slope water on Calanus does not appear to carry through the spring, with local production decoupling warm slope water proportions and integrated annual Calanus abundance (Record et al., 2019). Thus the mechanism behind warm slope water's effect on sand 
lance abundance could manifest in two ways: indirectly through decreasing prey availability to spawners - thus lowering parental condition and spawning output—or through a direct negative effect on over-winter survival of adult sand lance via elevated bottom temperatures and lower winter prey availability. Our observations suggest that the latter scenario is more likely as biological sampling showed that reproductive sand lance have their lowest energy reserves in winter, making mature individuals (age-2+) susceptible to mortality from increased metabolism and lack of prey availability from elevated warm slope water proportions. Thus, we hypothesized that increasing warm slope water proportions would have a deleterious effect at a 0 -year lag, given the slope water conditions that either favor age-2+ survival or mortality would occur in the winter prior to the spring trawl survey (i.e. in the same year as the survey). We also note that warm slope water may influence the catchability of sand lance in the survey due to its effect on bottom temperature. However, schooling behavior of congeners have been shown to be primarily linked to feeding and food availability (van Deurs et al. 2011), thus we believe this effect would be small relative the changes in true abundance given the survey overlaps with peak feeding for sand lance (see Results). Additionally, hindcast bottom temperatures from a hydrographic model on the Northeast US shelf indicate that mean bottom temperatures during the survey do not correlate with sand lance abundance in the survey (Chen et al. 2011, see Supplementary Information and Figures 2-S13-15).

Slope water proportions were extracted from the ecodata package in R (Fratantoni, 2019; Mountain, 2012). Slope water proportions were derived from bathythermograph data, CTD data, and water samples collected from Niskin bottles from Northeast Fisheries Science Center surveys from the 1977 to present between $150-200 \mathrm{~m}$ in the Northeast Channel $\left(42.2-42.6^{\circ} \mathrm{N}\right.$, $66-66.8^{\circ} \mathrm{W}$, Figure 2-1). Data collected from $150-200 \mathrm{~m}$ are assumed to be waters sourced from 
three sources, Scotian Shelf water $\left(2^{\circ} \mathrm{C}, 32\right.$ salinity $)$, Labrador slope water $\left(6^{\circ} \mathrm{C}, 34.7\right.$ salinity), and warm slope water from off the Northeast US Shelf $\left(10^{\circ} \mathrm{C}, 35\right.$ salinity). The relative proportion of each source was calculated via a 3-point mixing algorithm following Mountain, (2012). These temperature and salinity end-member values of each water mass are assumed to be constant over time, though local heat fluxes and mixing likely alter these values. Despite these fluctuations, warm slope water proportion provides a reliable estimate of warmer waters entering the Gulf of Maine and provides an estimate of winter thermal conditions for sand lance over this period. While buoy data exist in the Northeast Channel from 2004-2018 (NERACOOS buoy N), annual estimates of slope water proportions were selected in order to extend the time series back to 1977 , thus matching the length of available zooplankton data.

\subsubsection{Sand lance abundance regression}

Log sand lance abundance from NEFSC bottom trawl surveys were related to Calanus abundance, the composite Atlantic herring index, and warm slope water proportion using a multiple linear regression written as follows:

$$
\log \left(S L_{t}\right)=\beta_{o}+\beta_{1} * \text { Calanus }_{t-3,4}+\beta_{2} * \text { Atlantic herring }_{t-2,3}+\beta_{3} * W S W_{t}
$$

Where SL represents stratified mean spring trawl survey abundance of sand lance in year $t$, Calanus represents winter-summer Calanus abundance anomaly at a 3-4 year lag, Atlantic herring represents the Atlantic herring index at a 2-3 year lag, and $W S W$ represents warm slope water proportion in year $t$. Predictor variables were not strongly correlated $(\mathrm{r}<0.5)$. We inspected model residuals for temporal autocorrelation (see Figure 2-S11) and used generalized additive models to confirm linear relationships and use of linear regression. We also considered a model including a population dynamics term either in the form of a transformed response 
variable $\log \left(S L_{t} / S L_{t-3}\right)$ and an autoregressive term $\left(S L_{t-3}\right)$ to allow the model to represent the current abundance relative to the parent population.

We performed a leave-one-out cross-validation to test the predictive capability of our regression within our dataset. This method iteratively trains the model using $\mathrm{n}-1$ observations and uses the model fitted to the training set to predict the left-out observation. The $\mathrm{R}^{2}$ and rootmean-square-error for the predicted vs. observed values were calculated to determine model predictive performance.

\subsubsection{Change in slope water proportions with time}

A changepoint beta regression was fit to the time series of warm slope water to determine if a changepoint occurred in warm slope water proportion after 2000 , concurrent with other changes in regional hydrography near this time (Andres, 2016; McCarthy et al., 2018;

Gangopadhyay et al., 2019; Friedland et al., 2020a). Beta distributions were used because warm slope water values are represented as proportions. The stepwise beta regression was written as follows:

$$
\begin{aligned}
\log \left(\frac{W S W}{(1-W S W)}\right) & =\beta_{o}+\beta_{1} t+\beta_{2}(t-\tau) I_{\tau}(t) \\
I_{\tau}(t) & =0 \text { if } t \leq \tau \\
& =1 \text { if } t>\tau
\end{aligned}
$$

where WSW represents the proportion of warm slope water, $\mathrm{t}$ is time in years, and $\tau$ is the changepoint. The parameters $\beta_{0}, \beta_{1}, \beta_{2}$, $\tau$, and $\theta$ (the dispersion parameter) were fit via maximum $\log$ likelihood using the fmincon function in Matlab. Significance $(\alpha=0.05)$ was determined through parametric bootstrap (1000 simulations). The p-value was defined as the proportion of times the simulated difference in maximized log likelihood of the changepoint beta regression 
and the beta regression without a changepoint exceeded the difference between these regressions using our observed values, as described in the following equation:

$$
\begin{gathered}
p=\frac{\sum_{i=1}^{1000} X(i)}{1000} \\
X(i)=1 \text { if }\left(L L(i)_{C P_{s i m}}-L L(i)_{\beta_{s i m}}\right)>\left(L L_{C P_{o b s}}-L L_{\beta_{o b s}}\right) \\
=0 \text { if }\left(L L(i)_{C P_{s i m}}-L L(i)_{\beta_{s i m}}\right)<\left(L L_{C P_{o b s}}-L L_{\beta_{o b s}}\right)
\end{gathered}
$$

Where LL represents the maximum log likelihood, CP represents the changepoint regression, and $\beta$ represents the standard beta regression.

\subsubsection{Projections of sand lance abundance}

Log sand lance abundance was projected from 2020-2100 using multiple combinations of time-series predictor variables to represent several future scenarios. Eight scenarios were simulated, encompassed by four groupings ("current trajectory," "optimistic," “average herring," "reduced warm slope water"; Table 2-1; Figure 2-S3). Owing to observed declines in Atlantic herring biomass and recruitment (NEFSC, 2018), predicted declines in Calanus abundance (Grieve et al., 2017), and our observation of increases in warm slope water proportion, we termed the predictors following this pattern as the "current trajectory" scenario. Long-term projections indicate suitable Calanus habitat throughout the Northeast US Shelf will decrease in the coming century, although there is regional variability in observations and projections of this trend (Reygondeau and Beaugrand, 2011; Grieve et al., 2017; Ji et al., 2017). Atlantic herring recruitment has been below average since 2013, with six of the eight worst recorded recruitment years occurring since 2013 (NEFSC, 2020). Herring spawning stock biomass is also below 
average and declining, despite stable to decreasing fishing mortality rates (NEFSC, 2020). Such declines, which are not easily attributable to fishing mortality, led to speculation that aspects of the rapidly changing Northeast US shelf ecosystem may be the cause of poor herring recruitment and result in continued declines in Atlantic herring (though egg predation by haddock may also be a cause; Richardson et al., 2011). While it is impossible to know if Atlantic herring populations will eventually recover, it will likely at least take multiple years for the stock to recover from the historically poor recruitment levels seen since 2013.

Importantly, in each of the four groupings of projection scenarios, Calanus abundance was represented by a normal random variable with a linearly decreasing abundance of Calanus from the mean of the existing time series to $68 \%$ percent of its mean to represent the projected decrease in Calanus under Representative Concentration Pathway (RCP) 4.5 or to $50 \%$ of its mean, representing the projected decrease in Calanus abundance under RCP 8.5 (variance was assumed to remain constant in time; rates of decline follow Grieve et al., 2017). Each predictor was simulated independently owing to the lack of strong correlation among predictor variables. Sand lance abundance was then estimated using our fitted multiple linear regression and these simulated regressors. This was then repeated 1000 times to get a mean simulated log sand lance abundance, along with interquartile range, for each year from 2020-2100.

\subsubsection{Projection metrics}

For each scenario, we calculated the percent decline in sand lance abundance from the beginning of the simulation through the following equation:

$$
\text { Percent Decline }=\left(\frac{\overline{S L}_{x}-\overline{S L}_{2020}}{\overline{S L}_{2020}}\right) * 100
$$


Where $\overline{S L}_{x}$ represents the average projected sand lance abundance in year $x$.

We also calculated the proportion of years in each simulation of each scenario that had below average sand lance abundance and proportion of years that had below average abundances of both sand lance and Atlantic herring in the same year. This latter metric is perhaps most informative as this represents an ecosystem with below average abundance of both dominant lipid-rich forage fishes on the Northeast US shelf.

Table 2-1. Description of scenarios used in predictions of sand lance abundance through the end of the $21^{\text {st }}$ century.

\begin{tabular}{|c|c|c|c|c|c|}
\hline Scenario & & Description & Calanus & Atlantic herring & Warm slope water \\
\hline $\begin{array}{l}\text { Current } \\
\text { Trajectory }\end{array}$ & O & $\begin{array}{l}\text { Declining } \\
\text { Calanus } \\
\text { Low Atlantic } \\
\text { herring } \\
\text { Increasing warm } \\
\text { slope water }\end{array}$ & $\begin{array}{l}\text { Normal random variable } \\
\text { with linearly decreasing } \\
\text { mean }(32 \% \text { decrease in } \\
\text { RCP } 4.5,50 \% \text { decrease in } \\
8.5) \text {. Constant variance } \\
\text { with time corresponding } \\
\text { to variance of used time } \\
\text { series }(1977-2008)\end{array}$ & $\begin{array}{l}\text { Normal random } \\
\text { variable with } \\
\text { mean and } \\
\text { variance } \\
\text { corresponding to } \\
\text { previous decline } \\
\text { (1973-1988) }\end{array}$ & $\begin{array}{l}\text { Beta random variable } \\
\text { with mean and } \\
\text { dispersion parameter } \\
\text { following fitted } \\
\text { changepoint } \\
\text { regression }\end{array}$ \\
\hline Optimistic & $\begin{array}{l}0 \\
0\end{array}$ & $\begin{array}{l}\text { Declining } \\
\text { Calanus } \\
\text { Average Atlantic } \\
\text { herring } \\
\text { Pre-2009 warm } \\
\text { slope water }\end{array}$ & $\begin{array}{l}\text { Normal random variable } \\
\text { with linearly decreasing } \\
\text { mean }(32 \% \text { decrease in } \\
\text { RCP } 4.5,50 \% \text { decrease in } \\
8.5) \text {. Constant variance } \\
\text { with time corresponding } \\
\text { to variance of used time } \\
\text { series }(1977-2008)\end{array}$ & $\begin{array}{c}\text { Normal random } \\
\text { variable where } \\
\mu=0, \sigma=1\end{array}$ & $\begin{array}{l}\text { Beta random variable } \\
\text { with mean and } \\
\text { dispersion parameter } \\
\text { corresponding to pre- } \\
2009 \text { time series } \\
(1977-2008)\end{array}$ \\
\hline $\begin{array}{c}\text { Average } \\
\text { Herring }\end{array}$ & O & $\begin{array}{l}\text { Declining } \\
\text { Calanus } \\
\text { Average Atlantic } \\
\text { herring } \\
\text { Increasing warm } \\
\text { slope water }\end{array}$ & $\begin{array}{l}\text { Normal random variable } \\
\text { with linearly decreasing } \\
\text { mean }(32 \% \text { decrease in } \\
\text { RCP } 4.5,50 \% \text { decrease in } \\
8.5) \text {. Constant variance } \\
\text { with time corresponding } \\
\text { to variance of used time } \\
\text { series }(1977-2008)\end{array}$ & $\begin{array}{c}\text { Normal random } \\
\text { variable where } \\
\mu=0, \sigma=1\end{array}$ & $\begin{array}{l}\text { Beta random variable } \\
\text { with mean and } \\
\text { dispersion parameter } \\
\text { following fitted } \\
\text { changepoint } \\
\text { regression }\end{array}$ \\
\hline $\begin{array}{c}\text { Reduced } \\
\text { Warm Slope } \\
\text { Water }\end{array}$ & 0 & $\begin{array}{l}\text { Declining } \\
\text { Calanus } \\
\text { Low Atlantic } \\
\text { herring } \\
\text { Pre-2009 warm } \\
\text { slope water }\end{array}$ & $\begin{array}{l}\text { Normal random variable } \\
\text { with linearly decreasing } \\
\text { mean }(32 \% \text { decrease in } \\
\text { RCP } 4.5,50 \% \text { decrease in } \\
8.5) \text {. Constant variance } \\
\text { with time corresponding } \\
\text { to variance of used time } \\
\text { series }(1977-2008)\end{array}$ & $\begin{array}{l}\text { Normal random } \\
\text { variable with } \\
\text { mean and } \\
\text { variance } \\
\text { corresponding to } \\
\text { previous decline } \\
\text { (1973-1988) }\end{array}$ & $\begin{array}{l}\text { Beta random variable } \\
\text { with mean and } \\
\text { dispersion parameter } \\
\text { corresponding to pre- } \\
2009 \text { time series } \\
(1977-2008)\end{array}$ \\
\hline
\end{tabular}




\subsection{Results}

\subsubsection{Sand lance feeding, lipid accumulation, and growth}

Feeding incidence (the percentage of stomachs with prey) varied monthly for sand lance collected in 2019, with highest values occurring in the winter and spring $(52-84 \% ; \mathrm{n}=212$; Figure 2-2A). Feeding incidence decreased to zero in August and remained at zero through October, followed by a reappearance of prey in the guts in November-consistent with patterns of monthly feeding incidence from previous years (Figure 2-2A; Figure 2-S4). During months of feeding (other than November and February), the copepod Calanus finmarchicus (Calanus hereafter) dominated stomach contents, ranging from $30.4 \%$ of diet by biomass in February to $78 \%$ of the diet by biomass in April (Figure 2-2B).

Whole body lipid content of sand lance varied significantly by day of year and by region within Stellwagen Bank, peaking throughout the bank in August $(\mathrm{n}=197$; deviance explained $=$ $35.2 \%$; Figure 2-2C; Figure 2-S5). Notably, lipid content decreased rapidly between October and November in connection with spawning during this time window as evidenced by the sharp increase and subsequent decrease in gonadosomatic index (day of year $\Delta \mathrm{DE}=32.5 \%$, Figure 22E). Additionally, lipid content varied spatially within the bank, with highest lipid content values occurring on the northern portion of the bank in each month (region $\Delta \mathrm{DE}=3.0 \%$ ).

Intra-annual size-at-age for both age-2 $(\mathrm{n}=54)$ and age-3 $(\mathrm{n}=45)$ fish approached their annual maximum in the summer, concurrent with the cessation of feeding and lipid accumulation (Figure 2-2D). Age-2 fish reached their annual maximum length in June (mean $\mathrm{SL}=168.3 \mathrm{~mm}$, median $\mathrm{SL}=171.0 \mathrm{~mm}, \mathrm{~L}_{\infty}=170.8 \mathrm{~mm}$ ) and age-3 fish reached their annual maximum length by August (mean SL $=184.3 \mathrm{~mm}$, median $\mathrm{SL}=182.5 \mathrm{~mm}, \mathrm{~L} \infty=184.0 \mathrm{~mm}$ ). 

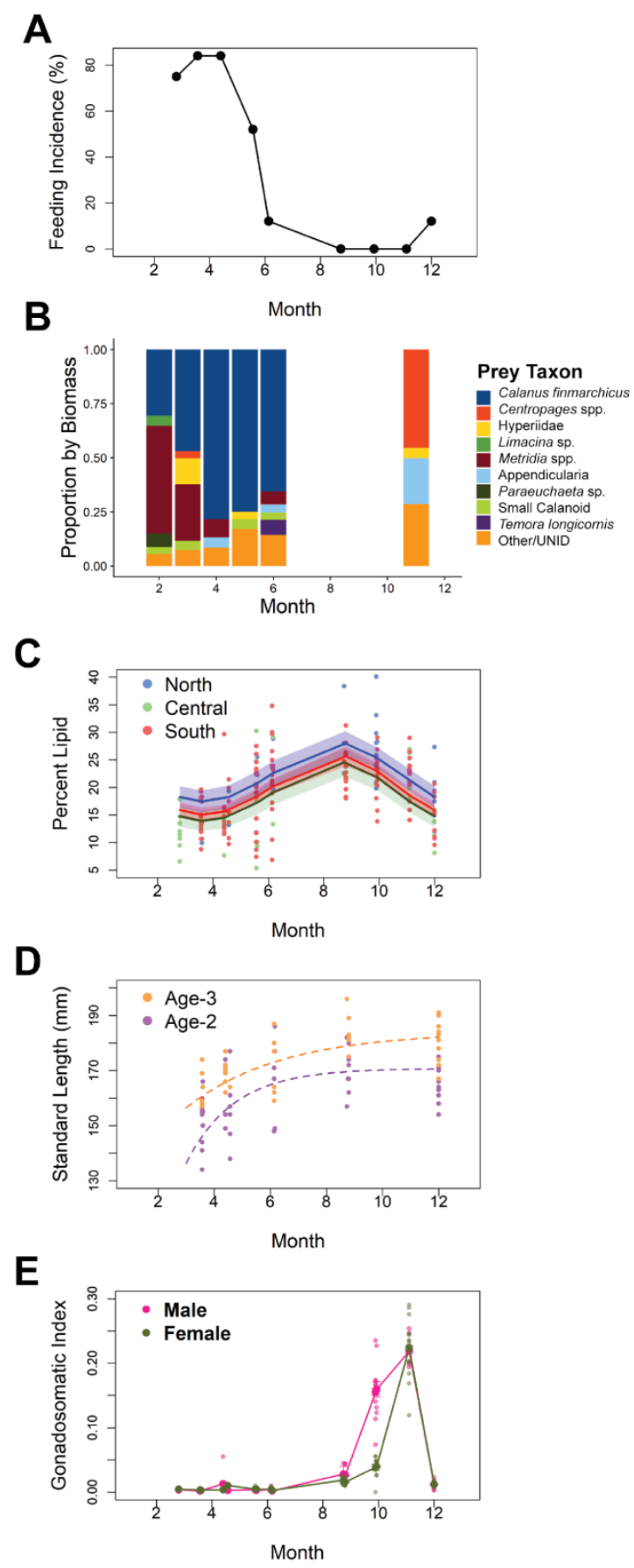

Figure 2-2. Ecology and phenology of adult sand lance collected on Stellwagen Bank in 2019. (a) Feeding incidence by DOY for fish collected in $2019(\mathrm{n}=202)$. (b) Sand lance diet by proportion of biomass for each month ( $\mathrm{n}=70$ fish containing prey, $\mathrm{n}=15279$ prey). (c) Per cent lipid of whole fish for sand lance separated by region and DOY on Stellwagen Bank $(n=197)$. Solid lines represent fitted values from a generalized additive model including month and region with shading representing $95 \%$ confidence intervals (deviance explained $=38.5 \%)$. (d) Standard length by DOY for age-2 $(n=54)$ and age-3 $(n=45)$ and dashed lines represent fit von-Bertalanffy curves for each age class. (e) Gonadosomatic index (GSI) by DOYs for males $(n=105)$ and females $(n=107)$ along with mean \pm SEM GSI for each sex by monthly collection. Horizontal axis ticks in each plot represent first of the respective month. 


\subsubsection{Sand lance abundance regression}

Sand lance abundance and lagged winter-summer Calanus abundance anomalies were significantly correlated throughout the time series $\left(R^{2}=0.21, \mathrm{p}=0.015\right)$, and particularly well in the 1980s and 1990s $\left(R^{2}=0.46, \mathrm{p}<0.01\right.$; Figure 2-3A). However, the relationship decouples later in the time series and no longer correlated, concurrent with an increase in Atlantic herring in the region (Figure 2-3A). Lagged Atlantic herring index and sand lance abundance were negatively correlated $\left(R^{2}=0.28, \mathrm{p}<0.01\right)$ throughout the time series, with Atlantic herring in low abundance during the 1980s "boom" of sand lance and in high abundance when the sand lance time series began to decouple from lagged Calanus abundances in the late 1990s and early 2000s (Figure 2-3A).
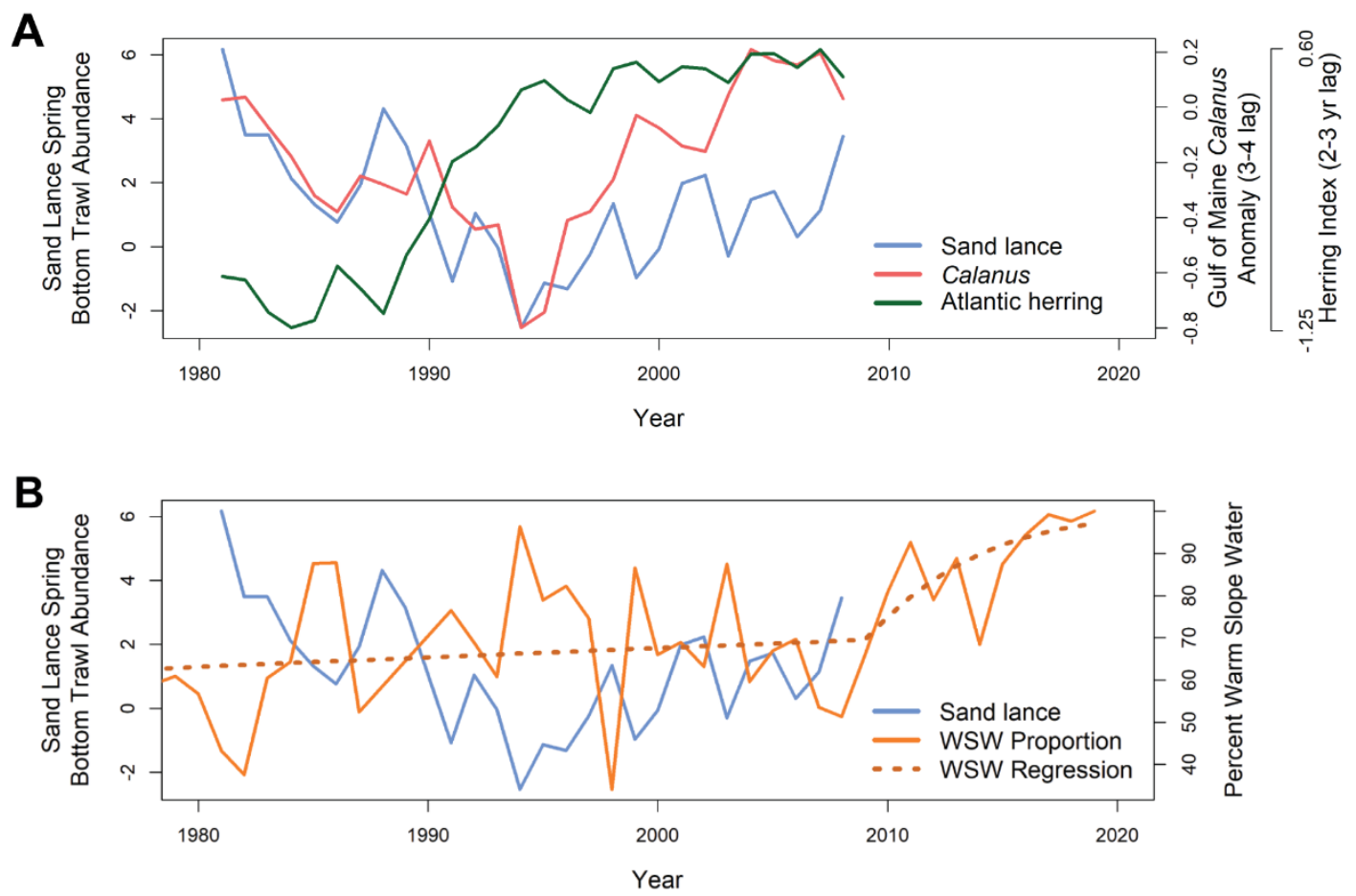

Figure 2-3. Time series of the environmental drivers of sand lance abundance. (a) NEFSC spring bottom trawl sand lance abundance (log scale; blue), 3- to 4-year lagged wintersummer Calanus abundance anomaly in the Gulf of Maine (red), and 2- to 3-year lagged Atlantic herring index (green). (b) NEFSC spring bottom trawl sand lance abundance (log scale; blue) and warm slope water proportion entering the Northeast Channel (gold). Dashed line indicates fitted changepoint beta regression (changepoint $=2009, p<0.001)$. 
Warm slope water proportion was negatively correlated to log sand lance abundance $\left(R^{2}\right.$ $=0.52, \mathrm{p}<0.01 ;$ Figure 2-3B). A cross-correlation analysis indicated that only a 0 -year lag between warm slope water proportion and sand lance abundance was significant (adjusted for autocorrelation; Figure 2-S6). Incorporating 3-4 year lagged Calanus abundance, 2-3 year lagged Atlantic herring index, and unlagged warm slope water proportion in a multiple linear regression explains a majority of the interannual variance in the northern sand lance spring trawl survey, indicating these three mechanisms are likely the dominant drivers of northern sand lance throughout the Northeast US shelf $\left(R^{2}=0.76\right.$; Figure 2-3; Table 2-2). Inclusion of population dynamics terms either as a transformed response variable or as an autoregressive term did not improve model fit and thus were not included.

Leave-one-out cross-validation indicated high predictive performance within the dataset $\left(\mathrm{R}^{2}=0.68, \mathrm{RMSE}=1.07\right)$ and showed no notable outliers between the predicted and observed values (Figure 2-S7).

Table 2-2. Fitted parameter estimates for the multiple linear regression of sand lance abundance anomaly ( $\mathrm{n}=25 \mathrm{yrs})$.

\begin{tabular}{ccc} 
Regressor & $\begin{array}{c}\text { Slope } \\
\text { Estimate }\end{array}$ & p-value \\
\hline Gulf of Maine Calanus Anomaly & 2.48 & 0.009 \\
Atlantic herring index & -1.27 & $<0.001$ \\
Warm slope water proportion & -5.89 & $<0.001$
\end{tabular}

\subsubsection{Warm slope water changepoint}

The fitted changepoint beta regression indicated a significant changepoint in 2009 $(\mathrm{p}<0.001)$, with the rate of warm slope water proportions increasing with time rising by over tenfold after $2009\left(\beta_{1}=0.01 ; \beta_{2}=0.26\right.$; Figure 2-3B; Table 2-3). Slope water proportions showed 
no significant mean change with time prior to this observed change point (i.e. from 1977-2008;

Figure 2-3B; Table 2-3).

Table 2-3. Fitted parameter estimates for the changepoint beta regression of warm slope water proportion with time $(\mathrm{n}=39 \mathrm{yrs})$. Model $\mathrm{p}$-value $<0.001$.

\begin{tabular}{cc} 
Parameter & Estimate \\
\hline$\beta_{\mathrm{o}}$ & -18.8 \\
$\beta_{1}$ & 0.01 \\
$\beta_{2}$ & 0.26 \\
$\tau$ & 2009
\end{tabular}

\subsubsection{Projections of sand lance abundance}

Rates of sand lance decline were similar for each RCP projection in the four scenarios (current trajectory, reduced warm slope water, average Atlantic herring, and optimistic). The average decline in sand lance abundance was $45.6 \%$ and $74.6 \%$ by 2100 for RCP 4.5 and 8.5 , respectively (Figure 2-4). The minimum decline for both RCP 4.5 and 8.5 was in the "reduced warm slope water" scenario, with percent declines of $38.5 \%$ and in the "optimistic" scenarios for RCP 8.5 at $71.4 \%$. The maximum percent decline for both RCP scenarios was in the "average Atlantic herring" scenario at $52.0 \%$ and in the "current trjectory" scenario at $76.9 \%$.

Scenarios varied drastically in both the proportion of years with below average sand lance abundance and proportion of years with below average sand lance and Atlantic herring abundance (Figure 2-4, Table 2-4). The "reduced warm slope water" scenario had the lowest average proportion of years with below average sand lance abundance, with $34 \%$ and $47 \%$ of years having below average sand lance abundance for RCP 4.5 and 8.5, respectively. The “average Atlantic herring" scenario resulted in the highest number of years with below average sand lance abundance, averaging $97 \%$ and $98 \%$ of years for RCP 4.5 and 8.5 , respectively. 


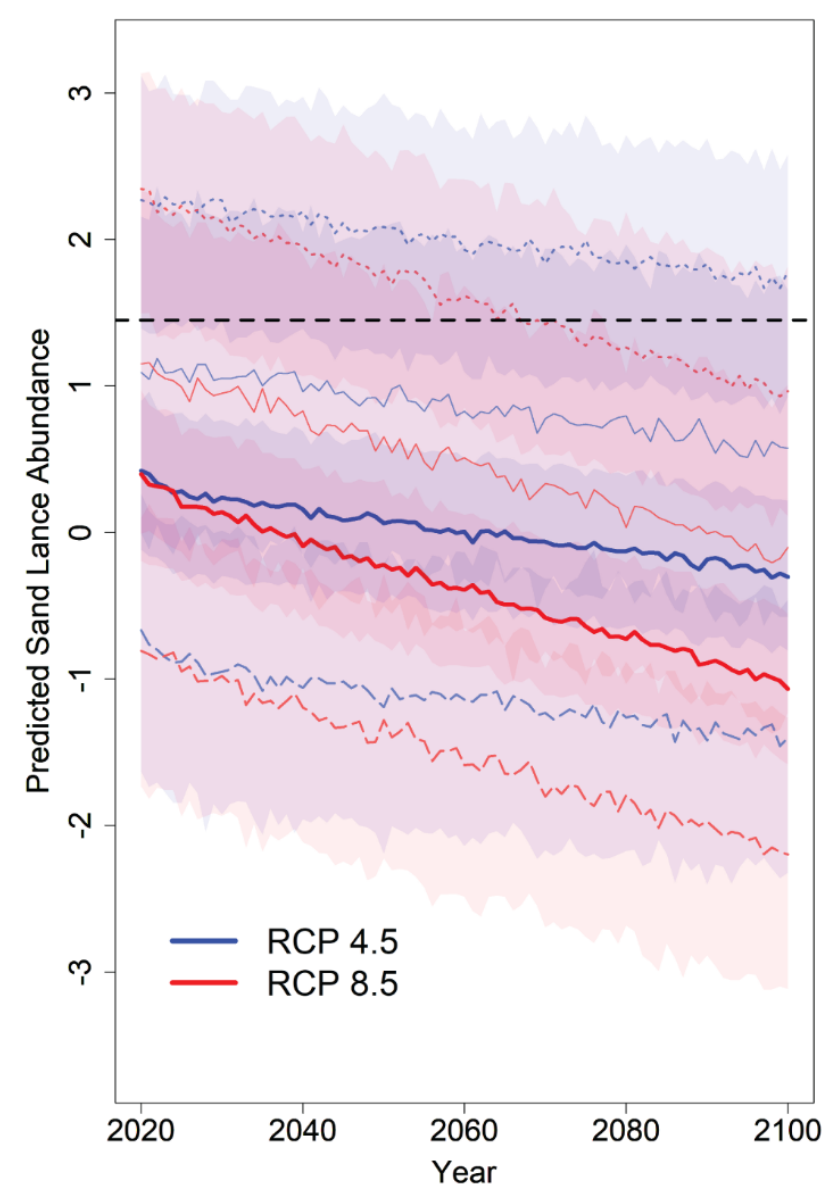

Figure 2-4. Projections of sand lance abundance under various scenarios. Predicted sand lance abundance (log) under "reduced warm slope water" scenario (dotted lines), "optimistic" scenario (thin solid lines), "current trajectory" scenario (thick solid lines), and "average Atlantic herring" scenario (dashed lines). Color represents the projected decline of Calanus under RCP 4.5 (blue) or the projected decline of Calanus under RCP 8.5 (red). Shaded regions represent bounds for the upper $(75 \%)$ and lower $(25 \%)$ quantiles. Black dashed line represents mean sand lance abundance from 1968 to 2008 .

When Atlantic herring are included in the calculation of below average years of abundance, the "current trajectory" scenario predicts the most below average years, while the "optimistic scenario" results in the lowest number of these years (Figure 2-5). An average of $20 \%$ of years in RCP 4.5 and $26 \%$ of years in RCP 8.5 of the "optimistic" scenario had both negative sand lance and negative Atlantic herring anomalies. However, an average of $94 \%$ of years in RCP 4.5 and $96 \%$ of years in RCP 8.5 of the "current trajectory" scenario had both 
negative sand lance and negative Atlantic herring anomalies indicating nearly all years having below average sand lance and Atlantic herring in the future.

Table 2-4. Percent sand lance decline under four scenarios and each RCP projection of Calanus decline and proportions of years from 2020-2100 with negative sand lance anomalies and with both negative sand lance and negative Atlantic herring anomalies.

\begin{tabular}{ccccccc} 
Scenario & $\begin{array}{c}\text { RCP 4.5 } \\
\text { Decline } \\
(\%)\end{array}$ & $\begin{array}{c}\text { Proportion of } \\
\text { Years with } \\
\text { Negative Sand } \\
\text { Lance } \\
\text { Anomalies }\end{array}$ & $\begin{array}{c}\text { Proportion of } \\
\text { Years with } \\
\text { Negative Sand } \\
\text { lance \& } \\
\text { Herring } \\
\text { Anomalies }\end{array}$ & $\begin{array}{c}\text { RCP 8.5 } \\
\text { Decline } \\
(\%)\end{array}$ & $\begin{array}{c}\text { Proportion of } \\
\text { Years with } \\
\text { Negative Sand } \\
\text { Lance } \\
\text { Anomalies }\end{array}$ & $\begin{array}{c}\text { Proportion of } \\
\text { Years with } \\
\text { Negative Sand } \\
\text { Lance \& } \\
\text { Herring } \\
\text { Anomalies }\end{array}$ \\
\hline $\begin{array}{c}\text { Current } \\
\text { trajectory } \\
\text { Reduced warm } \\
\text { slope water } \\
\text { Average } \\
\text { Atlantic } \\
\text { herring }\end{array}$ & -51.6 & 0.96 & 0.95 & -76.9 & 0.98 & 0.97 \\
Optimistic & -38.5 & 0.34 & 0.33 & -74.8 & 0.47 & 0.46 \\
\hline
\end{tabular}
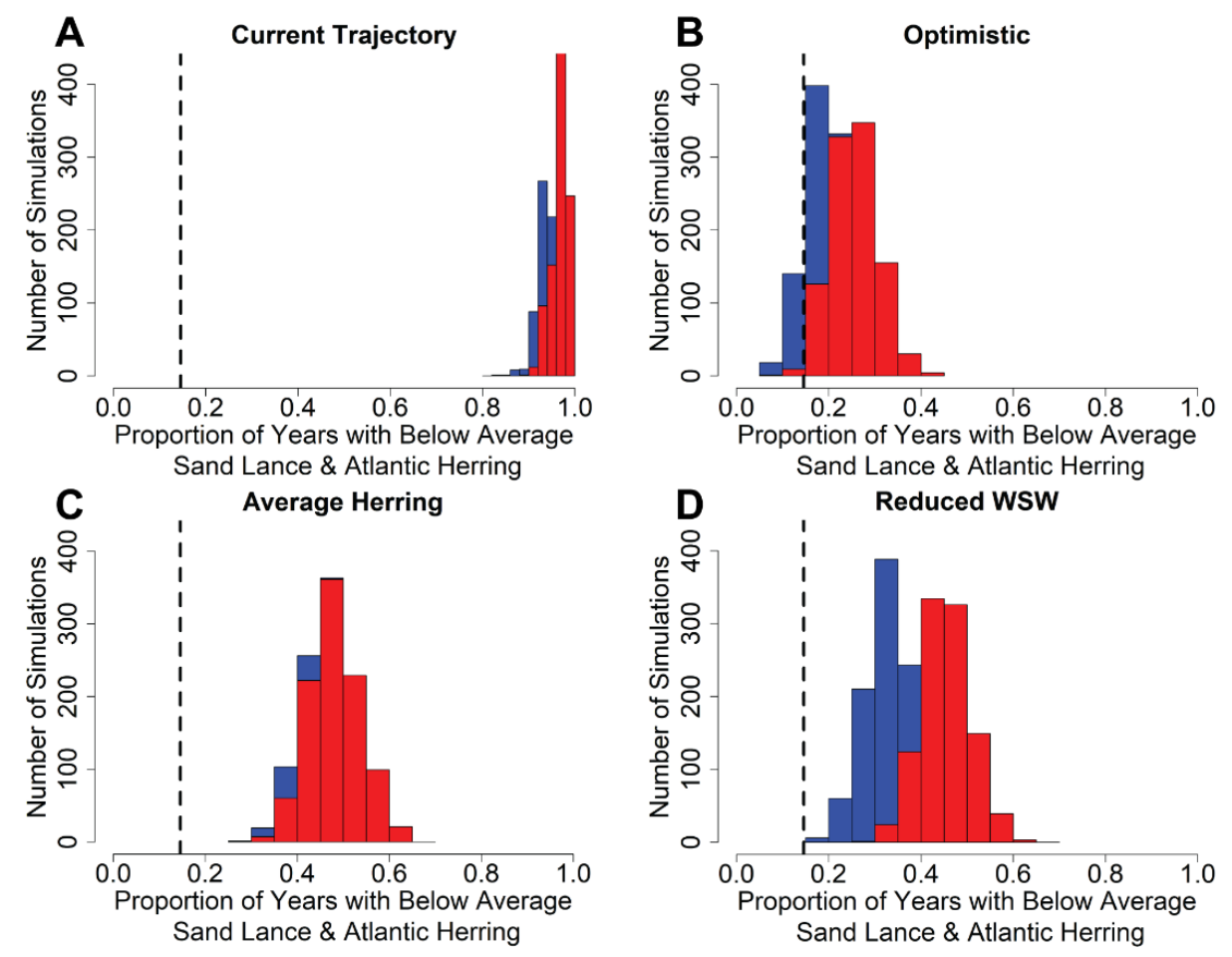

Figure 2-5. Histograms representing proportion of years between 2020 and 2100 that each simulation had negative sand lance abundance anomalies and negative Atlantic herring anomalies for (a) the "current trajectory" scenario, (b) "optimistic" scenario, (c) "average herring" scenario, and (d) "reduced warm slope water" scenario. Color represents RCP 4.5 (blue) 
and 8.5 (red) rates of Calanus decline. Thick dashed line represents proportion of years from 1968 to 2008 with both negative sand lance and Atlantic herring anomalies.

\subsection{Discussion}

Our work indicates that the future of adult northern sand lance in the Northeast US shelf ecosystem is tenuous, owing to the observed and predicted changes in hydrography and prey availability across the region. The sensitivity of sand lance to these changing factors are directly linked to their capital breeding strategy, whereby the species has a defined feeding and growth period, and individual lipid reserves undergo a two-fold change within one breeding season to allocate energy for reproduction. Further, if ongoing declines in Atlantic herring recruitment and biomass persist for decades to come (NEFSC, 2018), our predictions suggest the Northeast US shelf will be in a state of low adult abundances of its two most dominant lipid-rich forage fishes for much of the $21^{\text {st }}$ century.

Projections of long-term declines in sand lance abundance indicate marked change in the forage fish complex of one of the world's most economically valuable shelf ecosystems (Hoagland et al., 2005) as concurrent negative anomalies of northern sand lance and Atlantic herring have only occurred in six years from 1968-2008. Such a shift may open niche space for higher abundances of warm, temperate small pelagic species such as Atlantic butterfish (Peprilus triacanthus) and Atlantic menhaden (Brevoortia tyrannus), diversifying the forage fish complex (Friedland et al., 2020b). This, combined with and linked to changes to Calanus' distribution, will likely alter the food web of the Northeast US shelf and represent a northward contraction of the region's "lipidscape" (Record et al., 2018). The timing and implications of a shift in forage

fish community warrants continued, targeted estimates of forage fish abundances and concurrent measurements of the condition of top predator taxa throughout the Northeast US shelf. 
Tropicalization and shifts in forage community are likely to be detrimental to lipid-rich piscivores, such as humpback whales and bluefin tuna (Thunnus thynnus), while simultaneously ushering in piscivores commonly seen at lower latitudes such as black sea bass (Centropristis striata) and summer flounder (Paralichthys dentatus) (Henderson et al., 2017; Kleisner et al., 2017). This potential shift in community composition, from forage fish to top predators, would change much of the food web and fisheries of this region.

Declines in Ammodytes condition and catch have been documented in the Pacific, suggesting this key type of forage fish may be in global jeopardy due to shifting climate (Nishikawa et al., 2020; Von Biela et al., 2019). Suggestions of sensitivity of European congeners to temperature further this concern (Lindegren et al., 2018). Many protected species on the Northeast US shelf, such as humpback whales and seabirds, consistently target sand lance as their primary forage and may be in jeopardy from declining sand lance regardless of Atlantic herring's abundance (Staudinger et al., 2020). Populations of seabirds in the Northeast Atlantic suffer high chick mortality when local sand eel (A. marinus) abundances decline (Harris and Wanless, 1991; Rindorf et al., 2000). Recent reports indicate that declines in local sand lance populations even decrease adult survival of Arctic terns (Sterna paradisaea) in Iceland (Peterson et al., 2020). We may thus expect similar levels of repercussions to sand lance-reliant top predators on the Northeast US shelf within this century with recent data suggesting that declines in productivity of the endangered roseate tern (Sterna dougallii) in the Northeast US due to decreasing sand lance are already underway (J. Walsh, pers. comm.).

The lines of concurrent evidence of a capital breeding strategy for northern sand lance are consistent with observations of congeners around both the Pacific and Northeast Atlantic (Robards et al., 1999; Wright et al., 2017; Von Biela et al., 2019). However, one major 
difference is timing of the dormancy period. Ammodytes in the Northeast Atlantic are largely considered to be dormant in the winter, along with Ammodytes dubius populations in Greenland (van Deurs et al., 2011; Danielsen et al., 2016; Wright et al., 2017). Our observations of late summer dormancy indicate aestivation - a pattern observed in the warmer water Ammodytes japonicus - as opposed to hibernation observed in Northeast Atlantic congeners (Kuzuhara et al., 2019). Robards et al. (1999) also suggest that Ammodytes personatus in the Pacific undergo winter dormancy, though they did not analyze stomach contents and their observations of seasonal lipid accumulation match the pattern we observe. It is therefore possible Ammodytes personatus also undergoes aestivation and feeds in the winter, contrary to current theory.

Our work further supports the importance of prey availability, namely lipid-rich zooplankton, to the life history of Ammodytes. Studies throughout the Pacific have indicated sand lance growth is linked to food availability (Kuzuhara et al., 2019; Von Biela et al., 2019) and, further, that recruitment follows changes in zooplankton abundance on decadal scales (Nishikawa et al., 2020). We observed that the seasonal feeding pattern of Ammodytes dubius was consistent with times of historically high Calanus abundance in the Northeast US Shelf ecosystem where peaks in abundance typically occur from April through June, after which Calanus enter diapause in the late summer (Kane, 2007; Figure 2-S8,2-S9). This suggests the timing of sand lance feeding and subsequent reproduction may be linked to the phenology of Calanus. Additionally, the overlap of lipid accumulation and somatic growth with feeding, and the subsequent cessation of feeding, growth, and lipid accumulation during gonad development, indicate that northern sand lance condition and reproduction may be sensitive to bottom-up forcing of prey availability. Indeed, even spatial differences in Calanus availability appear to drive differences in lipid accumulation in northern sand lance (Figure 2-2C). Elevated lipid 
content on the northern portion of Stellwagen bank corresponds with localized increases in seasonal Calanus abundance brought by the western Gulf of Maine Coastal Current that intercepts this region (Figure 2-S1, 2-S2). Such a link between sand lance condition and Calanus abundance indicates that projected decreases in Calanus on the Northeast US shelf will likely lead to a decrease in availability of high-quality prey for sand lance, and thus may decrease parental condition and spawning output (Grieve et al., 2017).

While consistent with other studies in indicating the importance of Calanus to Ammodytes, the mechanism suggested from our data differs from larval match-mismatch hypotheses proposed to drive Ammodytes recruitment in the Northeast Atlantic (T. Régnier et al., 2017) in that our data suggest Calanus abundance is linked to adult sand lance condition. While the three year lag of sand lance behind Calanus abundance may represent both an effect of Calanus on parental condition of age- 2 fish and larval feeding for age3 fish, the strongest time-lag correlations between sand lance abundance and Calanus anomalies occur at a 3-4 year lag as opposed to a 2-3 year lag, indicating the effect of parental condition is, at the very least, more pronounced than an effect of Calanus abundance on larval feeding (Figure 2-S10). However, it is important to note that this does not exclude the possibility that Calanus abundance plays a role in the early life history of sand lance and further research is needed regarding this question. An effect of parental condition on offspring abundance and/or survival has been both theorized and observed in multiple systems (Green, 2008; Hare, 2014; Hixon et al., 2014, Saenz-Agudelo et al., 2015), including for haddock on Georges Bank (Friedland et al., 2008), and has even been incorporated into population models for herring in Iceland (Oskarsson and Taggart, 2010). It is noteworthy that this effect of Calanus on sand lance recruitment appears to be largely independent of the sand lance spawning stock as population dynamics terms did not 
improve model fit. This may be due to parental condition overwhelming an effect of abundance and/or the per capita benefit of increased Calanus on parental condition being reduced in years and areas with high densities of sand lance. Both scenarios could lead to present populations of sand lance being largely independent of the size of their parents' population, as observed here. We are also presently unsure if increased Calanus abundance only plays a role in lipid accumulation, or a role in both lipid accumulation and growth. Future studies are needed to assess changes in length-at-age and lipid accumulation for sand lance with changing zooplankton abundance and regimes.

In addition to the capital breeding strategy driving recruitment through parental condition, the large intra-annual change in lipid content for sand lance makes them susceptible to overwinter conditions. Individuals are at their lowest energy reserves after spawning and are thus sensitive to increased temperatures and shortages of prey. Such sensitivity to winter conditions has been shown in Ammodytes marinus, indicating this scenario is not unique to northern sand lance (van Deurs et al., 2011). This sensitivity becomes problematic for sand lance populations with recent shifts in hydrography, particularly the changepoint in warm slope water proportion entering the Northeast Channel (Figure 2-3). This changepoint in hydrography will likely lead to northern sand lance enduring winter regimes with consistently high temperatures and low prey (Record et al., 2019).

The changepoint in warm slope water proportion is noteworthy for the Northeast US shelf ecosystem. Other changepoints have been identified in advective processes in the Northeast US shelf region since 2000 , notably a near doubling in the number of warm core rings shed from the Gulf Stream, a westward shift of the Gulf Stream destabilization point, and a rapid shift to an earlier spring transition date throughout the Northeast US shelf after 2008 (Friedland et al., 2015; 
Andres, 2016; Gangopadhyay et al., 2019). The cause of this changepoint is still undetermined, but hypotheses include a slowing of the Gulf Stream and warming of Slope Sea waters on the coastal side of the Gulf Stream (Andres, 2016; Gangopadhyay et al., 2019; McCarthy et al., 2018). While a change in survey gear precludes consistent estimates of northern sand lance abundance after 2008, this rapid increase in warm slope water proportion following 2009 is likely to be detrimental to sand lance populations throughout the Northeast US shelf via increasing overwinter mortality of this species.

Our work also indicates that sand lance populations may be heavily regulated by intraguild predation from Atlantic herring. This mechanism has been proposed before (Fogarty et al., 1991; Polis et al., 1989), and subsequent diet studies indicate larval sand lance are important prey for Atlantic herring and Atlantic mackerel (though the overall abundance of the former is much greater; Suca et al., 2018). These dynamics largely allow either Atlantic herring or northern sand lance to be the dominant forage fish throughout the Northeast US shelf in any given year. However, when other drivers prevent a species from rebounding when their intraguild predator is low, concurrent low abundances of both species can occur. While this has not happened often in the case of the Northeast US shelf, our projections indicate this situation of low northern sand lance and Atlantic herring abundances may happen frequently in the coming decades, and thus the ecosystem level implications of this change require monitoring.

Perhaps the most alarming result of our projections is that the "current trajectory" scenario - based on current trends and knowledge regarding the future of Calanus, herring, and warm slope water-indicates the worst outcome for the future of forage fish complex on the Northeast US shelf. These projections were also robust to the rate of decline of Calanus, with both RCP 4.5 and 8.5 rates of decline resulting in greater than $90 \%$ of years between $2020-2100$ 
having below average abundance of both sand lance and Atlantic herring. Given concurrent changepoints in warming rates and advection throughout the region (Andres, 2016;

Gangopadhyay et al., 2019; Friedland et al., 2020a), and Calanus' sensitivity to changing temperature and salinity (Grieve et al., 2017), the least certain aspect of these projections is the future of Atlantic herring. However, even if Atlantic herring are to return to oscillating around their historic mean, it would take a drastic decline in warm slope water proportions to allow sand lance and Atlantic herring abundances on the Northeast US shelf to return to similar levels observed prior to 2008. Even this "optimistic" scenario results in a higher proportion of years with negative anomalies of sand lance and Atlantic herring than observed from 1968-2008, showing the projections of change to the forage fish complex on the Northeast US shelf-most notably a clear decline in sand lance - are consistent among projections. However, the true disappearance of northern sand lance may take longer than the NEFSC trawl survey indicates. The deleterious effect of warm slope water occurs for post-spawning adults (age-2+) and thus it is likely age-1 sand lance will be able to withstand this change in hydrography. These younger fish may not be sufficient for many predators though, as the ongoing decline in roseate tern productivity indicates (J. Walsh, pers. comm.). Further, if warm slope water affects catchability of sand lance in the NEFSC spring survey, even if the effect is small relative to changes in abundance, this would lead to sand lance disappearing at a slower rate than many of our projections suggest. Such an effect would result in a future more closely following either the "reduced warm slope water" or "optimistic" scenario. Our analysis of seasonal bottom temperatures suggests a catchability effect is unlikely, but sand lance focused surveys could better resolve this question and refine projections of their abundance. While the future of the forage fish on the Northeast US shelf will certainly have a great degree of spatiotemporal 
complexity not incorporated or assessed in our projections, large scale changes to sand lance abundance are likely to have ecosystem-wide effects and need to be considered in management and protection of top predator populations throughout the region.

\subsection{Supplemental Methods, Figures, and Tables}

\subsubsection{Stomach Content Analysis}

Stomach contents were analyzed using a Leica 205C stereomicroscope. Prey were identified to lowest possible taxonomic unit, except for small calanoids comprising the genera Pseudocalanus, Paracalanus, Clausocalanus, and Microcalanus which were collectively referred to as "small calanoid" due to difficulty in identifying them morphologically (Suca et al., 2018). The first ten individuals of each prey taxon in each stomach were measured using an optical micrometer and measurements were incorporated into length-weight relationships to estimate the biomass contribution of each prey taxon (see Table S-S2 for length weight relationships). Prey copepods were not staged, however, Calanus finmarchicus prey were separated to into juvenile (CI-CIV) and late-stage (CV and adults) given the size difference and tendency for the stage-specific abundances of this taxon to vary independently (Greene et al., 2013). When possible, damaged copepods that precluded identification were grouped into small and large groups and enumerated separately. As proxies for size of damaged copepods for biomass estimates, the average size for small calanoids, Centropages spp., and Temora longicornis within each stomach was assigned as the length for small damaged copepods while the average size for Metridia spp. and late stage Calanus finmarchicus were used for the approximate length of large damaged copepods. 


\subsubsection{Age and Growth}

Whole otoliths were extracted from each fish, cleaned with deionized water and a Kimwipe and photographed through a Leica DSLR phototube connected to a Leica M205C stereomicroscope. Right sagittal otoliths were imaged and used for ageing. Whole otoliths were read twice independently by the same reader. If age estimates did not match, a third read was performed to determine a final age for the individual, assuming it matched an age from the previous two reads (Matta and Baker, 2020). Ageing of Ammodytes using whole otoliths is consistent with age analysis performed on the congener Ammodytes personatus (Von Biela et al., 2019; Matta and Baker, 2020).

\subsubsection{Lipid Extraction}

Each whole fish (minus stomach, head, and intestine contents) was freeze-dried, pulverized, and $0.3000 \mathrm{~g}$ of dried tissue weighed for lipid extraction. Each dried tissue aliquot was treated with 2:1 chloroform methanol $(\mathrm{v} / \mathrm{v})$, homogenized for $30 \mathrm{~s}$ and centrifuged for $5 \mathrm{~min}$ at $4000 \mathrm{rpm}$. The supernatant was decanted to a fresh tube, and the extraction repeated. $3 \mathrm{ml}$ of $0.9 \% \mathrm{NaCl}$ solution was added to the combined supernatant, followed by centrifugation for 5 min to create a biphasic system. The organic layer was then decanted to a pre-weighed vial and dried at $40^{\circ} \mathrm{C}$ until the weight of the vial changed less than $0.0001 \mathrm{~g}$. Vials cooled to room temperature in a desiccator before final weights were taken. Percent lipid was determined by dividing the difference in weight of the dried vial and its empty weight by the initial amount of tissue used for the extraction.

\subsubsection{FVCOM Bottom Temperature Analysis}

Bottom temperature analyses were performed using the hindcasts from the third generation Gulf of Maine Finite Volume Community Ocean Model (FVCOM-GOM3; Chen et 
al., 2011). FVCOM-GOM3 assimilates satellite-derived SST and CTD data from buoys and surveys (Xue et al., 2014), resulting in reliable temperature hindcasts. For temperature analyses, daily bottom temperatures were averaged for each node of the model domain located west of $65^{\circ} \mathrm{W}$, south of $44.5^{\circ} \mathrm{N}$, deeper than $20 \mathrm{~m}$, and shallower than $300 \mathrm{~m}$ (Figure 2-S13) for January through March (winter) and March through April (spring, overlapping with the survey) of each year. These values were then averaged to $0.25^{\circ} \times 0.25^{\circ}$ bins to reduce spatial bias toward regions with high numbers of nodes before calculating an average bottom temperature for each season of each year. The log area weighted stratified mean abundance of sand lance from the NEFSC spring survey was weakly negatively correlated with mean winter bottom temperature $(r=-0.11$, $\mathrm{p}=0.55$, Figure $2-\mathrm{S} 14$ ) and very weakly positively correlated with mean spring bottom temperature $(\mathrm{r}=0.07, \mathrm{p}=0.68$, Figure $2-\mathrm{S} 15)$. 


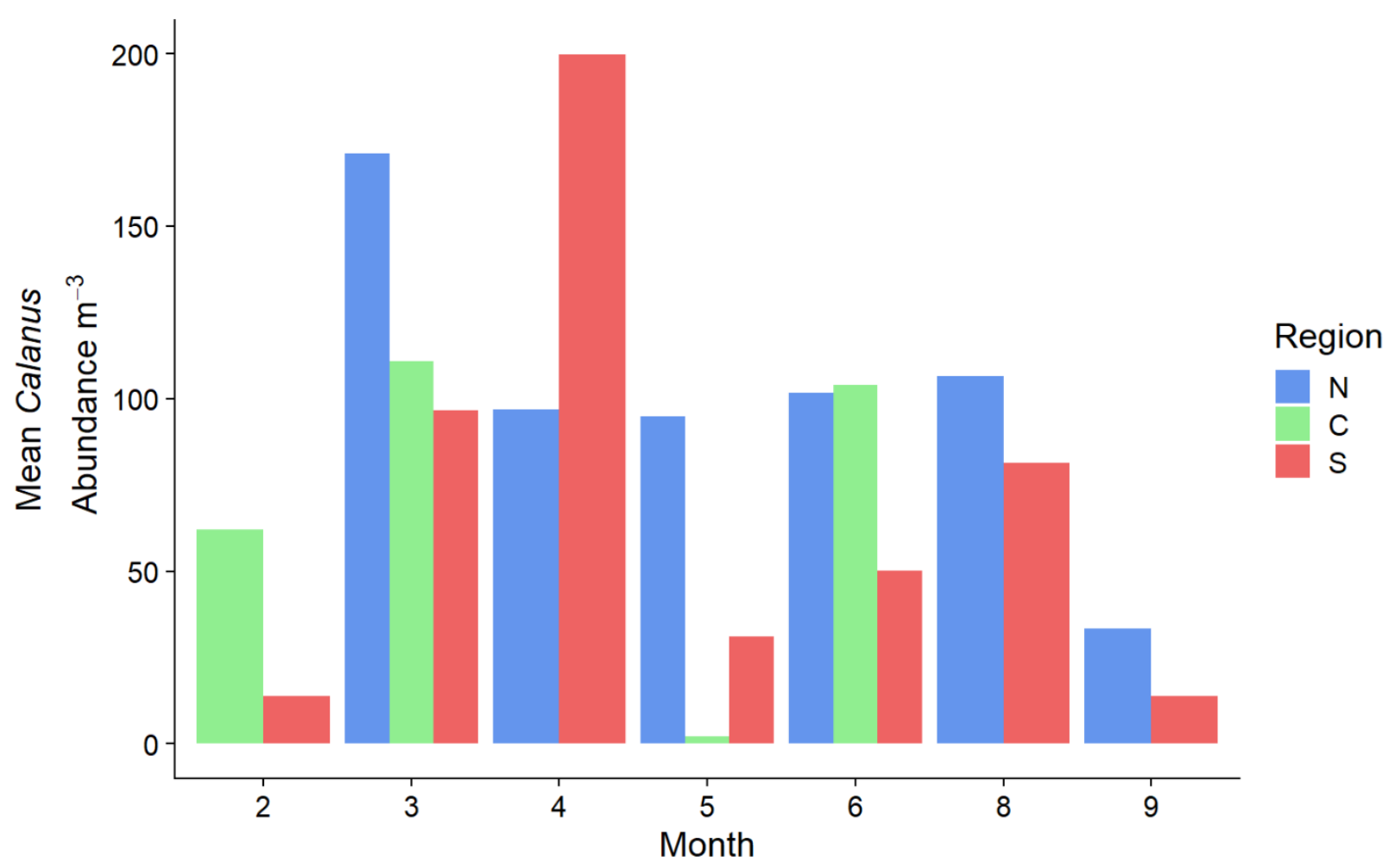

Figure 2-S1. Mean Calanus abundance by region on Stellwagen Bank by month in 2019. Colors represent region ( $\mathrm{n}=52$ casts). 

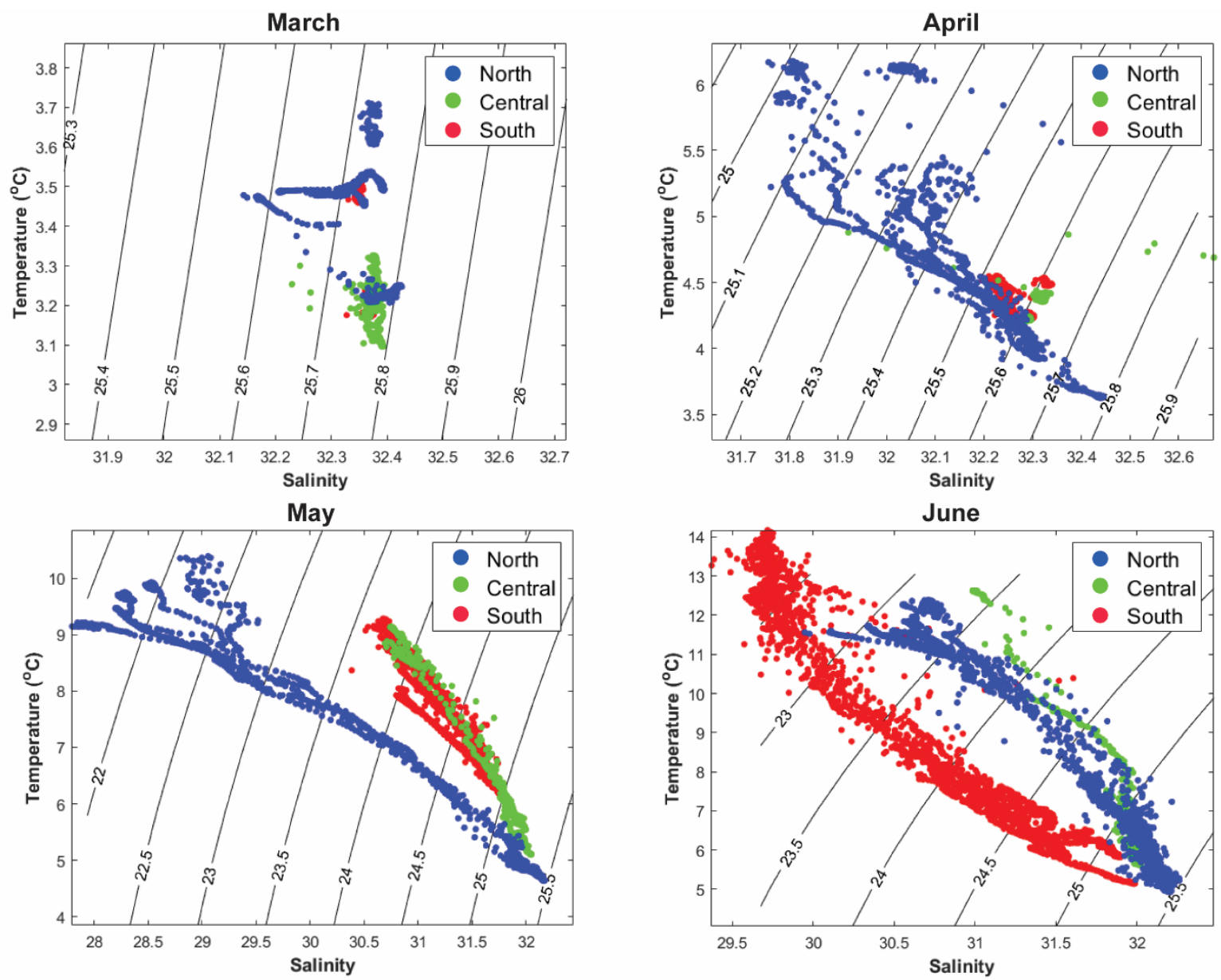

Figure 2-S2. Monthly temperature-salinity plots of CTD casts on Stellwagen in 2019. Colors represent region and sold lines represent isopycnals. 

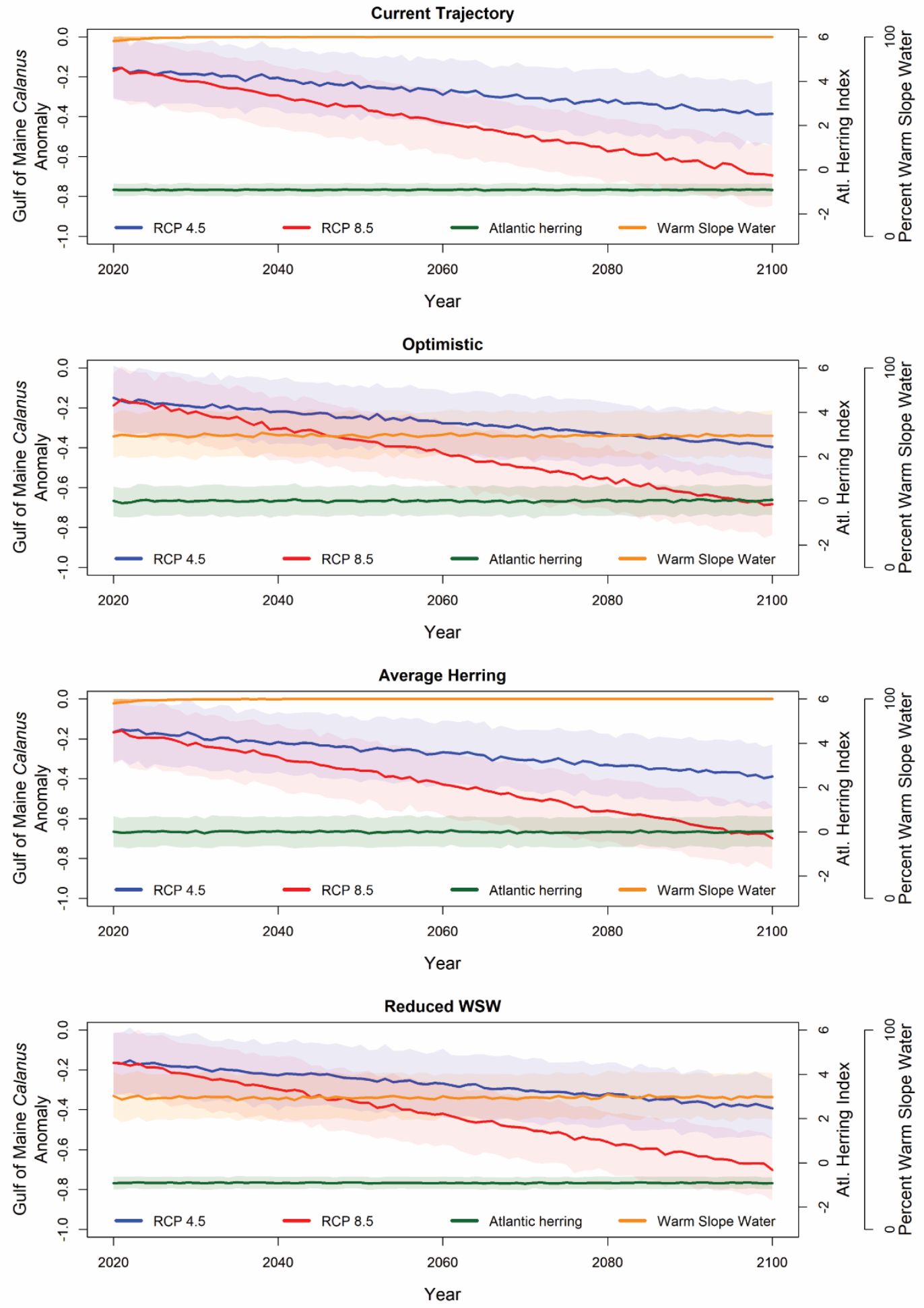

Figure 2-S3. Time series of projected sand lance drivers. Blue and red represent rate of Calanus decline under different RCPs. Shading represents bounds of the upper (75\%) and lower (25\%) quantiles. 


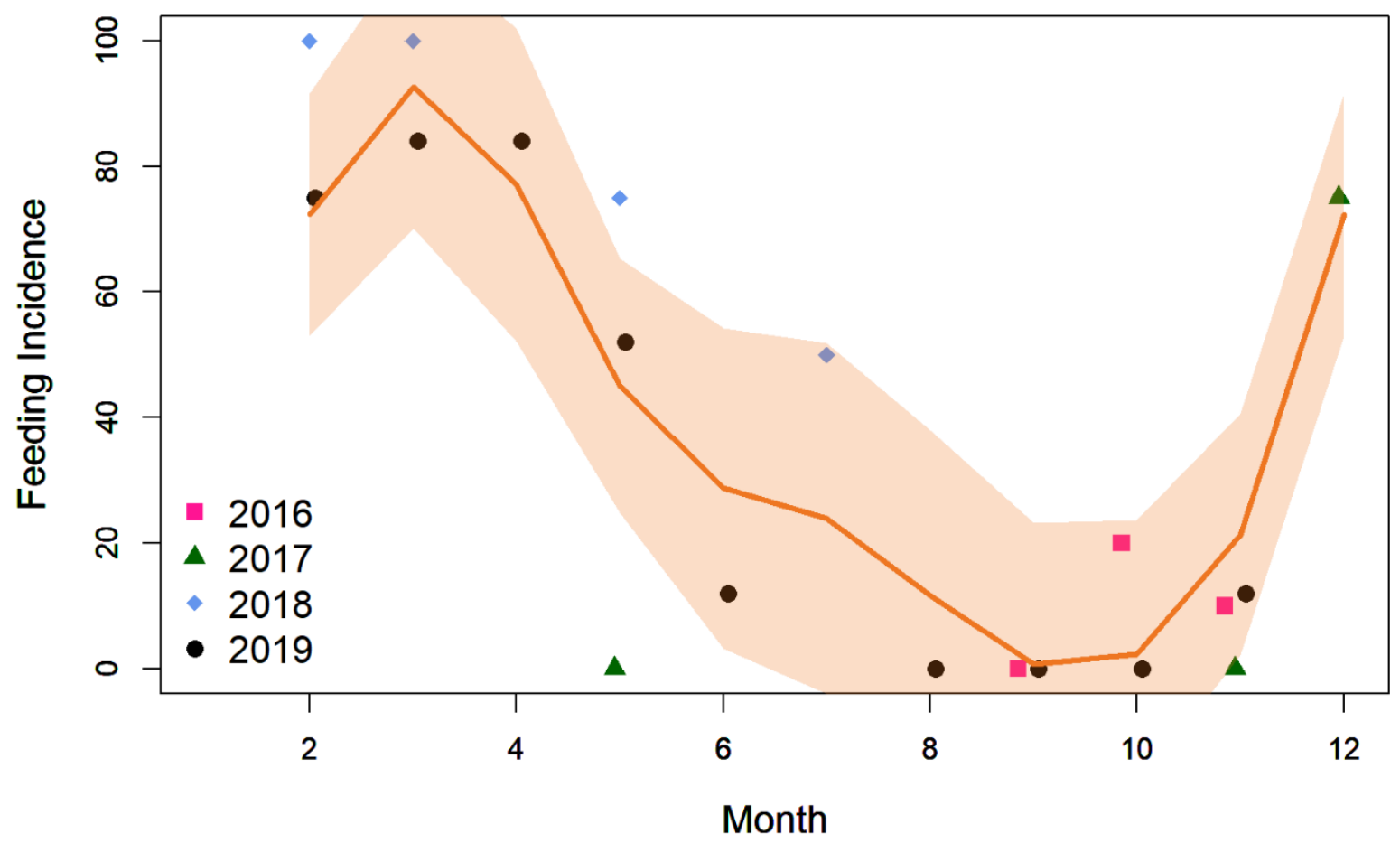

Figure 2-S4. Feeding incidence by month for fish collected 2016-2019. Solid line represents fitted values from a generalized additive model of feeding incidence by month fit with a cyclic cubic regression spline $(\mathrm{n}=300$ fish, deviance explained $=78.1 \%$ ). Shading represents $95 \%$ confidence intervals. 


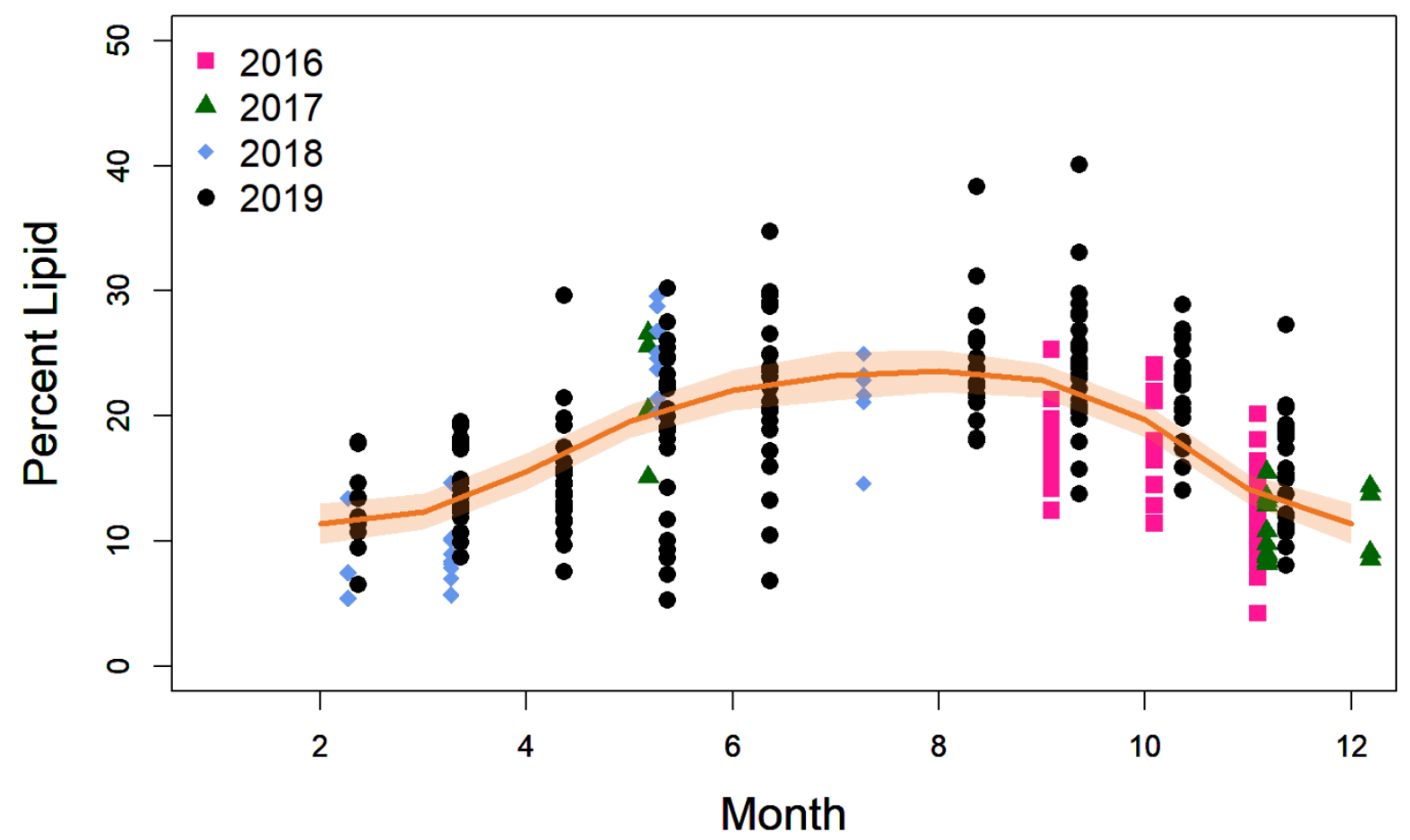

Figure 2-S5. Percent lipid of whole fish of sand lance collected on Stellwagen Bank from 20162019. Solid line represents fitted values from a generalized additive model of percent lipid by month fit with a cyclic cubic regression spline and shading represents $95 \%$ confidence intervals $(\mathrm{n}=284$, deviance explained $=46.2 \%)$. 


\section{Sand Lance Anomaly and WSW Proportion}

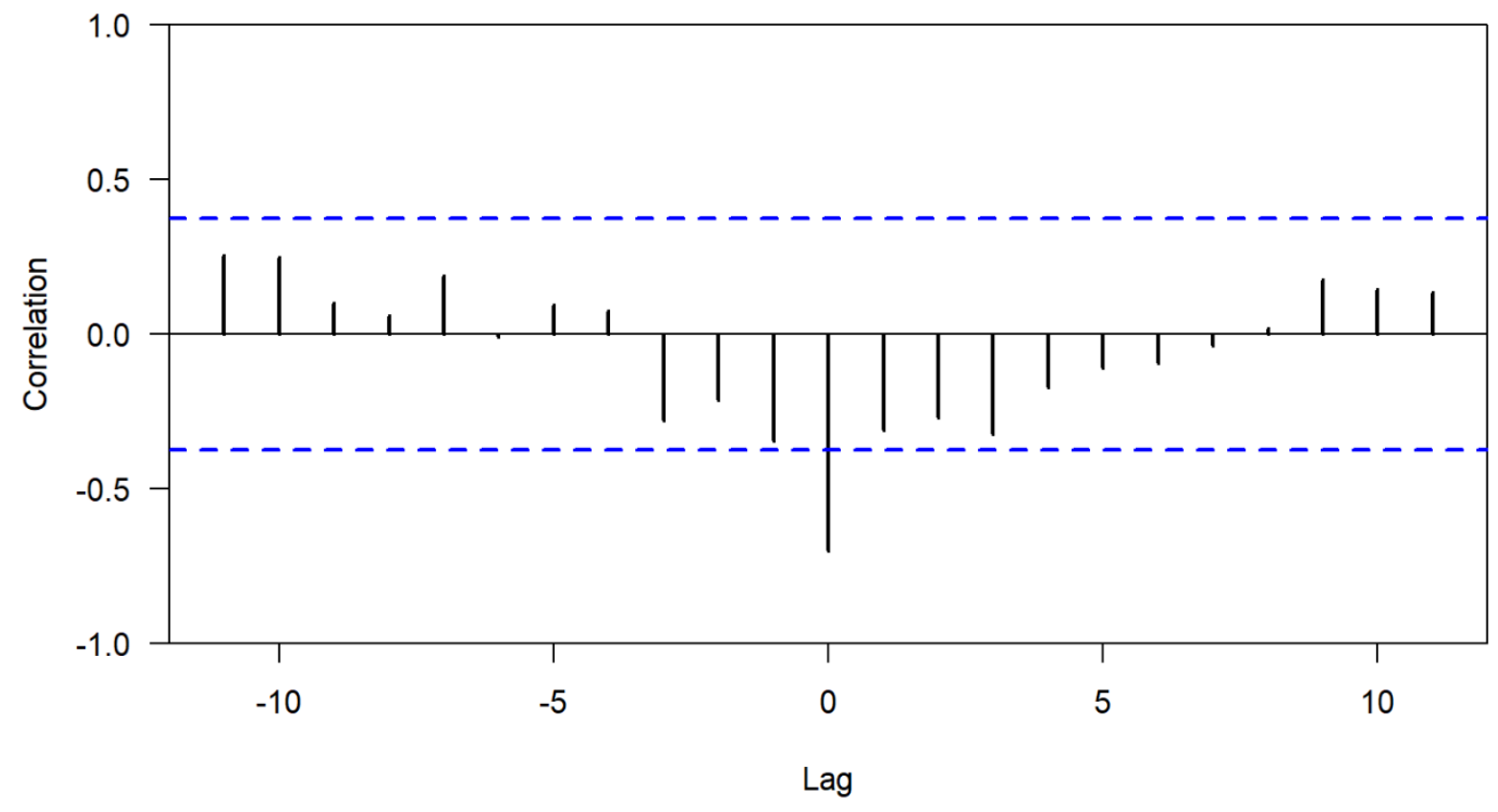

Figure 2-S6. Cross-correlation analysis of NEFSC spring bottom trawl log area weighted mean sand lance abundance and warm slope water proportion $(n=28$ years). Vertical axis represents correlation coefficients and dashed blue lines represent significance threshold of 0.05 (adjusted for autocorrelation following Pyper \& Peterman 1998). 


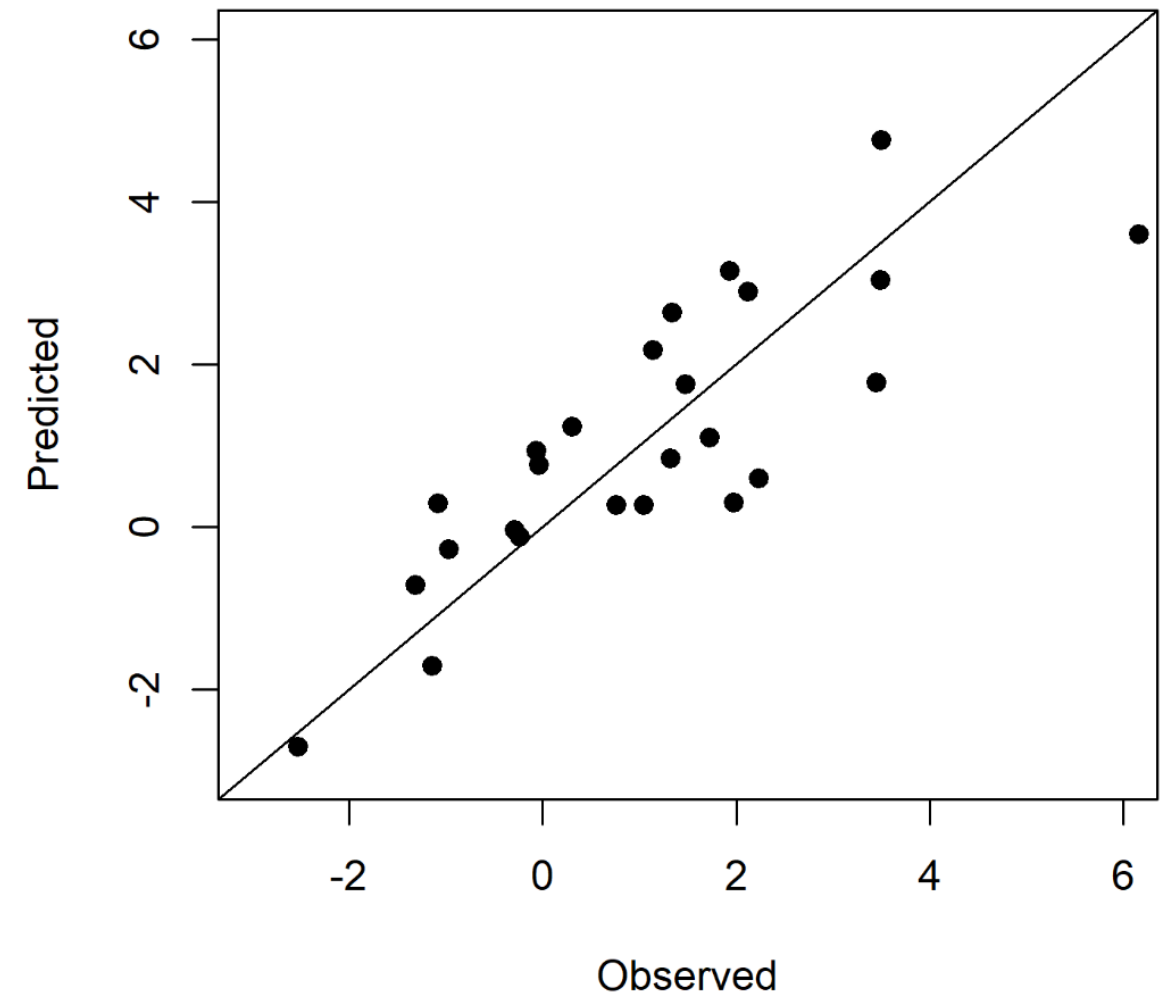

Figure 2-S7. Predicted vs. observed value for each iteration of the leave-one-out cross-validation along with a one-to-one line. 


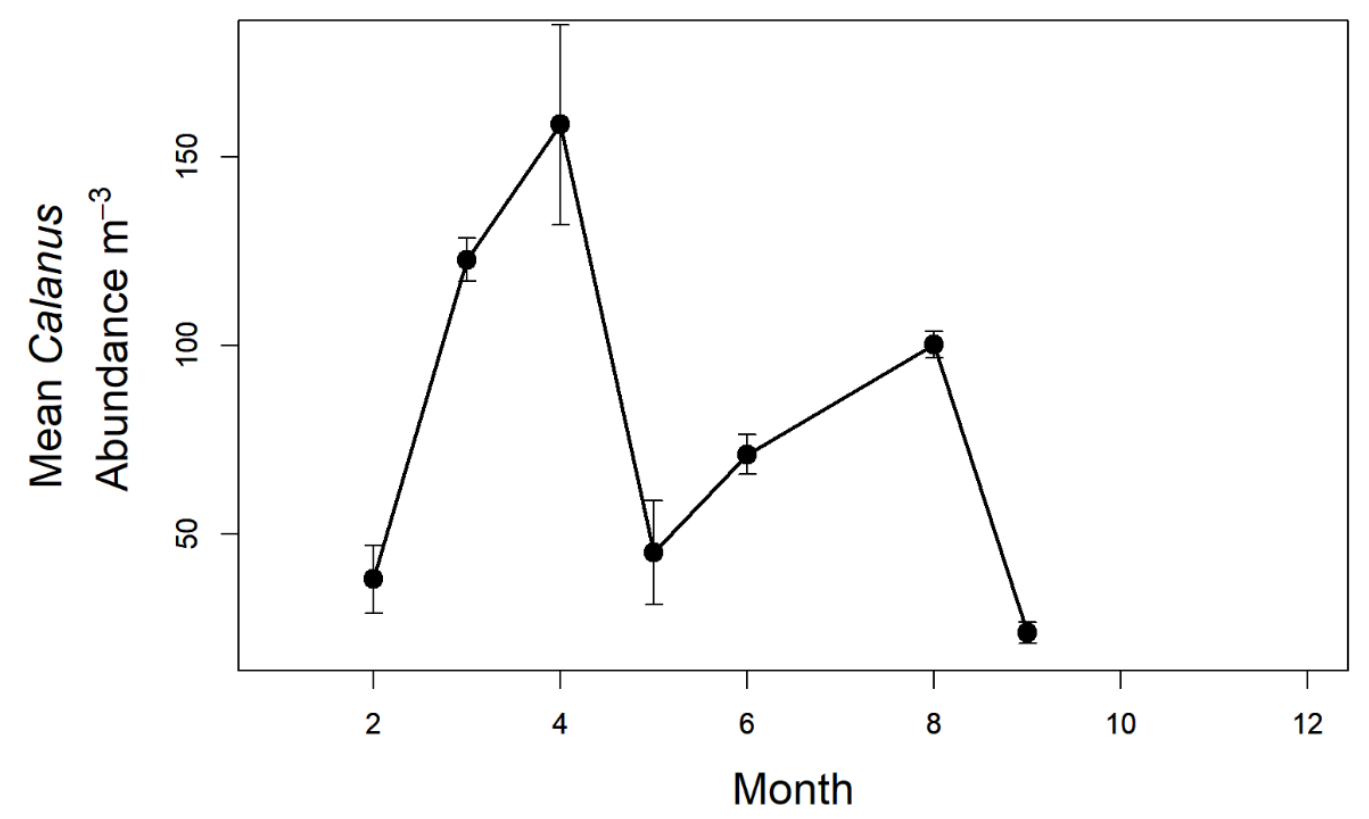

Figure 2-S8. Calanus abundance by month of collection on Stellwagen Bank. Mean abundance of Calanus finmarchicus +/- SEM by month for vertical zooplankton casts on Stellwagen Bank concomitant with beam trawl collections of adult sand lance $(n=52$ casts). 


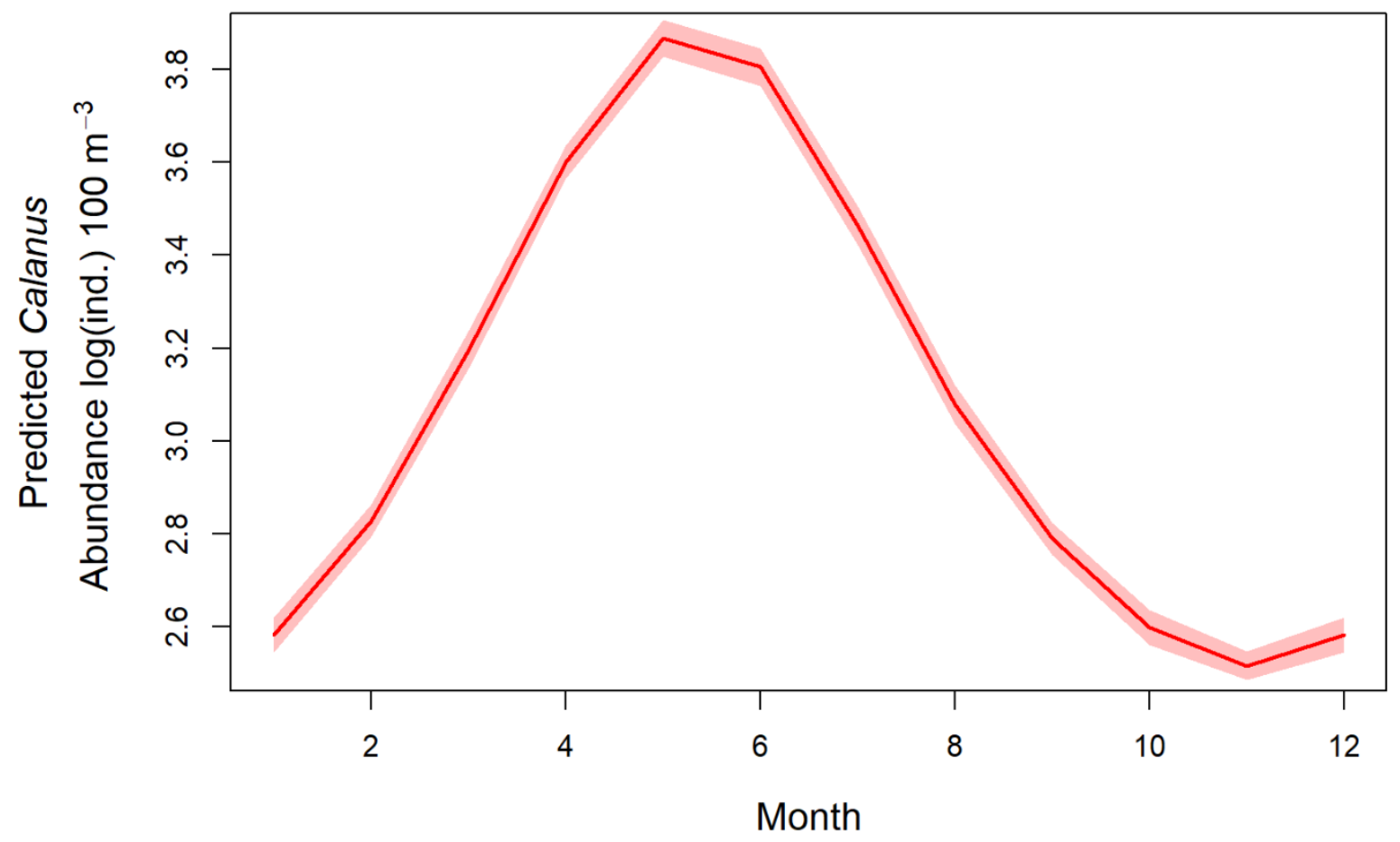

Figure 2-S9. Phenology of Calanus abundance on the Northeast US Shelf from the NEFSC EcoMon collections. Solid line represents fitted values from a generalized additive model of Calanus abundance by month fit with a cyclic cubic regression spline $(n=27,727$ casts, deviance explained $=10.4 \%$ ). Shaded areas represent $95 \%$ confidence intervals. 


\section{Sand Lance and Gulf of Maine Calanus}

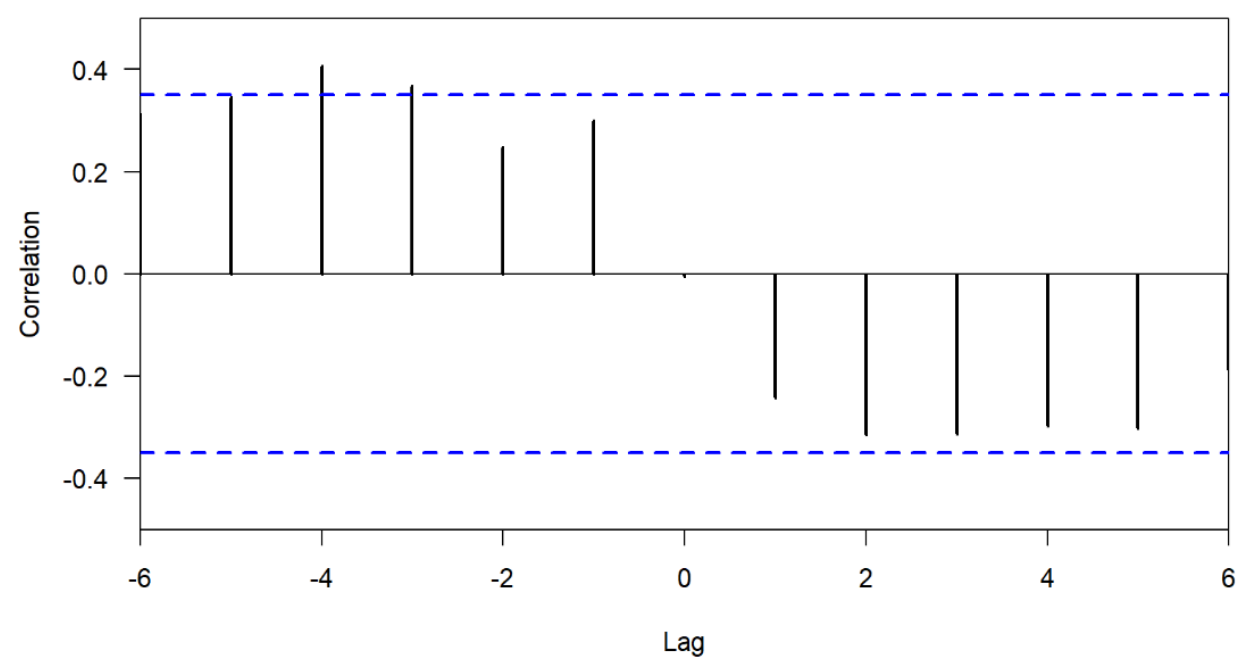

Figure 2-S10. Cross-correlation analysis of NEFSC spring bottom trawl log area weighted mean sand lance abundance and Gulf of Main Calanus abundance anomaly ( $\mathrm{n}=32$ years). Vertical axis represents correlation coefficients and dashed blue lines represent significance threshold of 0.05 (adjusted for autocorrelation following Pyper \& Peterman 1998). Negative lags (in years) are when sand lance abundance lags behind Calanus abundance. 


\section{Model Residuals}

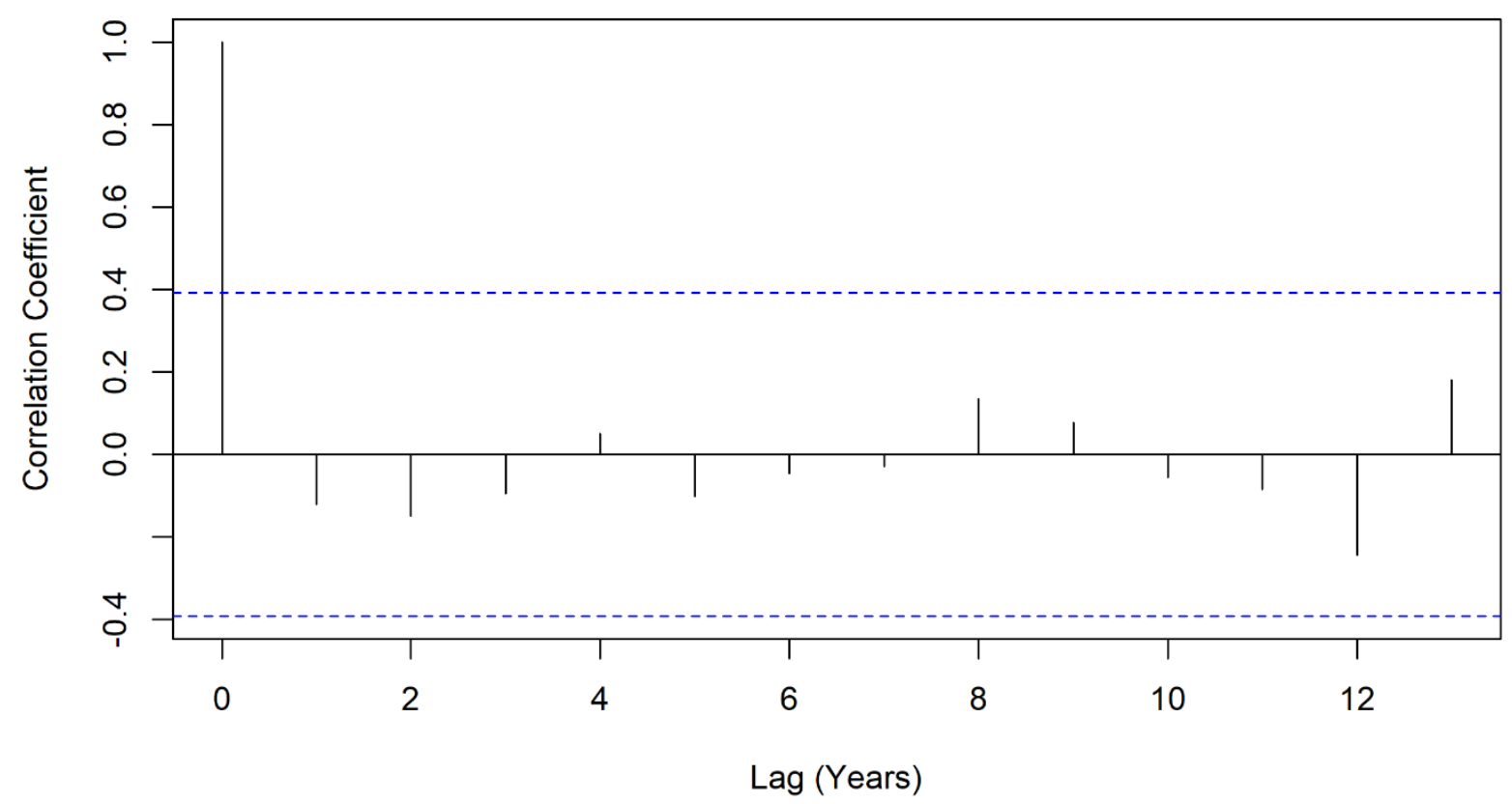

Figure 2-S11. Autocorrelation analysis of the sand lance abundance regression residuals. Vertical axis represents correlation coefficients and dashed blue lines represent significance threshold of 0.05 . 


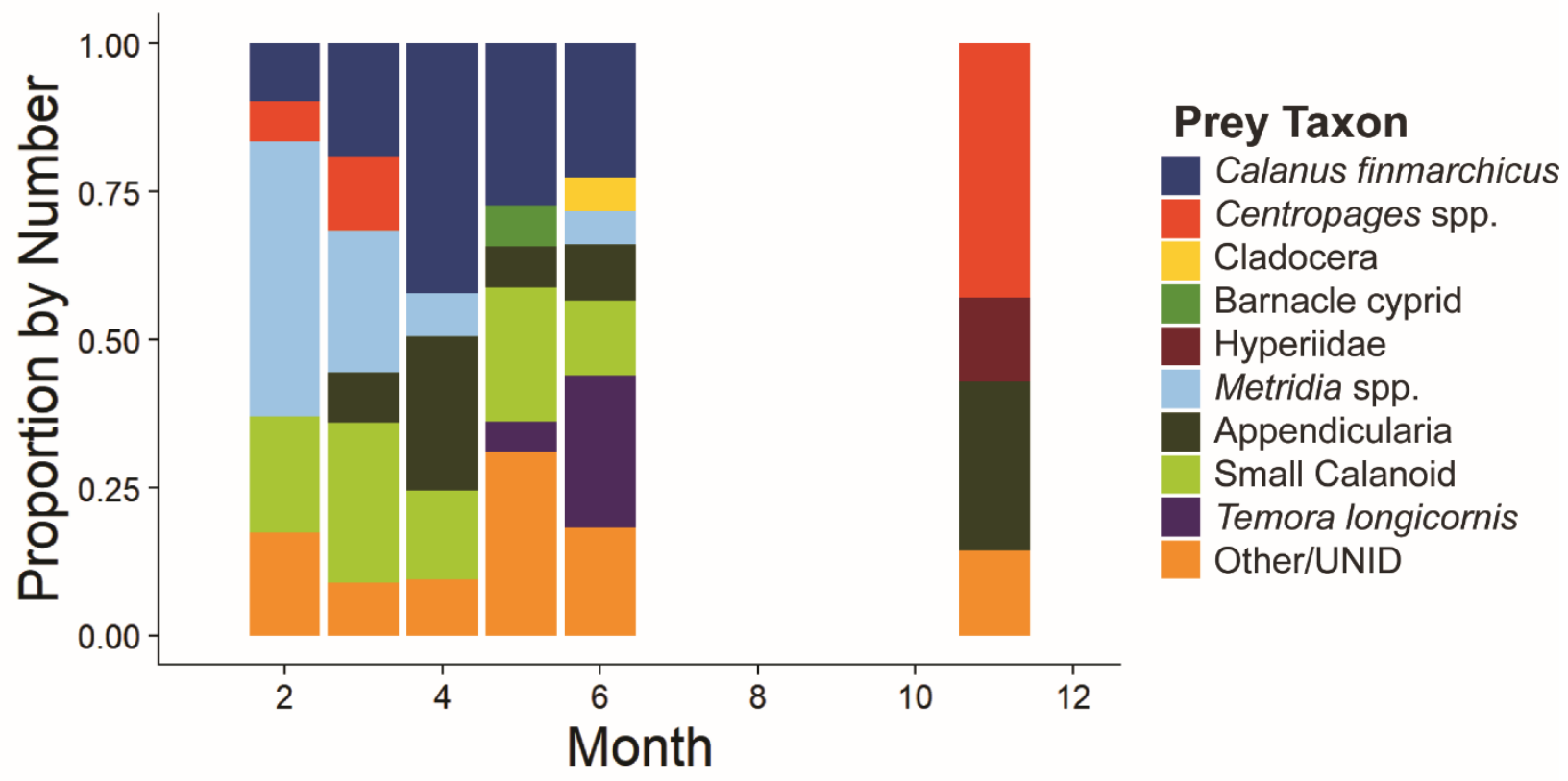

Figure 2-S12. Sand lance diet by month as proportion by number for fish collected on Stellwagen Bank in 2019. 


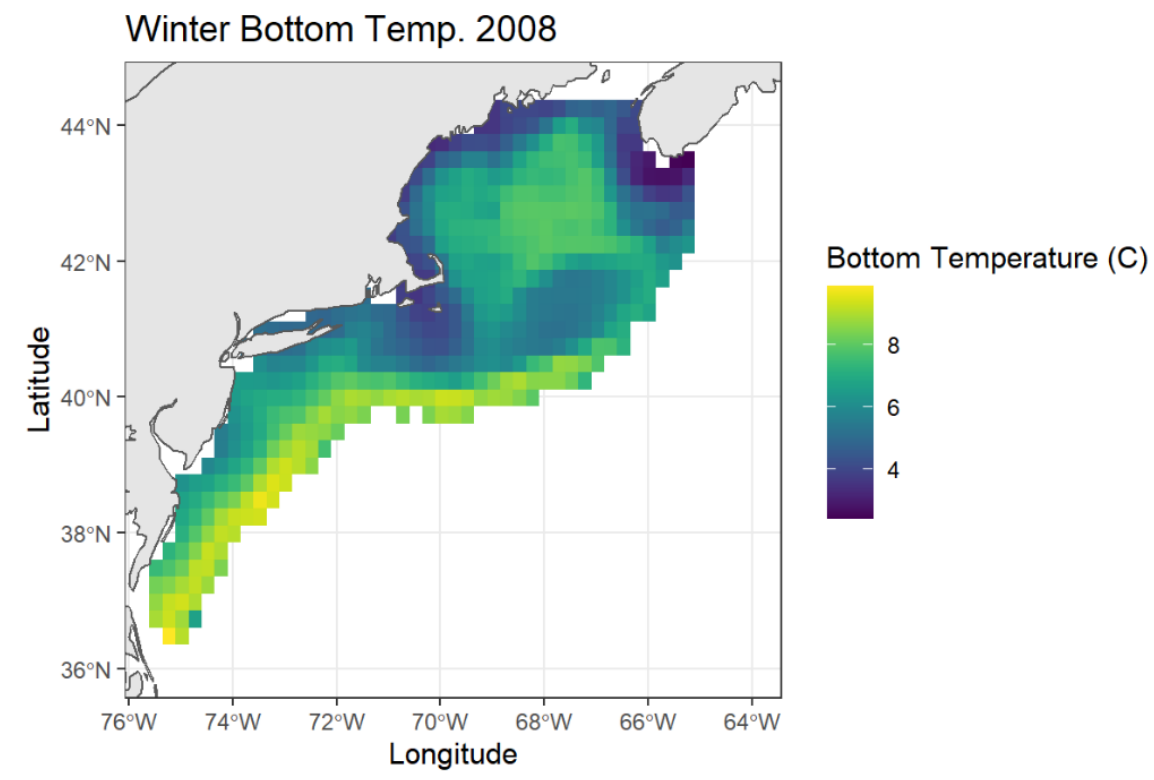

Figure 2-S13. Mean winter (January-March) daily bottom temperatures for 2008. Bottom temperature data were gridded to $0.25^{\circ} \times 0.25^{\circ}$ bins for estimating shelf-wide bottom temperatures in each year (1978-2008) using the third generation Gulf of Maine Finite Volume Community Ocean Model (FVCOM-GOM3). 


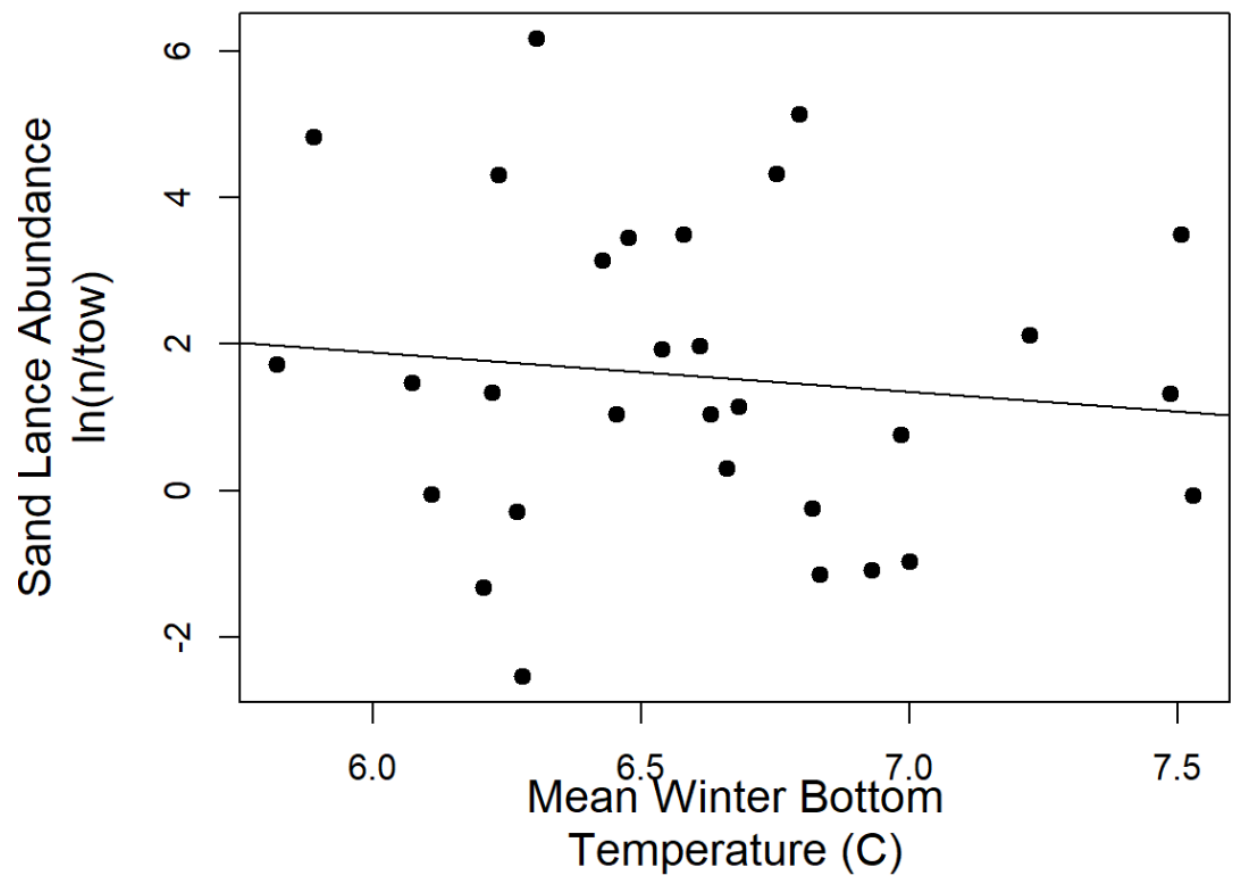

Figure 2-S14. Annual log area weighted stratified mean abundance of sand lance from the NEFSC's spring survey plotted against annual mean winter (January-March) bottom temperature from FVCOM-GOM3. 


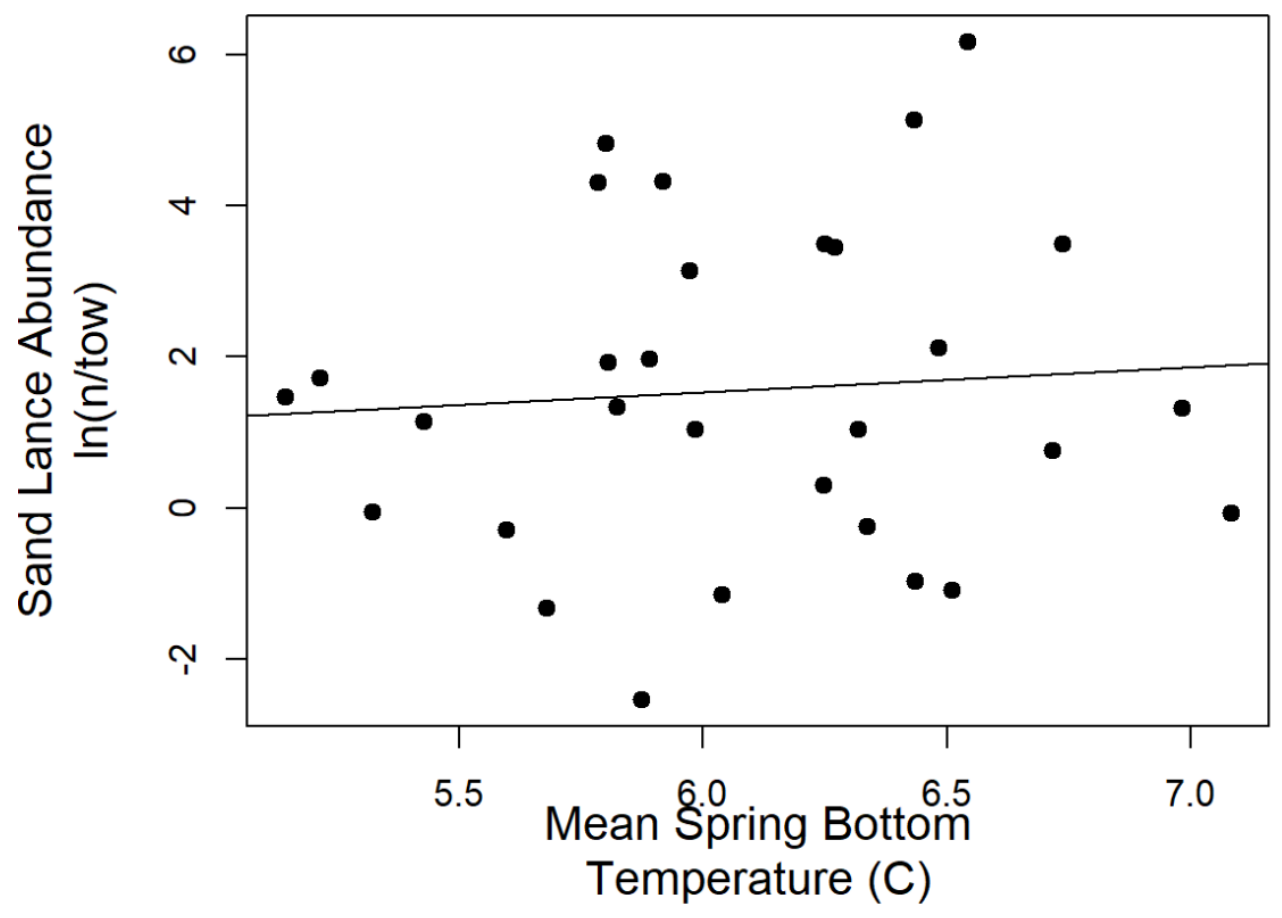

Figure 2-S15. Annual log area weighted stratified mean abundance of sand lance from the NEFSC's spring survey plotted against annual mean spring (March-April) bottom temperature from FVCOM-GOM3. 
Table 2-S1. Summary of biological data collected on sand lance from Stellwagen Bank. GSI=Gonadosomatic Index

\begin{tabular}{ccccccc} 
Year & Month & $\begin{array}{c}\text { Number } \\
\text { Processed }\end{array}$ & $\begin{array}{c}\text { Feeding } \\
\text { Incidence } \%\end{array}$ & $\begin{array}{c}\text { Mean Number } \\
\text { of Prey (SD) }\end{array}$ & $\begin{array}{c}\text { Mean Lipid } \\
\%(\text { SD })\end{array}$ & $\begin{array}{c}\text { Mean GSI } \\
(\text { SD) }\end{array}$ \\
\hline 2016 & 9 & 10 & 0 & NA & $18.1(3.7)$ & $0.027(0.014)$ \\
2016 & 10 & 10 & 20 & NA & $18.1(4.4)$ & $0.148(0.058)$ \\
2016 & 11 & 20 & 10 & NA & $12.1(4.2)$ & $0.249(0.107)$ \\
2017 & 5 & 4 & 0 & NA & $22.0(5.3)$ & $0.002(0.001)$ \\
2017 & 11 & 20 & 0 & NA & $11.0(2.6)$ & $0.243(0.085)$ \\
2017 & 12 & 4 & 75 & NA & $11.5(3.0)$ & $0.003(0.001)$ \\
2018 & 2 & 6 & 100 & NA & $7.86(3.3)$ & $0.003(0.001)$ \\
2018 & 3 & 10 & 100 & NA & $8.7(2.6)$ & $0.003(0.002)$ \\
2018 & 5 & 8 & 75 & NA & $25.0(3.3)$ & $0.003(0.001)$ \\
2018 & 7 & 6 & 50 & NA & $21.4(3.6)$ & $0.012(0.013)$ \\
2019 & 2 & 12 & 75 & $77(116)$ & $12.7(3.6)$ & $0.004(0.002)$ \\
2019 & 3 & 25 & 84 & $502(373)$ & $14.2(3.2)$ & $0.002(0.001)$ \\
2019 & 4 & 25 & 84 & $172(213)$ & $15.0(4.4)$ & $0.007(0.012)$ \\
2019 & 5 & 20 & 52 & $20(20)$ & $18.1(7.1)$ & $0.004(0.002)$ \\
2019 & 6 & 25 & 12 & $53(73)$ & $22.1(6.4)$ & $0.004(0.002)$ \\
2019 & 8 & 20 & 0 & 0 & $24.0(4.9)$ & $0.021(0.011)$ \\
2019 & 9 & 25 & 0 & 0 & $24.2(5.5)$ & $0.100(0.068)$ \\
2019 & 10 & 20 & 0 & 0 & $22.5(4.1)$ & $0.222(0.041)$ \\
2019 & 11 & 35 & 12 & $3(0.5)$ & $15.8(4.4)$ & $0.012(0.004)$
\end{tabular}


Table S2. Length-dry weight relationship for common prey taxa found in stomach contents of sand lance.

\begin{tabular}{|c|c|c|}
\hline Prey Taxon & Equation & Reference \\
\hline Calanus finmarchicus & $\mathrm{DW}=0.0257^{*} \mathrm{~L}^{\wedge}(3.141)$ & (Cohen \& Lough, 1981) \\
\hline $\begin{array}{l}\text { Small Calanoid \& Temora } \\
\text { (used Pseudocalanus) }\end{array}$ & $\mathrm{DW}=0.0237^{*} \mathrm{~L}^{\wedge}(3.745)$ & (Cohen \& Lough, 1981) \\
\hline Centropages spp. & $\mathrm{DW}=0.0214 * \mathrm{~L}^{\wedge}(3.87)$ & (Cohen \& Lough, 1981) \\
\hline Appendicularia & $\log (\mathrm{DW})=2.47 * \log (\mathrm{L})-6.1$ & $\begin{array}{c}\text { (Hopcroft, Roff, \& Bouman, } \\
\text { 1998) }\end{array}$ \\
\hline Chaetognatha & $\mathrm{DW}=0.00046^{*} \mathrm{~L}^{\wedge}(3.727)$ & (Pearre, 1981) \\
\hline Limacina sp. & $\mathrm{DW}=0.137 * \mathrm{~L}^{\wedge}(1.5005)$ & $\begin{array}{c}\text { (Bednaršek, Tarling, Fielding, \& } \\
\text { Bakker, 2012) }\end{array}$ \\
\hline Barnacle cyprid & $\mathrm{DW}=0.00422 * \mathrm{~L}^{\wedge}(3.141)$ & (Muxagata \& Williams, 2011) \\
\hline Cladocera & $\mathrm{DW}=0.00189^{*} \mathrm{~L}^{\wedge}(2.25)$ & $\begin{array}{c}\text { (Dumont, Van de Velde, \& } \\
\text { Dumont, 1975) }\end{array}$ \\
\hline Mysidae & $\mathrm{DW}=0.0066^{*} \mathrm{~L}^{\wedge}(2.57)$ & (Chigbu \& Sibley, 1996) \\
\hline Euphausicea & $\log (\mathrm{DW})=0.3681 * \log (\mathrm{L})+0.3696$ & (Society, 2016) \\
\hline Other copepods & $\mathrm{DW}=0.0257^{*} \mathrm{~L}^{\wedge}(3.141)$ & (Cohen \& Lough, 1981) \\
\hline
\end{tabular}




\section{Chapter 3}

\section{Environmental drivers and trends in forage fish occupancy of the Northeast US shelf}

\subsection{Abstract}

The Northeast US shelf ecosystem is undergoing unprecedented changes due to long-term warming trends and shifts in regional hydrography leading to changes in community composition. However, it remains uncertain how shelf occupancy by the region's dominant, offshore small pelagic fishes, also known as forage fishes, has changed throughout the late $20^{\text {th }}$ and early $21^{\text {st }}$ centuries. Here, we use species distribution models to estimate the change in shelf occupancy, mean weighted latitude, and mean weighted depth of six forage fishes on the Northeast US shelf and whether those trends were linked to coincident hydrographic conditions. Our results suggest that shelf occupancy is increasing or unchanging for most species in both spring and fall, largely linked to increasing temperature and bottom salinity. Exceptions include decreases to shelf occupancy by sand lance and decreases to coincident favorable environmental conditions for Atlantic herring in the fall. Our work shows that changes in shelf occupancy and favorability of coincident environmental conditions have varying coherence, indicating complex mechanisms behind observed shelf occupancy for many species. Future work and management can use these results to better isolate the aspects of forage fish life histories that are important for determining their occupancy of the Northeast US shelf. 


\subsection{Introduction}

Small pelagic fishes dominate the biomass of many productive coastal ecosystems, including upwelling systems and temperate shelves (Cury et al., 2000; Pikitch et al., 2014). These fishes represent both important local fisheries and serve as the focal prey of numerous top predators, giving these fishes the moniker of "forage fishes" in many regions (Pikitch et al., 2014). The coastal Northwest Atlantic is one of these productive, forage fish rich ecosystems, particularly in northern regions such as the Gulf of Maine and Scotian Shelf. The Northeast US shelf occupies a large portion of the coastal Northwest Atlantic, spanning oceanographic and ecological gradients that are temporally dynamic (Chen et al., 2020; Friedland et al., 2020a). Accordingly, the composition of the forage fish community of the region has historically oscillated on both small and large spatio-temporal scales (Fogarty et al., 1991; Richardson et al., 2014). These oscillations include seasonal changes in shelf occupancy by forage fish taxa based on spawning migrations and drastic interannual variability in overall abundance of each species (Fogarty, 1989; Suca et al., 2021). These oscillations have notable effects on both fisheries catches of small pelagic fishes and the diet and distribution of their predators (Overholtz, 2002; Overholtz and Link, 2007; Smith and Link, 2010; Richardson et al., 2014).

The Northeast US shelf hosts a moderate diversity of small pelagic fishes from a variety of taxonomic families with differing life history strategies. Throughout much of the middle to late $20^{\text {th }}$ century, the offshore forage fish complex of the Northeast US shelf was dominated in biomass by northern sand lance (Ammodytes dubius) and Atlantic herring (Clupea harengus; Suca et al., 2021; Richardson et al., 2014) with high abundances of Atlantic butterfish (Peprilus triacanthus) occupying the shelf in the fall (Adams et al., 2015; Adams, 2017). Of these species, sand lance distribution is the only one with minimal seasonal variability. This is in large part due to their reliance on sandy substrates for burying (Nøttestad et al., 1999; Staudinger et al., 2020). 
Despite this obligate connection with substrate, sand lance presence is highly variable on small spatial scales and interannual scales (Staudinger et al., 2020). The cause of broad scale interannual variability has been linked to drivers of recruitment and overwinter survival given the lack of fishery for this species (Suca et al., 2021), yet the favorability of coincident environmental conditions (often referred to as habitat suitability) has not been explored for this species.

Unlike the non-targeted sand lance, historical Atlantic herring abundance has been driven by both fishing, including heavy exploitation until the 1980s (Overholtz and Link, 2007), and environmental conditions, such as haddock predation on herring eggs (Richardson et al., 2011). Atlantic herring exhibit seasonal migrations, moving to portions of the Mid-Atlantic Bight in the winter and spring (in addition to portions of the coastal Gulf of Maine) and move to more specific spawning locations such as Georges Bank in the fall (Sinclair and Iles, 1985; Overholtz, 2002). While Atlantic herring exhibit some predictable behaviors, such as spawning migrations, the pelagic and schooling behavior of these fish lead to highly dynamic and variable distribution patterns in space (Overholtz, 2002). The degree to which coincident environmental conditions play a role in herring shelf occupancy has not be explored in depth. Recent work suggests that shelf occupancy for Atlantic herring might be increasing as part of a larger tropicalization of the Northeast US shelf (Friedland et al., 2020b).

Alewife (Alosa pseudoharengus) and blueback herring (Alosa aestivalis), collectively known as river herring, are other important clupeids in the offshore Northeast US shelf forage fish complex. These species are known to school with Atlantic herring during offshore foraging periods, leading to high bycatch despite lacking targeted fisheries for much of the $20^{\text {th }}$ century (Turner et al., 2015, 2017). A notable separation in life history from Atlantic herring is the 
anadromous spawning behavior of river herring, with mature adults moving into rivers and lakes in the spring to spawn and post-spawn adults exiting these freshwater systems in the early to mid-summer to return to the ocean-based foraging (Turner et al., 2017). Of the two species, alewife is considered a more northerly species and constitute most of the river herring biomass throughout the offshore Northeast US shelf, in part due to the more coastal distribution of blueback herring (Lynch et al., 2020). Despite their lower abundance, blueback also overlap with Atlantic herring in trawl survey catches, indicating potential for bycatch and mixed schools of forage species (Turner et al., 2015). Previous studies have shown both species of river herring are sensitive to temperature which can drive increased overlap with Atlantic herring and Atlantic mackerel (Turner et al., 2017).

Atlantic mackerel (Scomber scombrus), another forage species that often mixes with Atlantic herring, exhibit notable migratory behavior throughout the Northeast US shelf with highly variable occupancy in spring and migration in the fall after spring spawning, largely in Canadian waters (Radlinski et al. 2013). Atlantic mackerel populations on the Northeast US shelf are composed of two spawning contingents, a southern contingent that spawns in US waters throughout southern New England and the Gulf of Maine, and a northern contingent that spawns on the Scotian shelf and Gulf of St. Lawrence (Overholtz, 1976; McManus et al., 2018).

Atlantic mackerel are thought to be highly sensitive to temperature regimes that affect spawning, larval survival, and adult migration patterns (Radlinski et al. 2013; McManus et al., 2018). As planktivorous fishes, Atlantic mackerel larvae have been shown to correspond with areas of higher zooplankton abundance in both the northwest and Northeast Atlantic, suggesting an important link between Atlantic mackerel distribution and prey fields (Macy et al., 1998; McManus et al., 2018). However, catch of Atlantic mackerel in surveys has been highly variable 
in the region, leading to efforts to better understand what drives Atlantic mackerel catchability and shelf occupancy through time (Radlinski et al. 2013; Deroba et al., 2010).

Atlantic butterfish (butterfish hereafter), the final members of the offshore Northeast US shelf forage fish complex, are a sub-tropical to temperate species than the temperate to sub-polar distribution of sand lance and Atlantic herring (Adams et al., 2015). They also have the distinction of primarily consuming gelatinous zooplankton (Smith and Link, 2010; Suca et al., 2018). Butterfish fisheries on the Northeast US shelf have been historically inconsistent with the largest fishing pressure occurring in the 1980s and a recent implementation of a directed fishery in 2013 (Adams et al., 2015). Like Atlantic herring, butterfish exhibit notable seasonal patterns in distribution due to spawning behavior, with large butterfish largely moving to the Northeast US shelf edge in the winter and returning to more nearshore shelf waters in summer and fall during spawning, tightly linked to temperature regimes (Adams, 2017).These fish also exhibit age-specific differences in shelf occupancy, particularly in the fall when young butterfish occupy more nearshore water while larger individuals remain offshore (Adams, 2017).

The Northeast US shelf is one of the most rapidly warming regions of the global oceans (Pershing et al., 2015; Chen et al., 2020). This warming has led to observed and predicted changes to the thermal habitat area available to the forage fishes of the region (Kleisner et al., 2017; Friedland et al., 2019). However, the description of a species' niche and habitat often goes beyond just thermal constraints (Friedland et al., 2020b). Previous studies have used a broad suite of potential predictors to describe such habitat and indicated that occupiable habitat by the collective forage fish community of the Northeast US shelf is increasing (Friedland et al., 2020b), though abundance trends do not always align (Friedland et al., 2021). However, the explicit relationships and mechanisms underlying these changes on individual species levels is 
less clear. Additionally, it is uncertain to what degree coincident environmental conditions are the drivers of this change in occupancy or if external factors, such as recruitment variability, contribute the observed changes.

Here, we use species distribution models to estimate the change in shelf occupancy, mean weighted latitude, and mean weighted bottom depth of six forage fishes of the Northeast US shelf. We further explore the extent to which coincident measures of hydrographic and hydrodynamic conditions control the observed interannual patterns in shelf occupancy compared to changes in external factors such as overall abundance. We hypothesize that shelf occupancy in the Northeast US shelf will vary markedly by season but is generally decreasing for the historically abundant, colder-water species (northern sand lance, Atlantic herring, and alewife), increasing for the more sub-tropical species (butterfish and blueback herring), and variable for the migratory Atlantic mackerel. We also hypothesize that each species will likely be changing their mean weighted depth and moving northward with time, depending on temperature sensitivity. We believe this will be particularly notable in fall due to warming trends both constraining northerly species habitat to higher latitudes and deeper waters while expanding the northern range and depth of occupiable shelf for southerly species. Finally, we assess the degree to which patterns in shelf occupancy are connected to changes in coincident hydrography and hydrodynamics, or if they are linked to external factors such as recruitment or other parameters that covary with year.

\subsection{Materials and Methods}

\subsubsection{Survey collections}

Catches of forage fishes on the Northeast US shelf came from the spring and fall Northeast Fisheries Science Center (NEFSC) bottom trawl surveys, spanning 1968 to present for 
the spring survey and 1963 to present for the fall survey. During each survey, 300-400 stations are sampled in a random stratified design, ranging from the Western Scotian Shelf to Cape Hatteras. At each station, catches of each species are weighed and individuals are measured, with sub-sampling occurring when catches were large. Further details of the survey and sampling gear are found within (Politis et al., 2014). We note that this survey is a bottom trawl and thus does not fully or perfectly capture the habitat of pelagic, schooling fishes. However, this survey is used to attain indices of abundance for the purpose of stock size for these fishes and is reliable for understanding their distribution (Deroba et al. 2018; NEFSC, 2020). The one possible exception to this is Atlantic mackerel, for which the survey is considered less reliable (see discussion; Deroba et al. 2010).

The survey has changed gears on multiple occasions, including a change in survey vessel. In 1985, during the tenure of the first vessel, Albatross $I V$, the trawl doors were changed which resulted in a notable change in Atlantic herring catches in the survey (NEFSC, 2020). Given noted mixed school behavior of river herring (alewife and blueback herring) with Atlantic herring, we assumed this change also affected catches of river herrings (Turner et al., 2015). The change in doors was not considered to have as large an effect on the catch of the other forage fishes included in this study and is thus only considered for the clupeids. In 2009, the survey switched from the R/V Albatross IV to the R/V Henry Bigelow resulting in notable changes in catches for all species in this study (Miller et al., 2010). This change in ship was coupled with a change in cod-end liner for collections, widening the mesh from $1 / 2$ " to 1 " and rendering sand lance catchability unreliable after 2009 (Richardson et al., 2014). A suite of inshore strata was also lost in the transition from the R/V Albatross IV to the R/V Henry Bigelow. We decided to retain inshore strata from the $\mathrm{R} / \mathrm{V}$ Albatross $I V$ because these strata represent important habitat 
for some taxa and an exploratory analysis indicated that models using only offshore strata did not influence the predictive capability of predominantly offshore species.

Fall butterfish catches were split into two size classes based on age and known differences in distribution (Adams, 2017). Small butterfish, known to inhabit more nearshore waters in fall, were classified as those $\leq 11 \mathrm{~cm}$, while large butterfish were all fish $>11 \mathrm{~cm}$. This was only done for the fall survey as the spring survey primarily catches large individuals (Adams, 2017).

\subsubsection{Environmental Data}

Conductivity, temperature, and depth sensors (CTDs) became commonplace on the bottom trawl surveys in 1992, and this in situ data was used for sea surface temperature (SST), sea surface salinity (SSS), bottom temperature (BT), and bottom salinity (BS) when available. To fill in data from years prior to 1992, hindcast estimates of hourly surface and bottom temperature and salinity were used from the third generation Gulf of Maine Finite Volume Community Ocean Model (FVCOM-GOM3; (Chen et al., 2011; Li et al., 2017)). Horizontal resolution ranges from 0.3 to $10 \mathrm{~km}$, with finer horizontal resolution in coastal regions and tidal mixing fronts (e.g. Georges Bank, Figure 3-S1) and coarser resolution at the boundaries near the shelf break (Chen et al., 2011; Xue et al., 2014; Ji et al., 2017). GOM-FVCOM is nested within the FVCOM-Global model to ensure water property conservation at its boundaries (Chen et al., 2011). Previous studies have confirmed that GOM-FVCOM accurately recreates hourly to interannual variability in currents (Sun et al., 2016; Li et al., 2017), including a comparison with observed drifters (Sun et al. 2014). GOM-FVCOM assimilates satellite SST, and CTD data from surveys and a buoy array, leading to accurate representations of temperature and salinity throughout much of the survey domain (Xue et al., 2014). 
To ensure FVCOM accurately represented temperature and salinity fields during the trawl surveys, hourly estimates from GOM-FVCOM were matched to every station from 19922016 for salinity and every station with available temperature data from 1979-2016 from in situ CTD casts or expendable bathythermographs. Overall trends show good agreement with surface temperature (Spring $\mathrm{R}^{2}=0.81$, Fall $\mathrm{R}^{2}=0.95$ ) and moderately good agreement for surface salinity (Spring $\mathrm{R}^{2}=0.79$, Fall $\mathrm{R}^{2}=0.72$ ), bottom temperature $\left(\right.$ Spring $\mathrm{R}^{2}=0.71$, Fall $\left.\mathrm{R}^{2}=0.79\right)$, and bottom salinity $\left(\mathrm{R}^{2}=0.77\right.$, Fall $\left.\mathrm{R}^{2}=0.80\right)$. The residuals from these trends were grouped by stratum and any stratum that had an average residual $>2{ }^{\circ} \mathrm{C}$ for spring and $>3{ }^{\circ} \mathrm{C}$ for fall for temperature or $>1$ for salinity was excluded from analyses in all years (Figure 3-1). The more relaxed threshold for fall was to ensure there were sufficient strata to represent the habitat of the fishes in the study due to FVCOM's poorer performance of recreating bottom temperatures in the summer and early fall (Li et al., 2017). This strategy of removing entire strata across years was to retain the random stratified nature of the survey so that interannual differences were not driven by spatial biases. This led to the exclusion of 17 strata in the fall (4.9\% of the cumulative area) and 35 strata in the spring (10.1\% of cumulative area; Figure $3-1)$. In the case of the spring survey, slope strata were excluded which represents known habitat for Atlantic mackerel and butterfish (Overholtz et al. 2011; Adams, 2017). It is thus important to acknowledge that our metrics represent shelf occupancy within the strata included in each model and do not always represent the full shelf occupancy for each species, namely spring Atlantic mackerel and butterfish. 
NEFSC Spring Trawl Strata

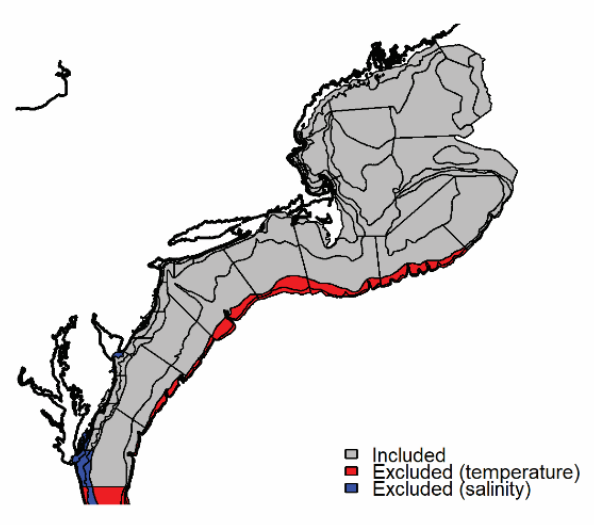

NEFSC Fall Trawl Strata

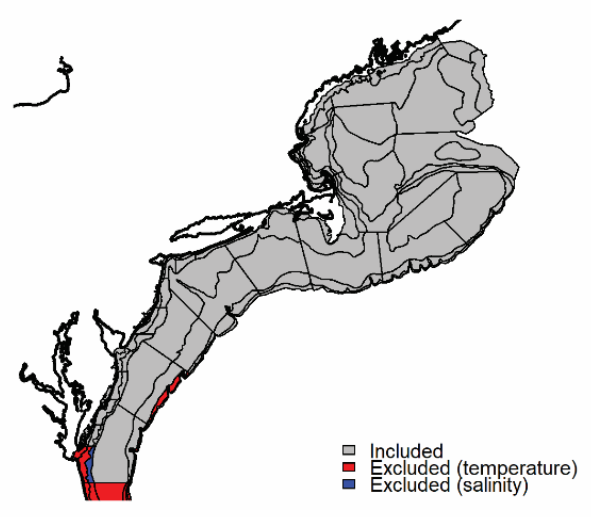

Figure 3-1. Map of Northeast US shelf and strata from the Northeast Fisheries Science Center spring and fall bottom trawl survey. Strata are color coded by whether they were used for modeling for the given season based on accuracy of FVCOM temperature or salinity estimates.

Daily mean total kinetic energy (TKE) was used to incorporate kinetic energy generated from tidal dynamics along many shallow banks on the Northeast US shelf that represent zooplankton aggregations and feeding hotspots ( Lough and Manning, 2001; Wishner et al., 2006). Use of daily current averages negates tidal effects due to the multiple shifts in direction throughout the course of the day. We thus calculated an estimate of daily mean kinetic energy based on hourly data with the following equation:

$$
T K E_{\text {Daily }}=\frac{\sum_{i=1}^{24} \frac{1}{2}\left(u^{2}{ }_{i}+v^{2}{ }_{i}\right)}{24}
$$

Where $u_{i}$ and $v_{i}$ represent vertically averaged hourly zonal and meridional velocities at a given location. $u_{i}$ and $v_{i}$ estimates originated from FVCOM-GOM3.

Sediment grain size data were estimated based on point observations in the US Geological Survey East Coast Sediment Texture Database 
(http://pubs.usgs.gov/of/2005/1001/data/surficial_sediments/ecstdb2005.zip). Sediment grain size were interpolated to each collection location using inverse distance weighting in the gstat package in R (S.G., 2021).

Bathymetric slope estimates were calculated from NOAA NCEI bathymetry data. A twokilometer slope was used as the metric to represent local scale slope that is less likely to be associated with the offshore slope of the Northeast US shelf, where strong correlations exist between bottom hydrography and slope (Mountain, 2012).

\subsubsection{Species distribution model formation}

Species distribution models were formed using generalized additive models (Wood, 2017). Generalized additive models are non-parametric extensions of generalized linear models, with the assumption that variables are additive. GAMs can represent complex, nonlinear relationships between predictor and response variables, a common occurrence with ecological data (Guisan and Thuiller, 2005).

For each taxon, the full suite of hydrographic and benthic variables were included. Year was included as a random intercept for each species and season to account for changes in overall abundance of each taxon driven by dynamics other than habitat availability (Brodie et al., 2015; Thorson, 2019). These year effects were coupled with a fixed gear effect, reflecting a change in intercept based on catchability by the gear changes described above. This resulted in the following general equation:

$$
\begin{aligned}
\log \left(\frac{p r}{1-p r}\right)= & \left.\beta+\text { Gear }+s\left(E n v_{1}, k=6\right)+s\left(E n v_{2}, k=6\right) \ldots+s\left(E n v_{n}, k=6\right)+\right) \\
& + \text { te (Longitude, Latitude })+s(\text { Year, "re" })
\end{aligned}
$$


where Pr represents the probability of occurrence of a given species, s represents a thin-plate regression spline, $\mathrm{k}$ represents the number knots for the basis functions of the spline, Env represents an environmental predictor (e.g. temperature), te represents a tensor product, re represents a random effect, and $\beta$ represents the model intercept. The number of knots were capped at six to prevent overfitting of data, ensuring the relationships between the predictor variables and the response are ecologically feasible (Rooker et al. 2012). Models were fit to all but the final three years of the usable time series for each taxon (1979-2013 Atlantic herring, alewife, blueback herring, Atlantic mackerel, and butterfish; 1979-2005 for sand lance).

We used the information theory approach to model selection and fitting (DeLeeuw, 1973). Variance inflation factors (VIF) were used for determination of which variables to drop from consideration before model selection. These values were determined using the vif.gam function in the mgcv.helper package (Clifford, 2019). Variables with a VIF $>10$ were removed from consideration. While this value is fairy relaxed, we chose this value to include as many possible predictors in model selection as reasonably possible. If multiple variables resulted in VIF $>10$, single variable GAMs (including year effects and longitude, latitude tensor product) were fit to the data for each variable and the model containing the variable with the lowest AIC was retained. This process was repeated until the largest possible suite of variables with VIFs $<10$ remained.

\subsubsection{Model selection and averaging}

After predictors resulting in high VIF values were removed, all possible combinations of predictors for each taxon and season were compared using Akaike Information Criterion (AIC) via the dredge function within the MuMIn package in R (Barton, 2010). In all cases, year random intercepts and the tensor product of longitude, latitude were included to reduce run time. Models 
with AIC values $<4$ from the best fit model were averaged to account for uncertainty in model selection given the exploratory nature of our analyses and information theory-based approach. These model averages for each taxon and season were used for all subsequent analyses and predictions.

\subsubsection{Model Validation}

Predictive capability of models was tested using receiver operating characteristic curves (ROC). ROC curves measure true positive rate (specificity) against false positive rate (sensitivity) at different thresholds. The area under this curve (AUC) can be used as a metric of predictive strength of presence/absence models, with values close to 1 representing high predictive capability and values close to 0.5 representing capability approaching random chance. AUC values were calculated for model predictions over the final three years of each time series.

Individual variable importance for the final, averaged models were determined through the sum of Akaike weights. Akaike weights were calculated as follows:

$$
w_{i}=\frac{\exp \left[-\frac{1}{2} \Delta_{i}\right]}{\sum_{i=0}^{n} \exp \left[-\frac{1}{2} \Delta_{i}\right]}
$$

Where $\Delta_{\mathrm{i}}$ represents the difference in AIC of a particular model from the lowest AIC for any model iteration for a given species and season. The Akaike weight for each model in which a variable was included was then summed to reach the sum of Akaike weights (SW) for the variable. Values close to 1 represent high variable importance, with values close to 0 representing low importance (Giam and Olden, 2016).

\subsubsection{Proportion of suitable habitat}

Environmental covariates for each year of the survey (1979-2016 for all species but sand lance; $1979-2008$ for sand lance) were averaged over $0.1^{\circ} \mathrm{x} 0.1^{\circ}$ bins across "usable" strata for 
each season. For FVCOM sourced data (temperature, salinity, mean kinetic energy), these values were averaged over March-April for the spring surveys and September-October for the fall survey, corresponding to the primary months of each survey. In each case, a small portion of grid cells $(\sim 3 \%)$ did not contain an FVCOM node and thus did not have temperature, salinity, or kinetic energy estimates. Values for these cells were estimated using inverse distance weighting with the gstat package in R (S.G. 2021).

For each year, the final, averaged model for each taxon and season was used to predict probability of occurrence within each grid cell. If a grid cell had a probability of occurrence greater than the mean prevalence for a given species and season, it was deemed suitable. Mean prevalence was used instead of a threshold such as 0.5 as using prevalence has been identified as minimizing the discrepancy between specificity and sensitivity (Jiminez-Valverde \& Bobo 2007). Annual proportion of suitable habitat for each season was calculated as the proportion of grid cells exceeding this threshold.

We performed predictions and calculations of shelf occupancy both using models that included the random year intercepts and gear effects, thus including a proxy for likelihood of occurrence due to factors other than environmental covariates, and we performed these predictions and calculations using models where the random year intercepts were set to 0 and the gear effect was set to that of the $R / V$ Albatross $I V$ after the door change (1985-2008), representing the gear type with an intermediate catchability and smallest standard error of the three gear types. These methods allow for comparison of trends in shelf occupancy that incorporate interannual differences due to factors like recruitment or catchability which are not explicitly measured by the model (inclusion of random year intercepts and gear effects) to trends 
that solely assess changes to shelf occupancy due to changes in the environmental predictors (no random intercepts and fixed gear).

To estimate how much year intercepts and gear were related to total abundance of a given species caught in a given season, we calculated the correlation between year and gear specific intercept values and log stratified area-weighted mean abundance of a given taxon in a given season throughout the shelf. These models were fit as a simple linear regression (although note the $\log$ transform of the abundance metric).

Temporal trends in proportion of shelf occupancy for both fixed and random intercept predictions were tested with beta regression using the $\mathrm{R}$ package betar, with annual proportion of suitable habitat as the response variable and year as the predictor.

We also calculated mean weighted latitude and depth of occurrence for each taxon and season. Depth values were assigned to each grid cell from $0.1^{\circ}$ by $0.1^{\circ}$ spatial averages and temporal trends in mean weighted latitude and depth were calculated for both shelf occupancy estimates with and without year and gear-specific intercepts. This has the advantage over direct survey observations in making these calculations over a fixed grid each year, removing any potential for subtle biases from changes in trawl locations within each strata by year that may confound these calculations (Mauread et al. 2021).

\subsection{Results}

\subsubsection{Predictor importance and predictive capability}

Predictor importance, as determined by sum of Akaike weights, varied notably by forage fish species in spring (Table 3-1). Sea surface temperature and eddy kinetic energy were the environmental predictors with the most consistently high sum of Akaike weights, with both having a $\mathrm{SW}>0.9$ for four of the six species (Figure 3-2). Temperature and/or salinity were 
important predictors for all species in the spring. Daily mean kinetic energy had high SW values for sand lance, Atlantic mackerel, alewife, and Atlantic mackerel. Sediment grain size had high SW values for sand lance and blueback herring and bathymetric slope only had an SW $>0.9$ for alewife.

Table 3-1: Sum of Akaike weights for variables for spring models. Variables with no value were not included in the model because of variance inflation (see methods). AUC represents the area under the receiver operating curve for predictions of the test set of data for each model.

\begin{tabular}{|c|c|c|c|c|c|c|}
\hline \multirow[b]{2}{*}{ Variable } & \multicolumn{6}{|c|}{ Spring } \\
\hline & Sand lance & Butterfish & Atl. herring & Alewife & Blueback herring & Atl. mackerel \\
\hline Bottom temperature & - & 1 & - & 1 & - & 1 \\
\hline Bottom salinity & 0.999 & - & 1 & - & - & - \\
\hline Surface temperature & 0.716 & - & 1 & 1 & 1 & 1 \\
\hline Surface salinity & - & - & 0.142 & 0.999 & 0.895 & 1 \\
\hline EKE & 1 & - & 0.962 & 1 & - & 0.999 \\
\hline Bathymetric slope & - & - & - & 0.987 & - & - \\
\hline Grain Size & 0.962 & - & 0.786 & 0.379 & 0.999 & 0.891 \\
\hline
\end{tabular}

AUC

0.822

0.888

0.724

0.762

0.713

0.610

Fall models were less complex, often including only one environmental predictor. Bottom temperature was overwhelmingly important in fall models, included in all species models except sand lance (Table 3-2; Figure 3-3). Bottom temperature was the only predictor included for Atlantic herring, alewife, blueback herring, and Atlantic mackerel due to its high predictive capability leading to high variance inflation factors with other predictors. Both large and small butterfish fall models included more predictors, such as mean kinetic energy and grain size.

Variance estimates of the random year effects varied notably among species in both seasons, with the highest values for sand lance in both seasons. Blueback herring and alewife generally had low variance estimates compared to the other forage species (Table 3-S1,3-S2). Atlantic herring and Atlantic mackerel had moderate variance estimates in both seasons. Gear 
effects varied notably by species, with minimal effects for butterfish and mackerel for both seasons, while gear effects were strongest for Atlantic herring.

Table 3-2: Sum of Akaike weights for variables for fall models. Variables with no value were not included in the model because of variance inflation (see methods). AUC represents the area under the receiver operating curve for predictions of the test set of data for each model.

\begin{tabular}{|c|c|c|c|c|c|c|c|}
\multicolumn{1}{c}{} & \multicolumn{1}{c}{$\begin{array}{c}\text { Sand } \\
\text { Variable }\end{array}$} & $\begin{array}{c}\text { Butterfish } \\
(<11 \mathrm{~cm})\end{array}$ & \multicolumn{1}{c}{$\begin{array}{c}\text { Butterfish } \\
(>11 \mathrm{~cm})\end{array}$} & \multicolumn{1}{c}{$\begin{array}{c}\text { Aall } \\
\text { Atl. } \\
\text { herring }\end{array}$} & \multicolumn{2}{c|}{$\begin{array}{c}\text { Alewife } \\
\text { Blueback } \\
\text { herring }\end{array}$} & $\begin{array}{c}\text { Atl. } \\
\text { mackerel }\end{array}$ \\
\hline Bottom temperature & - & 1 & 1 & 1 & 1 & 1 & 1 \\
\hline Bottom salinity & - & - & - & - & - & - & - \\
\hline Surface temperature & - & - & 0.995 & - & - & - & - \\
\hline Surface salinity & - & 0.999 & 0.672 & - & - & - & - \\
\hline EKE & 1 & 0.451 & 0.998 & - & - & - & - \\
\hline Bathymetric slope & - & - & 1 & - & - & - & - \\
\hline Grain Size & - & 0.461 & 0.965 & - & - & - & - \\
\hline AUC & $\mathbf{0 . 8 2 6}$ & $\mathbf{0 . 6 1 5}$ & $\mathbf{0 . 6 8 7}$ & $\mathbf{0 . 9 7 7}$ & $\mathbf{0 . 9 7 3}$ & $\mathbf{0 . 9 7 1}$ & $\mathbf{0 . 9 3 6}$ \\
\hline
\end{tabular}

Most spring models showed reliable predictive capability for stations and years outside of the dataset (AUC > 0.70) while Atlantic mackerel model had an AUC of 0.61 (Table 3-1). The butterfish model had the highest predictive capability $(\mathrm{AUC}=0.89)$ and was the most parsimonious. Fall models only containing bottom temperatures had high predictive capability, with AUC $>0.9$ for all four taxa. Similarly, daily mean kinetic energy was the only environmental predictor included in the sand lance model due to high variance inflation factors when coupled with other predictors, though the predictive capability was lower ( $\mathrm{AUC}=0.83$; Table 3-2). Unlike spring, both large and small butterfish models, which included multiple environmental predictors, had low AUC values ( 0.61 for small butterfish, 0.69 for large butterfish). 

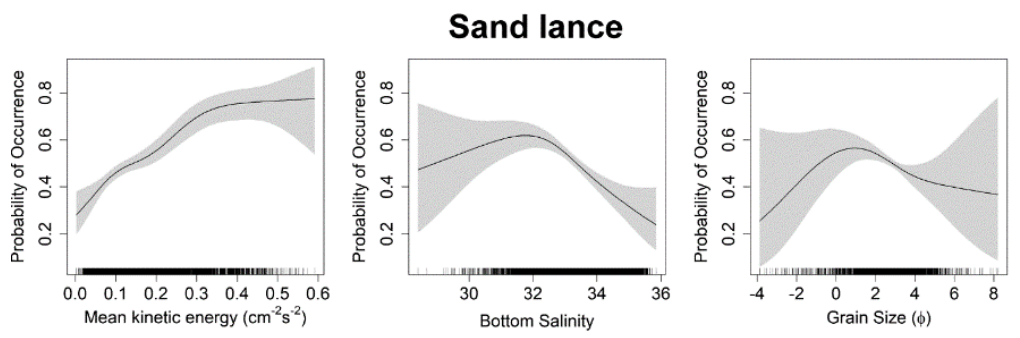

Atl. herring
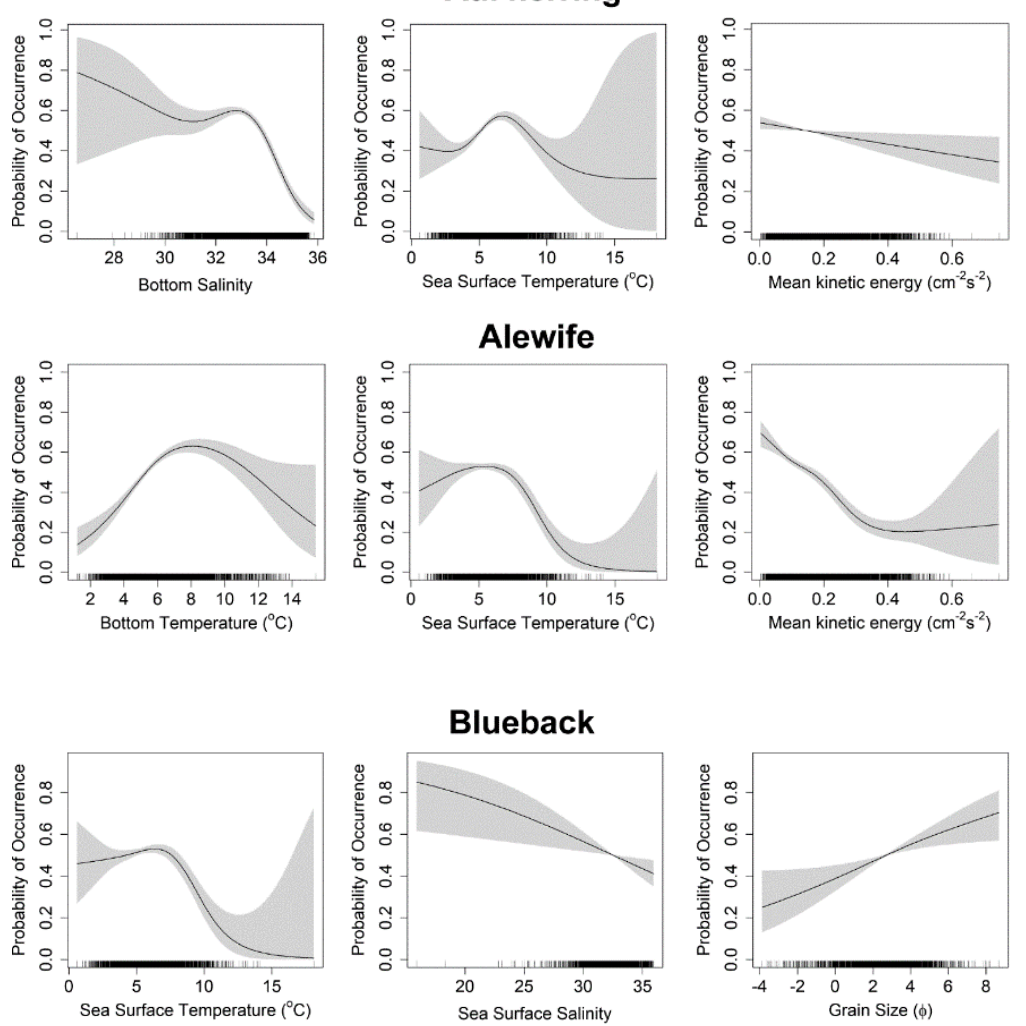

Atl. mackerel
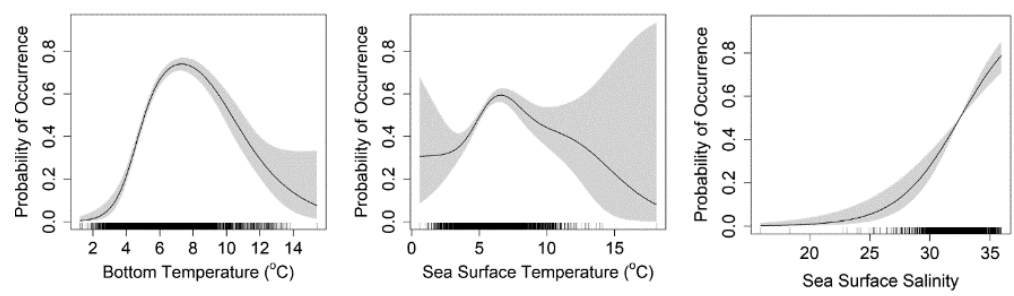

Butterfish

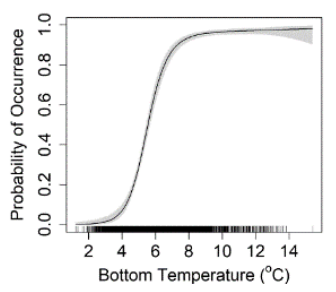

Figure 3-2: Response curves for variables with the three highest sum of Akaike weights per species for spring models. 

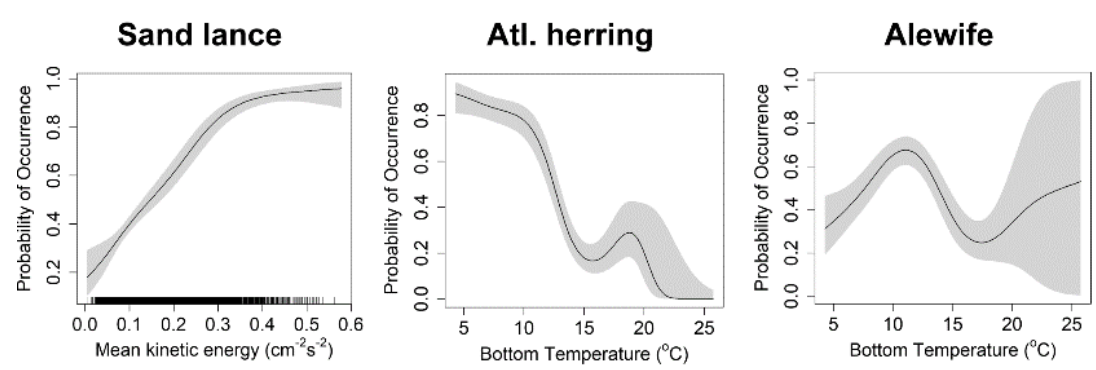

Blueback

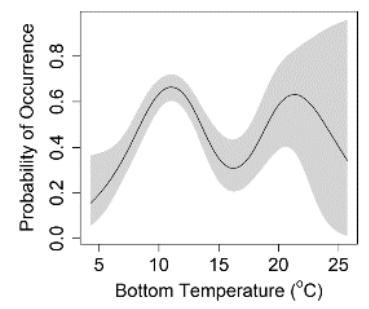

Atl. mackerel
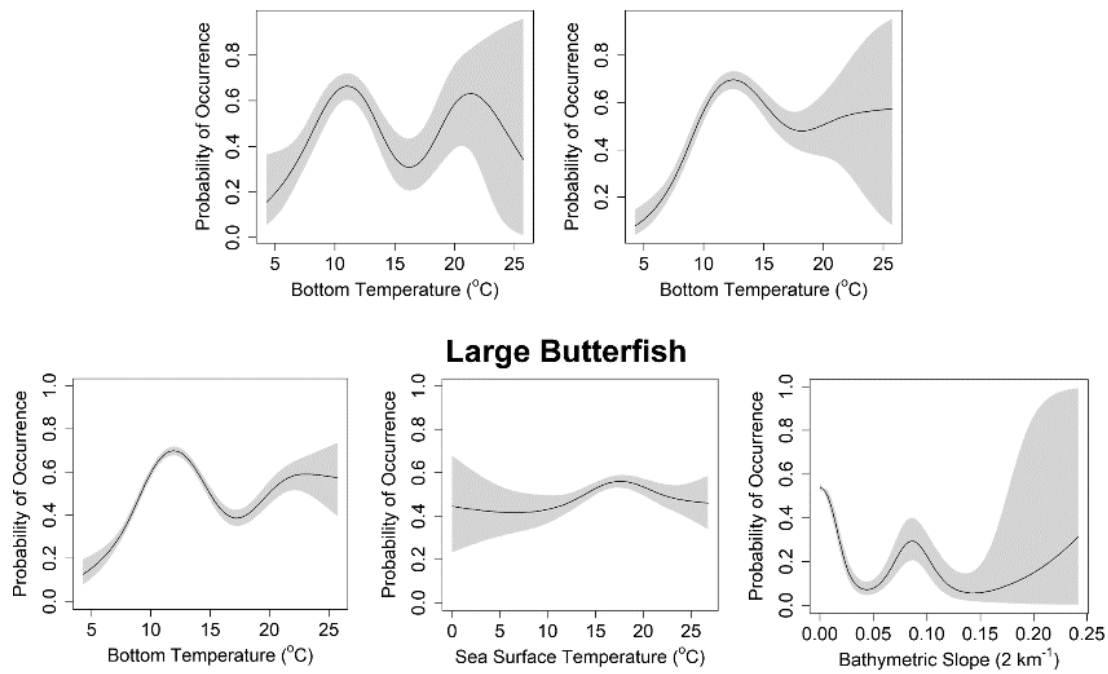

Small Butterfish
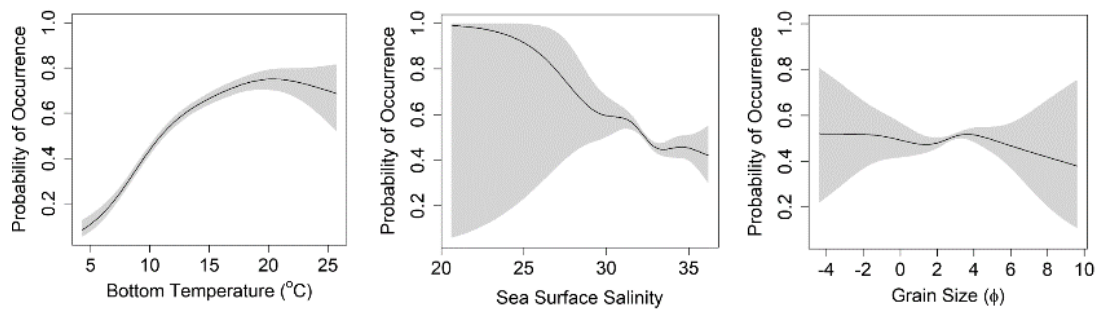

Figure 3-3. Response curves for variables with the three highest sum of Akaike weights per species for fall models.

\subsubsection{Year and gear-specific intercepts and catch comparisons}

Intercept estimates and stratified area-weighted mean abundance estimates from the survey were strongly correlated for most species in both seasons (Table 3-3; Figures 3-S2, 3-S3). Exceptions were alewife and blueback herring in the spring and blueback, Atlantic mackerel, and large butterfish in the fall. Sand lance and Atlantic herring had the strongest correlations in both 
season between year and gear-specific intercept estimates and log stratified area-weighted mean abundance.

Table 3-3. Correlation between year-specific intercepts and mean stratified area-weighted number of individuals per tow for spring and fall models.

\begin{tabular}{llcc} 
Species & Season & $\begin{array}{c}\text { Corr. } \\
\text { Coefficient }\end{array}$ & p-value \\
\hline Sand lance & Spring & 0.890 & $<0.001$ \\
& Fall & 0.653 & $<0.001$ \\
Butterfish & Spring & 0.447 & 0.007 \\
& Fall-Large & 0.195 & 0.262 \\
& Fall-Small & 0.487 & 0.00 \\
Atl. herring & Spring & 0.747 & $<0.001$ \\
& Fall & 0.929 & $<0.001$ \\
Alewife & Spring & 0.011 & 0.946 \\
& Fall & 0.511 & 0.001 \\
Blueback & Spring & -0.051 & 0.773 \\
& Fall & 0.242 & 0.160 \\
Atl. mackerel & Spring & 0.554 & $<0.001$ \\
& Fall & 0.207 & 0.232
\end{tabular}

\subsubsection{Trends in occupiable habitat}

Annual trends in spring occupiable habitat varied by species and by whether gear and year intercepts were incorporated (Table 3-3; Figure 3-4). Using year-specific random intercepts Atlantic herring, blueback herring, Atlantic mackerel, and butterfish showed significant increases in spring proportion of shelf occupancy while sand lance showed a significant decrease in shelf occupancy with time. Using a fixed gear and removing year-specific intercepts, sand lance and butterfish showed a significant increase in occupancy with time while all other species had nonsignificant trends. Slope estimates for alewife, blueback herring, and sand lance showed opposite signs between shelf occupancy with and without year-specific intercepts and gear effects. 

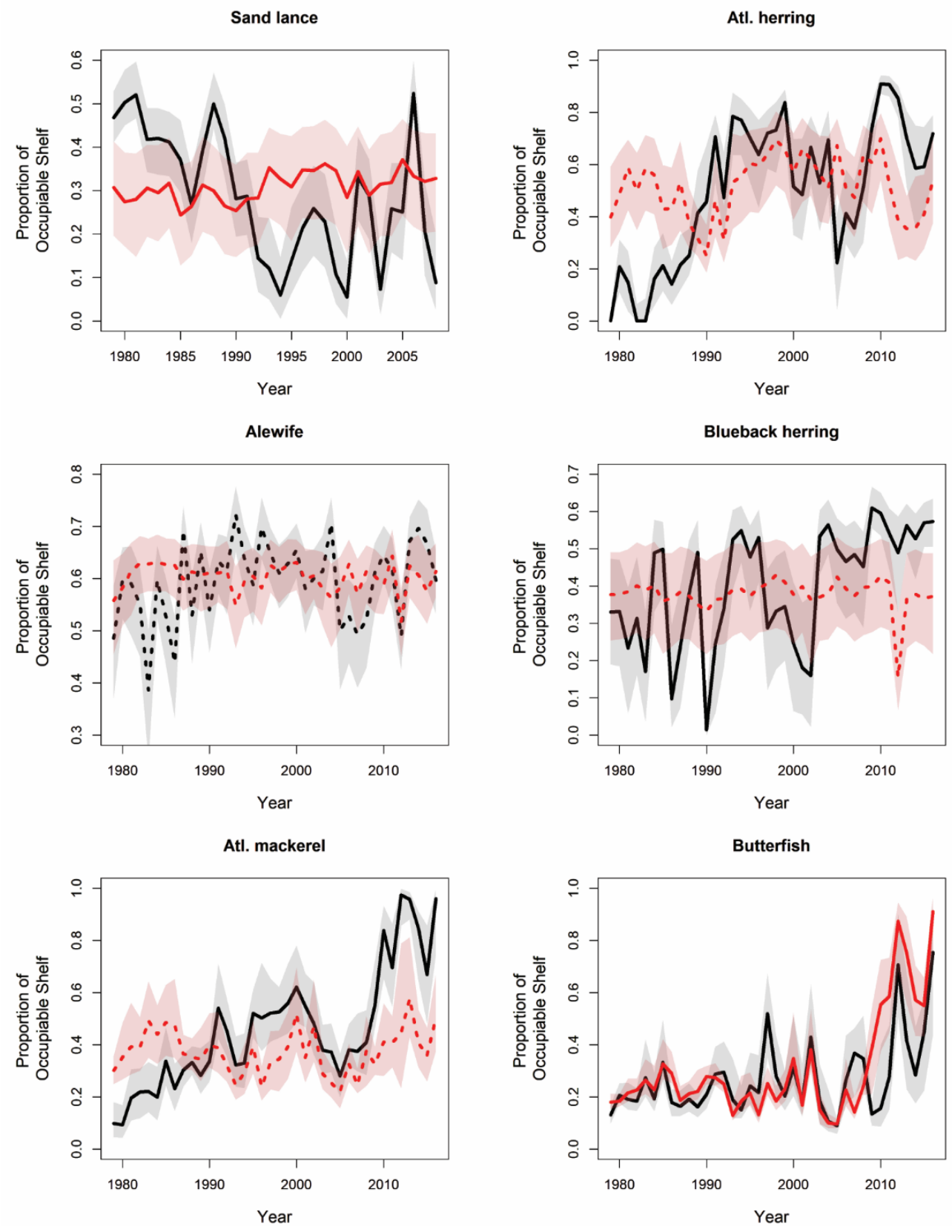

Figure 3-4. Trends in proportion of occupiable shelf including (red) and excluding year and gear-specific intercepts (black) in spring. Significant trends are indicated by a solid line. Shading reflects $95 \%$ confidence intervals.

Fall trends in shelf occupancy were stronger (greater slope estimates) and more frequently significant than in spring (Table 3-4; Figure 3-5). Trends in occupiable shelf in fall were also more coherent between year-specific and fixed intercept models for most species (Table 3-4). The notable exception was Atlantic herring which had a significant increase in 
occupiable shelf in year and gear-specific model predictions, while having a significant negative trend with model predictions with fixed gear and no year intercepts.
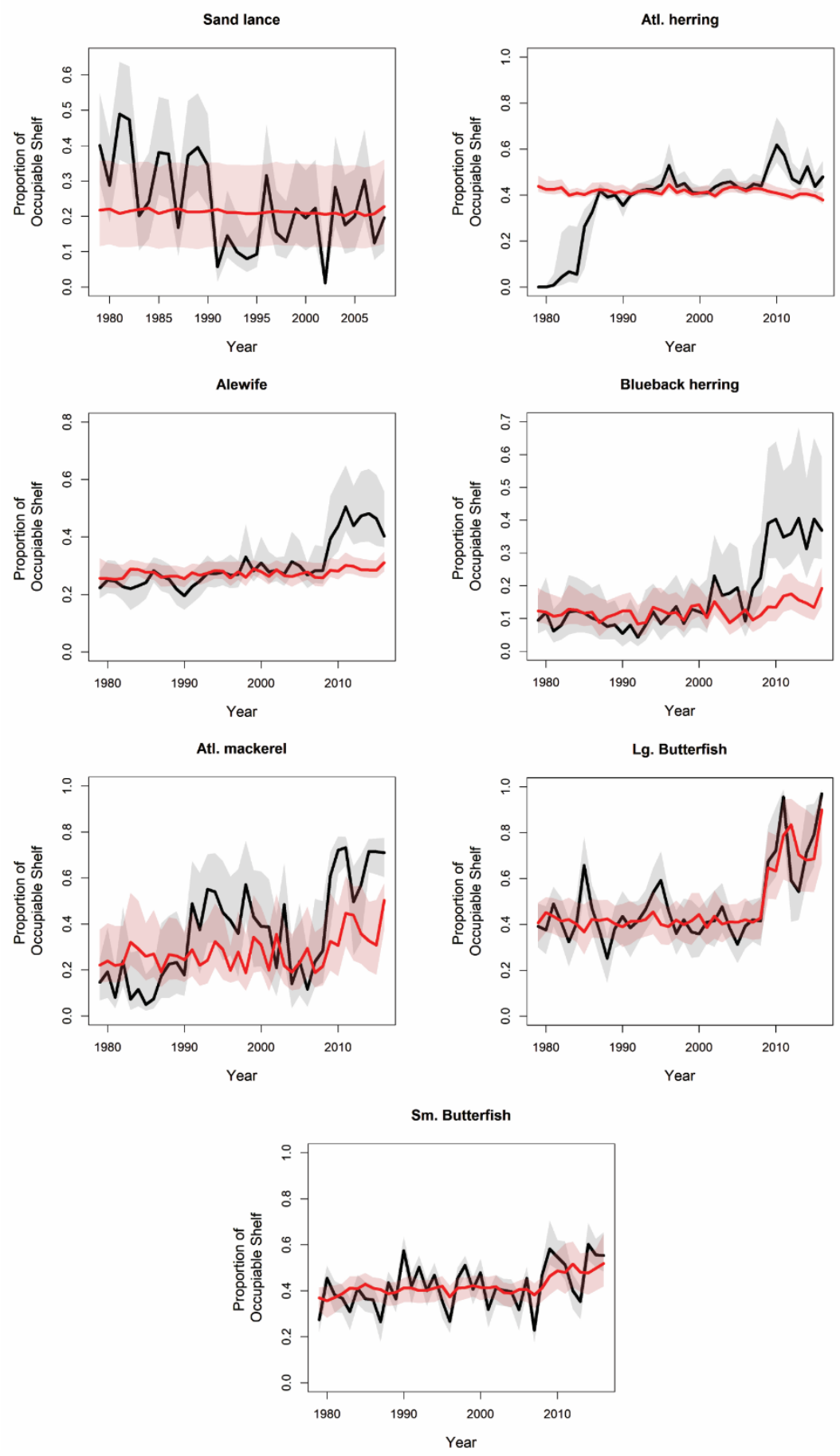

Figure 3-5. Trends in proportion of occupiable shelf including (red) and excluding year and gear-specific intercepts (black) in fall. Significant trends are indicated by a solid line. Shading reflects $95 \%$ confidence intervals. 
Table 3-4: Trends in shelf occupancy without year and gear-specific intercepts (fixed intercept) and shelf occupancy (year-specific intercept) with time as estimated through beta regression. Butterfish were only split into small and large groups for fall models.

\begin{tabular}{|c|c|c|c|c|c|}
\hline Species & Season & Intercept & Slope estimate & Pseudo- $\mathrm{R}^{2}$ & $\mathrm{p}$-value \\
\hline \multirow[t]{4}{*}{ Sand lance } & Spring & Year-Specific & -0.053 & 0.300 & $<0.001$ \\
\hline & & Fixed & 0.010 & 0.294 & $<0.001$ \\
\hline & Fall & Year-Specific & -0.044 & 0.188 & 0.001 \\
\hline & & Fixed & -0.002 & 0.163 & 0.016 \\
\hline \multirow[t]{6}{*}{ Butterfish } & Spring & Year-Specific & 0.026 & 0.173 & 0.005 \\
\hline & & Fixed & 0.047 & 0.282 & $<0.001$ \\
\hline & Fall-Large & Year-Specific & 0.041 & 0.282 & $<0.001$ \\
\hline & & Fixed & 0.037 & 0.429 & $<0.001$ \\
\hline & Fall-Small & Year-Specific & 0.014 & 0.163 & 0.006 \\
\hline & & Fixed & 0.011 & 0.538 & $<0.001$ \\
\hline \multirow[t]{4}{*}{ Atl. herring } & Spring & Year-Specific & 0.101 & 0.266 & $<0.001$ \\
\hline & & Fixed & 0.006 & 0.020 & 0.374 \\
\hline & Fall & Year-Specific & 0.096 & 0.29 & $<0.001$ \\
\hline & & Fixed & -0.002 & 0.122 & 0.021 \\
\hline \multirow[t]{4}{*}{ Alewife } & Spring & Year-Specific & 0.008 & 0.067 & 0.096 \\
\hline & & Fixed & -0.002 & 0.029 & 0.287 \\
\hline & Fall & Year-Specific & 0.027 & 0.689 & $<0.001$ \\
\hline & & Fixed & 0.004 & 0.253 & $<0.001$ \\
\hline \multirow[t]{4}{*}{ Blueback } & Spring & Year-Specific & 0.035 & 0.215 & $<0.001$ \\
\hline & & Fixed & -0.003 & 0.016 & 0.415 \\
\hline & Fall & Year-Specific & 0.063 & 0.662 & $<0.001$ \\
\hline & & Fixed & 0.010 & 0.201 & 0.001 \\
\hline \multirow[t]{4}{*}{ Atl. mackerel } & Spring & Year-Specific & 0.078 & 0.613 & $<0.001$ \\
\hline & & Fixed & 0.001 & 0.001 & 0.843 \\
\hline & Fall & Year-Specific & 0.057 & 0.484 & $<0.001$ \\
\hline & & Fixed & 0.015 & 0.204 & 0.001 \\
\hline
\end{tabular}

\subsubsection{Mean weighted latitude and depth}

Spring annual trends in mean weighted latitude and depth varied with species, but generally trended north and deeper with time (Table 3-5). Butterfish and Atlantic mackerel showed the most pronounced and significant northward shift in weighted mean latitude while Atlantic herring and alewife showed the least change in weighted mean latitude (Figure 3-6). 
Butterfish and Atlantic mackerel also showed the most pronounced and significant increase in mean weighted depth (Figure 3-7).
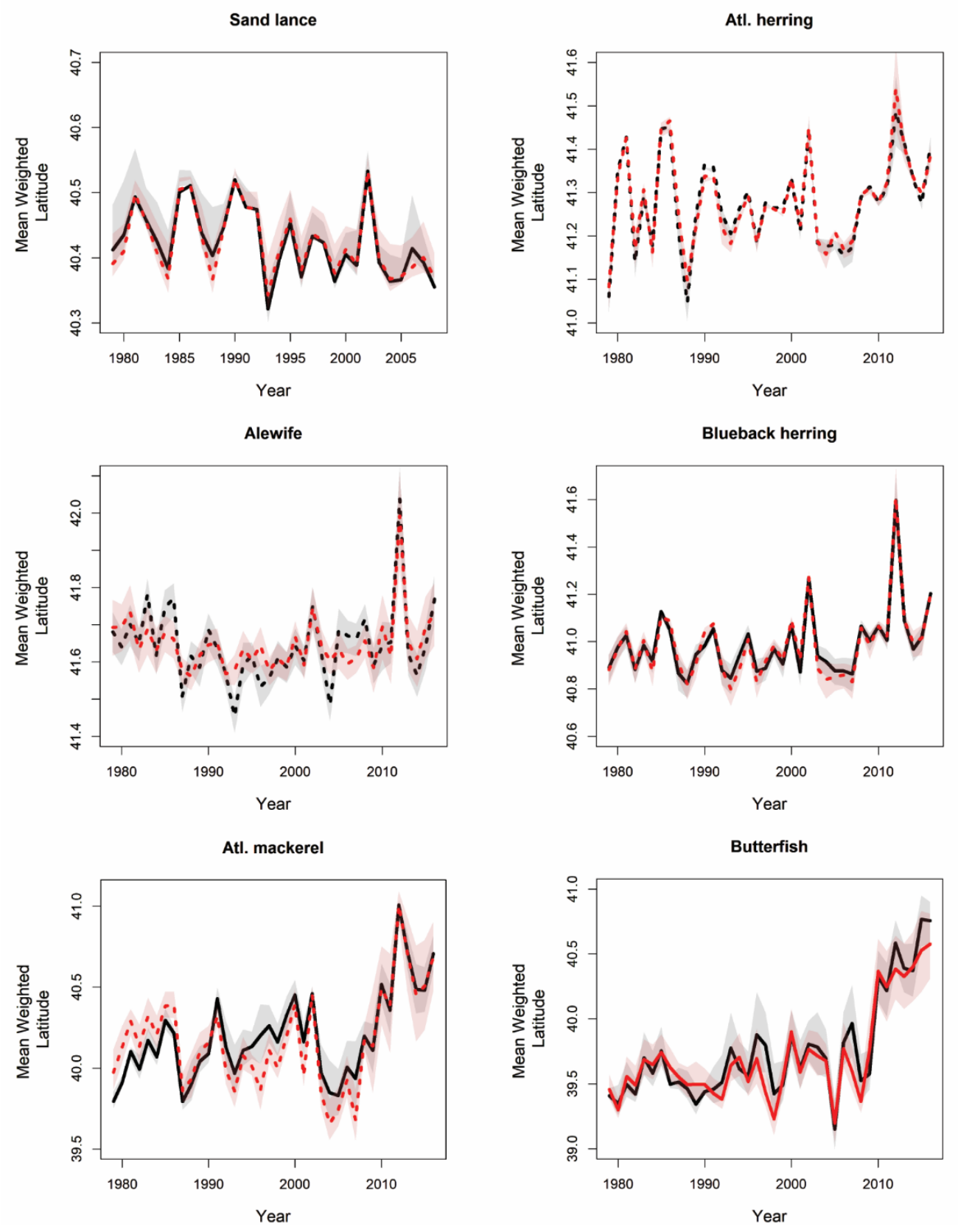

Figure 3-6. Trends in spring weighted mean latitude based on including (red) and excluding year and gear-specific intercepts (black) in spring. Significant trends are indicated by a solid line. Shading reflects $95 \%$ confidence intervals. 

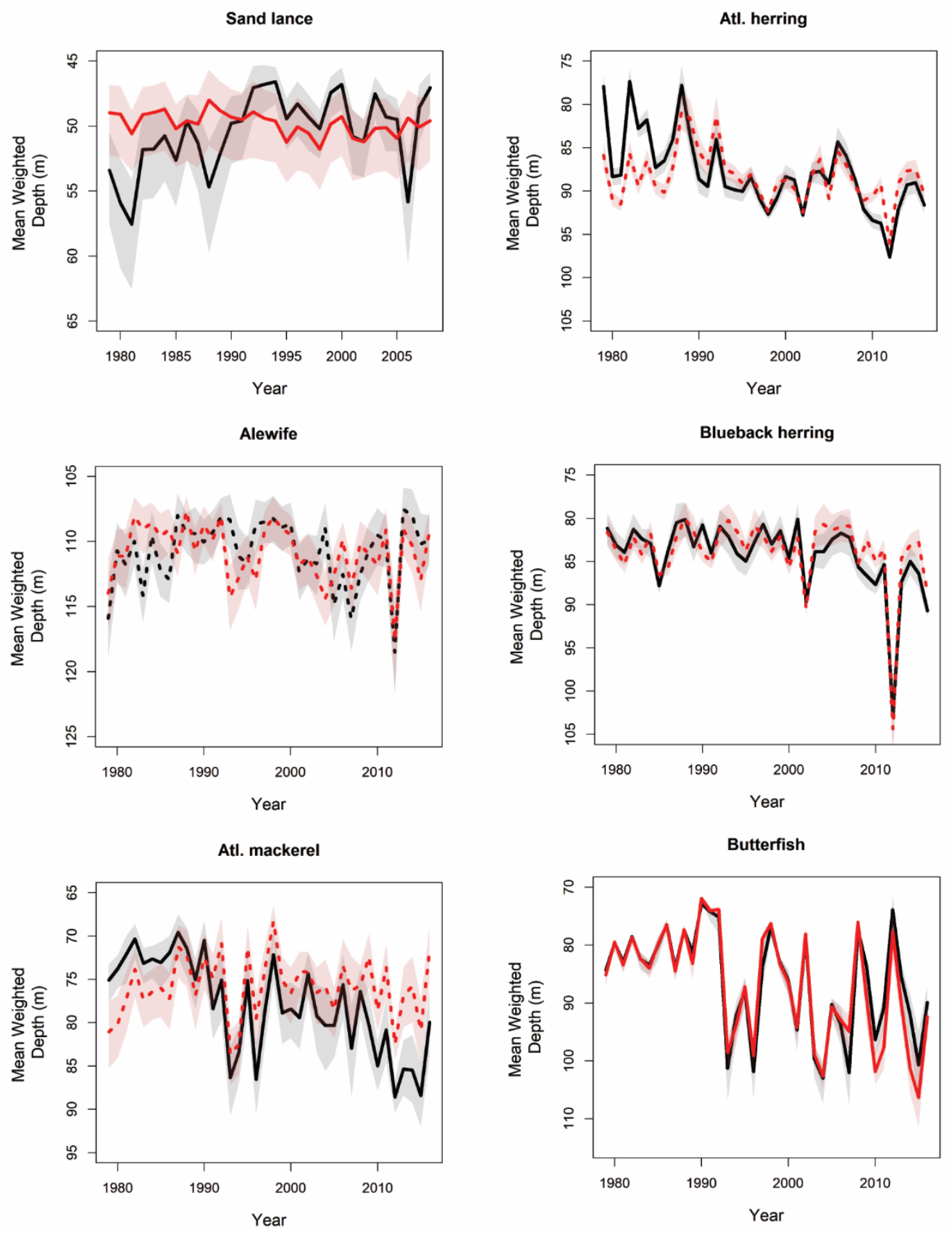

Figure 3-7. Trends in spring weighted mean depth based on including (red) and excluding year and gear-specific intercepts (black) in spring. Significant trends are indicated by a solid line. Shading reflects $95 \%$ confidence intervals. 
Table 3-5: Trends in annual mean weighted latitude and depth of shelf occupancy based on intercept condition for spring models.

\begin{tabular}{|c|c|c|c|c|c|}
\hline Species & Predictor & Intercept & $\begin{array}{c}\begin{array}{c}\text { Slope } \\
\text { estimate }\end{array} \\
\end{array}$ & $\mathrm{R}^{2}$ & p-value \\
\hline \multirow[t]{4}{*}{ Sand lance } & \multirow[t]{2}{*}{ Latitude } & Year-Specific & -0.003 & 0.194 & 0.015 \\
\hline & & Fixed & -0.003 & 0.133 & 0.048 \\
\hline & \multirow[t]{2}{*}{ Depth } & Year-Specific & 0.170 & 0.269 & 0.003 \\
\hline & & Fixed & -0.040 & 0.168 & 0.024 \\
\hline \multirow[t]{4}{*}{ Butterfish } & \multirow[t]{2}{*}{ Latitude } & Year-Specific & 0.016 & 0.429 & $<0.001$ \\
\hline & & Fixed & 0.023 & 0.457 & $<0.001$ \\
\hline & \multirow[t]{2}{*}{ Depth } & Year-Specific & -0.375 & 0.176 & 0.009 \\
\hline & & Fixed & -0.495 & 0.282 & $<0.001$ \\
\hline \multirow[t]{4}{*}{ Atl. herring } & \multirow[t]{2}{*}{ Latitude } & Year-Specific & 0.001 & 0.022 & 0.378 \\
\hline & & Fixed & 0.001 & 0.009 & 0.571 \\
\hline & \multirow[t]{2}{*}{ Depth } & Year-Specific & -0.260 & 0.419 & $<0.001$ \\
\hline & & Fixed & -0.085 & 0.095 & 0.059 \\
\hline \multirow[t]{4}{*}{ Alewife } & \multirow[t]{2}{*}{ Latitude } & Year-Specific & 0.001 & 0.010 & 0.534 \\
\hline & & Fixed & 0.002 & 0.109 & 0.051 \\
\hline & \multirow[t]{2}{*}{ Depth } & Year-Specific & -0.002 & $<0.001$ & 0.958 \\
\hline & & Fixed & -0.050 & 0.066 & 0.118 \\
\hline \multirow[t]{4}{*}{ Blueback } & \multirow[t]{2}{*}{ Latitude } & Year-Specific & 0.004 & 0.091 & 0.066 \\
\hline & & Fixed & 0.003 & 0.034 & 0.266 \\
\hline & \multirow[t]{2}{*}{ Depth } & Year-Specific & -0.178 & 0.237 & 0.002 \\
\hline & & Fixed & -0.093 & 0.062 & 0.130 \\
\hline \multirow[t]{4}{*}{$\begin{array}{l}\text { Atl. } \\
\text { mackerel }\end{array}$} & \multirow[t]{2}{*}{ Latitude } & Year-Specific & 0.014 & 0.295 & $<0.001$ \\
\hline & & Fixed & 0.001 & 0.001 & 0.842 \\
\hline & \multirow[t]{2}{*}{ Depth } & Year-Specific & -0.351 & 0.498 & $<0.001$ \\
\hline & & Fixed & 0.011 & 0.001 & 0.840 \\
\hline
\end{tabular}

Fall annual trends in mean weighted latitude and depth varied more by species than in the spring (Table 3-6). Most species indicated no significant trend or a significant northward and deeper trend with time. However, Atlantic herring and alewife showed significant decreases in mean weighted latitude with time (Figure 3-8). Atlantic herring in fall had opposite trends in mean weighted depth in model predictions with and without year and gear-specific intercepts (Figure 3-9). 

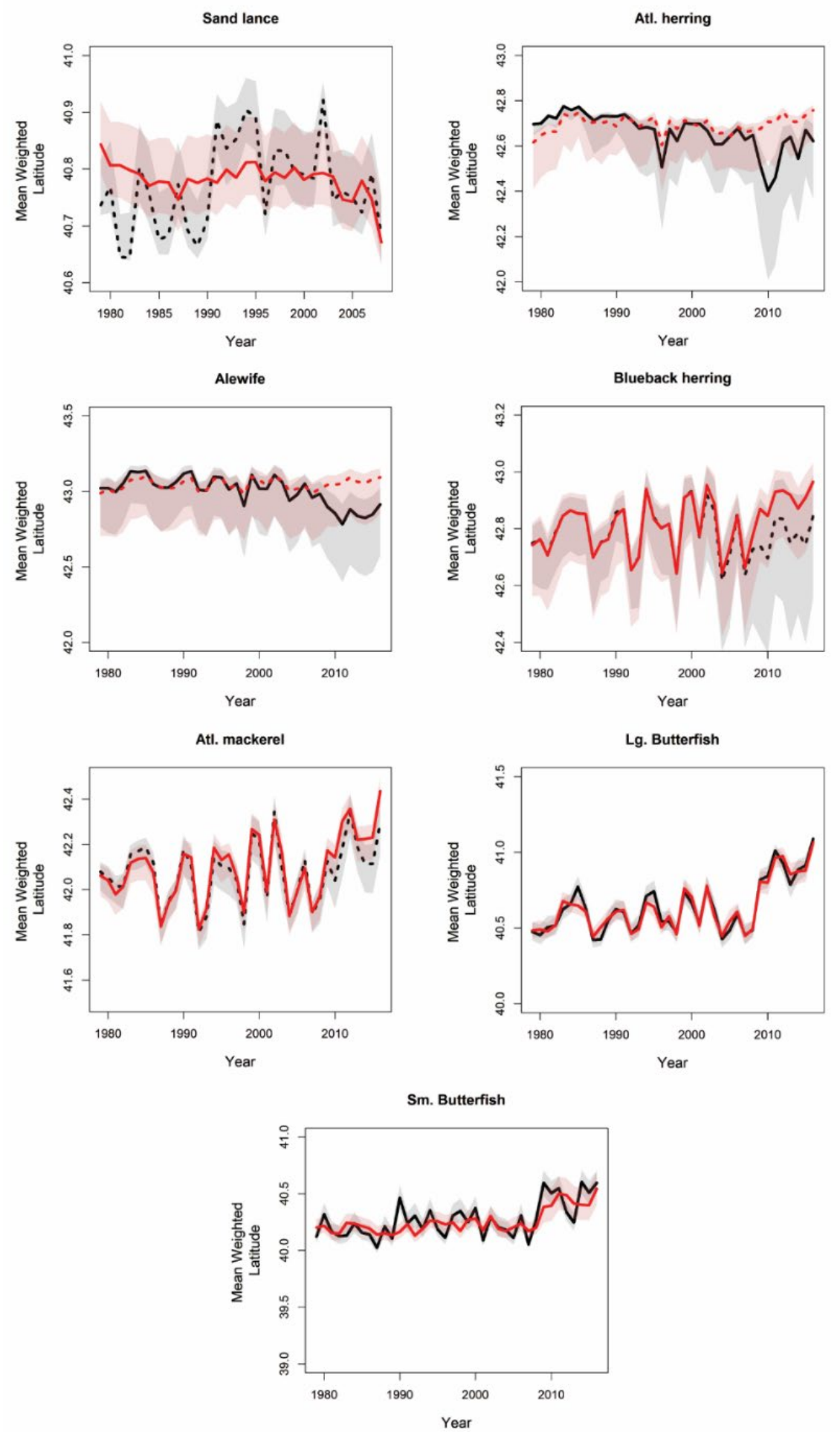

Figure 3-8. Trends in fall weighted mean latitude based on including (red) and excluding year and gear-specific intercepts (black). Significant trends are indicated by a solid line. Shading reflects $95 \%$ confidence intervals. 

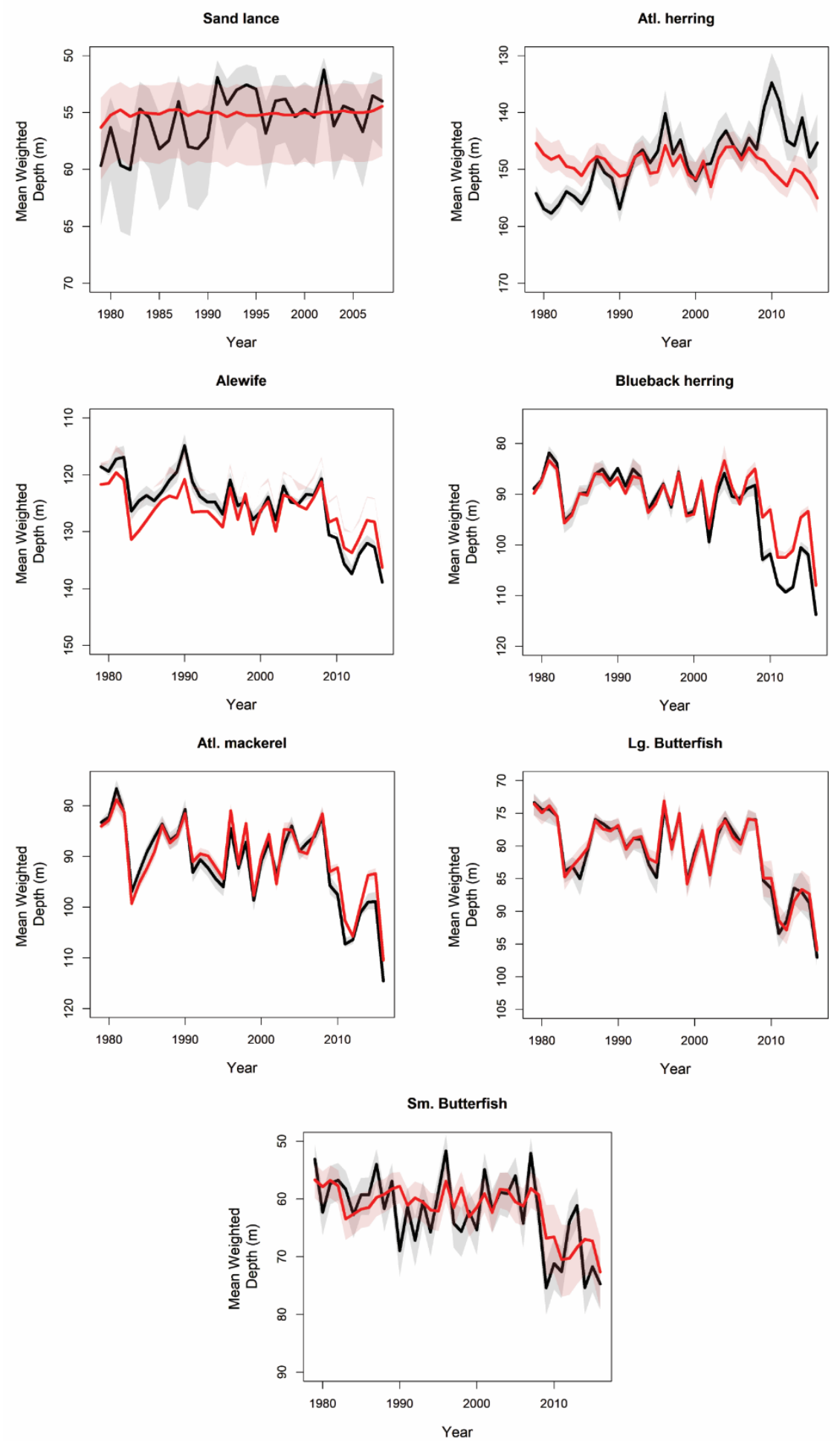

Figure 3-9. Trends in fall weighted mean depth based on including (red) and excluding year and gear-specific intercepts (black). Significant trends are indicated by a solid line. Shading reflects $95 \%$ confidence intervals. 
Table 3-6: Trends in annual mean weighted latitude and depth of shelf occupancy based on intercept condition for fall models.

\begin{tabular}{|c|c|c|c|c|c|}
\hline Species & Predictor & Intercept & $\begin{array}{c}\text { Slope } \\
\text { estimate }\end{array}$ & $\mathrm{R}^{2}$ & $\begin{array}{c}\mathrm{p}- \\
\text { value }\end{array}$ \\
\hline \multirow[t]{4}{*}{ Sand lance } & Latitude & Year-Specific & 0.002 & 0.070 & 0.157 \\
\hline & & Fixed & -0.002 & 0.283 & 0.002 \\
\hline & Depth & Year-Specific & 0.142 & 0.288 & 0.002 \\
\hline & & Fixed & 0.014 & 0.162 & 0.028 \\
\hline \multirow{5}{*}{$\begin{array}{l}\text { Lg. } \\
\text { Butterfish }\end{array}$} & & & & & \\
\hline & Latitude & Year-Specific & 0.009 & 0.347 & $<0.001$ \\
\hline & & Fixed & 0.009 & 0.383 & $<0.001$ \\
\hline & Depth & Year-Specific & -0.317 & 0.343 & $<0.001$ \\
\hline & & Fixed & -0.314 & 0.359 & $<0.001$ \\
\hline \multirow[t]{4}{*}{$\begin{array}{l}\text { Sm. } \\
\text { Butterfish }\end{array}$} & Latitude & Year-Specific & 0.008 & 0.331 & $<0.001$ \\
\hline & & Fixed & 0.007 & 0.490 & $<0.001$ \\
\hline & Depth & Year-Specific & -0.309 & 0.283 & $<0.001$ \\
\hline & & Fixed & -0.254 & 0.436 & $<0.001$ \\
\hline \multirow[t]{4}{*}{ Atl. herring } & Latitude & Year-Specific & -0.005 & 0.446 & 0.001 \\
\hline & & Fixed & 0.001 & 0.029 & 0.310 \\
\hline & Depth & Year-Specific & 0.388 & 0.600 & $<0.001$ \\
\hline & & Fixed & -0.072 & 0.128 & 0.028 \\
\hline \multirow[t]{4}{*}{ Alewife } & Latitude & Year-Specific & -0.006 & 0.507 & $<0.001$ \\
\hline & & Fixed & 0.001 & 0.053 & 0.163 \\
\hline & Depth & Year-Specific & -0.390 & 0.554 & $<0.001$ \\
\hline & & Fixed & -0.190 & 0.246 & 0.001 \\
\hline \multirow[t]{4}{*}{ Blueback } & Latitude & Year-Specific & -0.001 & 0.006 & 0.647 \\
\hline & & Fixed & 0.003 & 0.147 & 0.018 \\
\hline & Depth & Year-Specific & 0.511 & 0.481 & $<0.001$ \\
\hline & & Fixed & -0.278 & 0.275 & $<0.001$ \\
\hline \multirow[t]{4}{*}{$\begin{array}{l}\text { Atl. } \\
\text { mackerel }\end{array}$} & Latitude & Year-Specific & 0.003 & 0.059 & 0.141 \\
\hline & & Fixed & 0.006 & 0.193 & 0.006 \\
\hline & Depth & Year-Specific & -0.470 & 0.375 & $<0.001$ \\
\hline & & Fixed & -0.336 & 0.237 & 0.002 \\
\hline
\end{tabular}

\subsection{Discussion}

Our work suggests that the effects of tropicalization on the Northeast US shelf can be observed in changes to the forage fish community's shelf occupancy. Clear effects include the movement of weighted mean bottom depth and weighted mean latitude to largely deeper and 
more northward locations for species in both seasons. However, our work also elucidates a distinction between changes in observed shelf occupancy by forage fish species throughout the time series as driven by the combination of year and gear-specific versus changes driven by coincident environmental conditions. Identifying these differences is important for understanding the effects of climate change and variability on the life history of fishes as effects of fishing, recruitment, and local hydrographic conditions can lead to compounding or compensatory effects on a species' occurrence.

Atlantic herring provide a clear example of the distinction between trends in shelf occupancy as driven by coincident environmental conditions compared to external (year and gear-specific) factors. Atlantic herring had significant positive trends in shelf occupancy in both spring and fall through time, yet shelf occupancy as predicted by environmental covariates had no trend in spring and a significant decrease with time in the fall. These results reflect increasing catch of Atlantic herring throughout the trawl survey due to recovery from past fishing and shifts in survey gear, while the trends based on environmental covariates suggest that the area of favorable habitat for Atlantic herring is decreasing with increasing mean temperatures and bottom salinity. This decrease in habitat suitability is intuitive given the more northerly distribution and reliance on temperate to sub-polar zooplankton as food for Atlantic herring compared to other forage fishes in the region (Bowman et al. 2000; Suca et al. 2018).

Differences between trends in shelf occupancy and trends in shelf occupancy based on environmental covariates were not striking for all species, however, with spring butterfish catches showing strong coherence between interannual variability in these two metrics. This pattern in butterfish is consistent with existing literature tying their distribution and trawl survey catch to temperature, although we observe the strongest pattern being with bottom temperature as 
opposed to surface temperature (Adams, 2017). These notable differences in coherence between the two shelf occupancy metrics can provide direction to future studies of climate impacts on the forage fishes of the Northeast US shelf, with coincident environmental conditions being important for species such as butterfish and Atlantic mackerel, while external factors strongly outweigh these environmental covariates for Atlantic herring and sand lance during the time window of this study.

Coherence between shelf occupancy and shelf occupancy as described by environmental covariates was also slightly stronger across species in the fall than the spring. Bottom temperature was an important variable for all species except sand lance in the fall, indicating that fall shelf occupancy may be more tightly linked to thermal niche availability than it is for spring (with the exception of butterfish). Trends were often intuitive for both seasons, with Atlantic herring's environmental condition-driven shelf occupancy decreasing with time (and thus increasing bottom temperature), while all others increased, largely following our hypotheses. However, patterns in alewife shelf occupancy did not follow our expectations, with shelf occupancy not changing with time in spring and increasing in the fall. This is notably opposite of the trends observed in previous work modeling presence/absence data of alewife, though it is consistent with trends observed when modeling abundance of alewife (Lynch et al., 2020). Response curves for presence and temperature conditions often indicated season specific thermal windows of occurrence for fishes, supporting a strong role for thermal habitat availability in species occurrence (Kleisner et al., 2017; Morley et al., 2018). Notable exceptions were clear positive relationships between temperature and butterfish occurrence, and large uncertain probabilities of occurrence of alewife at high temperatures in the fall. These uncertain tails are likely due to high occurrence of these fishes in regions of the coastal Gulf of Maine, where north 
to south advection dominates in the form of the Gulf of Maine Coastal Current (Townsend et al. 2015; Figure 3-S4). The coastal current represents a pathway for transport of Calanus finmarchicus, an important prey item for many forage fish species, particularly alewife (Ji et al., 2017; Suca et al., 2018).

Contrary to the largely parsimonious bottom temperature-driven models for the fall, spring models often included other predictors, including sea surface temperature and mean kinetic energy. This may be linked with the spring representing an important time of feeding for these species and thus their distribution may be more variable corresponding to following food at small scales (Smith and Link 2010; Suca et al. 2018). We originally explored using zooplankton taxa as predictor variables, but the large loss of data caused by their inclusion (tows only occur at every third trawl and even these collections tend to be inconsistent) precluded many years from being included in model formation with often $<50$ stations remaining per year. The incorporation of prey as predictor variables will likely become more practical in coming decades as the EcoMon survey zooplankton collections became more consistent with trawls later in the time series. However, whether forage fishes even follow zooplankton aggregations remains an open question and it is likely that this prey following behavior, if it occurs at all, does so at scales too small for the Northeast Fisheries Science Center trawl survey to observe (Holland et al. 2021). Another possible cause of more complex and less accurate spring models is the more subtle and complex gradients in temperature and salinity properties in the spring compared to fall. In the early fall, during much of the survey, the region is highly stratified leading to decoupling of surface and bottom temperatures while both still follow known gradients by latitude and cross shelf distance (Townsend et al. 2015). In spring, waters are largely well-mixed and thus there is greater coherence between surface and bottom temperatures and salinities, 
making identifying the mechanisms driving shelf occupancy more difficult to elucidate. The only exceptions to this are regions of high bottom temperatures and bottom salinities in the deeper regions that contain Gulf Stream influenced slope water and elevated surface salinity from Gulf Stream intrusions which were important in identifying Atlantic herring and Atlantic mackerel spring occupancy, respectively (Mountain, 2012). The positive relationship between spring Atlantic mackerel presence and surface salinity may be an indication of preference for warm, saline Gulf Stream influenced water that enter the Northeast US shelf (Churchill and Cornillon, 1991), illustrated by habitat maps showing the highest occurrence near the shelf edge in the MidAtlantic Bight (Figure 3-S5). Multiple changepoints in Gulf Stream behavior occurred in the $21^{\text {st }}$ century, including a westward shift in the destabilization point (Andres, 2016) and near doubling in the production of warm core rings (Gangopadhyay et al., 2019). These changes in Gulf Stream behavior are also likely linked to changepoints observed in warm slope water entering the Gulf of Maine (Suca et al., 2021) and the marked change in bottom temperatures around 2009 (Friedland et al., 2020a). Collectively, these changes are likely to lead to increased bottom salinity throughout much of the shelf and increased intrusions of waters with high surface salinity. Our results suggest this may have negative consequences for Atlantic herring shelf occupancy in the spring, while increasing shelf occupancy for Atlantic mackerel in the spring. Changes in the Gulf Stream behavior is likely one of the largest factors driving the change of both hydrography and species composition observed in our study and others (Kleisner et al., 2017; Friedland et al., 2020b, 2020a). It is worth noting that Gulf Stream water is unlikely to influence small butterfish shelf occupancy in the fall. This is because the negative relationship between the occurrence of small butterfish and sea surface salinity is more likely due to a cross shelf effect rather than avoidance of Gulf Stream influenced water (see Figure 3-S4). 
Collectively, our results corroborate trends of species distribution shifts throughout the Northeast US shelf, including changes in shelf occupancy, depth, and latitude of the forage fish complex. Most species had deeper mean weighted depth with time, particularly in the fall which is consistent with past observations for species such as alewife (Nye et al., 2009). However, unlike Nye et al. (2009), we noticed significant changes in depth for Atlantic herring in both seasons and a different trend for Atlantic mackerel in the fall (deeper instead of shallower). The northward shifts in our study for many species is also consistent with those seen for similar species from previous studies (Kleisner et al., 2017; Friedland et al., 2020b).

However, a limitation of our study is our inability to address the drivers of non in-situ environmentally driven shelf occupancy for many species beyond abundance and survey gear, particularly Atlantic herring, sand lance, and river herring. For Atlantic herring and sand lance, shelf occupancy is tightly correlated with trawl abundance, suggesting shelf occupancy is primarily controlled by changes to collective biomass and gear catchability. The drivers of these fluctuations have been studied for both species, providing hypotheses for the mechanisms behind these patterns (Richardson et al., 2011; Suca et al., 2021). River herring intercept values, however, did not significantly correlate with abundance metrics in the spring (or for blueback herring in the fall), suggesting mechanisms other than environmental covariates used in this study and survey abundance drive interannual differences in shelf occupancy. This may be due to their spawning behavior in the spring and coastal distributions (Lynch et al., 2020), but further research is needed to refine hypotheses. Future work can also expand beyond our focus explicitly on presence/absence models to incorporate abundance. Previous research suggests opposite trends may occur in the relationships between a species' presence and abundance with a given environmental covariate (Lynch et al., 2020; Friedland et al., 2021). Abundance models for 
schooling small pelagic fishes often have poor fits and predictive capability when using trawl survey data (see methods; (Deroba, 2018), leading to presence/absence models driving hurdle model predictions (Deroba, 2018). This limitation is also related to issues with catching small pelagic fishes using bottom trawl survey gear. This survey is often used for forage fish studies, but catches may miss portions of these species' behaviors and niches by not sampling the full water column. An important example of this phenomenon is Atlantic mackerel, the species which had the lowest spring predictive capability of our models. In this case, not only does the trawl survey have issues with capturing the vertical distribution of this species, but mackerel habitat extends beyond the Northeast US shelf in the spring into the Slope Sea (Overholtz et al. 2011). Additionally, due to issues with re-creation of accurate bottom temperatures, we excluded many of the slope strata for our spring models. This caused a loss of strata where both Atlantic mackerel and butterfish are often caught, possibly leading to poorly constrained spring Atlantic mackerel models. Conversely, despite this loss of known habitat, spring butterfish models were the most accurate (as defined by AUC) of all spring models indicating we were able to accurately constrain the relationship between butterfish presence and bottom temperature for the non-slope strata of the Northeast US shelf. Incorporating alternative survey methods to accurately assess forage fish abundance in the vertical domain and expanding the horizontal sampling area for species that extend beyond the shelf will be essential in further research.

Shifts in shelf occupancy of forage species may have consequences on food web interactions and fisheries given the importance of forage fishes as prey for top predators on the Northeast US Shelf. This may be particularly true for predators that follow forage species in their distribution (Overholtz and Link, 2007; Richardson et al., 2014). While total shelf occupancy is largely driven by abundance and recruitment for many forage fish species, environmental 
covariates linked to shelf occupancy can provide insight into regions where they may occur frequently and can represent reliable feeding hotspots for predators (Silva et al., 2021). Mean weighted depth and latitude of habitat suitability for many of the forage fishes trended deeper and northward with time, potentially shifting foraging grounds for predators as well. These changes may shift the distance traveled from port for fishing vessels targeting predators reliant on these forage species or even change which port lies closest to fishing hotspots (Kleisner et al., 2017; Selden et al., 2020).

Ultimately, it will be important to study the interactions between future forage fish survey catches (observed year and gear-specific shelf occupancy) and environmental covariates associated with shelf occupancy. Our results show that these metrics do not always align, and may even show opposite trends, but future conditions may lead to coincident environmental covariates becoming a limiting factor in the life history of certain forage fishes. Understanding if or when this comes to fruition will be essential to our understanding of the future dynamics of the changing Northeast US shelf forage fish complex. 


\subsection{Supplemental Information}

Table 3-S1: Gear intercept estimates and year variance estimates for spring models by species.

Spring

\begin{tabular}{|c|c|c|c|c|c|c|}
\hline Variable & Sand lance & Butterfish & Atl. herring & Alewife & Blueback herring & Atl. mackerel \\
\hline Gear A & - & - & -0.968 & -0.383 & -2.133 & - \\
\hline Gear B & - & -4.117 & 1.263 & 0.315 & 0.181 & -2.239 \\
\hline Gear C & - & 1.365 & 2.324 & 0.418 & 0.925 & 1.273 \\
\hline Year & 0.889 & 0.435 & 0.210 & 0.190 & 0.150 & 0.628 \\
\hline
\end{tabular}


Table 3-S2: Gear intercept estimates and year variance estimates for fall models by species.

\begin{tabular}{|c|c|c|c|c|c|c|c|}
\hline Variable & $\begin{array}{l}\text { Sand } \\
\text { lance }\end{array}$ & $\begin{array}{c}\text { Lg. } \\
\text { Butterfish } \\
\end{array}$ & $\begin{array}{c}\text { Sm. } \\
\text { Butterfish } \\
\end{array}$ & $\begin{array}{c}\text { Fall } \\
\text { Atl. } \\
\text { herring }\end{array}$ & Alewife & $\begin{array}{c}\text { Blueback } \\
\text { herring }\end{array}$ & $\begin{array}{c}\text { Atl. } \\
\text { mackerel }\end{array}$ \\
\hline Gear A & - & - & - & -6.165 & -4.801 & -5.350 & - \\
\hline Gear B & - & -0.555 & -0.350 & 3.120 & 0.365 & 0.288 & -3.124 \\
\hline Gear C & - & 0.737 & 0.526 & 4.829 & 1.663 & 2.074 & 0.628 \\
\hline Year & 0.820 & 0.110 & 0.290 & 0.540 & 0.132 & 0.296 & 0.260 \\
\hline
\end{tabular}




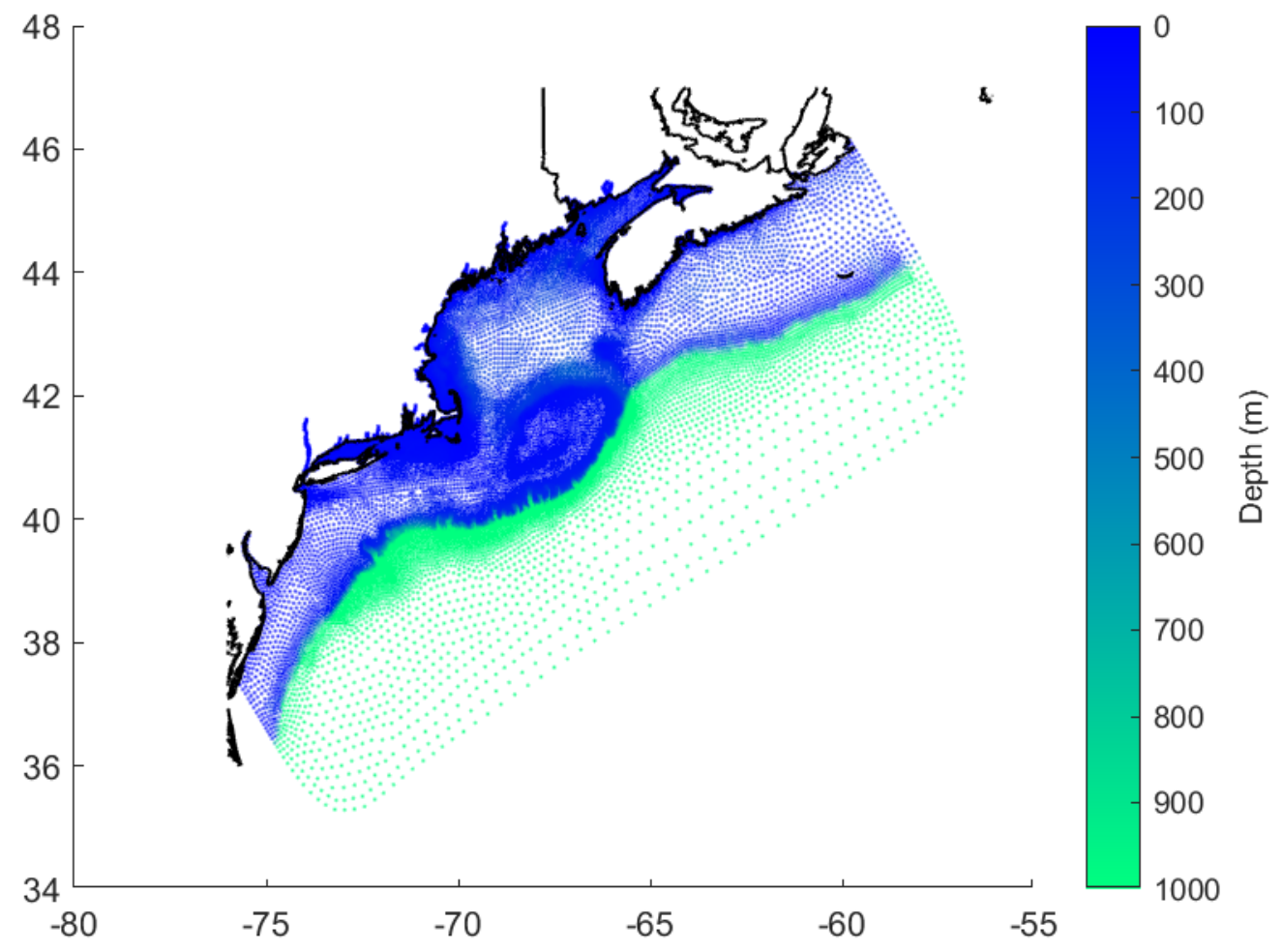

Figure 3-S1: Finite volume coastal ocean model grid used for temperature and salinity estimates for years prior to 1992. Color represents depth estimate of each grid point. 

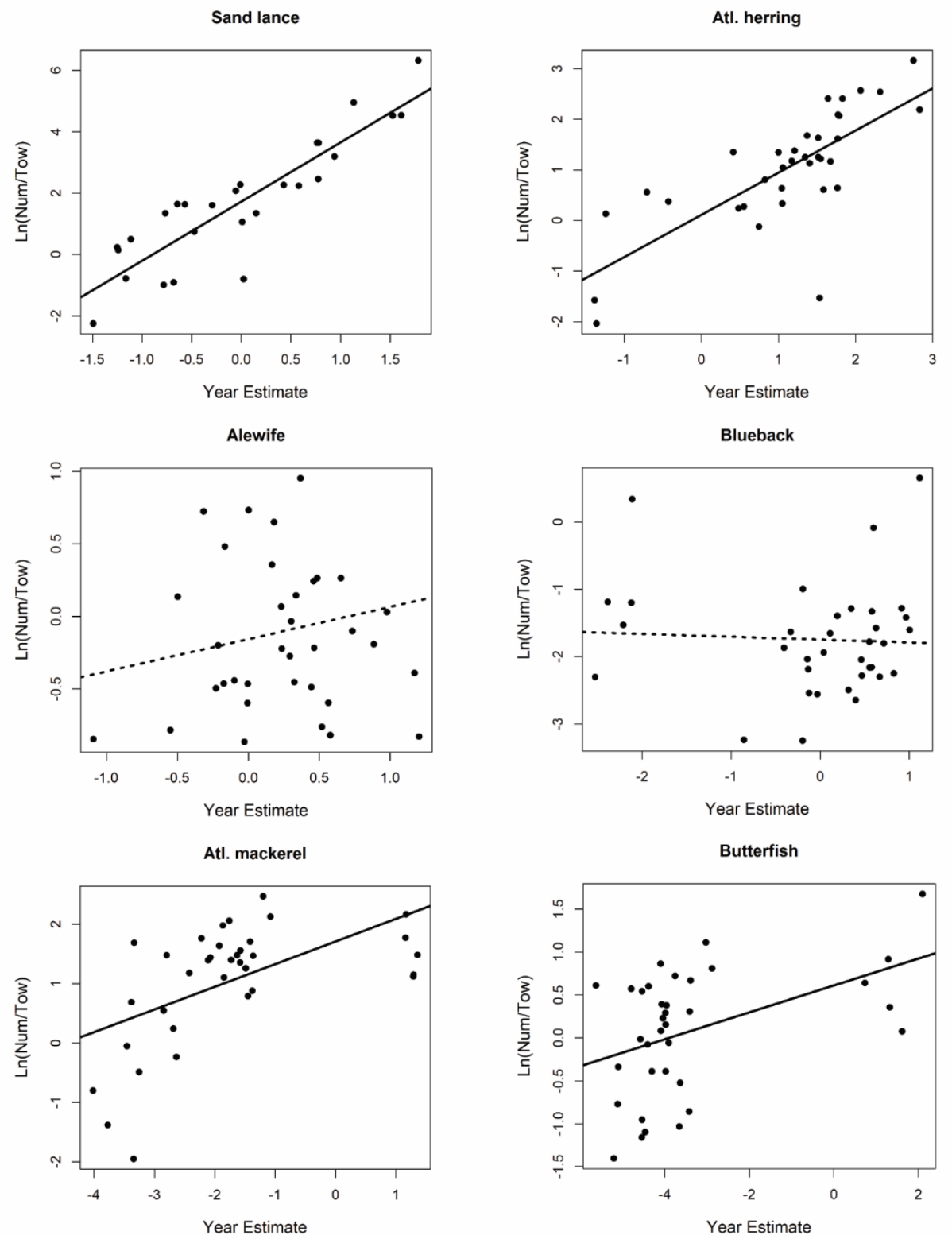

Figure 3-S2: Correlations between log stratified area-weighted mean abundance and year and gear intercept estimates for spring models. Solid lines indicate a significant correlation $(\mathrm{p}<0.05)$. 

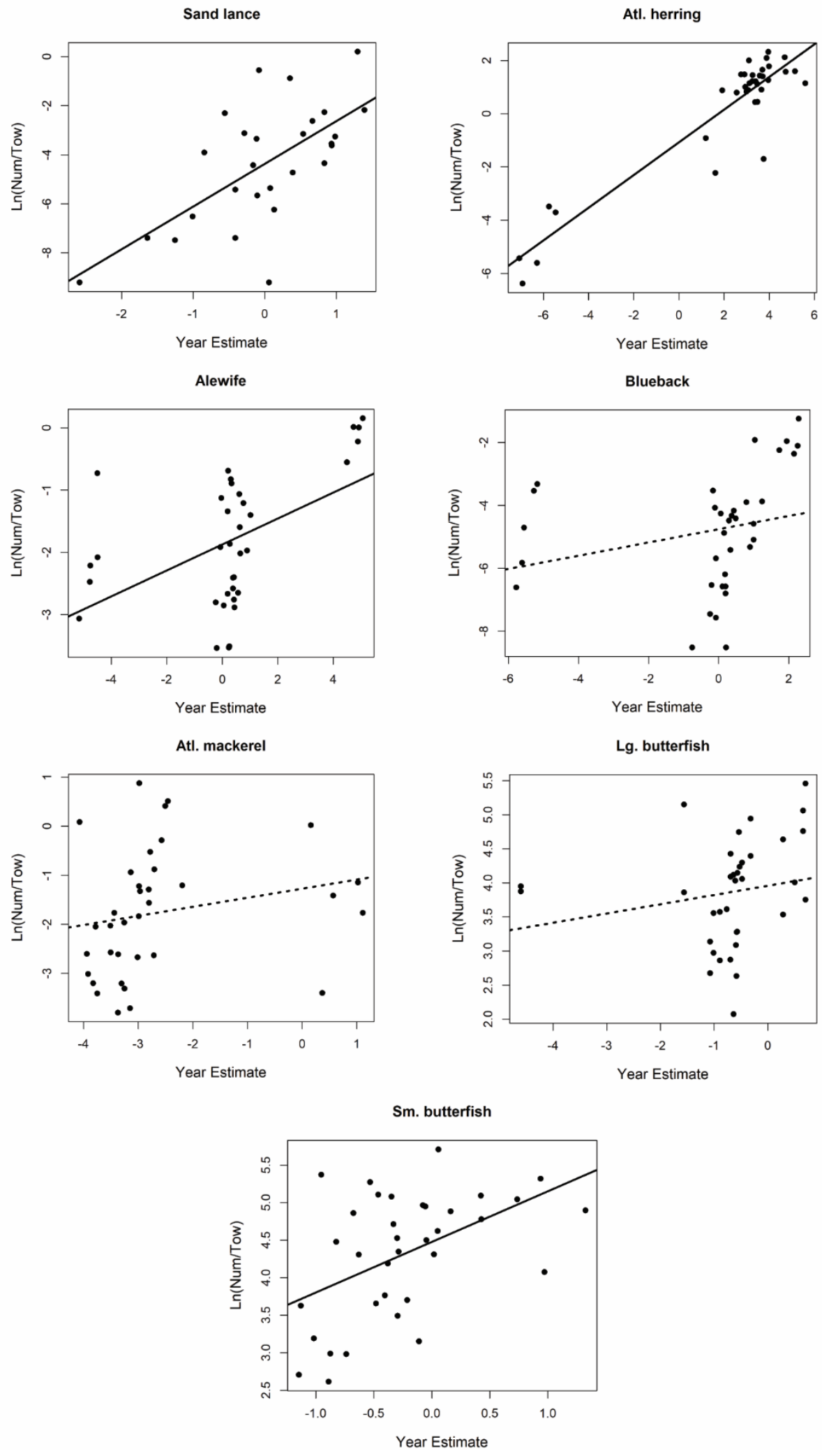

Figure 3-S3: Correlations between log stratified area-weighted mean abundance and year and gear intercept estimates for fall models. Solid lines indicate a significant correlation $(p<0.05)$. 

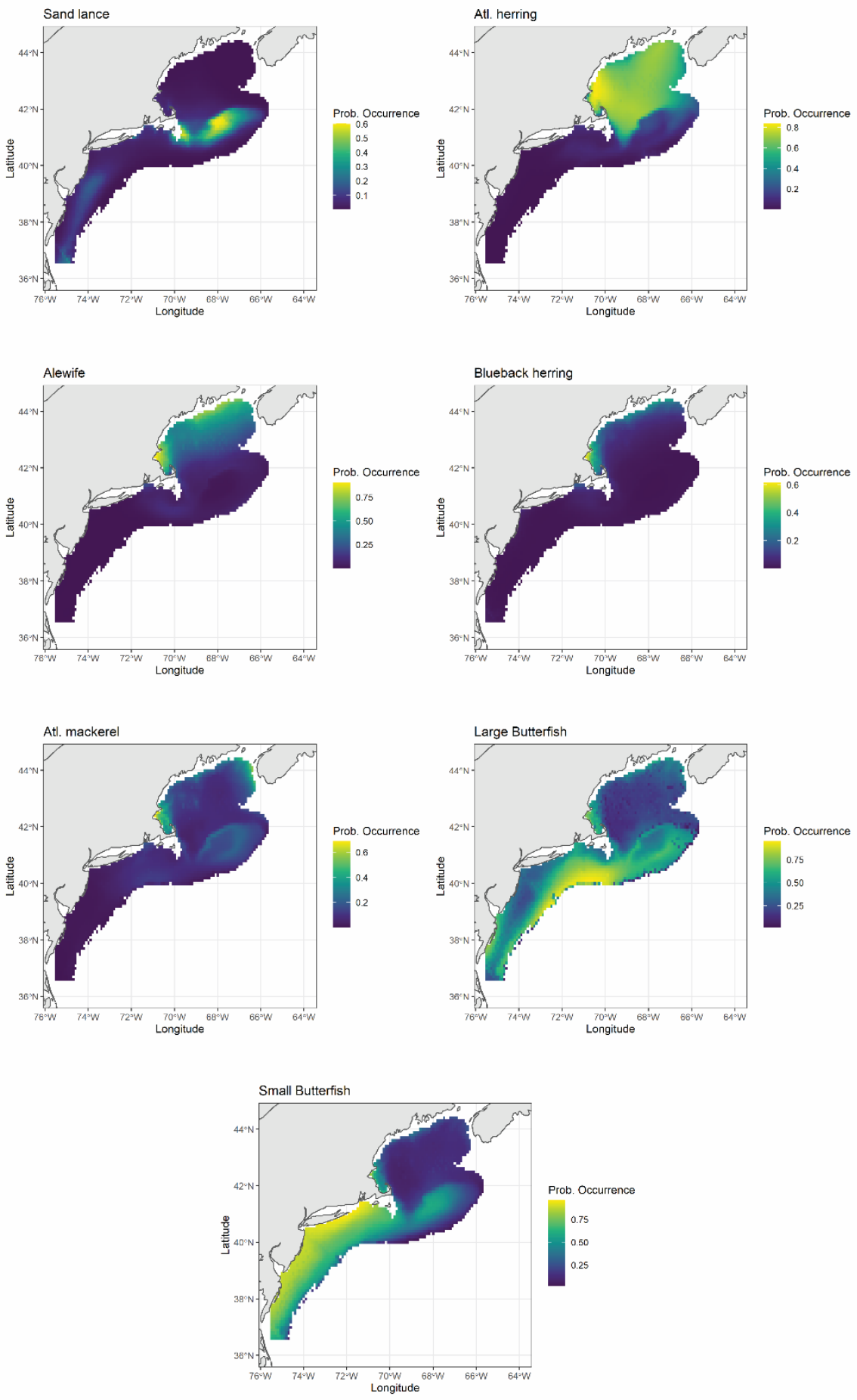

Figure 3-S4: Gridded $\left(0.1^{\circ} \mathrm{x} 0.1^{\circ}\right)$ probability of occurrence, as measured through habitat occupancy, averaged over all years used in each fall averaged model by species. Color ramp varies by species to highlight patterns within a given species. 

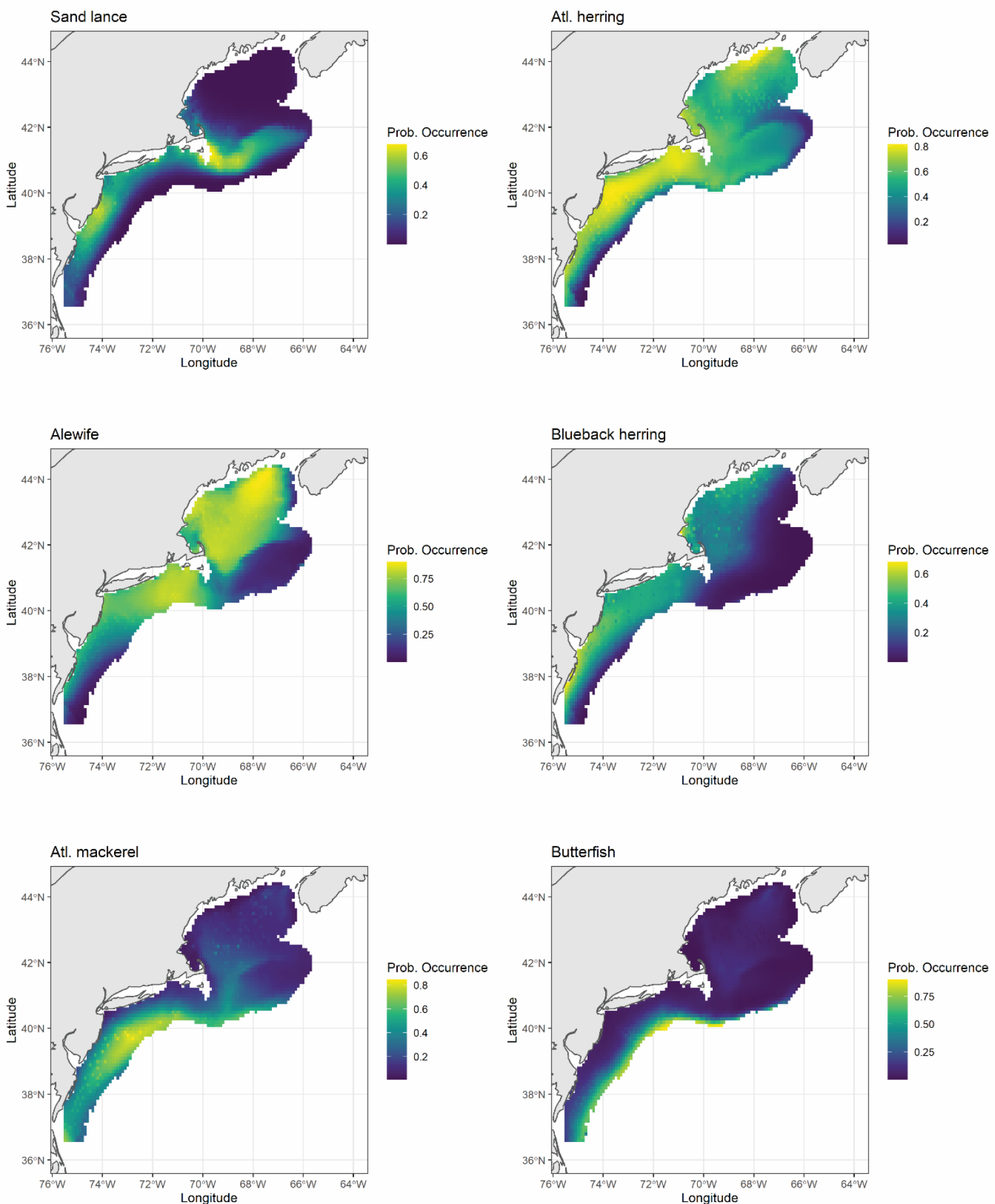

Figure 3-S5: Gridded $\left(0.1^{\circ} \times 0.1^{\circ}\right)$ probability of occurrence, as measured through habitat occupancy, averaged over all years used in each spring averaged model by species. Color ramp varies by species to highlight patterns within a given species. 


\section{Chapter 4}

\section{Larval transport pathways from three prominent sand lance hotspots in the Gulf of Maine/Georges Bank region}

\subsection{Abstract}

Northern sand lance (Ammodytes dubius) are one of the most critically important and abundant forage fishes throughout the Northeast US shelf. Despite their ecological importance, little is known about the larval transport pathways of this species. Here, we use otolith microstructure analysis to estimate settlement and hatch dates of sand lance, and then use these measurements to parametrize particle tracking experiments to assess the source-sink dynamics of three prominent sand lance "hotspots:" Stellwagen Bank, the Great South Channel/Nantucket Shoals, and Georges Bank. Our results indicate the larval duration of northern sand lance lasts about two months, with a broad range of hatch and settlement dates. Our particle tracking experiments suggest transport generally follows the north to south circulation of the Gulf of Maine region, with Stellwagen Bank serving as a source of larvae for the Great South Channel while the Great South Channel primarily serves as a sink of sand lance larvae from Stellwagen Bank and Georges Bank. Particle tracking experiments suggest retention is the primary source of larvae on Georges Bank. Retention within both Georges Bank and Stellwagen Bank varies interannually in response to changes in local wind events. In the case of Stellwagen Bank, larval transport pathways appear to contribute to small scale variability in adult presence based on the overlap of regions of high retention and predator hotspots. Collectively, these results provide a framework for the potential connectivity among these sand lance hotspots - essential information for understanding the recruitment dynamics of this forage fish. 


\subsection{Introduction}

Northern sand lance (Ammodytes dubius) represent one of the most critically important forage fishes on the Northeast US shelf, serving as prey for 72 different predators including numerous commercially fished species, marine mammals, and seabirds (Staudinger et al., 2020). Sand lance exhibit extremely large fluctuations in interannual abundance throughout the Northeast US shelf, in addition to a high degree of patchiness in space (Fogarty et al. 1991; Richardson et al., 2014; Suca et al., 2021). Despite their abundance, there is not an active fishery for northern sand lance in the Northwest Atlantic, a marked difference from congeners in the North Sea (Christensen et al., 2008). Due to the lack of a fishery, the dramatic interannual fluctuations in sand lance abundance and distribution are assumed to be linked to interannual variability in environmental conditions that cause large and small scale changes in recruitment and adult survival (Staudinger et al., 2020; Suca et al., 2021).

Little is known about the spawning time of sand lance throughout the Northeast US shelf, but existing studies suggest they are capital breeders with spawning occurring in the late fall or early winter (Murray et al. 2019; Nelson \& Ross, 1991; Suca et al., 2021). After spawning, eggs are demersal and adhere to substrate, leading to minimal transport from the time of spawning to hatch (Smigielski et al. 1984; Wright \& Bailey, 1996). Hatch duration for the congener Ammodytes americanus is long and temperature dependent, with egg durations lasting as long as 70 days in cold temperatures (Smigielski et al., 1984). The larval duration for northern sand lance, however, is largely unknown, though estimates based on collections of larvae range from 1-3 months (Potter \& Lough, 1987), similar to what has been observed for European congeners (Wright \& Bailey, 1996).

Northern sand lance are unique among the forage fishes of the Northeast US shelf in their requirement of sandy substrate for burying when they are not actively feeding on zooplankton 
(Gilman, 1994). This requirement contributes to a defined settlement phase for sand lance larvae whereby they transition from a pelagic stage to a benthopelagic lifestyle, similar to adults (Nanjo et al., 2017; van Deurs et al. 2009). While adult movement has not been studied for northern sand lance, congeners are assumed to have high site fidelity, not leaving the bank at which they settle throughout their adult life (Laugier et al., 2015; van Deurs et al., 2013). This site fidelity and sediment requirement leads to the emergence of sand lance "hotspots," or regions where adult sand lance occur consistently in interannual surveys. In the Gulf of Maine/Georges Bank region (Gulf of Maine hereafter), there are three dominant hotspots: Stellwagen Bank, the Great South Channel/Nantucket Shoals (GSC hereafter), and Georges Bank (Figure 4-1; Staudinger et al., 2020). These three hotspots vary dramatically in size and hydrography, generating different patterns in sand lance abundance among the three hotspots that often oscillate independently of shelf wide trends in sand lance abundance (Suca et al., 2021).

The most northern of the three hotspots, Stellwagen Bank, is a relatively small, sandy bank located north of Provincetown on Cape Cod, MA, USA. Stellwagen Bank is well known as a top predator hotspot, particularly for marine mammals and seabirds (Powers et al., 2020; Silva et al., 2019, 2021). Stellwagen Bank is also important for Atlantic cod, with their utilization of the bank depending on the availability of sand lance (Richardson et al., 2014). There is notable spatial heterogeneity of sand lance presence within Stellwagen Bank, with a shoal on the southwest corner that has the most persistent sand lance abundance (Wiley et al. 2003). The northern portion of the bank has highly variable sand lance abundance that can intermittently exceed sand lance abundances from the southwest corner (Richardson et al., 2014). Circulation on Stellwagen Bank and the adjacent Massachusetts Bay is heavily influenced by the Gulf of Maine Coastal Current, which regularly intercepts the northwest corner of the bank (Pettigrew et 
$a l ., 2005)$. The location and strength of the Gulf of Maine Coastal Current, in addition to local upwelling processes, are tightly linked to local wind phenomena, generating highly variable circulation on Stellwagen Bank on seasonal to interannual scales (Pettigrew et al., 2005; McManus et al., 2014).

The GSC region (including Nantucket Shoals) is a large sandy region to the east and south of Cape Cod, MA, USA. The region has less clearly defined boundaries than Stellwagen Bank and Georges Bank, but generally occupies the sandy shoals west of the deepest portions of the Great South Channel (Harris \& Stokesbury, 2010). Similar to Stellwagen Bank, the GSC region also represents a marine mammal and seabird feeding hotspot, particularly for sand lancereliant predators such as Roseate terns (Goyert, 2014; Powers et al., 2020). The hydrography of the region varies seasonally based on stratification, but prevailing currents move along the isobaths of the region from the northeast to the southwest (Beardsley et al. 1985). Despite being south of Cape Cod, the region is heavily influenced by Gulf of Maine water masses due to the strong north to south flow along the eastern coast of Cape Cod (Brooks, 1985). Variation in this general flow increases markedly in winter with strong influence of local wind forcing (Beardsley et al. 1985).

Georges Bank is one of the most productive fisheries regions in the world and the largest sand lance hotspot in the Gulf of Maine region (Cohen \& Wright, 1979; Ji et al., 2008). While Georges Bank includes a variety of substrates, the majority is sand and may serve as sand lance habitat (with the exception of gravel patches near the northern flank of the bank; Harris \& Stokesbury, 2010). The region's high productivity comes from the strong tidal fluxes and fronts, keeping large portions of Georges Bank well-mixed throughout the year (Horne et al., 1989; Ji et al., 2008), along with high production recycling rate in the central Bank (Townsend \& Petigrew, 
1997). The hydrography of the bank is also defined by a large, anti-cyclonic tidal rectification gyre that leads to high retention along the bank. However, this gyre is weakest in winter months, and thus susceptible to off-bank transport from wind events (Naimie et al., 1994; Lewis et al., 2001).

Here, we to aim better understand the larval transport pathways among the three prominent Gulf of Maine sand lance hotspots (Stellwagen Bank, the GSC, and Georges Bank), including their roles as sources or sinks of sand lance larvae. We first estimate hatch and settlement dates for northern sand lance through otolith microstructure analysis of settled age- 0 sand lance collected from two of these hotspots. We then use this information for tracking simulated sand lance larvae in forward and backward tracking experiments from each of the three hotspots. Specifically, we hypothesize that sand lance larvae hatched on Stellwagen Bank, the most northerly hotspot, will serve as a source of larvae to the GSC, while the GSC will serve as a local sink of sand lance larvae. We hypothesize that larvae hatched in the GSC will be swept south of all three hotspots to the more southerly Mid-Atlantic Bight. We also hypothesize Georges Bank will represent a semi-closed population whereby larvae hatched on Georges Bank are primarily retained on the bank with little contribution from the other two hotspots. These general trends in larval transport likely vary interannually, with local wind events enhancing or reducing retention. Understanding the larval transport pathways and the mechanisms driving interannual variability in these pathways can be used to better study the relevant scales and spatial connections for predicting sand lance recruitment in the Gulf of Maine. 


\subsection{Materials and Methods}

\subsubsection{Sand lance collections}

Settlement stage sand lance were collected from Stellwagen Bank and the GSC in May (GSC only) and June of 2019 (both Stellwagen and GSC; Figure 4-S1, Table 4-S1). Age-0 sand lance were collected with a fine mesh beam trawl as described in Suca et al. (2021). Individual sand lance $<10 \mathrm{~cm}$ were immediately preserved in ethanol upon net retrieval to maintain otolith quality.

\subsubsection{Otolith preparation and aging}

We extracted the sagittal otoliths from 50 individual sand lance from each sampling region and month of collection resulting in otoliths from 150 total individuals. Right sagittae were mounted on a slide using cyanoacrylate. Sagittae were polished using 10- $\mu \mathrm{m}$ lapping film until daily rings became apparent using a Leica DM2500 compound microscope with a 50X objective. Once daily rings were clearly visible, images of each sagitta were taken using a Leica MC120 HD camera and the Leica Application Suite software. Images were taken in horizontal sections across the otolith at 500x magnification, ranging from 3 to 6 sections. For each otolith section, multiple focal planes were captured and merged into multi-layer images to aid reading and interpreting the otolith microstructure (Pringle \& Baumann, 2020). Otolith images were imported as stacks for reading and rings were counted using ImageJ software.

Settlement timing was estimated as the change in growth axis of each sagitta (Laugier et al., 2015; Wright \& Bailey, 1996). We estimated each individual's larval duration as the number of rings from the sagitta's core to the change in growth axis. The juvenile period until day of collection was estimated as the number of rings between the change in growth axis and the otolith edge. We assumed the final ring would correspond to the day of capture, thus the day of 
settlement was estimated at the day of capture minus the number of days in the juvenile period. Hatch dates were estimated by subtracting the sum of the days from the juvenile period and larval period from the date of capture. We assumed the first ring represents the first day posthatch as has been shown for the congener Ammodytes marinus (Wright \& Bailey, 1996).

Each sagitta was read by two separate readers. Estimates of juvenile and larval period from each reader were compared separately. We did this to ensure accurate estimates of larval duration and settlement dates and to avoid the potential for "false" agreement among reader estimates resulting from similar cumulative age estimates despite differing larval and juvenile period estimates. If a larval or juvenile period estimate differed by more than five percent, the period was re-read by the second reader. If the third read agreed with either of the previous two reads (+/- 1 day), the matching estimate was used for the length of the given period. If the third estimate did not agree, the otolith was deemed unreadable and was not used for further analyses.

\subsubsection{Bio-physical individual based model}

The hydrographic and hydrodynamic conditions were generated using the third generation Gulf of Maine-Finite Volume Community Ocean Model (GOM-FVCOM; Chen et al., 2011) that has a horizontal resolution of $0.3-10 \mathrm{~km}$, with finer resolution in coastal regions and tidal mixing fronts (e.g. Georges Bank) and coarser resolution at the boundaries near the shelf break (Chen et al., 2011; Ji et al., 2017; Xue et al., 2014). The GOM-FVCOM is itself nested within the FVCOM-global model to ensure water property conservation at its boundaries (Chen et al., 2011). Previous studies have confirmed that the GOM-FVCOM accurately recreates hourly to interannual variability in currents (Chen et al., 2011; Sun et al., 2016), including a comparison with actual drifter observations (Sun et al., 2016). For our drift simulations, a particle tracking routine with a fourth order Runge-Kutta time stepping scheme was used to 
resolve advection, similar to the previous applications for the region, such as the tracking for haddock larvae (Boucher et al. 2013) and copepods (Ji et al., 2017).

A suite of particle tracking experiments, in both forward and backward tracking directions, was conducted at an annual scale for 27 years (1990-2016). Particles were released on a $0.01^{\circ} \times 0.01^{\circ}$ grid in waters $\leq 40 \mathrm{~m}$ depth on Stellwagen Bank (bounded within the box 42.13$42.5^{\circ} \mathrm{N}, 70.5-70.12^{\circ} \mathrm{W}$ ) and waters $>15 \mathrm{~m}$ and $\leq 40 \mathrm{~m}$ depth in the Great South Channel (bounded within the box $42.5-40.5^{\circ} \mathrm{N}, 70.0-69.0^{\circ} \mathrm{W}$; Figure 4-1). Particles were placed on a $0.05^{\circ} \times 0.05^{\circ}$ grid in waters $\leq 60 \mathrm{~m}$ depth on Georges Bank (bounded within a box $42.33^{\circ}-40.0^{\circ} \mathrm{N}, 69.2^{\circ}-65.5^{\circ}$ W). Particles were placed to a deeper depth on Georges Bank due to higher occurrence of sand lance at deeper depths on Georges Bank compared to other areas of the Northeast US shelf (see supplementary methods). Particles were not placed in regions shallower than $15 \mathrm{~m}$ in the GSC to minimize the inclusion of potential Ammodytes americanus habitat given this regions' proximity to the coast (Nizinski et al. 1990).

Particles were advected in 10-minute time steps through interpolation of hourly velocity fields. Random walk routines were not incorporated due the high model resolution and the depthkeeping nature of the particle tracking runs (Ji et al., 2017). Previous work suggests that sand lance larvae below $28 \mathrm{~mm}$ length are almost evenly distributed within the upper water column, while larger stages appear to move to greater depths later in spring (Potter \& Lough 1987). Observations of larger individuals at depth temporally overlap with our estimates of settlement; hence, this vertical movement might be the beginning of the settlement process. To represent the homogeneous vertical distribution of sand lance larvae, we used depth-keeping particle runs at $10 \mathrm{~m}$ spacing in the upper $40 \mathrm{~m}(5,15,25$, and $35 \mathrm{~m})$. Given the absence of clear behavioral information on northern sand lance larvae, we chose not to incorporate diel vertical migration 
patterns into our simulations. This framework resulted in 1230 particles per depth per day per direction for Stellwagen Bank, 4152 particles per depth per day per direction for the GSC, and 15,108 particles per depth per day per direction for Georges Bank.
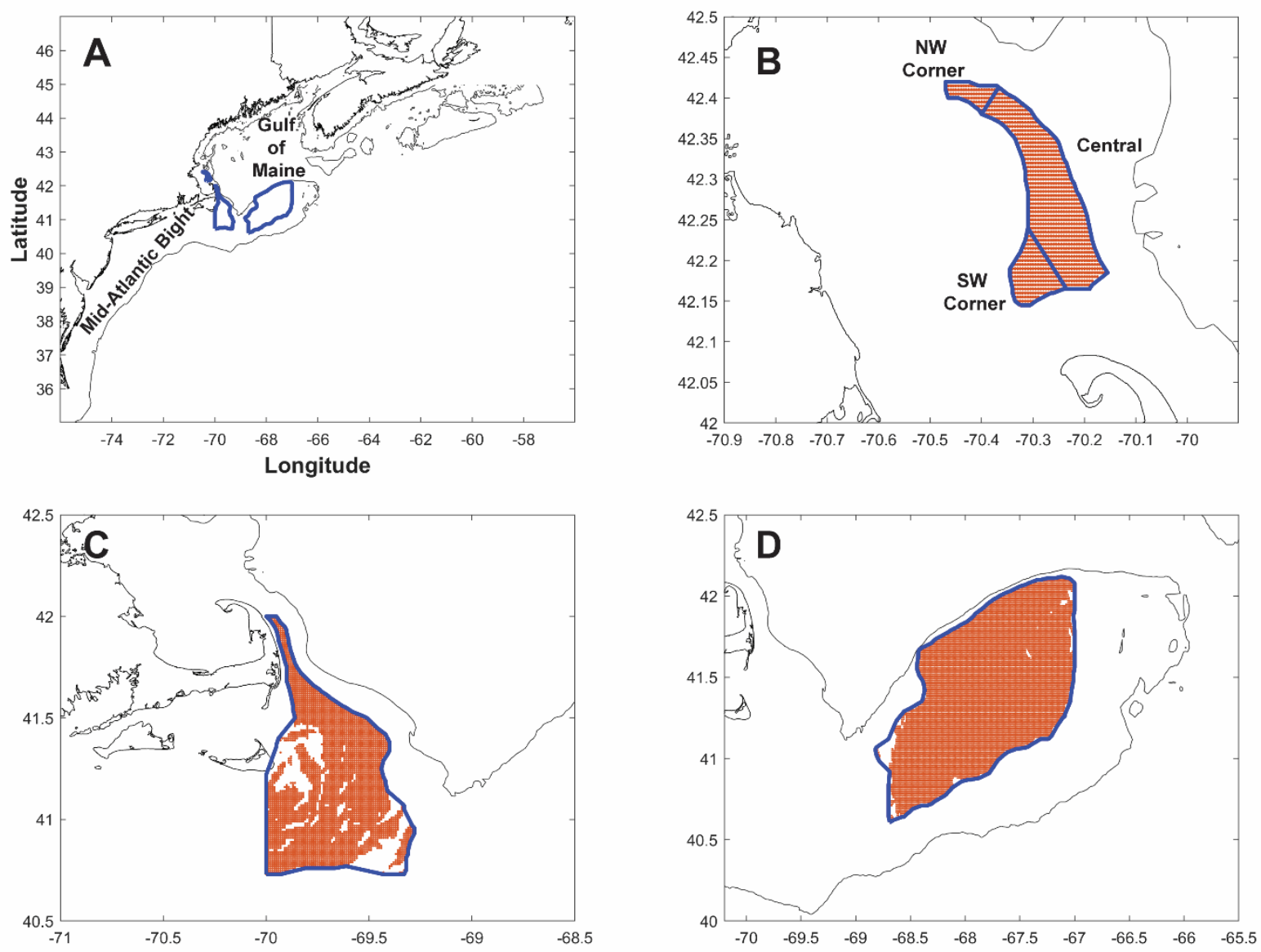

Figure 4-1. Map of regional sand lance "hotspots" (A) and particle seeding locations for (B) Stellwagen Bank, (C) the Great South Channel, and (D) Georges Bank. Contours represent the coastline and $100 \mathrm{~m}$ isobath. In panel B, Stellwagen Bank is divided into sub-regions and labeled. In panels $\mathrm{C}$ and $\mathrm{D}$, particle seeding locations are located too closely together to clearly see spacing.

Forward projections were released based on the mean hatch date $+/$ - standard deviation of hatch date. Particles were released from each location and depth each day at midnight. Particles were released only once daily since a test of releasing particles hourly showed minimal differences in end location based on hour of release (see supplementary methods). For backward 
projections, dates of release were based on the mean hatch date by region of collection $+/$ standard deviation + mean larval duration for a given region. This was done instead of the mean settlement date by region of collection $+/$ - standard deviation because hatch dates were more variable than settlement dates and thus this method encompassed the range of observed settlement dates while also ensuring a balanced number of releases between forward and backward tracking experiments. Since we did not collect any larvae from Georges Bank, we used the hatch and settlement date values from our collections in the GSC due to its similar hydrography and ecosystem dynamics (Lucey \& Fogarty, 2013).

\subsubsection{Temporal and spatial estimates of hotspot connectivity}

Particles were considered to have potentially "settled" or "hatched" in a given hotspot if they occurred over the region either during the mean $+/$-standard deviation of settlement or hatch dates. These values were set as the ranges from which the particles originated (i.e. Stellwagen Bank had a different set of hatch and settlement date ranges than the Great South Channel and Georges Bank based on otolith microstructure analysis).

Annual estimates of hotspot "connectivity" were estimated as the proportion of release locations that had at least one particle at a given depth and day that potentially "settled" or "hatched" at a given hotspot per day. This framework focuses on location of release as the sampling unit as opposed to individual particles. This was done to have particles at each release location represent a group of hatching sand lance that distribute throughout the water column. Given we know very little about the actual larval behavior of sand lance, we assumed a particle released from any of the four release depths reaching a hotspot may represent a connection between these hotspots. Additionally, while there is some variability in transport by release depth, the mixed layer depth of the region during the larval duration of sand lance is greater than 
our release depths, leading to less variable flow in the vertical domain compared to stratified systems and seasons (Paris \& Cowen, 2004; Townsend et al. 2015). A connectivity value of 1 represents a scenario where all release locations within a hotspot had at least one particle that originated or settled in a given hotspot per day of release. We calculated this annual estimate of hotspot connectivity for each location of release to each hotspot for both forward and backward tracking. We note that while we use the term connectivity to reference larvae potentially originating or settling from one hotspot to another, these metrics do not represent true population connectivity as this requires settled individuals to survive to reproductive maturity, which we do not explore (Pineda et al., 2007).

We also looked for spatial trends in hotspot connectivity. To do so, we estimated connectivity by release location through averaging annual hotspot connectivity for each release location within a given hotspot. This was done to elucidate small spatial scale patterns in connectivity_ particularly to see if certain release locations were favorable for retention in a given hotspot.

\subsubsection{Comparison with wind regimes}

Due to the observed importance of wind as a driver of winter/spring retention of groundfish larvae and zooplankton in Massachusetts Bay (Jiang et al., 2007; Runge et al., 2010) and Georges Bank (Lewis et al., 2001; D. Mountain et al., 2008; Werner et al., 1996), we analyzed the relationship between local wind stress and retention for Stellwagen Bank and Georges Bank. We aimed to test the hypothesis that the frequency of either north or south strong wind events influence retention on Stellwagen Bank and that strong north wind events on Georges Bank lead to lower retention. Daily mean wind stress estimates from FVCOM were spatially averaged into $0.1^{\circ} \times 0.1^{\circ}$ grid cells within the bounding box defining each sand lance 
hotspot from January to April of each year (see above for bounding box description). For both north and south winds, a strong wind day was considered a day where FVCOM estimates of wind stress exceeded $0.146 \mathrm{~Pa}$ in the given direction. This value corresponds to the wind stress generated from a mean daily wind velocity of $10 \mathrm{~m} \mathrm{~s}^{-1}$ (generating an approximate sea state of 6 on the Beaufort scale) based on the equations within Large and Pond (1981). The number of strong wind days were calculated for each $0.1^{\circ} \times 0.1^{\circ}$ grid cell over a given hotspot and then averaged over that grid to get an annual mean number of strong wind days for a hotspot. Annual retention metrics were then related to the mean number of strong wind days over a hotspot through beta regression.

In the case of Stellwagen, both north and south wind events were tested as both could lead to enhanced retention via different mechanisms. Near Stellwagen, north winds lead to onshore transport and thus retention in Massachusetts Bay directly west of Stellwagen Bank (Jiang et al., 2007; Runge et al., 2010), while strong south winds move these retention zones eastward and generate a retentive feature over the southwest corner of Stellwagen Bank (Jiang et al. 2007). For Georges Bank, we only focused on north winds as north winds push larvae to the southern flank of Georges Bank, into the slope current, thus transporting them away from Georges Bank and preventing retention (Mountain et al., 2008).

\subsubsection{Comparison with Stellwagen Bank surveys}

We compared our estimates of backward and forward retention on Stellwagen Bank to fall sand lance surveys on Stellwagen Bank using the U.S. Geological Survey's Seabed Observation and Sampling System (SEABOSS) equipped with a modified van Veen grab (0.1 $\mathrm{m}^{2}$; Figure 4-S2; Blackwood and Parolski, 2001). This survey is described in detail in Silva et al. 2021, but briefly 44 fixed stations were sampled each spring and fall from 2013-2016 across 
Stellwagen Bank, largely focused on sandy substrates. We only used fall surveys as age-0 sand lance are transitioning from the larval to juvenile stage during the timing of the spring surveys (March-May) leading to inconsistent catchability in the spring. We used the mean number of sand lance caught per station per year to represent an annual estimate of sand lance abundance. We then related this to the forward and backward retention metrics through simple linear regression. Correlations were calculated relating forward and backward metrics to survey catches from 2013-2016 and 2014-2016 (i.e. excluding 2013). This was done to account for the survey not collecting any sand lance in 2013, which may have been linked to high mortality from the record setting heatwave in 2012 (Mills et al., 2013).

\subsubsection{Connectivity and retention among Stellwagen Bank sub-regions}

In addition to looking at annual trends in connectivity and retention for Stellwagen Bank as a whole, we parsed the bank into three sub-regions (see Figure 4-1B) to identify spatial scale of retention within the bank. We specifically focus on the southwest corner of Stellwagen Bank to assess the importance of retention (southwest corner to southwest corner) relative to contributions from other portions of the bank in this well-known sand lance and top-predator hotspot within Stellwagen Bank (Hazen et al., 2009; Silva et al., 2021; Wiley et al., 2003). Connectivity metrics were calculated the exact same way as done for the three larger regional hotspots. Given the three sub-regions of Stellwagen Bank vary markedly in size, and thus particles are more likely to be connected to larger regions, we also divided this connectivity metric by the size of the sub-region of connection. This results in a metric of connectivity per $\mathrm{m}^{2}$, allowing for an understanding of the likelihood of sub-region connection or retention based on area. 


\subsection{Results}

\subsubsection{Hatch and settlement date estimates}

Mean hatch dates and settlement dates varied by region and month of collection (Table 41; Figure 4-S3). Settling individuals on Stellwagen Bank generally hatched and settled earlier than those collected in the GSC, with individuals hatching an average of 22.5 days earlier on Stellwagen Bank. Individuals also settled later in the GSC, with an average settlement date for Stellwagen Bank occurring an average of 18.6 days earlier than the GSC. Larval duration, however, was similar between the two regions, with Stellwagen individuals having a slightly longer mean larval duration of 69.2 days, while GSC individuals had a mean larval duration of 65.5 days. Hatch dates varied by month of collection in the GSC, but mean larval period was very similar (65.6 days in May and 65.4 in June; Table 4-1).

Table 4-1: Standard length, larval duration estimates, hatch dates, and settlement dates for age- 0 sand lance from otolith microstructure analysis. GSC represents the Great South Channel. $n$ represents the number of usable otoliths (see Methods).

\begin{tabular}{lllcccc} 
Region & Month & n & $\begin{array}{c}\text { Standard Length } \\
\text { (Mean +/- SD) }\end{array}$ & $\begin{array}{c}\text { Larval Duration } \\
\text { (Mean +/- SD) }\end{array}$ & $\begin{array}{c}\text { Hatch Dates } \\
\text { (Mean +/- SD) }\end{array}$ & $\begin{array}{c}\text { Settlement Dates } \\
\text { (Mean +/- SD) }\end{array}$ \\
\hline GSC & May & 50 & $45.36+/-7.21$ & $65.60+/-7.87$ & 21 Jan-21 Feb & 28 Mar-25 Apr \\
Stellwagen & June & 47 & $68.72+/-8.41$ & $69.23+/-5.94$ & 24 Dec-24 Jan & 5 Mar-2 Apr \\
GSC & June & 48 & $54.52+/-8.90$ & $65.44+/-6.98$ & 10 Jan-13 Feb & 20 Mar-17 Apr \\
GSC & Total & 98 & $50.54+/-9.27$ & $65.52+/-7.41$ & 15 Jan-18 Feb & 23 Mar-21 Apr
\end{tabular}

\subsubsection{Annual patterns in hotspot connectivity}

All three hotspots showed notable differences in interannual connectivity to other hotspots (Figure 4-2). As expected, retention metrics (connectivity metric from a hotspot to the same hotspot) were similar between forward and backward simulations, though absolute values differed. (Also as expected, connection to other hotspots varied notably between forward and backward tracking experiments). 

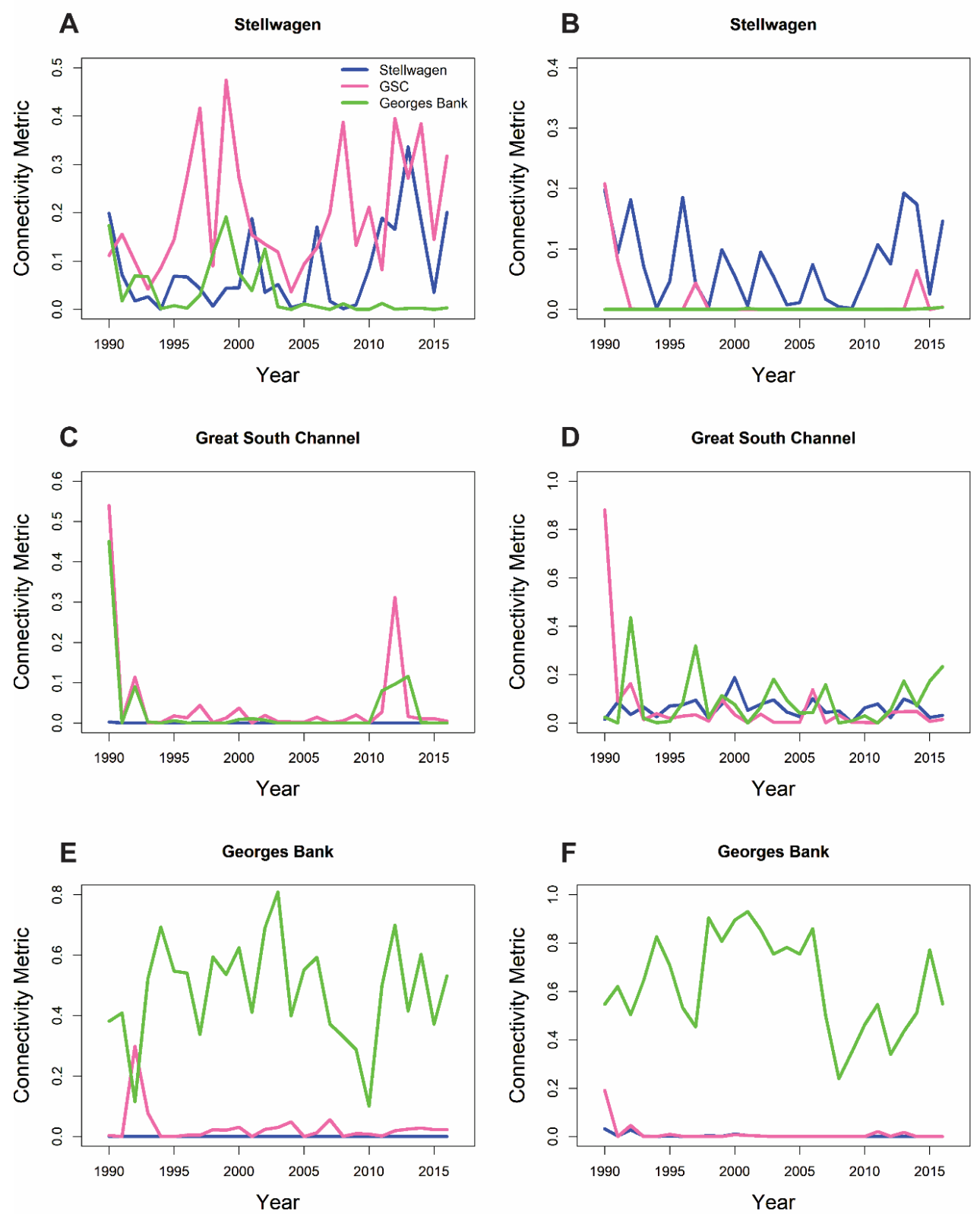

Figure 4-2. Interannual trends in the connectivity metric among the three hotspots for forward tracking $(A, C, E)$ and backward tracking $(B, D, F)$ experiments. The title of each panel represents the origin of the experiment, and colors represent connectivity to each hotspot. The connectivity metric represents the proportion of release locations at the origin hotspot that led to "settled" (forward) or "hatched" (backward) particles at a given hotspot (see methods for details).

Forward tracking experiments from Stellwagen Bank exhibited intermediate to high retention and high connectivity with the GSC (except for the early 2000s; mean connectivity 
value $=0.198$; Figure 4-2A). Forward connectivity of Stellwagen Bank with Georges Bank was intermittent with a mean connectivity value of only 0.036 , with connectivity higher in the $1990 \mathrm{~s}$ and decreasing in the 2000s. Backward tracking experiments from Stellwagen Bank (Figure 42B) had intermediate connectivity with Stellwagen Bank (mean connectivity value $=0.085$; retention and notable connection with the GSC and Georges Bank only in 1990.

Forward tracking experiments from the GSC had minimal connectivity with all three hotspots, averaging less than 0.05 connectivity except for 1990, when there was high connectivity to Georges Bank and retention within the GSC (Figure 4-2C). There was also intermediate connectivity with Georges Bank in 2011-2013 (peaking at 0.116) and retention within the GSC in 2012 (0.312), with nearly no connection with Stellwagen Bank in any year. Interannual backward tracking experiments from the GSC had variable connectivity with each of the three hotspots, with each of the three hotspots ranging from minimal (e.g. $<0.001$ connectivity with Georges Bank in 1998) to intermediate (e.g., 0.436 with Georges Bank in 1992) connectivity interannually with the GSC (Figure 4-2D). However, with the notable exception of 1990, when GSC retention was 0.881 , GSC retention had the lowest connection of the three hotspots for backward tracking experiments.

Georges Bank particle tracking experiments indicated retention had the highest degree of connectivity for both forward and backward runs, averaging retention of 0.480 for forward runs and 0.633 for backward runs (Figure 4-2E,F). Retention on Georges Bank was notably higher than retention on Stellwagen Bank and the GSC, while still having notable interannual variability, ranging from 0.10 to 0.809 for forward runs and 0.240 to 0.930 for backward runs. Forward tracking experiments from Georges Bank showed minimal connection to Stellwagen Bank and usually weak connection to the GSC, with the exception of 1992, where connectivity 
reached 0.298 (Figure 4-2E). Backward tracking experiments from Georges Bank indicated minimal connection with Stellwagen Bank and the GSC, except for a moderate contribution from the GSC in $1990(0.190)$.

\subsubsection{Spatial patterns in connectivity}

Each hotspot showed notable within-bank patterns of retention and connectivity to other hotspots. Stellwagen Bank had the strongest gradients of within hotspot spatial variability where both forward and backward particle tracking experiments had the highest values of retention on the southwest corner of the bank, with average values reaching 0.15 (Figure 4-3A,B). This was most pronounced in the backward tracking experiments, while forward tracking experiments had high retention values along much of the western flank of the bank and on the northwest corner.
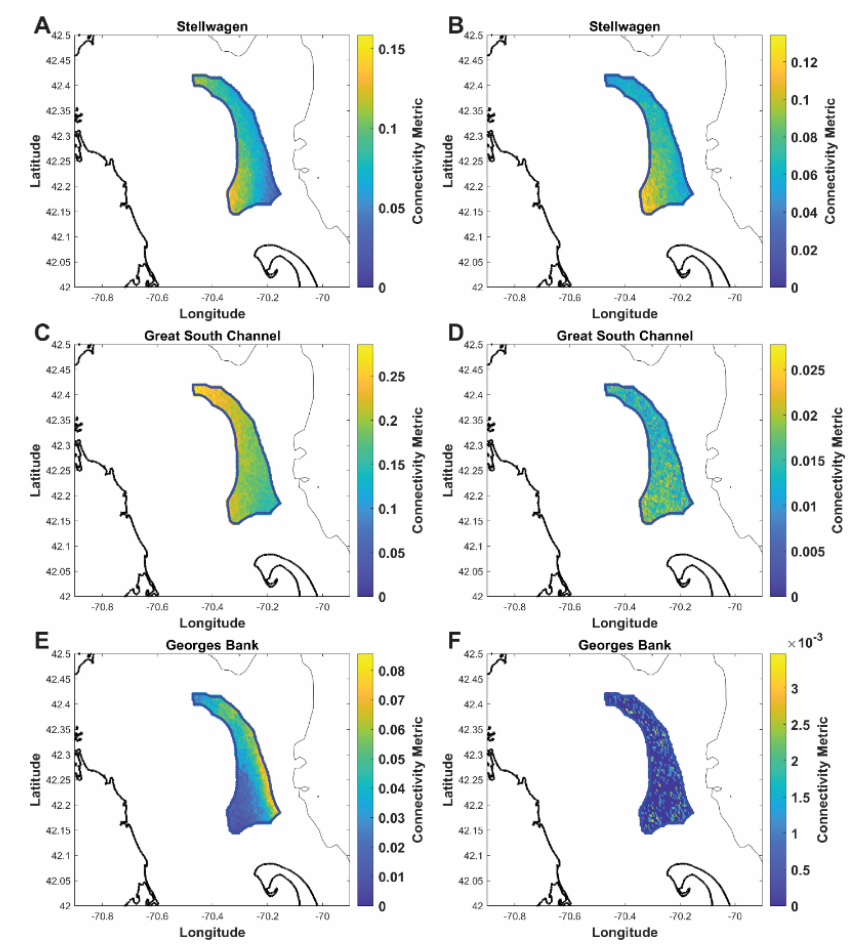

Figure 4-3: Spatial patterns in connectivity based on release locations from Stellwagen Bank for forward $(A, C, E)$ and backward tracking $(B, D, F)$ experiments. Titles represent the hotspot pairs for the connectivity metric. Contours represent the coastline and $100 \mathrm{~m}$ isobath. Note that color bars for connectivity are scaled for each panel. 
Forward connectivity from Stellwagen Bank to the GSC was more evenly distributed throughout Stellwagen, though the northwest corner had the highest connectivity values with the GSC with average connectivity values exceeding 0.25 (Figure 4-3C). Forward connectivity from Stellwagen to Georges Bank only occurred from the eastern flank of Stellwagen Bank, with no connectivity originating from the southwest corner (Figure 4-3E). Backward connectivity from Georges Bank and the GSC to Stellwagen did not show much pattern due to the very low overall connectivity in these cases (Figure 4-3D,F).
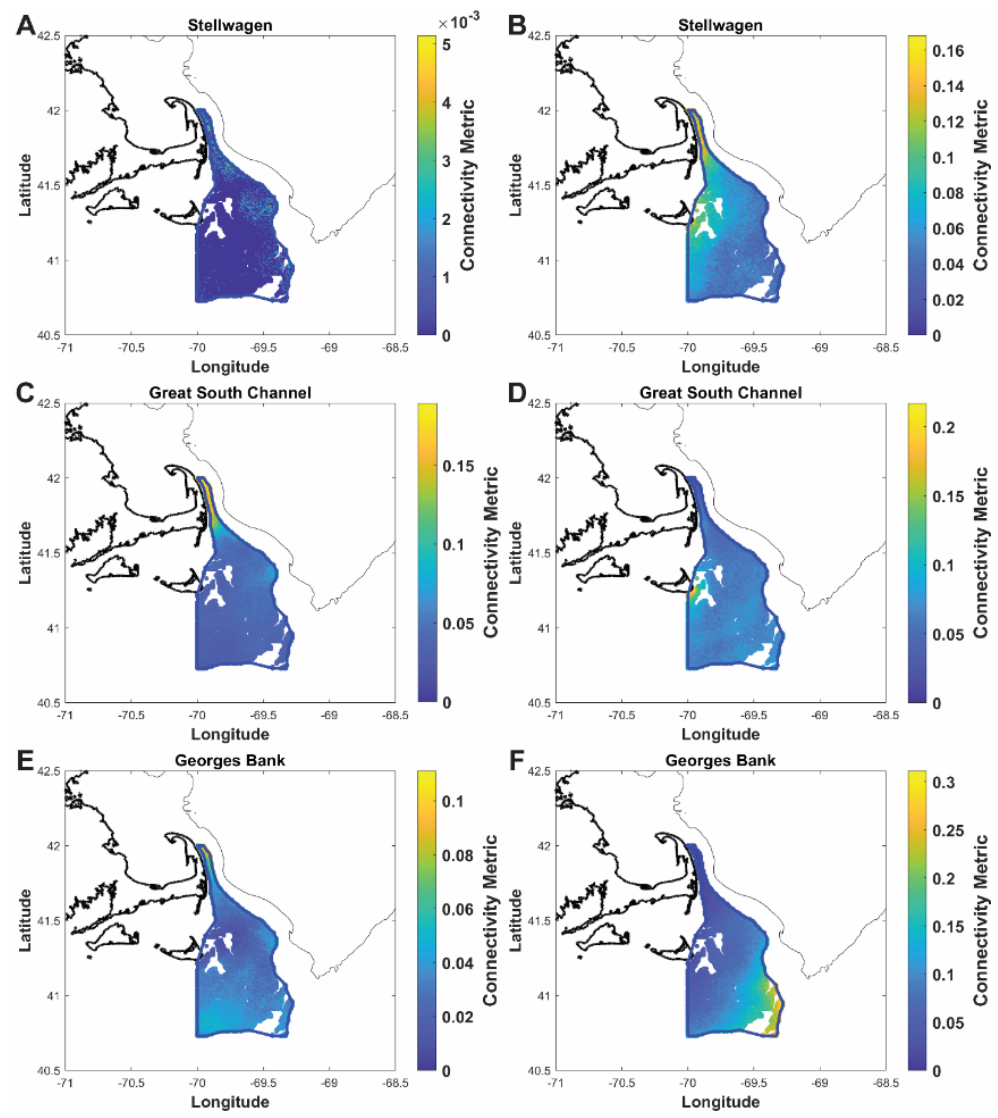

Figure 4-4. Spatial patterns in connectivity based on release locations from the Great South Channel for forward (A,C,E) and backward tracking (B,D,F) experiments. Titles represent the hotspot pairs for the connectivity metric. Contours represent the coastline and $100 \mathrm{~m}$ isobath. Note that color bars for connectivity are scaled for each panel. 
Spatial patterns in connectivity and retention in the GSC followed the dominant upstream-downstream patterns of the region, with highest forward retention occurring from releases in the northern (upstream) portion of the GSC and with lowest in the southwest portion (downstream; Figure 4-4C). Backward retention patterns showed the opposite pattern, with highest backward retention occurring in the southwest (downstream) and minimal retention in the northern portion of the GSC (upstream; Figure 4-4D). Backward connectivity from Stellwagen and Georges Bank to the GSC was highest in the portions of the GSC in closest proximity to these other hotspots, with high connectivity to Stellwagen Bank in the northern portion of the GSC (Figure 4-4B) and the highest connectivity to Georges Bank in the southeast portion of the GSC (Figure 4-4F). Forward connectivity from the GSC to Georges Bank was highest in the northern portion of the GSC with intermediate values in the southern portion of the GSC (Figure 4-4E). 

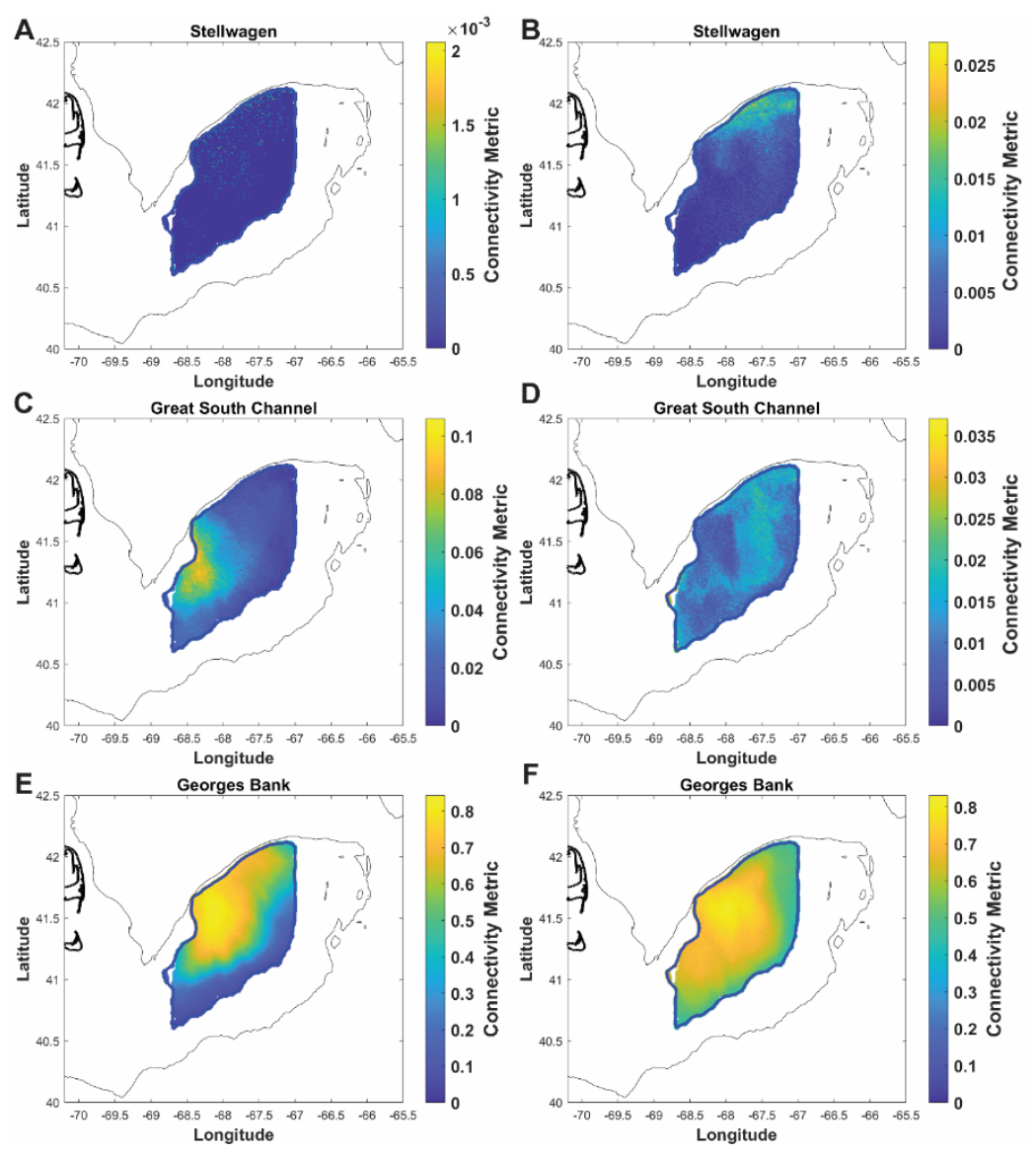

Figure 4-5. Spatial patterns in connectivity based on release locations from Georges Bank for forward $(\mathrm{A}, \mathrm{C}, \mathrm{E})$ and backward tracking $(\mathrm{B}, \mathrm{D}, \mathrm{F})$ experiments. Titles represent the hotspot pairs for the connectivity metric. Contours represent the coastline and $100 \mathrm{~m}$ isobath. Note that color bars for connectivity are scaled for each panel.

Spatial distribution of retention on Georges Bank varied between forward and backward tracking experiments (Figure 4-5 E,F). Forward tracking experiments showed highest retention in the shallowest region (western/central) of Georges Bank with average retention values reaching 0.80 , while backward retention was nearly homogenous across Georges Bank, with the exception of lower retention near the most offshore portions of the bank (eastern and southern). Forward connectivity from Georges Bank to the GSC was highest in the southwest portion of the bank, the region with the closest proximity to the GSC (Figure 4-5 C). All other connectivity metrics across Georges Bank were low. 


\subsubsection{Relationship of interannual retention with wind metrics}

The number of strong south wind days on Stellwagen Bank were significantly related to retention for both forward and backward tracking experiments (Table 4-2; Figure 4-6A,B). Years with few days of strong south winds resulted in many particles being swept to the south from Stellwagen Bank through the GSC to the Mid-Atlantic Bight (Figure 4-6C). In backward tracking experiments, years with few strong south wind days resulted in particles largely originating from more northerly regions such as the Bay of Fundy and Scotian Shelf (Figure 46D). Years with a high number strong south wind days resulted in particles remaining near Stellwagen Bank and in the western Gulf of Maine for both forward and backward tracking experiments (Figure 4-6E,F). The number of strong north wind days had no relationship with forward or backward retention on Stellwagen Bank (Table 4-2).

Table 4-2: Slope, pseudo- $\mathrm{R}^{2}$, and $\mathrm{p}$-values for beta regressions between wind patterns for forward and backward retention metrics for Stellwagen and Georges Bank.

\begin{tabular}{llllll} 
Region & Direction & Regressor & Slope & Pseudo-R $^{2}$ & p-value \\
\hline Stellwagen & Forward & Strong North Wind Days & 0.025 & 0.013 & 0.560 \\
Stellwagen & Backward Strong North Wind Days & -0.029 & 0.018 & 0.482 \\
Stellwagen & Forward & Strong South Wind Days & 0.197 & 0.089 & 0.029 \\
Stellwagen & Backward Strong South Wind Days & 0.240 & 0.152 & 0.003 \\
Georges Bank & Forward & Strong North Wind Days & -0.038 & 0.154 & 0.030 \\
Georges Bank & Backward Strong North Wind Days & -0.044 & 0.148 & 0.029
\end{tabular}

Retention on Georges Bank was significantly negatively related to the number of strong north wind days for both forward and backward particle tracking experiments (Figure 4-7A,B). In years with few strong north wind days, particles remained largely over Georges Bank for both forward and backward tracking experiments (Figure 4-7 C,D). In forward tracking experiments, years with large numbers of strong north wind days resulted in many particles being swept to the south from Georges Bank to the Mid-Atlantic Bight (Figure 4-7 E). Patterns of particle 
distributions during years with many strong north wind days for backward tracking experiments led to more particles originating from more north and easterly locations, such as the northeast peak of Georges Bank, than in years with few strong north wind days (Figure 4-7F).

\subsubsection{Comparison of retention with Stellwagen abundance}

Backward retention on Stellwagen Bank showed a strong relationship with mean abundance from the SEABOSS surveys for years 2014, 2015, and 2016 (Table 4-3; Figure 4-8). This relationship disappeared, however, with the inclusion of 2013 when no sand lance were collected despite high backward retention. Similar patterns were observed between forward retention and mean fall sand lance abundance on Stellwagen Bank, with a strong positive relationship for 2014-2016 and no fish caught in 2013 despite also having a high forward retention metric. 
A

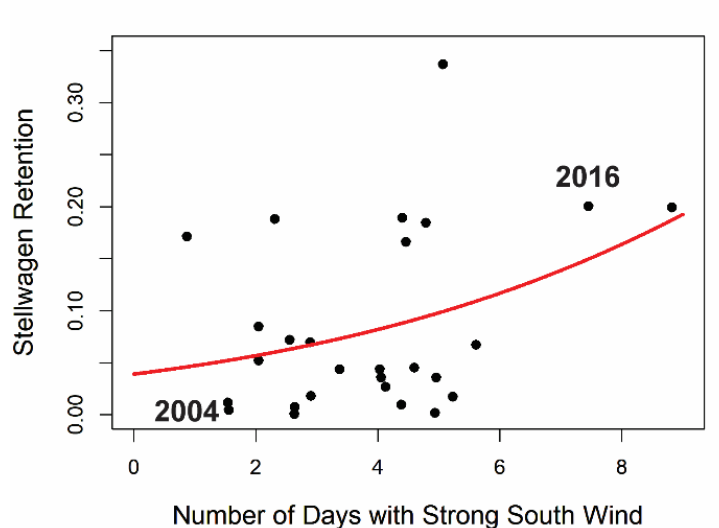

$\mathbf{C}_{<10^{-7}}<10^{-6} \quad<10^{-5} \quad<10^{-4} \quad 10^{-3} \quad 10^{-2}$

Stellwagen 75-day forward track from December/January 2004

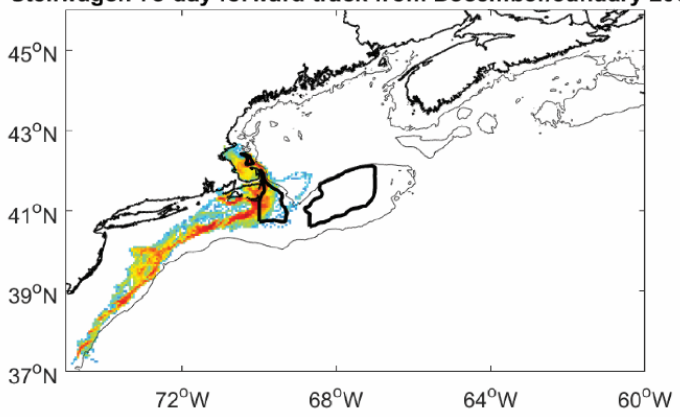

$E$

$\mathbf{E}_{<10^{-7}} \quad<10^{-6} \quad<10^{-5} \quad<10^{-4} \quad 10^{-3} \quad 10^{-2}$

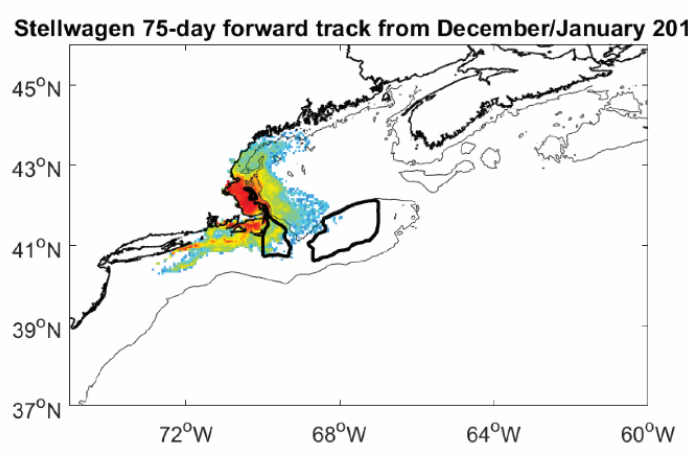

B

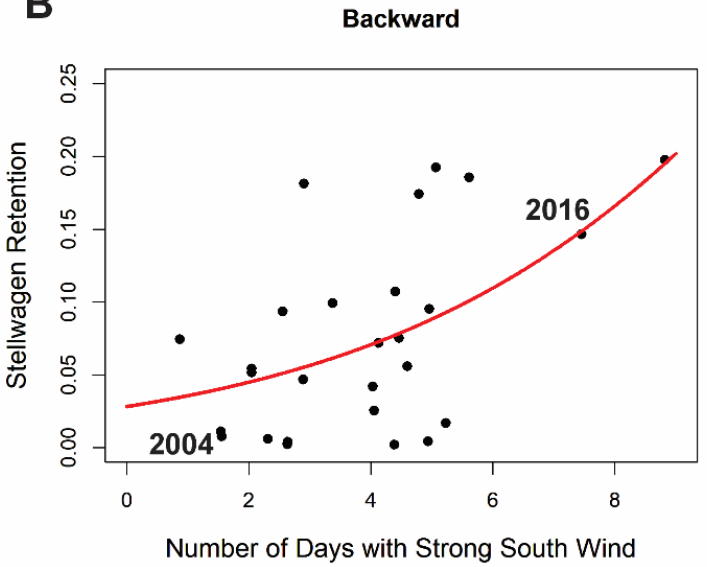

D
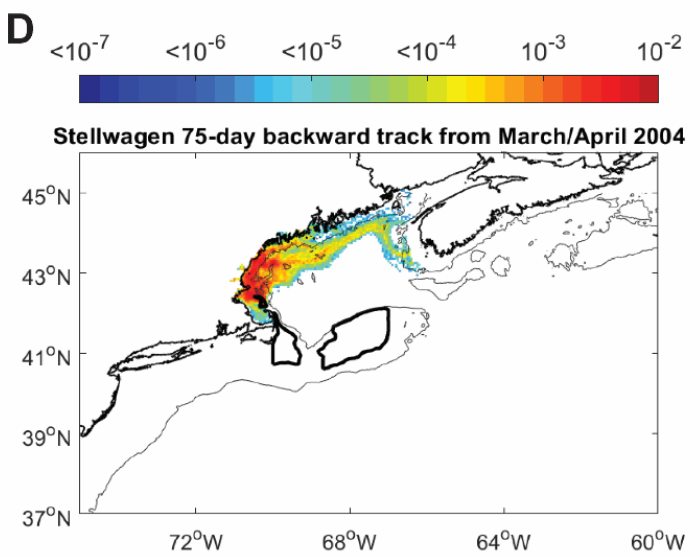

$\mathbf{F}_{<10^{-7}}<10^{-6} \quad<10^{-5} \quad<10^{-4} \quad 10^{-3} \quad 10^{-2}$

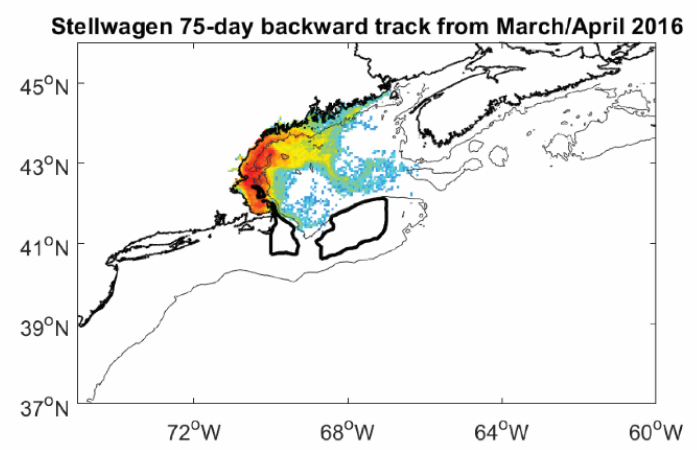

Figure 4-6. Relationship between number of days with strong south winds from January-April and (A) forward and (B) backward retention on Stellwagen Bank. Red lines represent fitted beta regression curves. Panels C-F show particle dispersal densities for 75-day forward $(\mathrm{C}, \mathrm{E})$ and backward (D,F) tracks during 2004 (C,D) a year with few days of strong south winds and 2016 $(\mathrm{E}, \mathrm{F})$, a year with many days of strong south winds. 
A

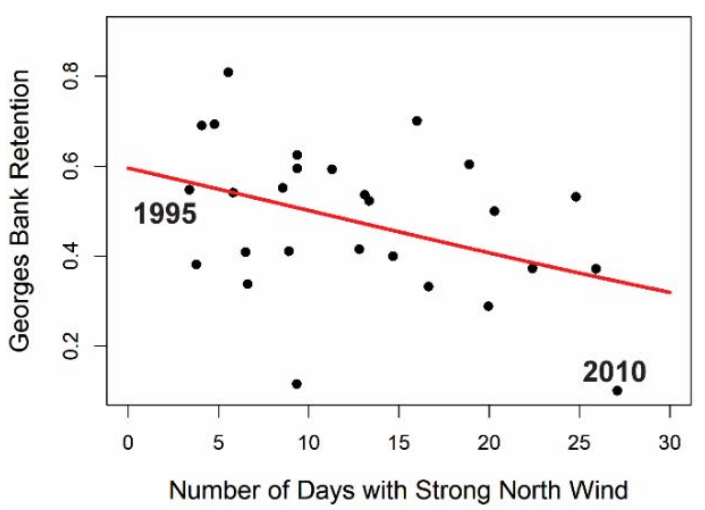

$\mathbf{C}_{<10^{-7}}<10^{-6} \quad<10^{-5} \quad<10^{-4} \quad 10^{-3} \quad 10^{-2}$

Georges Bank 73-day forward track from January/February 1995

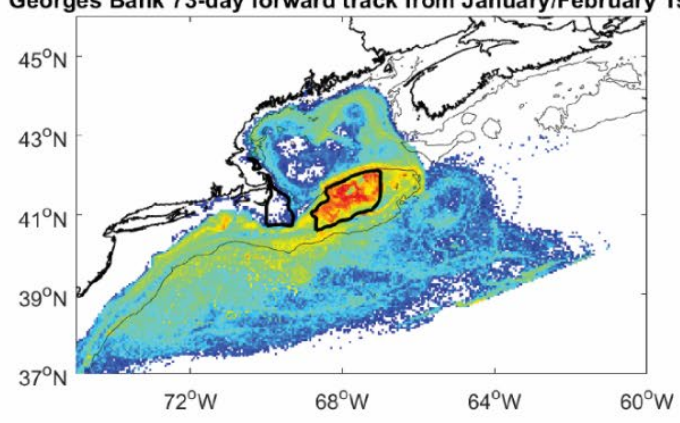

$\mathbf{E}_{<10^{-7}}<10^{-6} \quad<10^{-5} \quad<10^{-4} \quad 10^{-3} \quad 10^{-2}$

Georges Bank 73-day forward track from January/February 2010

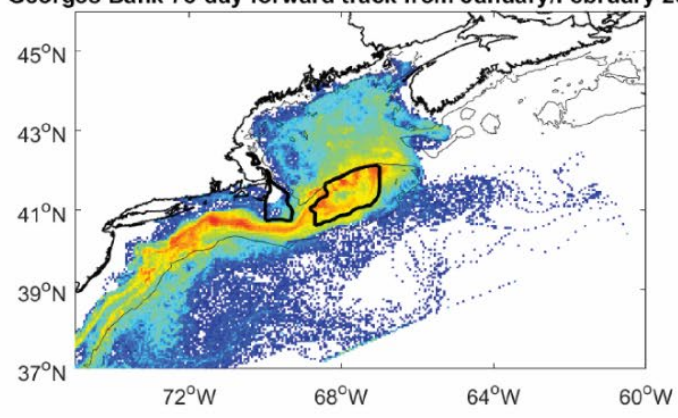

B Backward

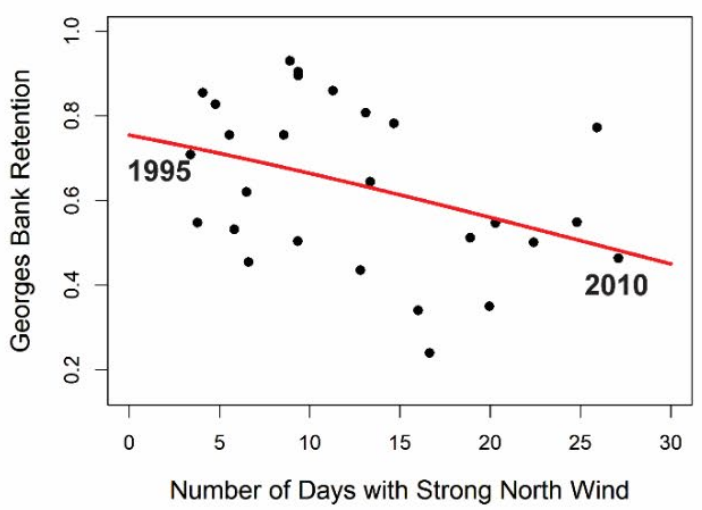

$\mathbf{D}_{<10^{-7}} \quad<10^{-6} \quad<10^{-5} \quad<10^{-4} \quad 10^{-3} \quad 10^{-2}$

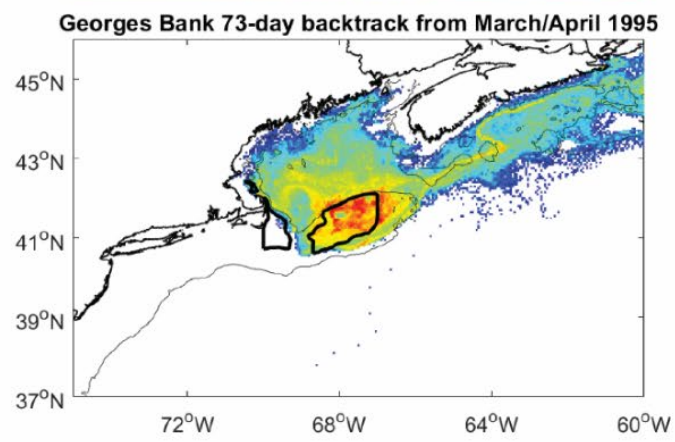

$\mathbf{F}_{<10^{-7}}<10^{-6} \quad<10^{-5} \quad<10^{-4} \quad 10^{-3} \quad 10^{-2}$

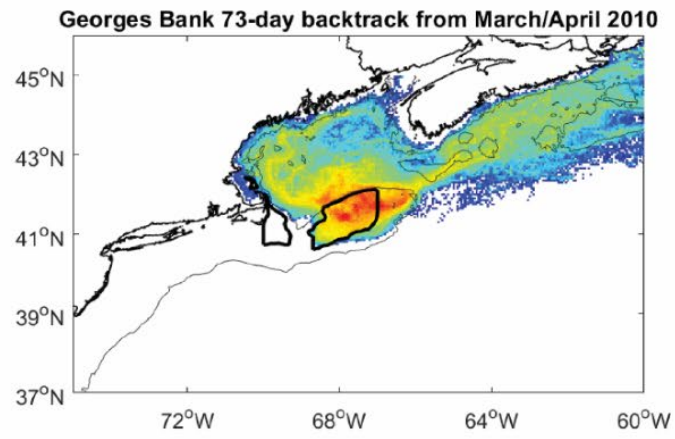

Figure 4-7: Relationship between number of days with strong north winds from January-April and (A) forward and (B) backward retention on Georges Bank. Red lines represent fitted beta regression curves. Panels $\mathrm{C}$-F show particle dispersal densities for 73-day forward $(\mathrm{C}, \mathrm{E})$ and backward (D,F) tracks during a 1995 (C,D) a year with few days of strong north winds and 2010 $(\mathrm{E}, \mathrm{F})$, a year with many days of strong north winds. 

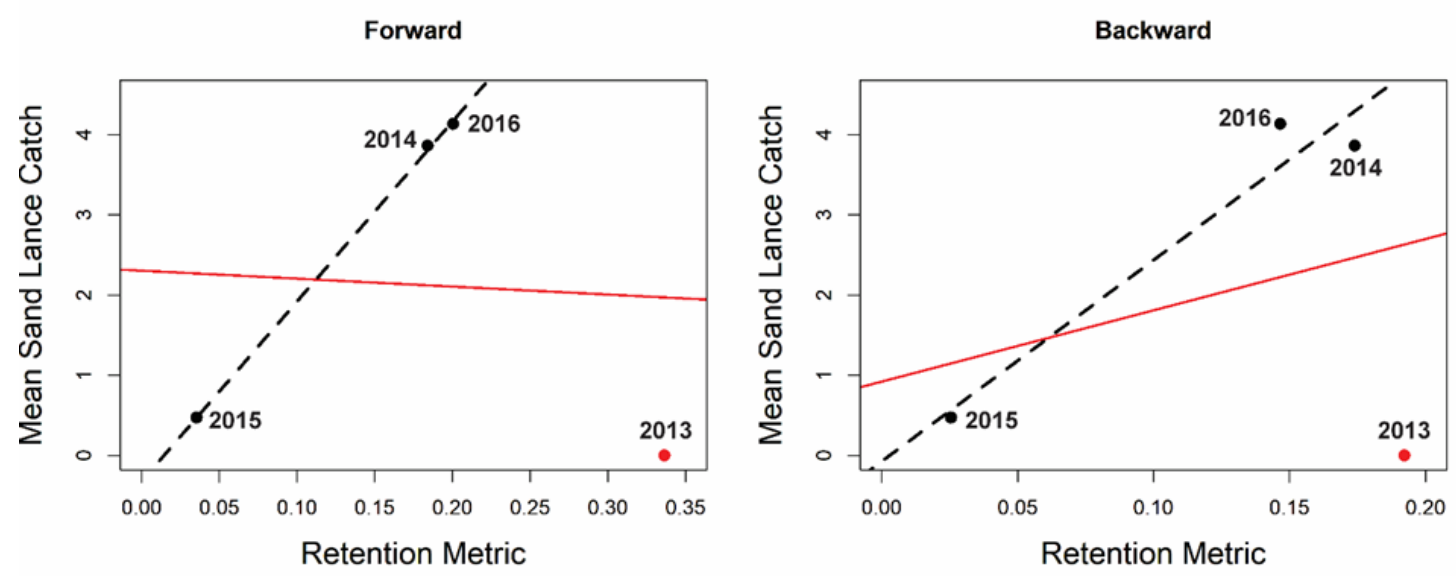

Figure 4- 8. Correlation of mean sand lance abundance from annual fall surveys and the forward and backward retention metric for Stellwagen Bank (connectivity metric for Stellwagen to Stellwagen) for 2014-2016 (dashed black line; forward $r=0.999$, backward $r=0.971$ ) and 20132016 (red line; forward $\mathrm{r}=-0.056$, backward $\mathrm{r}=0.305$ ).

\subsubsection{Connectivity and Retention among Stellwagen Bank Sub-regions}

The southwest corner of Stellwagen Bank had temporally variable connections with itself and the other sub-regions, with the most coherence occurring between retention (southwest corner to southwest corner) and connectivity with the central portion of the bank (Figure 4-9). Retention was notably the strongest route of forward connection when connectivity was standardized to area, exceeding that of the central portion of the bank (Figure 4-9C). Backward connectivity indicated weaker retention than forward connectivity, with connection to the northwest corner of the bank being the strongest for particles backtracked from the southwest corner when connectivity was standardized to area (Figure 4-9D). 
A

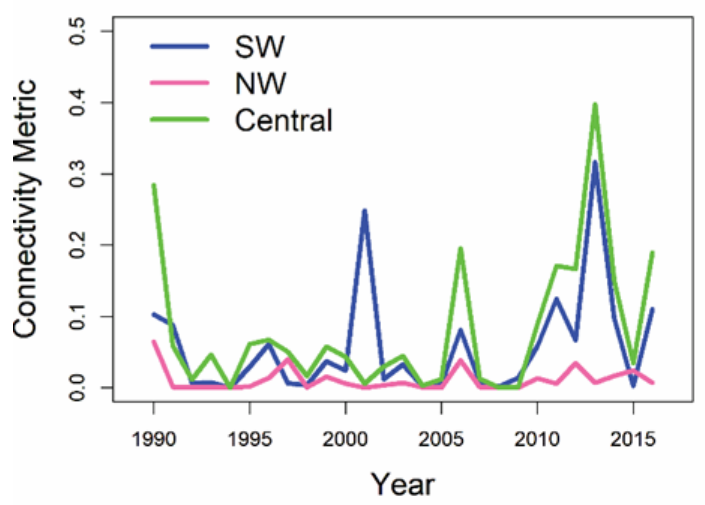

C

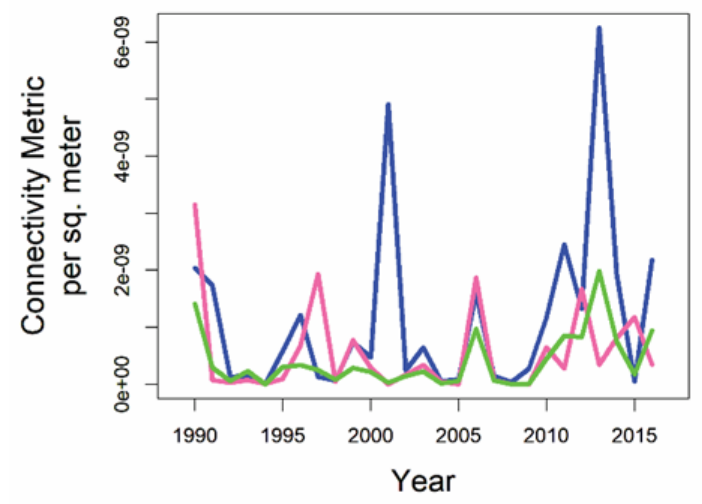

B

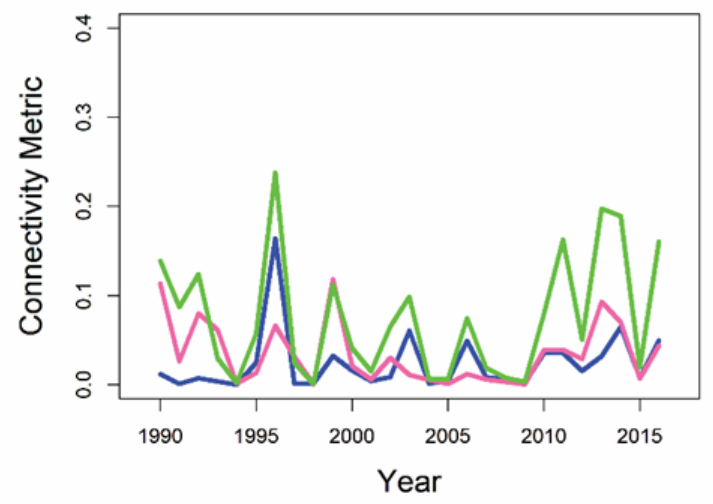

D

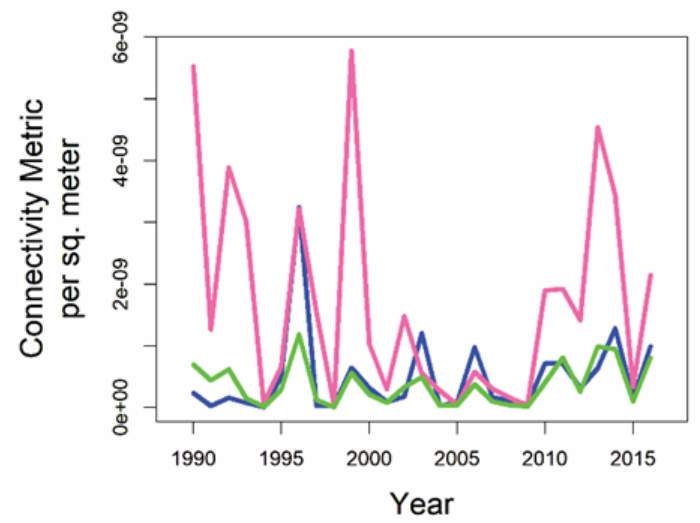

Figure 4-9. Connectivity metrics for particles originating from the southwest corner of Stellwagen Bank within Stellwagen Bank for forward $(A, C)$ and backward tracking (B,D) experiments. Colors represent connectivity to each sub-region within Stellwagen Bank. SW represents the southwest corner and NW represents the northwest corner. In panels C and D, connectivity metrics are standardized to the area of the sub-region of the connectivity metric.

\subsection{Discussion}

Our results indicate that connectivity among the three most pronounced sand lance hotspots in the Gulf of Maine varies notably on interannual and intraregional spatial scales. The drivers of these patterns are also linked to local wind forcing in the case of Stellwagen Bank and Georges Bank, which are highly variable from year to year. Our work also elucidates that the source-sink dynamics of these hotspots are variable from year to year yet have some consistent patterns - for example, Georges Bank and Stellwagen Bank relying on retention while the GSC 
largely relies on other hotspots for sources of larvae. Understanding these patterns in source-sink dynamics among the three major Gulf of Maine sand lance hotspots can help in our understanding of how the abundance of sand lance in each hotspot may be connected, along with identifying the scales that are important for sand lance recruitment.

Hotspot-specific differences in retention and connectivity indicate each location plays a different role in the larger source-sink dynamics of the region. Georges Bank is almost exclusively connected with itself (retention) and likely represents a semi-closed population of sand lance that only episodically receives larvae from other hotspots. The important tole of retention is consistent with other spawning fishes on Georges Bank, such as haddock (Werner et al., 1993; D. Mountain et al., 2008; Werner et al., 1996), Atlantic cod (Werner et al., 1993; Mountain et al., 2008; Werner et al., 1996), and Atlantic herring (Bakun, Babcock, \& Santora, 2009; Jech \& Stroman, 2012). The tidal rectification gyre over Georges Bank contributes to the high retention of particles on Georges Bank, though this gyre frequently breaks down on seasonal scales (Smith \& Morse, 1985). One notable difference between the ecology of sand lance on Georges Bank compared to haddock and Atlantic cod is the much earlier spawning and hatching period for sand lance, resulting in larvae being present on the bank from January through April, as opposed to Atlantic cod and haddock which spawn in March and April (Mountain et al., 2008; Potter \& Lough, 1987; Werner et al., 1996). This results in the larval period of sand lance coinciding with the weakest tidal rectification currents and the greatest influence of wind patterns on circulation (Naimie et al., 1994). Thus, the timing of sand lance spawning maximizes the susceptibility of larval retention to local wind forcing, leading to the negative relationship between number of strong north wind days and retention on Georges Bank. North winds are able to both move forward tracked particles to the southwest and thus off 
Georges Bank in addition to increasing the proportion of larvae that would have originated from the northeast peak of Georges Bank (where sand lance are not abundant) for backward tracking experiments. Lewis et al. (2001) observed similar patterns for simulated "plankton" across Georges Bank from 1968-1998, indicating both that this pattern is persistent through time, and may have additional effects on sand lance larval survival through regulating prey availability on Georges Bank. The combination of strong north winds moving larval sand lance off Georges Bank and these winds potentially reducing prey availability may have notable effects on sand lance recruitment in this region.

Unlike Georges Bank, the GSC averaged little retention throughout our particle tracking experiments. Apart from 1990, a year with anomalously strong south winds leading to a reversal of flow from south to north (see supplemental material), particles backtracked from the GSC were mostly sourced from Stellwagen Bank and Georges Bank. This pattern indicates that the GSC represents the most pronounced sink of sand lance larvae of the three hotspots in this study. This is further evidenced by the lack of the GSC as a source for other hotspots, with 1990 representing the only year when the GSC contributed a significant number of particles to another hotspot (Georges Bank). The GSC has stronger and more consistent residual current direction than much of Stellwagen Bank and Georges Bank, resulting in particles following the north to southwest flow regimes of the region (Beardsley et al. 1985). The location of the GSC leads particles being swept south from Stellwagen Bank and west off Georges Bank to cross the region and may cause the GSC to be one of most consistent sand lance hotspots of the Northeast US shelf. It is worth noting that particles released from the Great South Channel were transported to the Mid-Atlantic Bight, a region that historically represented a sand lance hotspot on the Northeast US shelf (Staudinger et al., 2020). The Mid-Atlantic Bight sand lance hotspot has 
largely disappeared in recent years (and was thus not included in this study; Suca et al. 2021) but it is likely the sand lance in the GSC region that served as a source population for this hotspot prior to its decline.

Surprisingly, our results show that substantial retention of simulated larvae can occur over Stellwagen Bank, particularly for particles released from the southwest corner. Local sand lance surveys even suggest that retention may play a large enough role to factor into the total abundance of sand lance on Stellwagen Bank, helping to elucidate why sand lance abundance and presence on Stellwagen Bank is so variable (Silva et al. 2021). Retention is not the sole driver of sand lance abundance, however, as evidenced by the lack of sand lance collected in 2013 despite high retention. The year prior, 2012, had a low abundance of Calanus finmarchicus, the primary prey of adult sand lance, and high winter temperatures (Table 4-S2). The combination of these two factors may have led to low recruitment for sand lance on Stellwagen Bank due to reduced capacity for adults to develop gonads and reduced adult survival (Suca et al. 2021). Thus, while recruitment may contribute to local abundance, this can be easily overwhelmed by additional environmental influences.

Our results show interannual variability in retention on Stellwagen Bank is coupled to local wind patterns, though it is noteworthy that the patterns suggest a different mechanism than proposed for other species in the region. Unlike Atlantic cod, which see enhanced retention and recruitment in the western Gulf of Maine during years with strong north winds from onshore Ekman transport (Runge et al., 2010), the enhanced retention of sand lance on Stellwagen Bank appears to be driven by the eastward movement of retentive features from Stellwagen Basin to the southwest corner of Stellwagen Bank during years with strong south winds (Jiang et al. 2007). This is further supported by our observation that backward retention metrics were highest 
for particles released from the southwest corner of Stellwagen Bank and that retention of particles on the southwest corner exceeded connectivity with other portions of the bank in many years in forward tracking experiments The association of spatial and interannual patterns in retention with local wind forcing suggest monitoring of wind strength over Stellwagen Bank is particularly important for understanding spatiotemporal patterns in local recruitment. However, we must note that, while statistically significant, the relationship between south wind and retention on Stellwagen Bank was weak. This is likely largely due to factors other than wind forcing modulating the western Gulf of Maine coastal current. Previous research has shown that flow patterns in the region are not solely controlled by wind forcing and more work is needed to elucidate the more complex drivers of these hydrodynamics, such as local eddies and meanders (Churchill et al., 2005).

Understanding spatial variability in retention is also a significant development in our understanding of the Stellwagen Bank ecosystem. Stellwagen Bank represents essential top predator foraging habitat, especially for humpback whales and seabirds (Powers et al. 2020; Silva et al. 2021). However, the drivers of the spatial heterogeneity in sand lance and sand lance predator distribution over Stellwagen Bank, namely the cause of the localized hotspot in the southwest corner (Lutcavage et al. 2000; Wiley et al. 2003; Hazen et al. 2009), has remained largely a mystery due to the broad availability of suitable substrate across the bank (Valentine and Cross, 2021). Hypotheses such as active fish aggregations from internal wave formation have not been supported by field observations (Pineda et al. 2015). This spatial heterogeneity in retention is also remarkable given the much smaller size of Stellwagen Bank compared to other sand lance hotspots. Our work suggests that even small sub-regions of banks like the southwest corner of Stellwagen may have high localized retention and be self-seeding. These larval 
retention patterns may be a large contributor to the persistence of the southwest corner as a sand lance hotspot and serves as a viable hypothesis for the mechanism behind the spatial heterogeneity in sand lance observations in the southern and central portions of the bank. However, our observations of spatial heterogeneity in retention metrics do not explain the episodic explosions of sand lance abundance on the northwest corner of Stellwagen Bank, which can intermittently exceed those on the southwest corner (Richardson et al., 2014). Our results do not show this region as having substantial backward retention or connectivity to the other hotspots studied. Our results do, however, show that forward connectivity from the northwest corner of Stellwagen Bank is high and thus spawning sand lance from the northwest corner may further contribute to sand lance abundance on the southwest corner of the bank. Our backtracking of particles from the southwest corner confirms this pathway, with backward connectivity from the southwest corner to the northwest corner being the strongest route of connectivity when standardized to area. Given the lack of backward retention on the northwest corner, it appears sand lance observed on the northwest corner must come from an external source, likely north of Stellwagen Bank due to the prevailing current structure (Bigelow 1927; Brooks 1985; Franks \& Anderson 1992; Townsend et al., 2015). The coastal Gulf of Maine lacks large regions of sand substrate and is thus unlikely to be a significant contributor of sand lance larvae to Stellwagen Bank (Ethratta \& Ink, 2006), but regions such as the Bay of Fundy and the Scotian Shelf further to the north have large populations of sand lance (Frank et al., 2011). However, transport from these distances likely requires years with strong north winds to generate sufficient southward flow along the coastal Gulf of Maine (e.g. 2010; Figure 4-7F). The requirement of an external source of sand lance larvae along with specific wind conditions may drive the inconsistency of sand lance observations on the northwest corner. This also suggests 
the mechanisms driving abundance of sand lance on Stellwagen Bank are specific to subregions within the bank and dispersal pathways in both the northern and the southern portions of the bank are linked to wind conditions.

The three sand lance hotspots detailed in this study are not the sole locations of adult sand lance throughout the Gulf of Maine, and thus there are other possible sources and sinks of sand lance larvae throughout the region. A key example of this is the aforementioned sources of larvae for the northwest corner of Stellwagen Bank. We restricted our analyses of hotspots to those within the Gulf of Maine/Georges Bank, but regions such as the Bay of Fundy and Scotian Shelf are likely to contribute to settling sand lance on Stellwagen Bank which would further decouple correlations between sand lance abundance and retention on Stellwagen Bank. Additionally, many of the simulated forward tracked larvae from all three hotspots that are not transported to another hotspot are likely able to settle in the Mid-Atlantic Bight. This region has large swaths of sandy substrate, representing a viable destination for many of the simulated spawned larvae (Nelson \& Ross, 1991). However, the abundance of sand lance observed in this region from the Northeast Fisheries Science Center bottom trawl survey is notably lower in recent years than in the 1980s (NEFSC, 2020). The exact cause of this is unknown but given the upstream hotspots (the GSC and Georges Bank) have not had an increase in retention, we believe that a lack of larval supply via hydrographic shifts is not the root cause.

An additional limitation to our study is the lack of understanding of larval sand lance biology. Potter and Lough (1987) represent the only study of larval sand lance vertical distribution, with their results showing a movement of larvae to deeper water as sand lance larvae grow to near settlement age. However, we lack understanding of larval sand lance vertical movements in the water column prior to this, leaving us unsure if larvae exhibit clear diel 
vertical migration patterns or what point they may exhibit concerted horizontal movements. If larvae do exhibit concerted vertical or horizontal movements prior to the settlement process, incorporating such behavior in our particle tracking experiments would likely alter some of our results. Numerous studies have shown that the inclusion of larval behaviors alter dispersal pathways (Faillettaz et al., 2018; Levin, 2006; Rypina et al., 2014). This is most notable for larvae that exhibit vertical movements in areas with high vertical velocity shear (Garwood et al., 2021; Tapia \& Pineda, 2007). The Gulf of Maine in winter is well mixed and thus vertical velocity shears are low on banks for much of the larval duration of sand lance (Mountain \& Manning, 1994), though waters begin to stratify in the spring and thus vertical gradients in velocity being to increase as sand lance larvae approach settlement (Mountain \& Manning, 1994; Naimie et al., 1994). While we did not attempt to incorporate larval behavior due to a lack of existing knowledge for this species, it is possible that vertical movements do occur among larvae and that these movements could affect the results presented here. Future work should focus on better understanding larval sand lance behavior and incorporating this behavior into dispersal models to see if emergent patterns in dispersal pathways and retention change among these three hotspots.

An additional source of unexplored variability may lie within the settlement and hatch timing of sand lance. For example, we did not include temperature dependent growth of sand lance larvae in our particle tracking experiments. Recent work suggests temperature regimes play an important role in larval transport trajectories of certain fish species (Raventos et al., 2021). Further, studies of sand lance congeners have incorporated interannual temperature differences into larval transport pathways (Christensen et al., 2008). However, these studies found temperature did not play a large role in the transport pathways and predicted recruitment of 
lesser sandeel (Ammodytes marinus; (Christensen et al., 2008; Jensen et al., 2003). We did not include temperature dependent growth in our particle tracking experiments given the lack of information on temperature dependent growth for northern sand lance and its connection to settlement timing. We expect the effects of including temperature dependent growth in this system to be minor given the well-mixed water column and more consistent temperatures in winter when compared to other seasons. However, future work should investigate the effects of temperature on the settlement timing of northern sand lance and if these effects lead to changes in modeled larval transport. Our estimates of settlement timing and hatch dates may also not be perfectly representative of the expected settlement and hatch dates of sand lance in a given region. Both of these metrics may be sensitive to origin of an individual, and since connectivity metrics vary interannually among these hotspots, observed settlement and hatch dates in a region may be sensitive to the degree of connectivity of that region with other hotspots. For example, if the settling individuals in the GSC are primarily from the GSC (e.g. 1990), the otoliths of settling individuals from the GSC likely accurately reflect hatch dates. However, if the settling individuals are a distribution of individuals hatched in the GSC, Georges Bank, and Stellwagen Bank, the observed hatch dates would reflect a mix of hatch dates from these regions and not truly represent the mean hatch date of larvae on the GSC. Unfortunately, hydrographic and hydrodynamic forcing from FVCOM for 2019 was not available when the experiments were conducted for this study, but future work should explore the variability in hatch and settlement dates observed on these hotspots based both on temperature regimes and the expected connectivity among the hotspots.

Our use of hydrographic and hydrodynamically coupled Lagrangian tracking models is another limitation when it comes to translating our results to realistic drivers of recruitment. 
Lagrangian particle tracking models are used frequently to estimate particle trajectories for movements of water parcels (Roach \& Speer, 2019), plankton (e.g. Miller et al., 1998; Ji et al., 2017), and larval stages of organisms, including fishes (Huret et al., 2007; Churchill et al., 2011; Boucher et al., 2013; Petrik et al., 2014) and shellfish species (e.g. Chen et al., 2021 and references therein) in our study area. However, fine scale differences in velocity interpolation and chaotic trajectories near stagnation points can lead to vastly different trajectories for nearly placed particles within Lagrangian tracking models (see supplementary methods). These large discrepancies even appear when using small time steps if the particle tracking experiments last for long periods, as is the case in our work. Therefore, we must caution that our experiments represent a subset of the potential drift trajectories of water parcels (and thus larval sand lance) released from each of our hotspots and not a full representation of the fate of larvae hatched or backtracked from each location. Discrepancies also arise when comparing forward and backward tracked particles. These discrepancies are not due to the random walk nature of the water parcels as illustrated by Christensen et al. (2007) because random walk is not considered in our calculation. Instead, they are largely due to the difference between the forward and backward velocities before and after a particle was tracked. However, this can result in a different location than the particle would be in a forward tracking experiment as multiple pathways can result in the same location. This leads to an impossibility of backtracking a particle to repeat the forward tracking path in a reversed direction which is particularly difficult at stagnation points or convergent flows where the Lagrangian coherence scale is small. While we believe our backtracking experiments (and backtracking experiments generally), can assess the dispersal probability and capture the general connectivity patterns, we must note this concern when interpreting the results of such studies. 
Collectively, our results indicate that larval dispersal pathways among Stellwagen Bank, the GSC, and Georges Bank vary interannually and spatially within each hotspot. Interannual variability and the spatial distributions of retention are also linked to local wind phenomena. This connection between retention and wind phenomena allows managers and stakeholders interested in local sand lance retention to focus on winter-spring wind patterns as indicators of likely strong or weak retention for Stellwagen Bank and Georges Bank. Given settling sand lance are difficult to collect due to their small size and patchy distribution, these metrics may be helpful to ameliorate our lack of direct recruitment estimates from trawl surveys. However, wind events are not the sole driver of local retention and more research into other mechanisms is warranted, especially for retention over Stellwagen Bank. While our work does not provide a clear correlation between larval dispersal pathways and adult abundance, our results do indicate that local presence of sand lance may be linked to larval dispersal pathways and that larval retention may play a role in local sand lance abundance if other conditions are stable. However, environmental conditions are rarely stable for multiple consecutive years, and thus interannual changes in retention and dispersal must be paired with observations of drivers of adult sand lance abundance drivers when ultimately predicting spawning stock biomass. Future research should work toward incorporating environmental drivers of adult abundance and larval dispersal pathways into a stock assessment and stock recruitment relationships for this critical, yet understudied forage fish.

\subsection{Supplemental Methods, Figures, and Tables}

\subsubsection{Depth cut-off analysis}

We used the Northeast Fisheries Science Center spring bottom trawl survey to assess the mean depth sand lance occur on Georges Bank compared to the surrounding Northeast US shelf. 
Details of the survey and sampling gear are found within Politis et al. (2014). Briefly, the survey spans from 1968 to present, with each survey encompassing 300-400 stations sampled in a random stratified design, ranging from the Western Scotian Shelf to Cape Hatteras.

We performed a logistic regression for the presence/absence of sand lance in relation to depth for trawls on Georges Bank and a logistic regression for the presence/absence of sand lance in relation to depth for trawls on the rest of the Northeast US shelf. Given our knowledge that sand lance are rarely caught at depths $>40 \mathrm{~m}$ on Stellwagen Bank (Silva et al. 2021), we estimated the depth that had the equivalent probability of occurrence of sand lance for Georges Bank as the probability of occurrence at $40 \mathrm{~m}$ for the rest of the Northeast US shelf. This value was then used as the depth cut-off for particle seeding on Georges Bank.

\subsubsection{Tidal experiment}

We released particles hourly on January 1, 2002 (date arbitrary) to compare the effect of hour of release (and therefore initial tidal state) on the final locations of particles released from Stellwagen Bank. As with other simulations, 1230 particles were released from each 5, 15, 25, and $35 \mathrm{~m}$ depths and were treated as depth-keeping. Final destinations were visualized by hour of release to see if particle trajectories were noticeably different by time of release.

\subsubsection{Calanus and sea surface temperature calculations}

Annual Gulf of Maine Calanus anomalies were calculated following Perretti et al. 2017 and Morse et al. 2017. Daily sea surface temperature values and anomalies were extracted for the region over Stellwagen Bank (42.5-42.0 N, 70.5 -70.0 W) from NOAA Optimum Interpolation SST V2 dataset provided by the NOAA/OAR/ESRL PSL, Boulder, Colorado, USA, from their Web site at / https://psl.noaa.gov/data/gridded/data.noaa.oisst.v2.highres.html. Values were averaged spatially over the region and then by time of interest. Winter SST and winter SST 
anomalies were calculated as an average of daily values from January-March of each year, representing the time which post-spawn adult sand lance would be susceptible to mortality from elevated temperatures (Suca et al. 2021). Mean daily SST and SST anomalies for the entire year were also calculated.

\subsubsection{Particle dispersal comparison}

To look at small scale discrepancies in dispersal trajectories due to numerical interpolation errors and chaotic flows near stagnation points, we seeded particles at $10 \mathrm{~m}$ spacing (484 particles) at the center of Georges Bank and tracked their forward trajectory for 75 days from January 15, 2002. The results are visualized in Figure 4-S6 (ten minute time step) and 4-S7 (one minute time step). Results show that particles disperse and separate large distances even when placed very close together. While such phenomena are unavoidable, it can serve effectively as a diffusion pattern. 
Table 4-S1: Collection locations, dates, and counts for age-0 sand lance used for otolith microstructure analysis. GSC represents the Great South Channel.

\begin{tabular}{lccccc}
\multicolumn{1}{c}{ Region } & Date & Station & Longitude & Latitude & Count \\
\hline GSC & 190521 & Ch 2 & -69.78 & 41.57 & 2 \\
GSC & 190521 & Ch 3 & -69.77 & 41.59 & 3 \\
GSC & 190521 & Ch 4 & -69.79 & 41.58 & 4 \\
GSC & 190521 & Ch 5 & -69.83 & 41.58 & 4 \\
GSC & 190521 & Ch 6 & -69.87 & 41.56 & 4 \\
GSC & 190523 & Ch 7 & -69.87 & 41.75 & 2 \\
GSC & 190523 & Ch 8 & -69.87 & 41.75 & 7 \\
GSC & 190523 & Ch 9 & -69.87 & 41.73 & 10 \\
GSC & 190523 & Ch 10 & -69.87 & 41.71 & 9 \\
GSC & 190523 & Ch 11 & -69.87 & 41.70 & 5 \\
Stellwagen & 190603 & S11 & -70.24 & 42.18 & 4 \\
Stellwagen & 190603 & S12 & -70.27 & 42.18 & 8 \\
Stellwagen & 190603 & S13 & -70.31 & 42.17 & 9 \\
Stellwagen & 190604 & N13 & -70.40 & 42.39 & 2 \\
Stellwagen & 190604 & N14 & -70.42 & 42.40 & 9 \\
Stellwagen & 190604 & N15 & -70.44 & 42.41 & 15 \\
GSC & 190617 & Ch 9 & -69.87 & 41.73 & 1 \\
GSC & 190617 & Ch10 & -69.87 & 41.71 & 10 \\
GSC & 190617 & Ch 12 & -69.86 & 41.70 & 7 \\
GSC & 190617 & Ch 13 & -69.88 & 41.72 & 10 \\
GSC & 190617 & Ch 14 & -69.86 & 41.69 & 11 \\
GSC & 190617 & Ch 15 & -69.86 & 41.68 & 9
\end{tabular}


Table 4-S2: Annual Calanus anomalies for the Gulf of Maine and Stellwagen Bank sea surface temperature (SST) metrics.

\begin{tabular}{cccccc} 
Year & $\begin{array}{c}\text { Calanus } \\
\text { Anomaly }\end{array}$ & $\begin{array}{c}\text { Mean Daily } \\
\text { Winter SST }\left({ }^{\circ} \mathbf{C}\right)\end{array}$ & $\begin{array}{c}\text { Mean Daily } \\
\text { SST }\left({ }^{\circ} \mathbf{C}\right)\end{array}$ & $\begin{array}{c}\text { Mean Daily Winter } \\
\text { SST Anomaly }\left({ }^{\circ} \mathbf{C}\right)\end{array}$ & $\begin{array}{c}\text { Mean Daily SST } \\
\text { Anomaly }\left({ }^{\circ} \mathbf{C}\right)\end{array}$ \\
\hline 2012 & -0.174 & 6.428 & 12.452 & 2.079 & 2.262 \\
2013 & -0.083 & 5.958 & 11.730 & 1.603 & 1.532 \\
2014 & -0.102 & 4.410 & 11.152 & 0.060 & 0.955 \\
2015 & 0.138 & 4.473 & 11.270 & 0.123 & 1.073 \\
2016 & 0.235 & 5.981 & 12.083 & 1.632 & 1.893
\end{tabular}


Stellwagen Age-0 Collections

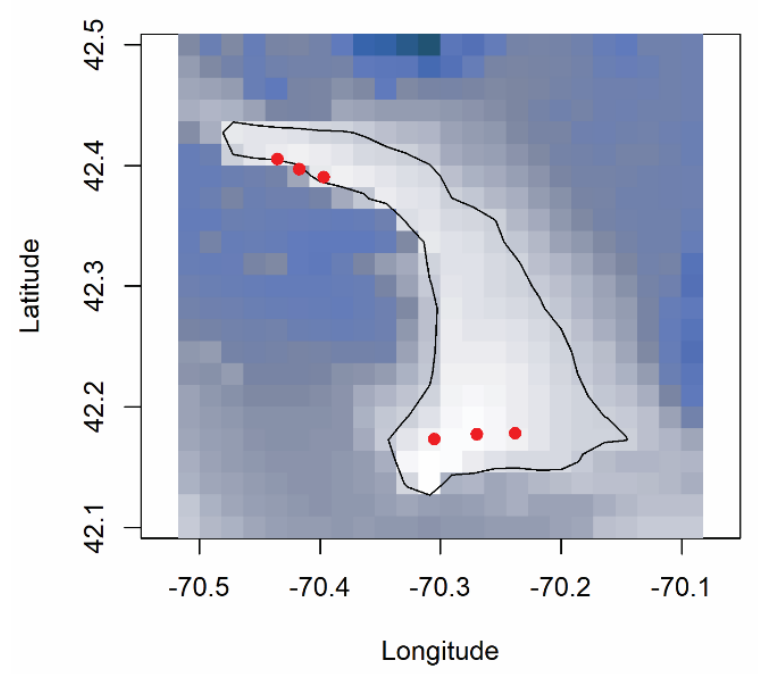

GSC Age-0 Collections

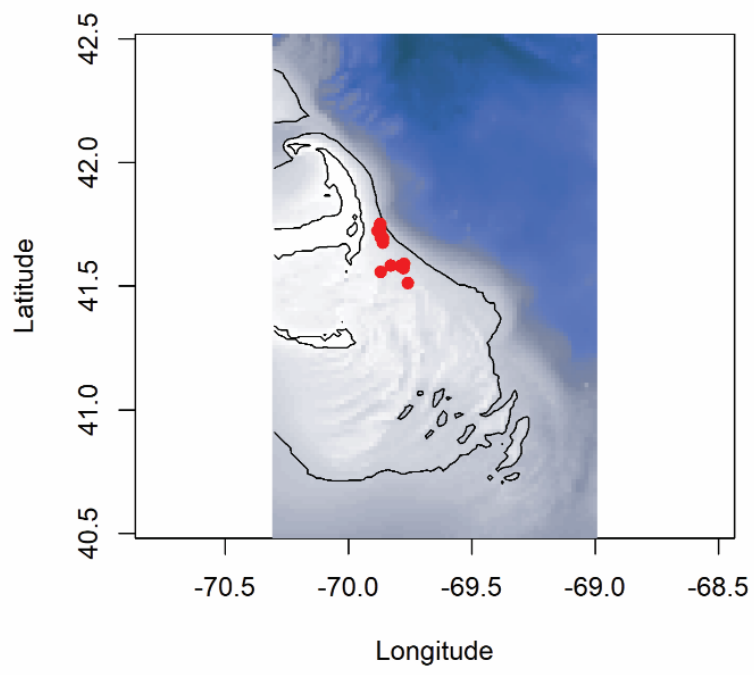

Figure 4-S1: Collection locations of age-0 sand lance on Stellwagen Bank and in the Great South Channel in summer 2019. Shading indicates bathymetry and contours represent the coastline and $40 \mathrm{~m}$ isobath. 


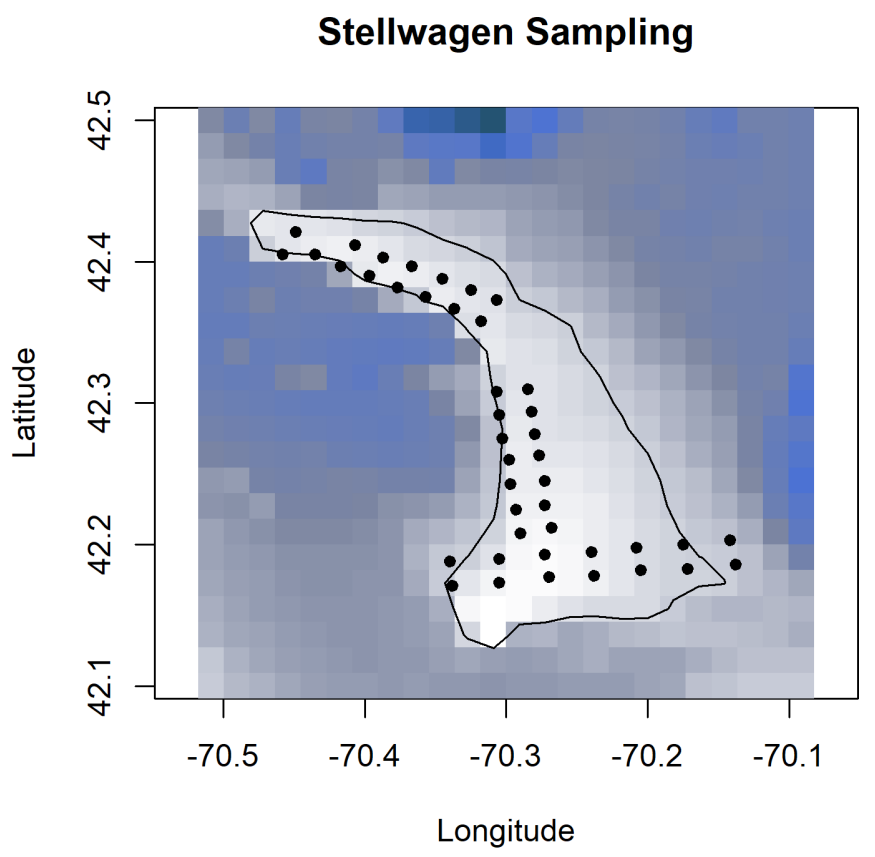

Figure 4-S2: Sampling location for the Stellwagen Bank SEABOSS sand lance survey. 

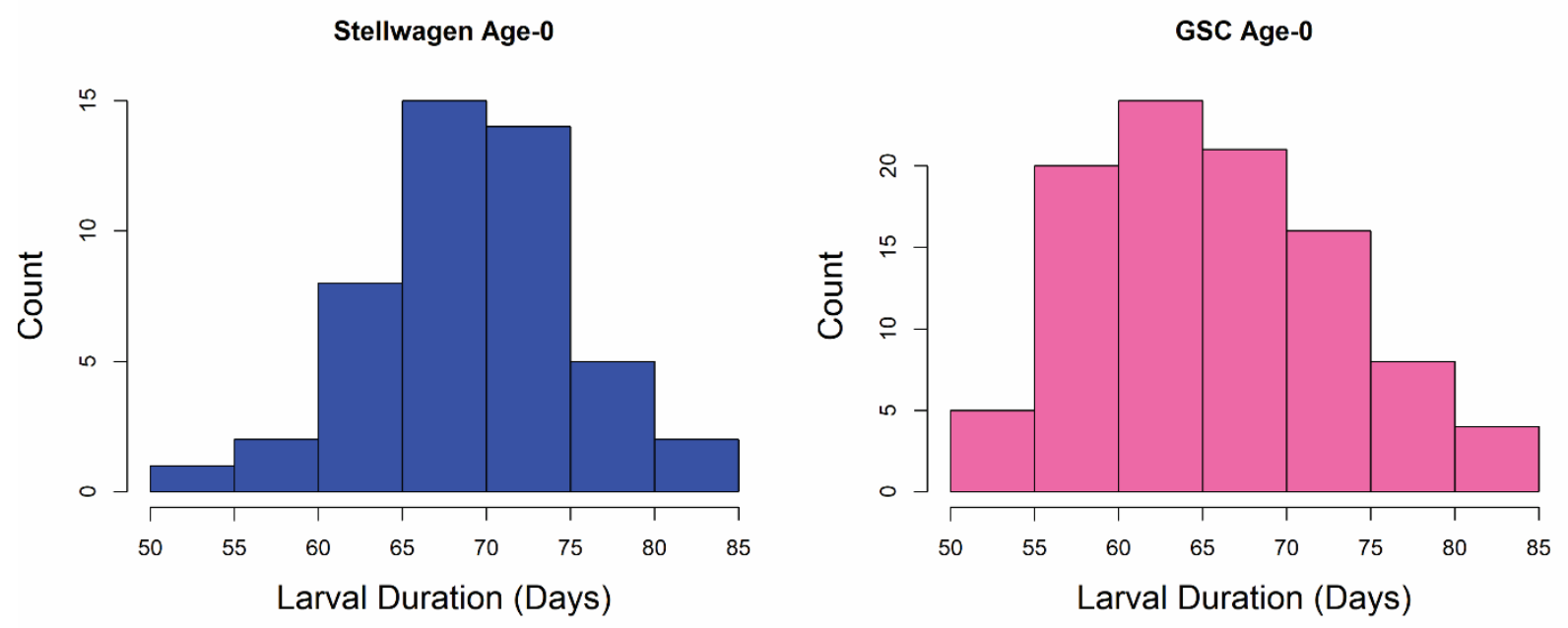

Figure 4-S3: Larval duration (LD) of age-0 sand lance collected on Stellwagen Bank and the Great South Channel (GSC) in summer 2019. LD estimates are from otolith microstructure analysis. 


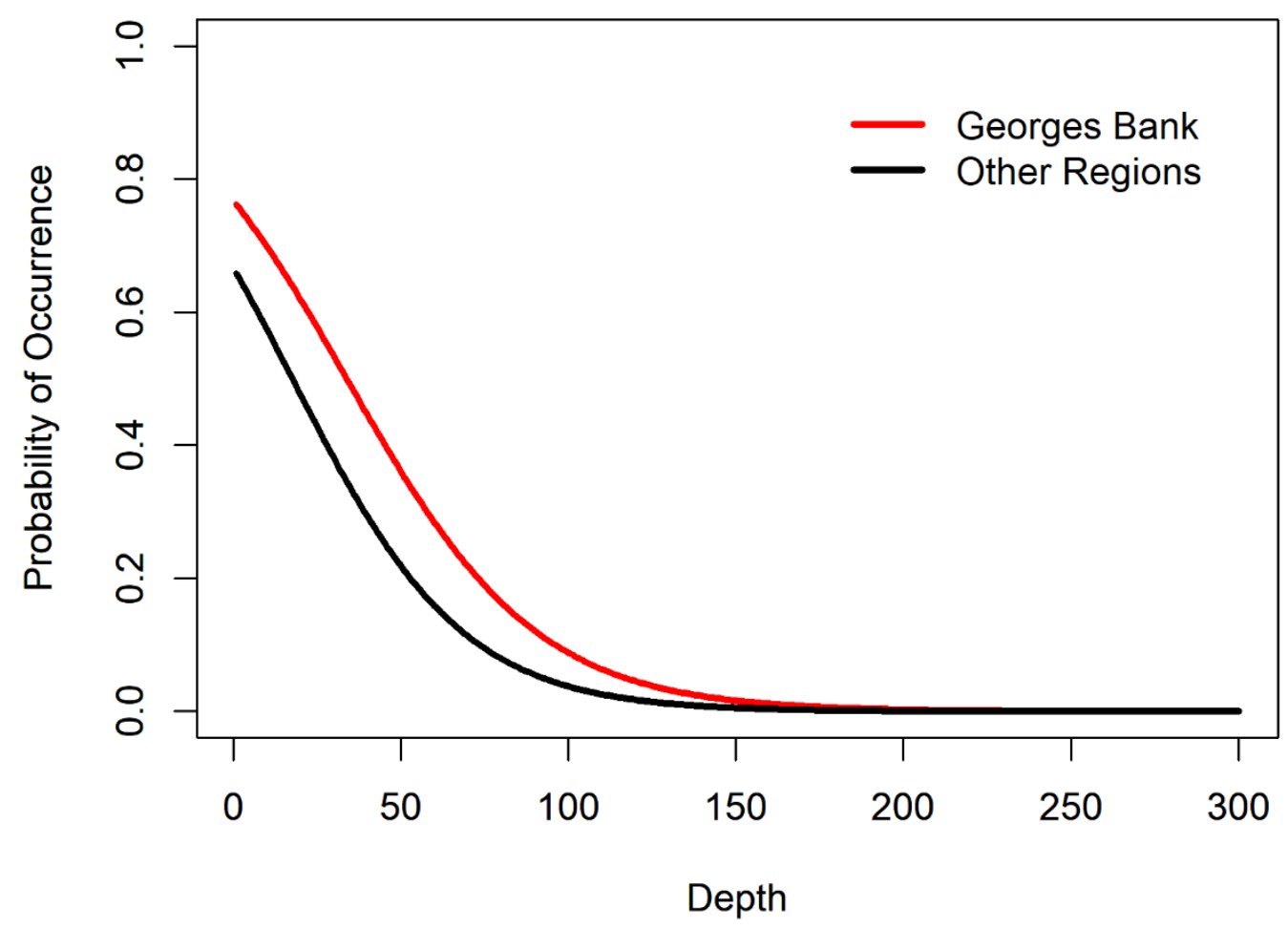

Figure 4-S4: Probability of sand lance occurrence of sand lance from the NEFSC spring bottom trawl survey in relation to depth on Georges Bank (red) and the rest of the Northeast US shelf. 


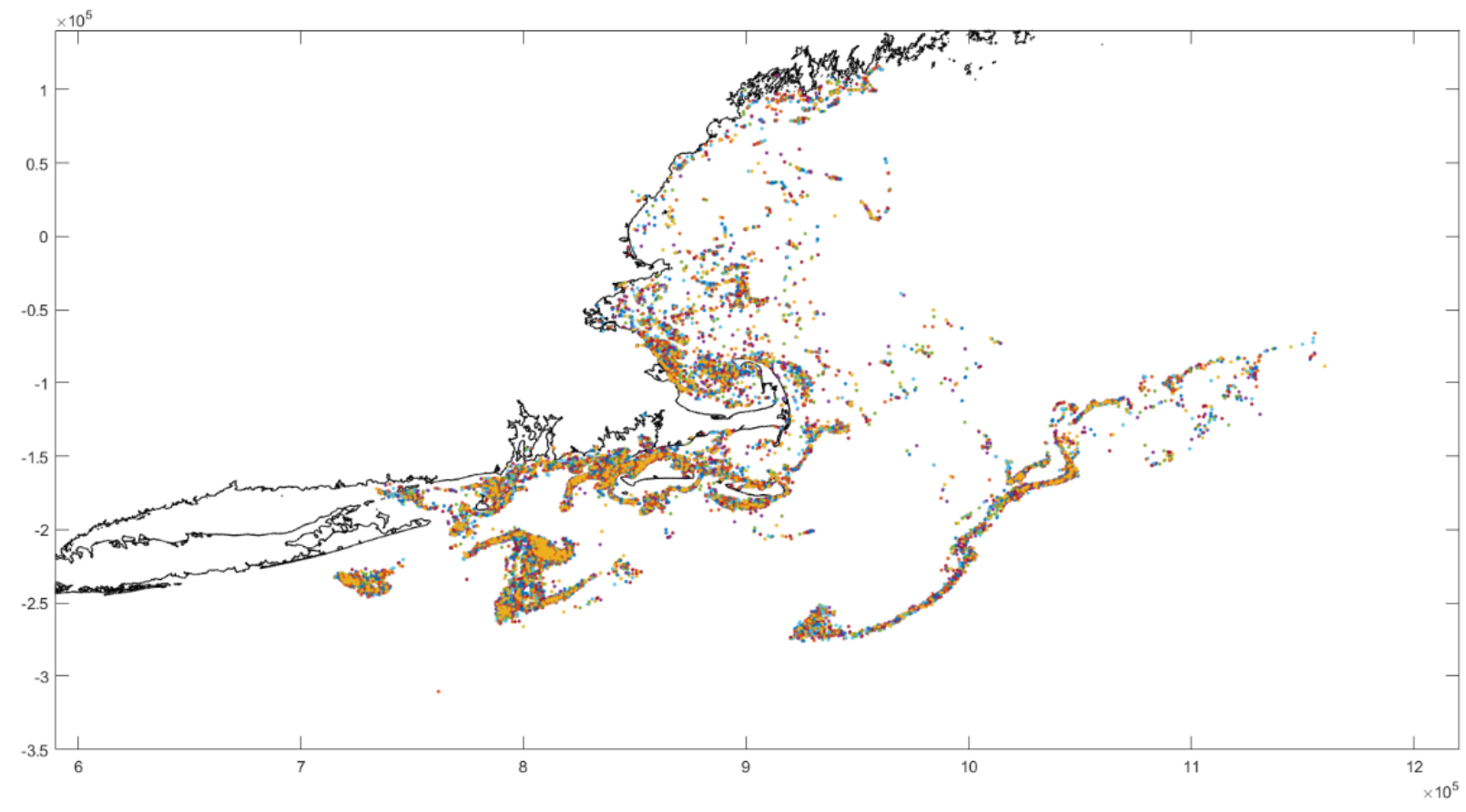

Figure 4-S5: Final locations (85 days after release) for particles released hourly on January 1, 2002. Colors represent hour of release. Aggregations indicate little variability among final locations based on hour of release. 

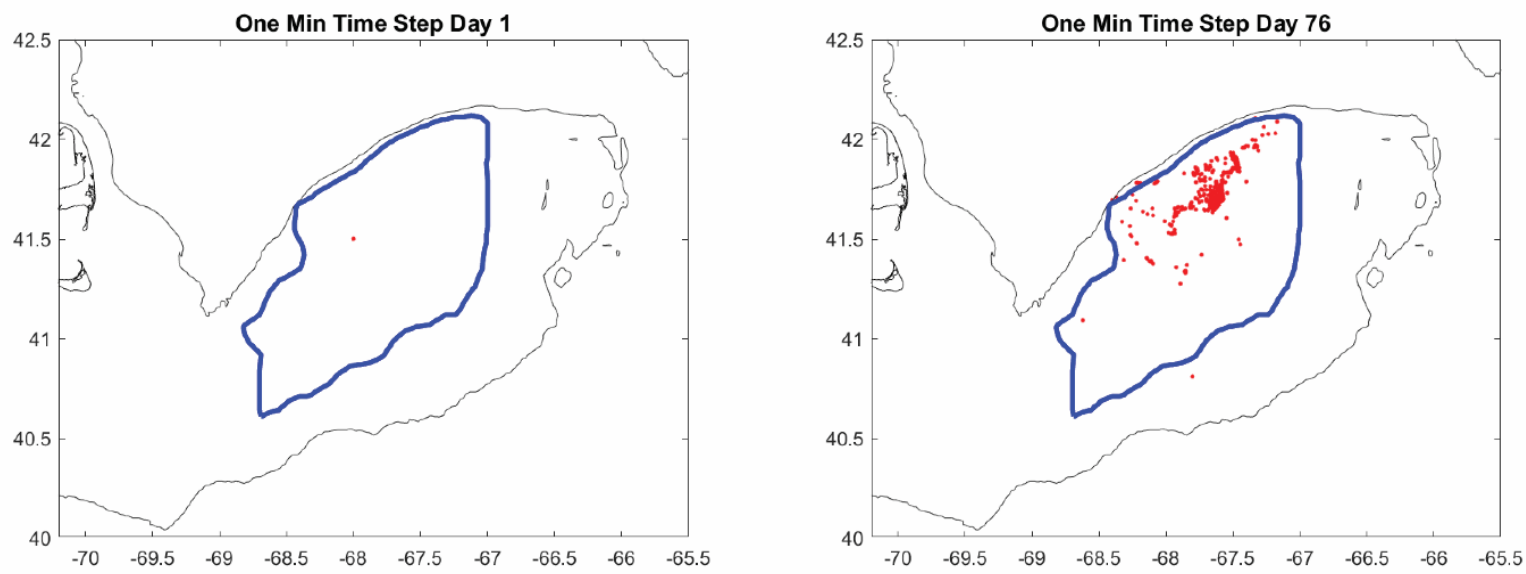

Figure 4-S6: Final locations ( 75 days after release) for particles released with $10 \mathrm{~m}$ spacing (left panel) from January 15, 2002 using one-minute time steps. 

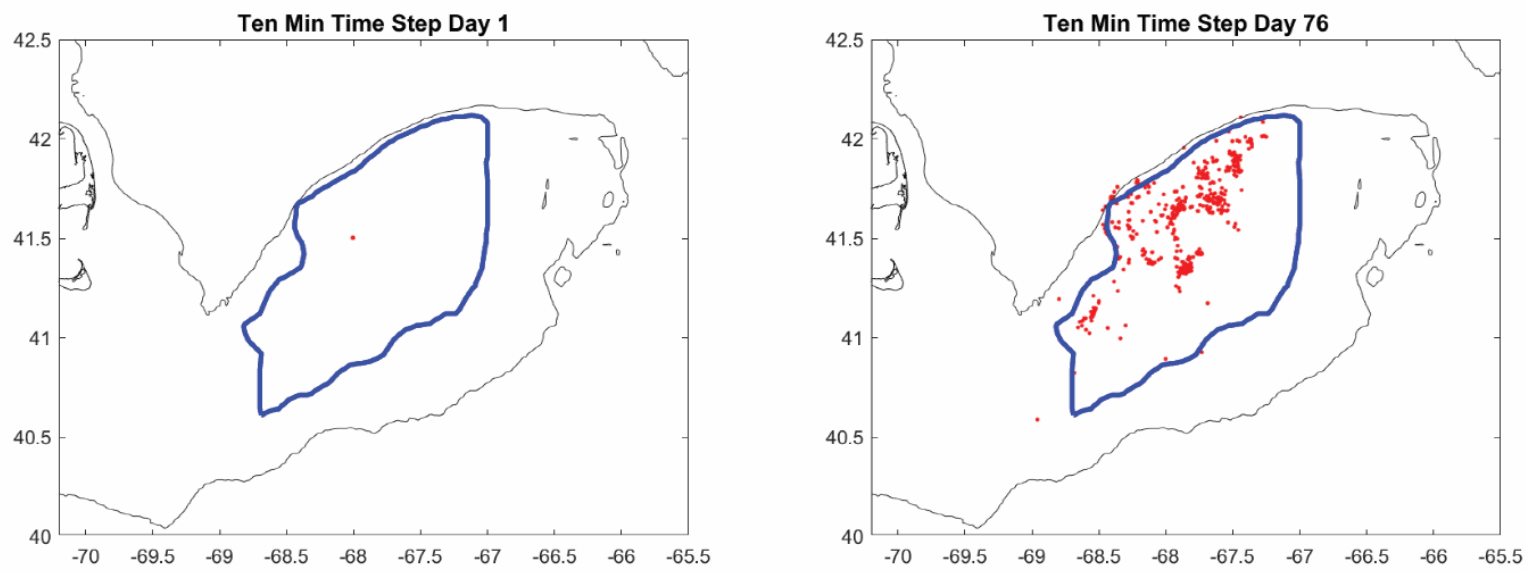

Figure 4-S7: Final locations (75 days after release) for particles released with $10 \mathrm{~m}$ spacing (left panel) from January 15, 2002 using ten-minute time steps. 


\section{Chapter 5}

\section{Conclusions}

Throughout my dissertation, I aimed to better understand the Northeast US shelf forage fish complex through studying the drivers of their distribution, and in the case of northern sand lance, their abundance and recruitment. The information garnered from these research projects improved this understanding, confirming that there are shifts in the distribution of many of the forage fishes of the region with causes ranging from cross and on-shelf redistribution of adult fish, changes in recruitment, and reductions in adult survivability. Perhaps most notably, we now have a much better understanding of the drivers of recruitment and abundance of northern sand lance, a species which we knew very little about despite their essential ecological role. These insights may serve to help managers plan for a shifting distribution and abundance of prey fishes for the commercially important and protected predators that rely on them as food.

In chapter 2, I elucidated the drivers of northern sand lance on shelf-wide scale. To do this, we explored their basic biology and ecology from collections on Stellwagen Bank, including that these fishes are capital breeders that rely heavily on Calanus finmarchicus copepods for energy in preparation for reproduction. Sand lance recruitment, in turn, is related to the abundance of these copepods, which we believe to be through the mechanism of parental condition. However, northern sand lance recruitment can be further regulated by intra-guild predation from the fellow forage fish Atlantic herring. Finally, adult sand lance appear to be highly sensitive to increases in warm slope water composition within the Gulf of Maine and the greater Northeast US shelf. The mechanism appears to be through overwinter mortality from increased temperatures leading to increases in metabolic costs and decreases in winter Calanus abundance, leading to both high temperatures and lower food availability for these fish during 
winter when warm slope water proportions are high. The future of these drivers spells out a precarious situation for age-2+ northern sand lance on the Northeast US shelf, with projected decreases in Calanus abundance and a sharp increase in warm slope water proportion starting in 2009. The one bright spot for sand lance is the decrease in Atlantic herring recruitment and abundance, likely leading to declines in intra-guild predation. This generates a concerning situation for the collective Northeast US shelf forage fish complex as these conditions would lead to most years from now through the end of century having below average abundances of both Atlantic herring and northern sand lance, fundamentally shifting prey availability for the myriad predators that rely on these lipid rich forage fishes. Some of these species, such as roseate terns and winter skate, rely heavily on sand lance as prey and it is possible that the decline of large sand lance may lead to detrimental effects on these species moving forward.

However, despite the historical reliance on sand lance and Atlantic herring, many of these predators forage on other species, ranging from invertebrates such as longfin squid to other forage fishes such as butterfish, Atlantic mackerel, and river herring. These latter species have not been as historically abundant as Atlantic herring and sand lance (with the exception of river herring prior to large scale dam implementation) and thus it is remains uncertain how well these fishes will be able to fill this role of prey. Increased reliance on these alternative prey species may have consequences on the distribution, condition, and behavior of these predators, which require monitoring going forward. While my second chapter was able to elucidate the primary drivers of the abundance of age-2 sand lance across the Northeast US shelf, including drivers of recruitment, we still know quite little about the detailed processes involved in sand lance recruitment. One specific example is the role of young Calanus stages on the feeding and survival of larval sand lance. Calanus appear to have a role in larval survival of congeners in the 
Northeast Atlantic, with increased Calanus production leading to increased larval survival and thus recruitment (Regnier et al. 2017). While we found the strongest connection between Calanus abundance and sand lance to occur at the lag corresponding to parental condition (which was also supported by our laboratory analyses), we did not explicitly explore the role of Calanus on larval survival and if this mechanism exists in addition to parental condition effects. Future research can aim to answer this outstanding question, particularly through a combined study of the diet of larval sand lance throughout the Northeast US shelf and if enhanced recruitment of sand lance occurs when local Calanus abundances are high. Additionally, the probable loss of older age classes by the end of the century leaves us with the question of whether age-1 fish will be able to generate enough reproductive output to sustain populations of sand lance. The role of environmental conditions on the growth and survival of age-1 fish remains an outstanding question. The Northeast Fisheries Science Center trawl survey primarily catches age-2+ individuals, with poor catchability of age-1 fish. This leads to difficulty in acquisition of age-1 samples or the ability to look at the dynamics of age-1 individuals throughout their first year. A combination of a modified trawl survey, such as using a modified scallop dredge (van Deurs et al. 2012), and larger scale sampling with van Veen grabs (Greenstreet et al. 2010) could ameliorate this issue and eventually develop a time series that would allow an exploration of age1 sand lance growth and survival in relation to environmental conditions. Given the plasticity of growth rates in congeners, it is possible that these age-1s could grow to larger sizes and contribute substantially to sand lance recruitment when prey availability is high (von Biela et al. 2019). Future research is needed to see if this can come to fruition and be sufficient for maintaining sand lance populations. 
In chapter 3, I analyzed how forage fish distributions are related to in-situ environmental variables to elucidate the habitat associations of these fishes during the spring and fall. The results indicated variance in the response of these fishes to different thermal regimes and hydrographic conditions. One notable result of this work is that the presence of these fishes in the Northeast Fisheries Science Center bottom trawl survey has variable coherence with coincident environmental conditions. Occurrence and shelf occupancy for some taxa, such as Atlantic butterfish, are tightly linked to interannual variably in coincident environmental conditions, while others, such as sand lance and Atlantic herring, show little to no coherence between the interannual variability in occurrence and in coincident environmental conditions. Instead, presence for these species were related to interannual variability in the year intercept (i.e. related to overall abundance), and in the case of Atlantic herring, changes to survey gear. This finding further supports the results of chapter 2 showing that interannual variability of sand lance observed in the survey is linked to changes in recruitment and survival and not changes in catchability or cross shelf movements. In the case of Atlantic herring, this suggests that the changes in survey presence are linked to factors external to coincident hydrography but that the favorability of coincident hydrography during these surveys is decreasing with time. This is consistent with classification of sand lance and Atlantic herring as more sub-polar to temperate species that may be declining in abundance and/or occurrence with warming conditions throughout the Northeast US shelf. Conversely, temperate to sub-tropical species such as Atlantic mackerel and butterfish show increasing occurrence in time, bolstering the conclusions from chapter 2 indicating the forage fish complex is likely shifting from sub-polar/temperate to temperate/sub-tropical taxa. How these generally warmer water species fill the role of forage for 
the numerous predators of the region remains an open question and will need to be monitored carefully in the coming decades.

While this chapter provides a good baseline for understanding the occupancy associations of the forage fishes, much more research and data collection is needed to refine the drivers of habitat suitability and abundance for these taxa. Namely, the use of the bottom trawl survey for pelagic forage fishes may cause conflation of gear selectivity and abundance and/or occurrence patterns. This could lead to unintuitive results, such as survey occurrence and landings being outof-phase or independent of each other. Trawl survey catches match well with landings for many of these species, but they do not for Atlantic mackerel (Deroba et al., 2010). Since this species is highly mobile and exhibits dense schooling behavior, the otter trawl gear used may not catch representative abundances of Atlantic mackerel. This emphasizes the need for additional survey methods that go beyond bottom trawl surveys for these mobile pelagic species. Examples may include acoustic trawl surveys such as those performed for Atlantic herring in the Northeast Atlantic and walleye pollock in the Gulf of Alaksa and Bering Sea, utilizing acoustics to estimate school density while confirming school compositions through mid-water trawls (Simmonds, 2003; Woillez et al. 2016). We also need to better utilize and acquire prey availability data for these species in the form of zooplankton collections. The Ecosystem Monitoring program of the Northeast Fisheries Science Center has collected a wealth of data on zooplankton densities already, exceeding the data availability of many regions. However, historical inconsistencies in the trawl data collection and zooplankton collection only on every third bottom trawl station (and often less) lead to a paucity of coupled bottom trawl collections and zooplankton data. In chapter 3, this led to an inconsistent sampling effort among years that precluded complete time series analyses if zooplankton were included. More targeted, finer scale studies relating species 
abundance and/or presence to zooplankton collections within the Gulf of Maine may demonstrate the ultimate utility of expanding zooplankton collections. These studies could inform scientists and managers of the role zooplankton play in shaping the distribution of forage fishes and whether expanding zooplankton sampling effort is necessary.

In chapter 4, I looked at the source-sink dynamics of three sand lance hotspots throughout the Gulf of Maine to better understand the potential connectivity of these regions. To do so, I used estimated hatch and settlement dates from sand lance collected in the Great South Channel and Stellwagen Bank to provide the first estimates for sand lance settlement timing on the Northeast US shelf. This information was then used to parameterize a bio-physical based Lagrangian tracking model to simulate larval transport of sand lance from 1990-2016 to look at mean source-sink pathways among the hotspots in addition to interannual variability in these patterns. The results indicated that Stellwagen Bank serves as a source of sand lance larvae for the Great South Channel, the Great South Channel serves as a sink for larvae from Stellwagen Bank and Georges Bank, and Georges Bank is a semi-closed population where retention is the primary mechanism for simulated larvae settling on Georges Bank. One surprising finding was the evidence of retention on Stellwagen Bank. Retention appears to even occur at sub-bank scales, with high retention on the southwest corner of Stellwagen Bank-the most persistent sand lance hotspot within Stellwagen Bank. Additionally, interannual variability in retention on both Stellwagen Bank and Georges Bank appears to be related to wind patterns, whereby the number of strong wind days leads to either enhanced (Stellwagen) or decreased (Georges Bank) retention. These insights are important for beginning to understand what might drive small scales patterns in sand lance recruitment and the degree to which sand lance hotspots may be connected or self-seeding. 
However, much remains to be learned about larval sand lance dispersal and ecology. One gap in knowledge is our lack of understanding of larval behavior and vertical distribution on diel and ontogenetic scales. Some research has been done on this topic, but the data were limited to Georges Bank and catchability issues appeared to confound the ability to gain understanding of the diel movements of sand lance larvae. If sand lance larvae undergo notable diel vertical migration, this may cause shifts in their larval transport trajectory, and thus the results from this chapter may change. Additionally, effort should be put toward generating a temperature dependent growth and survival curve for sand lance larvae. If settlement timing is temperature sensitive due to shifts in growth rate, this could fundamentally alter results and the degree of interannual variability, especially given the interannual variability in spring temperatures on the Northeast US shelf. Laboratory studies of temperature dependent growth should be coupled with observations of hatch and settlement dates over a range of years to see if winter/spring temperatures lead to shifts in mean settlement times for these fish. Shifting timing of hatch and settlement may also change the results from this chapter, especially if the shifts in timing result in a shift of simulated larvae's exposure to wind events or other ephemeral hydrodynamic processes throughout the region. The mechanisms behind retention need refining as well, as the number of strong wind days were only moderately related to the degree of retention, especially for Stellwagen Bank. A better understanding of fine scale hydrodynamic processes and the drivers of these processes is necessary to have a complete mechanistic understanding of retention and connection among these sand lance hotspots. Finally, this chapter further empathized the need to attain a metric of sand lance recruitment. Our collections on Stellwagen Bank provide something closer to recruitment than the Northeast Fisheries Science Center bottom trawl survey, yet this survey is small scale and not designed to specifically assess recruitment. Even with these 
caveats, catches on Stellwagen Bank showed evidence of retention increasing sand lance recruitment. Many more years and areas of collections are needed to better establish the relationship between recruitment and retention for Stellwagen Bank and to develop a similar metric for Georges Bank. These preliminary data do show that these kinds of surveys have the potential to provide valuable data and insight into sand lance population dynamics.

This thesis has collectively improved our understanding of the forage fish complex of the Northeast US shelf, especially our understanding of the biology and drivers of abundance of northern sand lance. The observed and forecasted changes to the forage fish complex require careful monitoring and consideration moving forward, as these changes are likely to affect predator distribution and behavior. However, this thesis does not provide a complete picture of how the forage fish complex operates, nor is it able to provide a certain vision of the future. Much more research is needed to attain these goals, and that research necessitates the improvement and development of survey techniques to accurately identify abundance trends for these species and the environmental drivers of these trends. In this thesis, I identified environmental associations of species occurrence for the dominant forage fishes, but I only took an in-depth look at the drivers of abundance and recruitment for northern sand lance. Similar indepth studies on the drivers of recruitment for each of the other forage fishes (or expanding upon existing studies in the case of Atlantic herring) are necessary for truly forecasting the dynamics of this trophic guild. Attaining these goals would serve to both protect fishers relying directly on forage species or their predators and ensure appropriate management of these taxa to prevent overexploitation. Though it will be difficult and nuanced, achieving these goals simultaneously should be the next line of research on the forage fishes of the Northeast US shelf. 


\section{Bibliography}

Adams, C. F., Miller, T. J., Manderson, J. P., Richardson, D. E., and Smith, B. E. 2015.

Butterfish 2014 Stock Assessment. US Dept Commer, Northeast Fish Sci Cent Ref Doc: $15-06$.

Adams, C. F. 2017. Age-specific differences in the seasonal spatial distribution of butterfish (Peprilus triacanthus). ICES Journal of Marine Science, 74: 170-179.

Alder, J., Campbell, B., Karpouzi, V., Kaschner, K., and Pauly, D. 2008. Forage fish: From ecosystems to markets. Annual Review of Environment and Resources, 33: 153-166.

Alheit, J., Licandro, P., Coombs, S., Garcia, A., Giráldez, A., Santamaría, M. T. G., Slotte, A., et al. 2014. Atlantic Multidecadal Oscillation (AMO) modulates dynamics of small pelagic fishes and ecosystem regime shifts in the eastern North and Central Atlantic. Journal of Marine Systems, 131: 21-35. Elsevier B.V. http://dx.doi.org/10.1016/j.jmarsys.2013.11.002.

Andres, M., 2016. On the recent destabilization of the Gulf Stream path downstream of Cape Hatteras. Geophysical Research Letters, 43(18), pp.9836-9842..

Bakun, A., and Broad, K. 2003. Environmental 'loopholes' and fish population dynamics: Comparative pattern recognition with focus on El Niño effects in the Pacific. Fisheries Oceanography, 12: 458-473.

Bakun, A., Babcock, E. A., and Santora, C. 2009. Regulating a complex adaptive system via its wasp-waist: Grappling with ecosystem-based management of the New England herring fishery. ICES Journal of Marine Science, 66: 1768-1775.

Bakun, A. 2017. Climate change and ocean deoxygenation within intensified surface-driven upwelling circulations. Philosophical Transactions of the Royal Society A: Mathematical, 
Physical and Engineering Sciences, 375(2102), 20160327.

Barrett, R. T., Nilsen, E. B., and Anker-Nilssen, T. 2012. Long-term decline in egg size of Atlantic puffins Fratercula arctica is related to changes in forage fish stocks and climate conditions. Marine Ecology Progress Series, 457: 1-10.

Bednaršek, N., Tarling, G. A., Fielding, S., \& Bakker, D. C. E. 2012. Population dynamics and biogeochemical significance of Limacina helicina antarctica in the Scotia Sea (Southern Ocean). Deep-Sea Research Part II: Topical Studies in Oceanography, 59-60, 105-116. https://doi.org/10.1016/j.dsr2.2011.08.003

Bertrand, A., Segura, M., Gutiérrez, M., \& Vásquez, L. 2004. From small-scale habitat loopholes to decadal cycles: a habitat-based hypothesis explaining fluctuation in pelagic fish populations off Peru. Fish and Fisheries, 5(4), 296-316.

Boucher, J. M., Chen, C., Sun, Y., and Beardsley, R. C. 2013. Effects of interannual environmental variability on the transport-retention dynamics in haddock Melanogrammus aeglefinus larvae on Georges Bank. Marine Ecology Progress Series, 487: 201-215.

Brodie, S., Hobday, A. J., Smith, J. A., Everett, J. D., Taylor, M. D., Gray, C. A., and Suthers, I. M. 2015. Modelling the oceanic habitats of two pelagic species using recreational fisheries data. Fisheries Oceanography, 24: 463-477.

Brooks, D.A., 1985. Vernal circulation in the Gulf of Maine. Journal of Geophysical Research: Oceans, 90(C3), pp.4687-4706.

Carroll, M. J., Bolton, M., Owen, E., Anderson, G. Q., Mackley, E. K., Dunn, E. K., \& Furness, R. W. 2017. Kittiwake breeding success in the southern North Sea correlates with prior sandeel fishing mortality. Aquatic Conservation: Marine and Freshwater Ecosystems, 27(6), 1164-1175. 
Chavez, F. P., Ryan, J., Lluch-Cota, S. E., and Ñiquen, C. M. 2003. Climate: From anchovies to sardines and back: Multidecadal change in the Pacific Ocean. Science, 299: 217-221.

Checkley, D. M., Asch, R. G., and Rykaczewski, R. R. 2017. Climate, Anchovy, and Sardine. Annual Review of Marine Science, 9: 469-493.

Chen, C., Huang, H., Beardsley, R. C., Xu, Q., Limeburner, R., Cowles, G. W., Sun, Y., et al. 2011. Tidal dynamics in the Gulf of Maine and New England Shelf: An application of FVCOM. Journal of Geophysical Research: Oceans, 116: 1-14.

Chen, C., Zhao, L., Gallager, S., Ji, R., He, P., Davis, C., Beardsley, R.C., Hart, D., Gentleman, W.C., Wang, L., Li, S., Lin, H., Stokesbury, K., Bethoney, D., 2021. Impact of larval behaviors on dispersal and connectivity of sea scallop larvae over the northeast U.S. shelf. Progress in Oceanography. 195, 102604.

Chen, Z., Curchitser, E., Chant, R., \& Kang, D. 2018. Seasonal variability of the cold pool over the Mid-Atlantic Bight continental shelf. Journal of Geophysical Research: Oceans, 123(11), 8203-8226.

Chen, Z., Kwon, Y. O., Chen, K., Fratantoni, P., and Gawarkiewicz, G. 2020. Long - Term SST Variability on the Northwest Atlantic Continental Shelf and Slope Geophysical Research Letters: $1-11$.

Chigbu, P., \& Sibley, T. H. 1996. Biometrical relationships, energy content and biochemical composition of Neomysis mercedis from Lake Washington. Hydrobiologia, 337(1-3), 145150. https://doi.org/10.1007/BF00028515

Church, G. E., Furness, R. W., Tyler, G., Gilbert, L., and Votier, S. C. 2019. Change in the North Sea ecosystem from the 1970s to the 2010s: Great skua diets reflect changing forage fish, seabirds, and fisheries. ICES Journal of Marine Science, 76: 925-937. 
Christensen, A., Jensen, H., Mosegaard, H., St. John, M., and Schrum, C. 2008. Sandeel (Ammodytes marinus) larval transport patterns in the North Sea from an individual-based hydrodynamic egg and larval model. Canadian Journal of Fisheries and Aquatic Sciences, 65: $1498-1511$.

Churchill, J. H., and Cornillon, P. C. 1991. Gulf Stream water on the shelf and upper slope north of Cape Hatteras. Continental Shelf Research, 11: 409-431.

Churchill, J. H., Pettigrew, N. R., and Signell, R. P. 2005. Structure and variability of the Western Maine Coastal Current. Deep-Sea Research Part II: Topical Studies in Oceanography, 52: 2392-2410.

Churchill, J. H., Runge, J., and Chen, C. 2011. Processes controlling retention of spring-spawned Atlantic cod (Gadus morhua) in the western Gulf of Maine and their relationship to an index of recruitment success. Fisheries Oceanography, 20: 32-46.

Clausen, L. W., Rindorf, A., van Deurs, M., Dickey-Collas, M., and Hintzen, N. T. 2018. Shifts in North Sea forage fish productivity and potential fisheries yield. Journal of Applied Ecology, 55: 1092-1101.

Cohen, E. B., and Wright, W. R. 1979. Primary productivity on Georges Bank with an explanation of why it is so high. NEFSC Fisheries Science Center Reference Document, 79-53: 10 .

Cohen, R. E., \& Lough, R. G. 1981. Length-Weight Relationships for Several Copepods Dominant in the Georges Bank-Gulf of Maine Area. Journal of Northwest Atlantic Fishery Science, 2(mm), 47-52. https://doi.org/10.2960/j.v2.a4

Cowen, R.K. and Sponaugle, S., 2009. Larval dispersal and marine population connectivity. Annual review of marine science, 1, pp.443-466. 
Currie, M., and Rios, J. M. 2002. Marine Science. The American Biology Teacher, 64: 382-383.

Cury, P., Bakun, A., Crawford, R. J. M., Jarre, A., Quiñones, R. A., Shannon, L. J., and Verheye, H. M. 2000. Small pelagics in upwelling systems: Patterns of interaction and structural changes in 'wasp-waist' ecosystems. ICES Journal of Marine Science, 57: 603-618.

Danielsen, N. S. T., Hedeholm, R. B., and Grønkjær, P. 2016. Seasonal changes in diet and lipid content of northern sand lance Ammodytes dubius on fyllas bank, west Greenland. Marine Ecology Progress Series, 558: 97-113.

DeLeeuw, J. 1973. Akaike_1973 with commentary.pdf. http://www.sortie-nd.org/lme/Statistical Papers/Akaike_1973 with commentary.pdf.

Derek, A., and Wheeler, P. 2020. Package ' FSA'.

Deroba, J. J., Shepherd, G., Grégoire, F., Nieland, J., and Link, J. 2010. Stock assessment of Atlantic mackerel in the Northwest Atlantic - 2009. TRAC Reference Document, 1: 64 p.

Deroba, J. J. 2018. Sources of variation in stomach contents of predators of Atlantic herring in the Northwest Atlantic during 1973-2014. ICES Journal of Marine Science, 75: 1439-1450.

Divoky, G. J., Lukacs, P. M., \& Druckenmiller, M. L. 2015. Effects of recent decreases in arctic sea ice on an ice-associated marine bird. Progress in Oceanography, 136, 151-161.

Dumont, H. J., Van de Velde, I., \& Dumont, S. 1975. The dry weight estimate of biomass in a selection of Cladocera, Copepoda and Rotifera from the plankton, periphyton and benthos of continental waters. Oecologia, 19(1), 75-97. https://doi.org/10.1007/BF00377592

Ethratta, E. L. T. M., and Ink, J. A. S. L. 2006. Associations between Surficial Sediments and Groundfish Distributions in the Gulf of Maine - Georges Bank Region: 473-489.

Faillettaz, R., Paris, C. B., and Irisson, J. O. 2018. Larval fish swimming behavior alters dispersal patterns from marine protected areas in the North-Western Mediterranean Sea. 
Frontiers in Marine Science, 5: 1-12.

Fogarty, M. J. 1989. Spawning-stock biomass: A source of error in recruitment/stock relationships and management advice. ICES Journal of Marine Science, 45: 131-135.

Fogarty, M. J., Sissenwine, M. P., and Cohen, E. B. 1991. Recruitment variability and the dynamics of exploited marine populations. Trends in Ecology and Evolution, 6: 241-246.

Frank, K. T., Petrie, B., Fisher, J. A. D., and Leggett, W. C. 2011. Transient dynamics of an altered large marine ecosystem. Nature, 477: 86-91.

Fréon, P., Cury, P., Shannon, L., and Roy, C. 2005. Sustainable exploitation of small pelagic fish stocks challenged by environmental and ecosystem changes: A review. Bulletin of Marine Science, 76: 385-462.

Friedland, K. D., Leaf, R. T., Kane, J., Tommasi, D., Asch, R. G., Rebuck, N., Ji, R., et al. 2015. Spring bloom dynamics and zooplankton biomass response on the US Northeast Continental Shelf. Continental Shelf Research, 102: 47-61. Elsevier. http://dx.doi.org/10.1016/j.csr.2015.04.005.

Friedland, K. D., McManus, M. C., Morse, R. E., Link, J. S., and Ojaveer, H. 2019. Event scale and persistent drivers of fish and macroinvertebrate distributions on the Northeast US Shelf. ICES Journal of Marine Science, 76: 1316-1334.

Friedland, K. D., Morse, R. E., Manning, J. P., Melrose, D. C., Miles, T., Goode, A. G., Brady, D. C., et al. 2020a. Trends and change points in surface and bottom thermal environments of the US Northeast Continental Shelf Ecosystem. Fisheries Oceanography: 1-19.

Friedland, K. D., Langan, J. A., Large, S. I., Selden, R. L., Link, J. S., Watson, R. A., and Collie, J. S. 2020b. Science of the Total Environment Changes in higher trophic level productivity, diversity and niche space in a rapidly warming continental shelf ecosystem. Science of the 
Total Environment, 704: 135270. Elsevier LTD.

https://doi.org/10.1016/j.scitotenv.2019.135270.

Friedland, K. D., Smoliński, S., and Tanaka, K. R. 2021. Contrasting patterns in the occurrence and biomass centers of gravity among fish and macroinvertebrates in a continental shelf ecosystem. Ecology and Evolution, 11: 2050-2063.

Gangopadhyay, A., Gawarkiewicz, G., Silva, E. N. S., Monim, M., and Clark, J. 2019. An

Observed Regime Shift in the Formation of Warm Core Rings from the Gulf Stream. Scientific Reports, 9: 1-9.

Garwood, J. C., Lucas, A. J., Naughton, P., Roberts, P. L. D., Jaffe, J. S., deGelleke, L., and Franks, P. J. S. 2021. Larval cross-shore transport estimated from internal waves with a background flow: The effects of larval vertical position and depth regulation. Limnology and Oceanography, 66: 678-693.

Giam, X., and Olden, J. D. 2016. Quantifying variable importance in a multimodel inference framework. Methods in Ecology and Evolution, 7: 388-397.

Gilman, S. L. 1994. An energy budget for northern sand lance, Ammodytes dubius, on Georges Bank, 1977-1986. Fishery Bulletin, 92: 647-654.

Goyert, H. F. 2014. Relationship among prey availability, habitat, and the foraging behavior, distribution, and abundance of common terns Sterna hirundo and roseate terns S. dougallii. Marine Ecology Progress Series, 506: 291-302

Greene, C. H., and Pershing, A. J. 2007. Climate Drives Sea Change, Science.315: 1084-1086.

Greene, C. H., Meyer-Gutbrod, E., Monger, B. C., McGarry, L. P., Pershing, A. J., Belkin, I. M., Fratantoni, P. S., et al. 2013. Remote climate forcing of decadal-scale regime shifts in Northwest Atlantic shelf ecosystems. Limnology and Oceanography, 58: 803-816. 
Greenstreet, S.P., Holland, G.J., Guirey, E.J., Armstrong, E., Fraser, H.M. and Gibb, I.M., 2010. Combining hydroacoustic seabed survey and grab sampling techniques to assess "local" sandeel population abundance. ICES Journal of Marine Science, 67(5), pp.971-984.

Gregory Lough, R., and Manning, J. P. 2001. Tidal-front entrainment and retention of fish larvae on the southern flank of Georges Bank. Deep-Sea Research Part II: Topical Studies in Oceanography, 48: 631-644.

Grieve, B. D., Hare, J. A., and Saba, V. S. 2017. Projecting the effects of climate change on Calanus finmarchicus distribution within the U . S . Northeast Continental Shelf. Scientific Reports: 1-12. Springer US. http://dx.doi.org/10.1038/s41598-017-06524-1.

Guisan, A., and Thuiller, W. 2005. Predicting species distribution: Offering more than simple habitat models. Ecology Letters, 8: 993-1009.

Harris, B. P., and Stokesbury, K. D. E. 2010. The spatial structure of local surficial sediment characteristics on Georges Bank, USA. Continental Shelf Research, 30: 1840-1853. Elsevier. http://dx.doi.org/10.1016/j.csr.2010.08.011.

Hazen, E. L., Friedlaender, A. S., Thompson, M. A., Ware, C. R., Weinrich, M. T., Halpin, P. N., and Wiley, D. N. 2009. Fine-scale prey aggregations and foraging ecology of humpback whales Megaptera novaeangliae. Marine Ecology Progress Series, 395: 75-89.

Henderson, M. E., Mills, K. E., Thomas, A. C., Pershing, A. J., and Nye, J. A. 2017. Effects of spring onset and summer duration on fish species distribution and biomass along the Northeast United States continental shelf. Reviews in Fish Biology and Fisheries, 27: 411424. Springer International Publishing.

Hoagland, P., Jin, D., Thunberg, E., and Steinback, S. 2005. 7 Economic activity associated with the northeast shelf large marine ecosystem: Application of an input-output approach. Large 
Marine Ecosystems, 13: 157-179.

Holland, M.M., Everett, J.D., Cox, M.J., Doblin, M.A. and Suthers, I.M., 2021. Pelagic forage fish distribution in a dynamic shelf ecosystem-Thermal demands and zooplankton prey distribution. Estuarine, Coastal and Shelf Science, 249, p.107074.

Hopcroft, R. R., Roff, J. C., \& Bouman, H. A. 1998. Zooplankton growth rates: The larvaceans Appendicularia, Fritillaria and Oikopleura in tropical waters. Journal of Plankton Research, 20(3), 539-555. https://doi.org/10.1093/plankt/20.3.539

Huret, M., Runge, J. A., Chen, C., Cowles, G., Xu, Q., and Pringle, J. M. 2007. Dispersal modeling of fish early life stages: Sensitivity with application to Atlantic cod in the western Gulf of Maine. Marine Ecology Progress Series, 347: 261-274.

Jech, J. M., and Stroman, F. 2012. Aggregative patterns of pre-spawning Atlantic herring on Georges Bank from 1999-2010. Aquatic Living Resources, 25: 1-14.

Ji, R., Davis, C., Chen, C., and Beardsley, R. 2008. Influence of local and external processes on the annual nitrogen cycle and primary productivity on Georges Bank: A 3-D biologicalphysical modeling study. Journal of Marine Systems, 73: 31-47.

Ji, R., Feng, Z., Jones, B. T., Thompson, C., Chen, C., Record, N. R., and Runge, J. A. 2017. Coastal amplification of supply and transport (CAST): A new hypothesis about the persistence of Calanus finmarchicus in the Gulf of Maine. ICES Journal of Marine Science, 74: $1865-1874$.

Jiang, M., Brown, M. W., Turner, J. T., Kenney, R. D., Mayo, C. A., Zhang, Z., and Zhou, M. 2007. Springtime transport and retention of Calanus finmarchicus in Massachusetts and Cape Cod Bays, USA, and implications for right whale foraging. Marine Ecology Progress Series, 349: 183-197. 
Jiménez-Valverde, A. and Lobo, J.M., 2007. Threshold criteria for conversion of probability of species presence to either-or presence-absence. Acta oecologica, 31(3), pp.361-369.

Kadin, M., Österblom, H., Hentati-Sundberg, J., and Olsson, O. 2012. Contrasting effects of food quality and quantity on a marine top predator. Marine Ecology Progress Series, 444: 239249.

Kane, J. 2005. The demography of Calanus finmarchicus (Copepoda: Calanoida) in the Middle Atlantic Bight, USA, 1977-2001. Journal of Plankton Research, 27: 401-414.

Kane, J. 2007. Zooplankton abundance trends on Georges Bank, 1977-2004. ICES Journal of Marine Science, 64: 909-919.

Kavanaugh, M. T., Rheuban, J. E., Luis, K. M. A., and Doney, S. C. 2017. Thirty-Three Years of Ocean Benthic Warming Along the U.S. Northeast Continental Shelf and Slope: Patterns, Drivers, and Ecological Consequences. Journal of Geophysical Research: Oceans, 122: 9399-9414.

Kleisner, K. M., Fogarty, M. J., McGee, S., Hare, J. A., Moret, S., Perretti, C. T., and Saba, V. S. 2017. Marine species distribution shifts on the U.S. Northeast Continental Shelf under continued ocean warming. Progress in Oceanography, 153: 24-36. http://dx.doi.org/10.1016/j.pocean.2017.04.001.

Kuzuhara, H., Yoneda, M., Tsuzaki, T., Takahashi, M., Kono, N., and Tomiyama, T. 2019. Food availability before aestivation governs growth and winter reproductive potential in the capital breeding fish, Ammodytes japonicas. PLoS ONE, 14: 1-16.

Laugier, F., Feunteun, E., Pecheyran, C., and Carpentier, A. 2015. Life history of the Small Sandeel, Ammodytes tobianus, inferred from otolith microchemistry. A methodological approach. Estuarine, Coastal and Shelf Science, 165: 237-246. Elsevier Ltd. 
http://dx.doi.org/10.1016/j.ecss.2015.05.022.

Levin, L. A. 2006. Recent progress in understanding larval dispersal: New directions and digressions. Integrative and Comparative Biology, 46: 282-297.

Lewis, C. V. W., Chen, C., and Davis, C. S. 2001. Effect of winter wind variability on plankton transport over Georges Bank. Deep-Sea Research Part II: Topical Studies in Oceanography, 48: $137-158$.

Li, B., Tanaka, K. R., Chen, Y., Brady, D. C., and Thomas, A. C. 2017. Assessing the quality of bottom water temperatures from the Finite-Volume Community Ocean Model (FVCOM) in the Northwest Atlantic Shelf region. Journal of Marine Systems, 173: 21-30. Elsevier B.V. http://dx.doi.org/10.1016/j.jmarsys.2017.04.001.

Lindegren, M., Van Deurs, M., MacKenzie, B. R., Worsoe Clausen, L., Christensen, A., and Rindorf, A. 2018. Productivity and recovery of forage fish under climate change and fishing: North Sea sandeel as a case study. Fisheries Oceanography, 27: 212-221.

Logan, J. M., Golet, W. J., \& Lutcavage, M. E. 2015. Diet and condition of Atlantic bluefin tuna (Thunnus thynnus) in the Gulf of Maine, 2004-2008. Environmental Biology of Fishes, 98(5), 1411-1430.

Lucey, S. M., and Fogarty, M. J. 2013. Operational fisheries in New England: Linking current fishing patterns to proposed ecological production units. Fisheries Research, 141: 3-12. Elsevier B.V. http://dx.doi.org/10.1016/j.fishres.2012.05.002.

Lutcavage, M.E., Brill, R.W., Skomal, G.B., Chase, B.C., Goldstein, J.L. and Tutein, J., 2000. Tracking adult North Atlantic bluefin tuna (Thunnus thynnus) in the northwestern Atlantic using ultrasonic telemetry. Marine Biology, 137(2), pp.347-358.

Lynch, P. D., Nye, J. A., Hare, J. A., Stock, C. A., Alexander, M. A., Scott, J. D., Curti, K. L., et 
al. 2020. Marine Science, 72: 374-387.

Macy, W. K., Sutherland, S. J., and Durbin, E. G. 1998. Effects of zooplankton size and concentration and light intensity on the feeding behavior of Atlantic mackerel Scomber scombrus. Marine Ecology Progress Series, 172: 89-100.

Matta, M. E., and Baker, M. R. 2020. Age and Growth of Pacific Sand Lance (Ammodytes Personatus) At the Latitudinal Extremes of the Gulf of Alaska Large Marine Ecosystem. Northwestern Naturalist, 101: 34.

Maureaud, A., Frelat, R., Pécuchet, L., Shackell, N., Mérigot, B., Pinsky, M.L., Amador, K., Anderson, S.C., Arkhipkin, A., Auber, A. and Barri, I., 2021. Are we ready to track climatedriven shifts in marine species across international boundaries?-A global survey of scientific bottom trawl data. Global change biology, 27(2), pp.220-236.

Mbaye, B., Doniol-Valcroze, T., Brosset, P., Castonguay, M., Van Beveren, E., Smith, A., Lehoux, C., et al. 2020. Modelling Atlantic mackerel spawning habitat suitability and its future distribution in the north-west Atlantic. Fisheries Oceanography, 29: 84-99.

McCarthy, G. D., Joyce, T. M., and Josey, S. A. 2018. Gulf Stream Variability in the Context of Quasi-Decadal and Multidecadal Atlantic Climate Variability. Geophysical Research Letters, 45: 11,257-11,264.

McManus, M. C., Hare, J. A., Richardson, D. E., and Collie, J. S. 2018. Tracking shifts in Atlantic mackerel (Scomber scombrus) larval habitat suitability on the Northeast U.S. Continental Shelf. Fisheries Oceanography, 27: 49-62.

Miller, T. J., Das, C., Politis, P. J., Miller, A. S., Lucey, S. M., Legault, C. M., Brown, R. W., et al. 2010. Estimation of Albatross IV to Henry B. Bigelow calibration factors. Northeast Fisheries Science Center Reference Document, 10-05: 233 p. 
Mills, K. E., Pershing, A. J., Brown, C. J., Chen, Y., Chiang, F. S., Holland, D. S., Lehuta, S., et al. 2013. Fisheries management in a changing climate: Lessons from the 2012 ocean heat wave in the Northwest Atlantic. Oceanography, 26.

Möllmann, C., Müller-Karulis, B., Kornilovs, G., and St John, M. A. 2008. Effects of climate and overfishing on zooplankton dynamics and ecosystem structure: Regime shifts, trophic cascade, and feedback loops in a simple ecosystem. ICES Journal of Marine Science, 65: $302-310$.

Morley, J. W., Selden, R. L., Latour, R. J., Frölicher, T. L., Seagraves, R. J., and Pinsky, M. L. 2018. Projecting shifts in thermal habitat for 686 species on the North American continental shelf. PLoS ONE, 13: 1-28.

Morse, R. E., Friedland, K. D., Tommasi, D., Stock, C., and Nye, J. 2017. Distinct zooplankton regime shift patterns across ecoregions of the U.S. Northeast continental shelf Large Marine Ecosystem. Journal of Marine Systems, 165: 77-91. Elsevier B.V. http://dx.doi.org/10.1016/j.jmarsys.2016.09.011.

Mountain, D. G. 2012. Labrador slope water entering the Gulf of Maine - response to the North Atlantic Oscillation. Continental Shelf Research, 47: 150-155. Elsevier. http://dx.doi.org/10.1016/j.csr.2012.07.008.

Murray, C. S., Wiley, D., and Baumann, H. 2019. High sensitivity of a keystone forage fish to elevated CO2 and temperature. Conservation Physiology, 7: 1-12.

Muxagata, E., \& Williams, J. A. 2011. Larval body size-mass relationships of barnacles common to the English Channel coast of the UK. Journal of the Marine Biological Association of the United Kingdom, 91(1), 181-189. https://doi.org/10.1017/S0025315410001402

Naimie, C. E., Loder, J. W., and Lynch, D. R. 1994. Circulation on Georges Bank, 99. 
Nanjo, N., Takatsu, T., Imura, K., Itoh, K., Takeya, Y., and Takahashi, T. 2017. Feeding, somatic condition and survival of sand lance Ammodytes sp. larvae in Mutsu Bay, Japan. Fisheries Science, 83: 199-214. Springer Japan.

Nelson, G. A., and Ross, M. R. 1991. Biology and population changes of northern sand lance (Ammodytes dubius) from the Gulf of Maine to the Middle Atlantic Bight. Journal of Northwest Atlantic Fishery Science, 11: 11-27.

Neto, A. G., Langan, J. A., \& Palter, J. B. 2021. Changes in the Gulf Stream preceded rapid warming of the Northwest Atlantic Shelf. Communications Earth \& Environment, 2(1), 1-10.

Nishikawa, T., Nakamura, Y., Okamoto, S., and Ueda, H. 2020. Interannual decrease in condition factor of the western sand lance Ammodytes japonicus in Japan in the last decade: Evidence for food-limited decline of the catch. Fisheries Oceanography, 29: 52-55.

Nizinski, M., Collette, B., and Washington, B. 1990. Separation of two species of sand lances, Ammodytes americanus and A. dubius, in the western North Atlantic. Nizinski, Martha S., Collette, Bruce B., and Washington, B. B.: 241.

Nøttestad, L., Giske, J., Holst, J. C., and Huse, G. 1999. A length-based hypothesis for feeding migrations in pelagic fish. Canadian Journal of Fisheries and Aquatic Sciences, 56: 26-34.

Nye, J. A., Link, J. S., Hare, J. A., and Overholtz, W. J. 2009. Changing spatial distribution of fish stocks in relation to climate and population size on the Northeast United States continental shelf, 393: 111-129.

Overholtz, W. J. 1976. Stock of Atlantic Mackerel ( Scomber scombrus ), 9: 115-121.

Overholtz, W. J. 2002. The Gulf of Maine-Georges Bank Atlantic herring (Clupea harengus): Spatial pattern analysis of the collapse and recovery of a large marine fish complex. 
Fisheries Research, 57: 237-254.

Overholtz, W. J., and Link, J. S. 2007. Consumption impacts by marine mammals, fish, and seabirds on the Gulf of Maine-Georges Bank Atlantic herring (Clupea harengus) complex during the years 1977-2002. ICES Journal of Marine Science, 64: 83-96.

Paris, C. B., and Cowen, R. K. 2004. Direct evidence of a biophysical retention mechanism for coral reef fish larvae. Limnology and Oceanography, 49: 1964-1979.

Pearre, S. 1981. Feeding by Chaetognatha: Energy Balance and Importance of Various Components of the Diet of Sagitta elegans. Marine Ecology Progress Series, 5(5), 45-54. https://doi.org/10.3354/meps005045

Perretti, C. T., Fogarty, M. J., Friedland, K. D., Hare, J. A., Lucey, S. M., McBride, R. S., Miller, T. J., et al. 2017. Regime shifts in fish recruitment on the Northeast US Continental Shelf. Marine Ecology Progress Series, 574: 1-11.

Pershing, A. J., Alexander, M. A., Hernandez, C. M., Kerr, L. A., Le Bris, A., Mills, K. E., ... \& Thomas, A. C. 2015. Slow adaptation in the face of rapid warming leads to collapse of the Gulf of Maine cod fishery. Science, 350(6262), 809-812.

Petrik, C. M., Ji, R., and Davis, C. S. 2014. Interannual differences in larval haddock survival: hypothesis testing with a 3D biophysical model of Georges Bank. Fisheries Oceanography, 23: 521-553.

Pettigrew, N. R., Churchill, J. H., Janzen, C. D., Mangum, L. J., Signell, R. P., Thomas, A. C., Townsend, D. W., et al. 2005. The kinematic and hydrographic structure of the Gulf of Maine Coastal Current. Deep-Sea Research Part II: Topical Studies in Oceanography, 52: 2369-2391.

Pikitch, E. K., Rountos, K. J., Essington, T. E., Santora, C., Pauly, D., Watson, R., Sumaila, U. 
R., et al. 2014. The global contribution of forage fish to marine fisheries and ecosystems. Fish and Fisheries, 15: 43-64.

Pineda, J., Hare, J. A., and Sponaugle, S. 2007. Larval transport and dispersal in the coastal ocean and consequences for population connectivity. Oceanography, 20: 22-39.

Pineda, J., Starczak, V., da Silva, J.C., Helfrich, K., Thompson, M. and Wiley, D., 2015. Whales and waves: Humpback whale foraging response and the shoaling of internal waves at Stellwagen Bank. Journal of Geophysical Research: Oceans, 120(4), pp.2555-2570.

Polis, G.A., Myers, C.A. and Holt, R.D., 1989. The ecology and evolution of intraguild predation: potential competitors that eat each other. Annual review of ecology and systematics, 20(1), pp.297-330.

Politis, P. J., Galbraith, J. K., Kostovick, P., and Brown, R. W. 2014. Northeast fisheries science center bottom trawl survey protocols for the NOAA ship Henry B. Bigelow: 138 .

Potter, D. C., and Lough, R. G. 1987. Vertical Distribution and Sampling Variability of Larval and Juvenile Sand Lance (Ammodytes sp.) on Nantucket Shoals and Georges Bank . Journal of Northwest Atlantic Fishery Science, 7: 107-116.

Powers, K. D., Wiley, D. N., Robuck, A. R., Olson, Z. H., Welch, L. J., Thompson, M. A., and Kaufman, L. 2020. Spatiotemporal characterization of non-breeding great shearwaters ardenna gravis within their wintering range. Marine Ornithology, 48: 215-229.

Pyper, B. J., \& Peterman, R. M. 1998. Comparison of methods to account for autocorrelation in correlation analyses of fish data. Canadian Journal of Fisheries and Aquatic Sciences, 55(9), 2127-2140. https://doi.org/10.1139/f98-104

Raventos, N., Torrado, H., Arthur, R., Alcoverro, T., and Macpherson, E. 2021. Temperature reduces fish dispersal as larvae grow faster to their settlement size. Journal of Animal 
Ecology: 1419-1432.

Record, N. R., Ji, R., Maps, F., Varpe, Ø., Runge, J. A., Petrik, C. M., and Johns, D. 2018.

Copepod diapause and the biogeography of the marine lipidscape. Journal of Biogeography, 45: $2238-2251$.

Régnier, T., Gibb, F. M., and Wright, P. J. 2017. Importance of trophic mismatch in a winterhatching species: Evidence from lesser sandeel. Marine Ecology Progress Series, 567: $185-197$.

Régnier, T., Gibb, F. M., and Wright, P. J. 2018. Temperature effects on egg development and larval condition in the lesser sandeel, Ammodytes marinus. Journal of Sea Research, 134: 34-41. Elsevier. https://doi.org/10.1016/j.seares.2018.01.003.

Reygondeau, G., and Beaugrand, G. 2011. Future climate-driven shifts in distribution of Calanus finmarchicus. Global Change Biology, 17: 756-766.

Richardson, D. E., Hare, J. A., Fogarty, M. J., and Link, J. S. 2011. Role of egg predation by haddock in the decline of an atlantic herring population. Proceedings of the National Academy of Sciences of the United States of America, 108: 13606-13611.

Richardson, D. E., Palmer, M. C., and Smith, B. E. 2014. The influence of forage fish abundance on the aggregation of Gulf of Maine Atlantic cod (Gadus morhua) and their catchability in the fishery. Canadian Journal of Fisheries and Aquatic Sciences, 71: 1349-1362.

Rindorf, A., Wanless, S., and Harris, M. P. 2000. Effects of changes in sandeel availability on the reproductive output of seabirds. Marine Ecology Progress Series, 202: 241-252.

Roach, C. J., and Speer, K. 2019. Exchange of Water Between the Ross Gyre and ACC Assessed by Lagrangian Particle Tracking. Journal of Geophysical Research: Oceans, 124: 46314643. 
Robbins, P. 2014. Marine Science. Encyclopedia of Environment and Society, 71: 1158-1169.

Robards, M. D., Anthony, J. A., Rose, G. A., and Piatt, J. F. 1999. Changes in proximate composition and somatic energy content for Pacific sand lance (Ammodytes hexapterus) from Kachemak Bay, Alaska relative to maturity and season. Journal of Experimental Marine Biology and Ecology, 242: 245-258.

Runge, J. A., Kovach, A. I., Churchill, J. H., Kerr, L. A., Morrison, J. R., Beardsley, R. C., Berlinsky, D. L., et al. 2010. Understanding climate impacts on recruitment and spatial dynamics of Atlantic cod in the Gulf of Maine: Integration of observations and modeling. Progress in Oceanography, 87: 251-263.

Runge, J. A., Ji, R., Thompson, C. R. S., Record, N. R., and Chen, C. 2015. Persistence of Calanus finmarchicus in the western Gulf of Maine during recent extreme warming, 37: $221-232$.

Rypina, I. I., Llopiz, J. K., Pratt, L. J., and Lozier, M. S. 2014. Dispersal pathways of American eel larvae from the Sargasso Sea. Limnology and Oceanography, 59: 1704-1714.

Selden, R. L., Thorson, J. T., Samhouri, J. F., Bograd, S. J., Brodie, S., Carroll, G., Haltuch, M. A., et al. 2020. Coupled changes in biomass and distribution drive trends in availability of fish stocks to US West Coast ports. ICES Journal of Marine Science, 77: 188-199.

Sherman, K., Jones, C., Sullivan, L., Smith, W., Berrien, P., and Ejsymont, L. 1981. Congruent shifts in sand eel abundance in western and eastern North Atlantic ecosystems. Nature, 291: 486-489.

Silva, T. L., Fay, G., Aran Mooney, T., Robbins, J., Weinrich, M. T., Carson, C. D., Cole, T. V. N., et al. 2019. Habitat use of toothed whales in a marine protected area based on point process models. Marine Ecology Progress Series, 609: 239-256. 
Silva, T. L., Wiley, D. N., Thompson, M. A., Hong, P., Kaufman, L., Suca, J. J., Llopiz, J. K., et al. 2021. High collocation of sand lance and protected top predators: Implications for conservation and management. Conservation Science and Practice, 3: 1-8.

Simmonds, E. J. 2003. Weighting of acoustic-and trawl-survey indices for the assessment of North Sea herring. ICES Journal of Marine Science, 60(3), 463-471.

Sinclair, M., and Iles, T. D. 1985. Atlantic Herring ( Clupea harengus ) Distributions in the Gulf of Maine - Scotian Shelf Area in Relation to Oceanographic Features . Canadian Journal of Fisheries and Aquatic Sciences, 42: 880-887.

Smigielski, A., Halavik, T., Buckley, L., Drew, S., and Laurence, G. 1984. Spawning, embryo development and growth of the American sand lance Ammodytes americanus in the laboratory. Marine Ecology Progress Series, 14: 287-292.

Smith, B. E., and Link, J. S. J. 2010. The Trophic Dynamics of 50 Finfish and 2 Squid Species on the Northeast US Continental Shelf. U.S. Dep. Commer. NOAA Technical Memorandum, NMFS-NE-21: 1-29.

Smith, W., and Morse, W. 1985. Retention of larval haddock Melanogrammus aeglefinus in the Georges Bank region, a gyre-influenced spawning area. Marine Ecology Progress Series, 24: $1-13$.

S. G. 2021. Spatial, T., and Modelling, Package ' gstat'.

Staudinger, M. D., Goyert, H., Suca, J. J., Coleman, K., Welch, L., Llopiz, J. K., Wiley, D., et al. 2020. The role of sand lances (Ammodytes sp .) in the Northwest Atlantic Ecosystem : A synthesis of current knowledge with implications for conservation and management: 1-34.

Suca, J. J., Pringle, J. W., Knorek, Z. R., Hamilton, S. L., Richardson, D. E., and Llopiz, J. K. 2018. Feeding dynamics of Northwest Atlantic small pelagic fishes. Progress in Oceanography, 165: 52-62. Elsevier. https://doi.org/10.1016/j.pocean.2018.04.014. 
Suca, J. J., Wiley, D. N., Silva, T. L., Robuck, A. R., Richardson, D. E., Glancy, S. G., Clancey, E., et al. 2021. Sensitivity of sand lance to shifting prey and hydrography indicates forthcoming change to the northeast US shelf forage fish complex. ICES Journal of Marine Science.

Sun, Y., Chen, C., Beardsley, R. C., Ullman, D., Butman, B., and Lin, H. 2016. Surface circulation in Block Island Sound and adjacent coastal and shelf regions: A FVCOMCODAR comparison. Progress in Oceanography, 143: 26-45. Elsevier Ltd. http://dx.doi.org/10.1016/j.pocean.2016.02.005.

Sydeman, W. J., Dedman, S., García-Reyes, M., Thompson, S. A., Thayer, J. A., Bakun, A., and MacCall, A. D. 2020. Sixty-five years of northern anchovy population studies in the southern California Current: A review and suggestion for sensible management. ICES Journal of Marine Science, 77: 486-499.

Tapia, F. J., and Pineda, J. 2007. Stage-specific distribution of barnacle larvae in nearshore waters: Potential for limited dispersal and high mortality rates. Marine Ecology Progress Series, 342: 177-190.

Thompson, A. R., Harvey, C. J., Sydeman, W. J., Barceló, C., Bograd, S. J., Brodeur, R. D., Fiechter, J., et al. 2019. Indicators of pelagic forage community shifts in the California Current Large Marine Ecosystem, 1998-2016. Ecological Indicators, 105: 215-228. Elsevier. https://doi.org/10.1016/j.ecolind.2019.05.057.

Thorson, J. T. 2019. Guidance for decisions using the Vector Autoregressive Spatio-Temporal (VAST) package in stock, ecosystem, habitat and climate assessments. Fisheries Research, 210: 143-161.

Tomiyama, M., and Yanagibashi, S. 2004. Effect of temperature, age class, and growth on 
induction of aestivation in Japanese sandeel (Ammodytes personatus) in Ise Bay, central Japan. Fisheries Oceanography, 13: 81-90.

Townsend, D.W. and Pettigrew, N.R., 1997. Nitrogen limitation of secondary production on Georges Bank. Journal of Plankton Research, 19(2), pp.221-235.

Townsend, D. W., Pettigrew, N. R., Thomas, M. A., Neary, M. G., McGillicuddy, D. J., and O'Donnell, J. 2015. Water masses and nutrient sources to the Gulf of Maine. Journal of Marine Research, 73: 93-122.

Turner, S. M., Manderson, J. P., Richardson, D. E., Hoey, J. J., and Hare, J. A. 2015. and Atlantic Mackerel : can incidental catches be reduced ?, 73: 1912-1924.

Turner, S. M., Hare, J. A., Richardson, D. E., Manderson, J. P., Turner, S. M., Hare, J. A., Richardson, D. E., et al. 2017. Trends and Potential Drivers of Distribution Overlap of River Herring and Commercially Exploited Pelagic Marine Fishes on the Northeast U . S . Continental Shelf Trends and Potential Drivers of Distribution Overlap of River Herring and Commercially Exploi. Marine and Coastal Fisheries, 9: 13-22. Taylor \& Francis. https://doi.org/10.1080/19425120.2016.1255683.

van Deurs, M., Van Hal, R., Tomczak, M. T., and Jónasdóttir, S. H. 2009. Recruitment of lesser sandeel Ammodytes marinus in relation to density dependence and zooplankton composition. Marine Ecology Progress Series, 381: 249-258.

van Deurs, M., Hartvig, M., and Steffensen, J. F. 2011. Critical threshold size for overwintering sandeels (Ammodytes marinus). Marine Biology, 158: 2755-2764.

van Deurs, M., Grome, T. M., Kaspersen, M., Jensen, H., Stenberg, C., Sørensen, T. K., ... \& Mosegaard, H. 2012. Short-and long-term effects of an offshore wind farm on three species of sandeel and their sand habitat. Marine Ecology Progress Series, 458, 169-180. 
van Deurs, M., Christensen, A., and Rindorf, A. 2013. Patchy zooplankton grazing and high energy conversion efficiency: Ecological implications of sandeel behavior and strategy. Marine Ecology Progress Series, 487: 123-133.

Von Biela, V. R., Arimitsu, M. L., Piatt, J. F., Heflin, B., Schoen, S. K., Trowbridge, J. L., and Clawson, C. M. 2019. Extreme reduction in nutritional value of a key forage fish during the pacific marine heatwave of 2014-2016. Marine Ecology Progress Series, 613: 171-182.

Werner, F. E., Ian Perry, R., Gregory Loughj, R., and Naimie, C. E. 1996. Trophodynamic and advective influences on Georges Bank larval cod and haddock. Deep-Sea Research Part II: Topical Studies in Oceanography, 43: 1793-1822.

Wiley, D. N., Moller, J. C., Zilinskas, K. A., and Wiley, D. N. 2003. The distribution and density of commercial fisheries and Baleen Whales within the Stellwagen Bank National Marine Sanctuary: July 2001-June 2002. Marine Technology Society Journal, 37: 35-53.

Winslade, P. 1974. Behavioural studies on the lesser sandeel Ammodytes marinus (Raitt) III. The effect of temperature on activity and the environmental control of the annual cycle of activity. Journal of Fish Biology, 6: 587-599.

Wishner, K. F., Outram, D. M., and Ullman, D. S. 2006. Zooplankton distributions and transport across the northeastern tidal front of Georges Bank. Deep-Sea Research Part II: Topical Studies in Oceanography, 53: 2570-2596.

Woillez, M., Walline, P. D., Ianelli, J. N., Dorn, M. W., Wilson, C. D., \& Punt, A. E. 2016. Evaluating total uncertainty for biomass-and abundance-at-age estimates from eastern Bering Sea walleye pollock acoustic-trawl surveys. ICES Journal of Marine Science, 73(9), 2208-2226.

Wood, S. N. 2017. Generalized additive models: An introduction with R, second edition. 1-476 
Wright, P. J., and Bailey, M. C. 1996. Timing of hatching in Ammodytes marinus from Shetland waters and its significance to early growth and survivorship. Marine Biology, 126: 143152.

Wright, P. J., Orpwood, J. E., and Scott, B. E. 2017. Impact of rising temperature on reproductive investment in a capital breeder: The lesser sandeel. Journal of Experimental Marine Biology and Ecology, 486: 52-58. Elsevier B.V. http://dx.doi.org/10.1016/j.jembe.2016.09.014.

Xue, P., Chen, C., Qi, J., Beardsley, R. C., Tian, R., Zhao, L., and Lin, H. 2014. Mechanism studies of seasonal variability of dissolved oxygen in Mass Bay: A multi-scale FVCOM/UG-RCA application. Journal of Marine Systems, 131: 102-119. Elsevier B.V. http://dx.doi.org/10.1016/j.jmarsys.2013.12.002. 